\title{
Development and Verification of Tritium Analyses Code for a Very High Temperature Reactor
}

Chang H. Oh

Eung S. Kim

September 2009
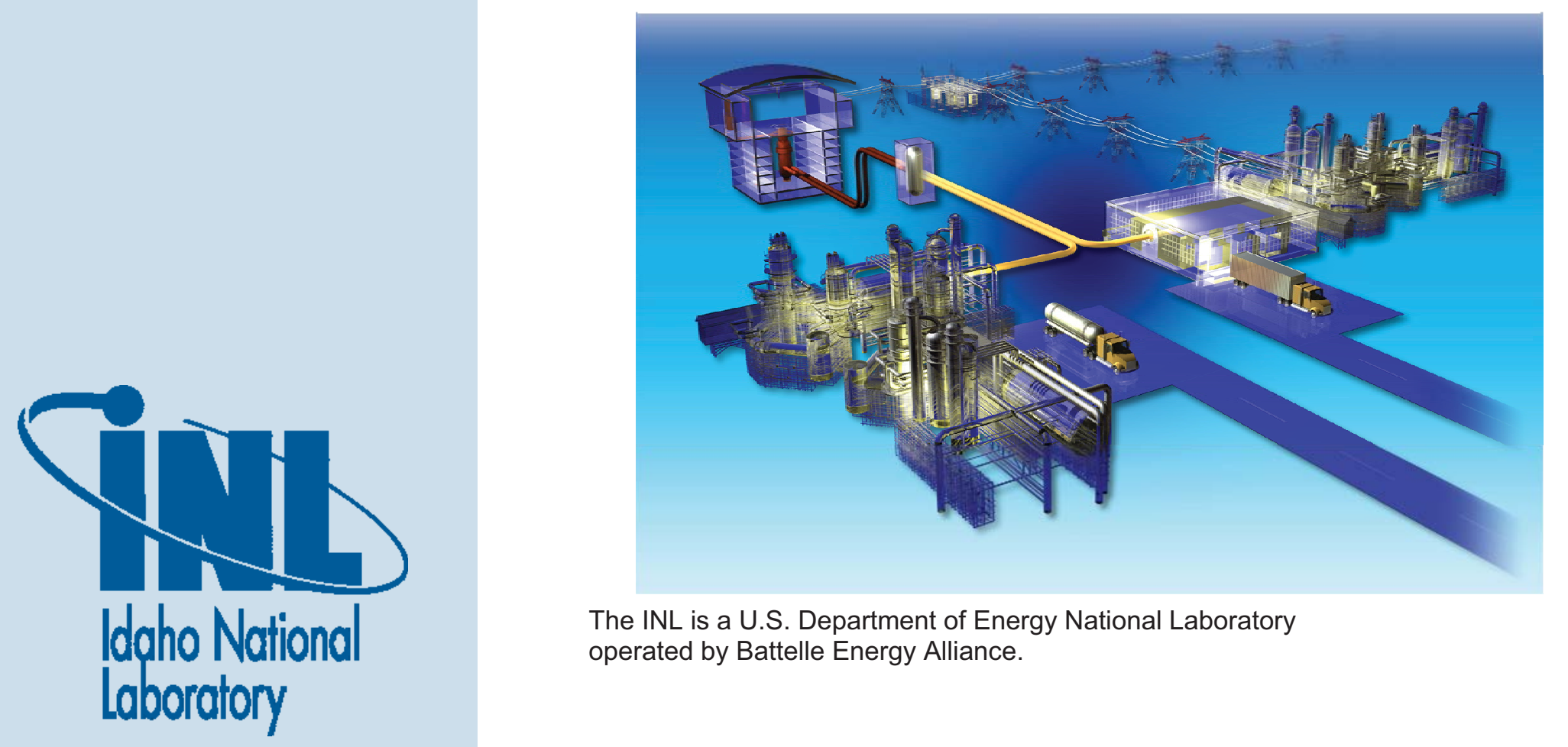

The INL is a U.S. Department of Energy National Laboratory operated by Battelle Energy Alliance. 


\section{DISCLAIMER}

This information was prepared as an account of work sponsored by an agency of the U.S. Government. Neither the U.S. Government nor any agency thereof, nor any of their employees, makes any warranty, expressed or implied, or assumes any legal liability or responsibility for the accuracy, completeness, or usefulness, of any information, apparatus, product, or process disclosed, or represents that its use would not infringe privately owned rights. References herein to any specific commercial product, process, or service by trade name, trade mark, manufacturer, or otherwise, does not necessarily constitute or imply its endorsement, recommendation, or favoring by the U.S. Government or any agency thereof. The views and opinions of authors expressed herein do not necessarily state or reflect those of the U.S. Government or any agency thereof. 


\section{Development and Verification of Tritium Analyses Code for a Very High Temperature Reactor}

Chang H. Oh

Eung S. Kim

September 2009

Idaho National Laboratory

Next Generation Nuclear Plant Project

Idaho Falls, Idaho 83415

Prepared for the

U.S. Department of Energy

Office of Nuclear Energy

Under DOE Idaho Operations Office

Contract DE-AC07-05ID14517 



\section{Next Generation Nuclear Plant Project}

\section{Development and Verification of Tritium Analyses Code for Very High Temperature Reactor}

INL/EXT-09-16743

September 2009

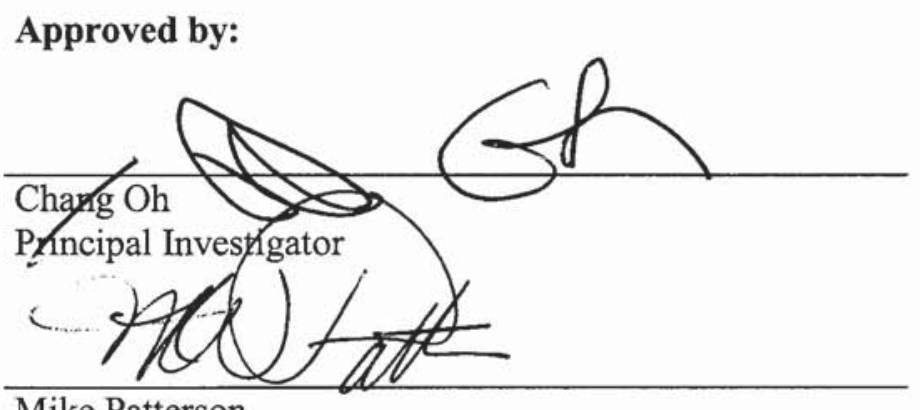

Mike Patterson

Engineering Technical Manager

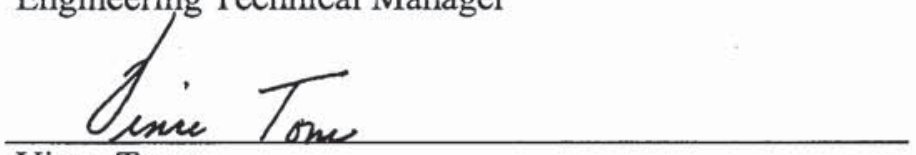

Vince Tonc

NGNP Engineering Director
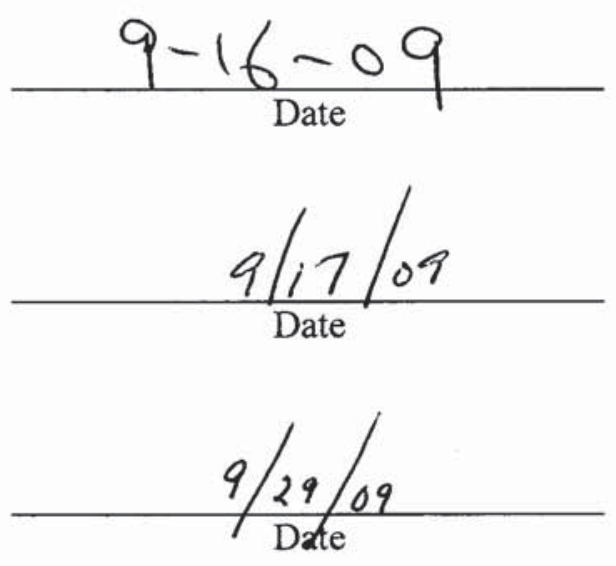


\section{ABSTRACT}

A tritium permeation analyses code (TPAC) was developed by Idaho National Laboratory for the purpose of analyzing tritium distributions in Very High Temperature Reactor (VHTR) VHTR systems, including integrated hydrogen production systems. A MATLAB SIMULINK software package was used for development of the code. The TPAC is based on the mass balance equations of tritium-containing species and various forms of hydrogen (i.e., HT, $\mathrm{H}_{2}, \mathrm{HTO}, \mathrm{HTSO}_{4}$, and TI) coupled with a variety of tritium sources, sinks, and permeation models. In the TPAC, ternary fission and neutron reactions with ${ }^{6} \mathrm{Li}$, ${ }^{7} \mathrm{Li}{ }^{10} \mathrm{~B}$, and ${ }^{3} \mathrm{He}$ were taken into considerations as tritium sources. Purification and leakage models were implemented as main tritium sinks. Permeation of HT and $\mathrm{H}_{2}$ through pipes, vessels, and heat exchangers were considered as the main tritium transport paths. In addition, electrolyzer and isotope exchange models were developed for analyzing hydrogen production systems, including hightemperature electrolysis and sulfur-iodine processes.

Tritium behaviors in a very high temperature reactor/high temperature steam electrolysis system were analyzed by the TPAC based on the reference indirect parallel configuration proposed by $\mathrm{Oh}$ et al. (2007). This analysis showed that only $0.4 \%$ of tritium released from the core is transferred to the product hydrogen. The amount of tritium in the product hydrogen was estimated to be approximately an order of magnitude less than the gaseous effluent limit for tritium.

The TPAC has unlimited flexibility for system configurations and provides easy drag-and-drops for making models by adopting a graphical user interface. Verification of the code was performed by comparisons with analytical solutions and the experimental data from the Peach Bottom reactor design. Calculations from the THYTAN code developed in Japan and adopted by Japan Atomic Energy Agency were also compared with the TPAC solutions. This report contains descriptions of the basic tritium pathways, theory, a simple user guide, verifications, sensitivity studies, sample cases, and code tutorials. 


\section{ACKNOWLEDGEMENTS}

This work was supported through the U.S. Department of Energy's NGNP-Engineering Program under DOE Idaho Operations Office Contract DE-AC07-05ID14517. 


\section{CONTENTS}

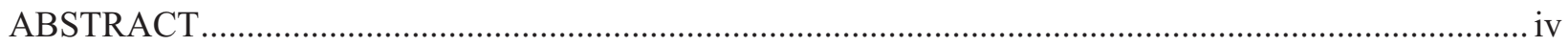

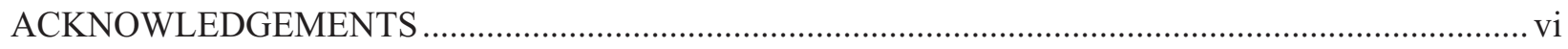

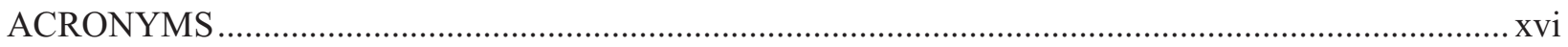

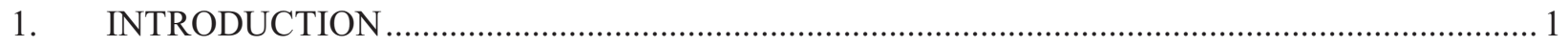

2. SOURCES AND PATHWAYS OF TRITIUM IN VHTR .......................................................... 4

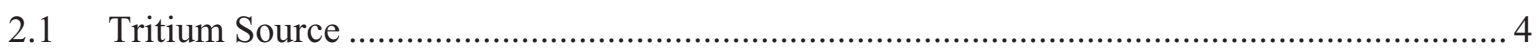

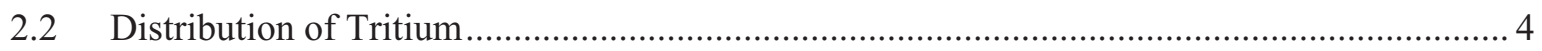

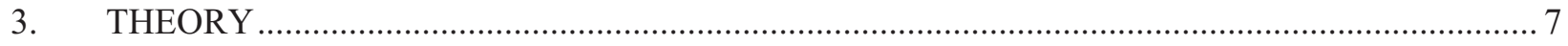

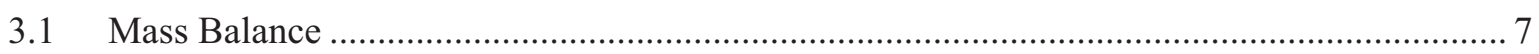

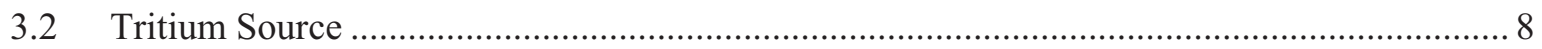

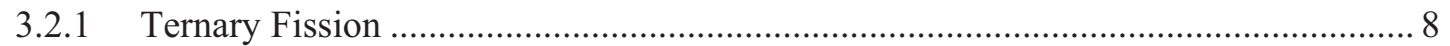

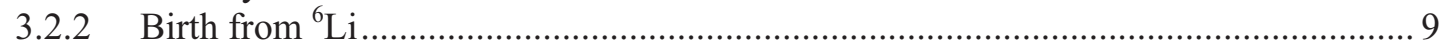

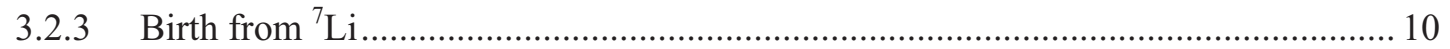

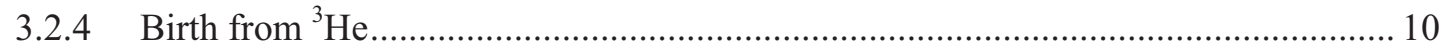

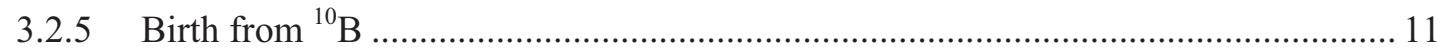

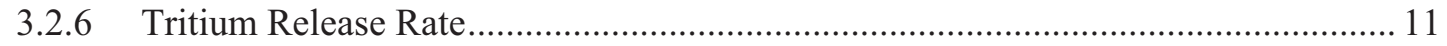

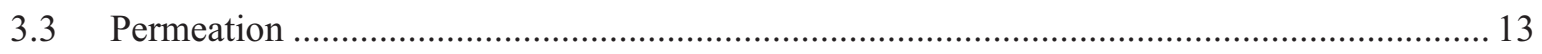

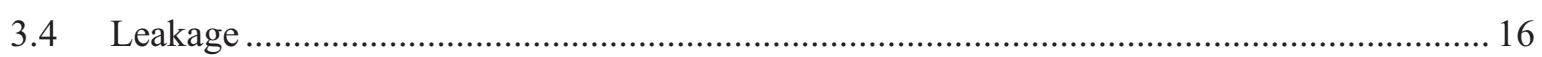

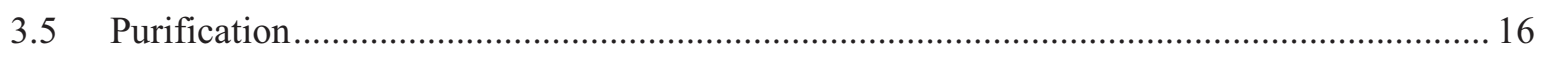

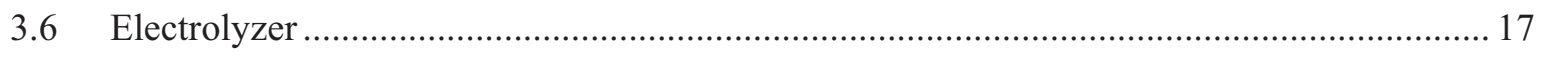

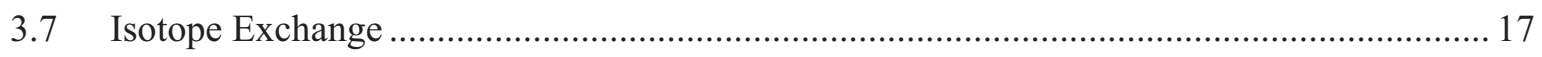

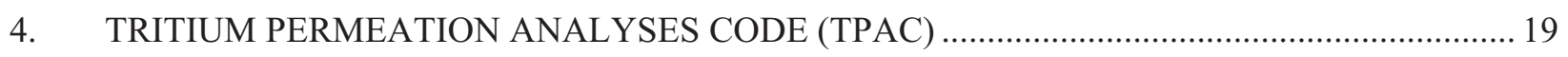

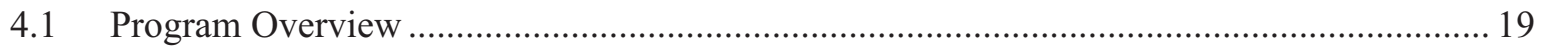

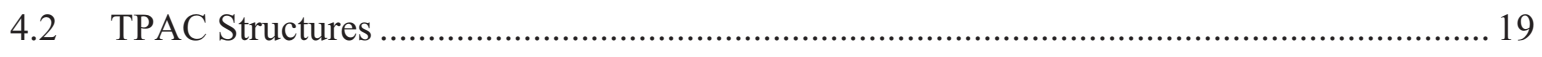

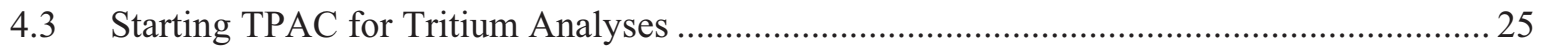

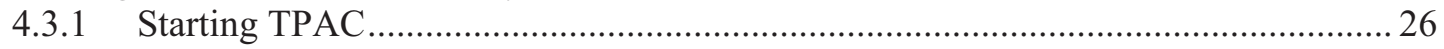

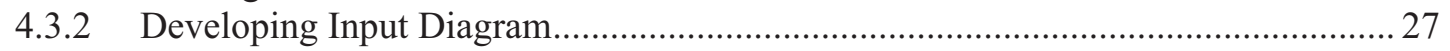

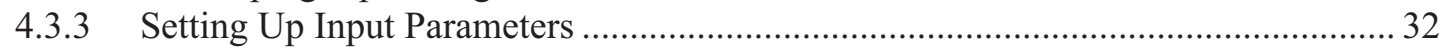

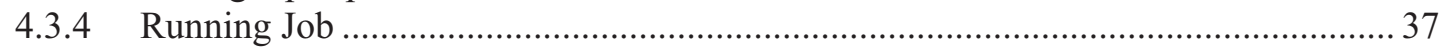

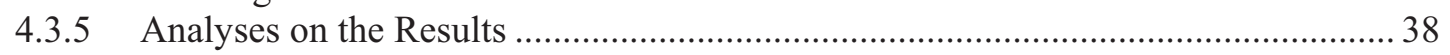

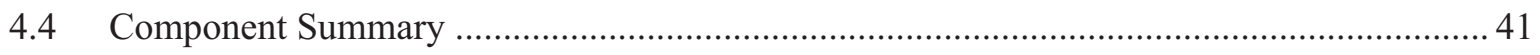

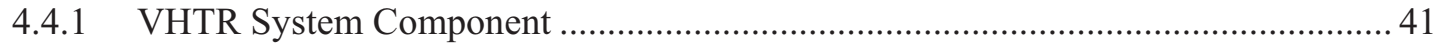

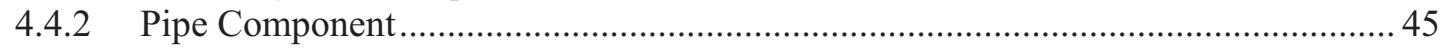

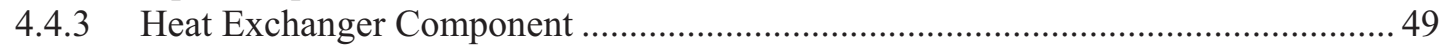

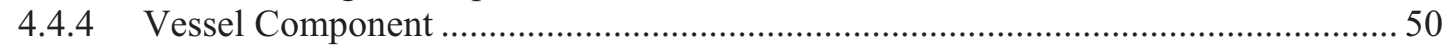

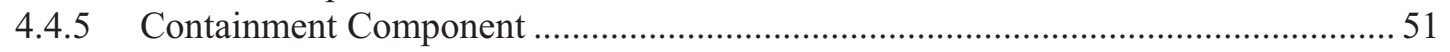

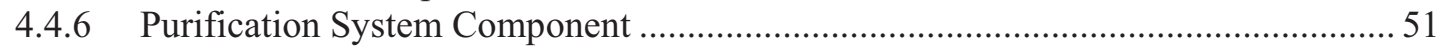

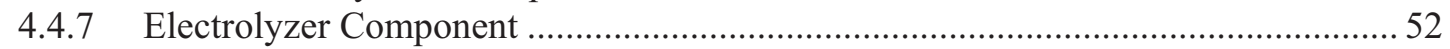

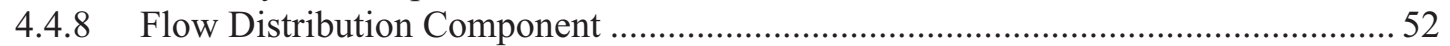

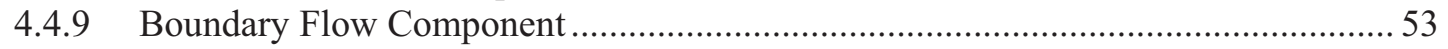




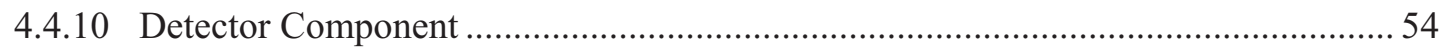

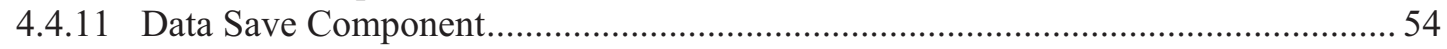

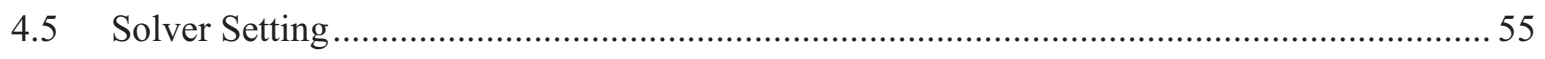

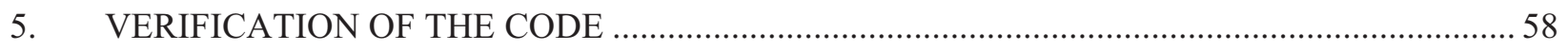

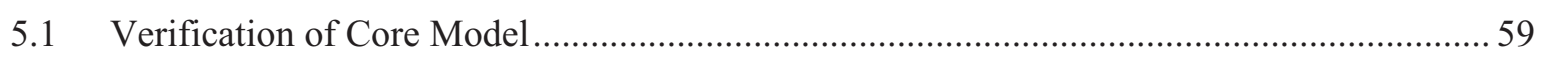

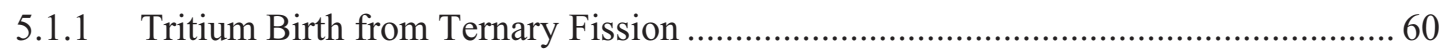

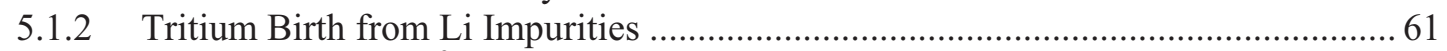

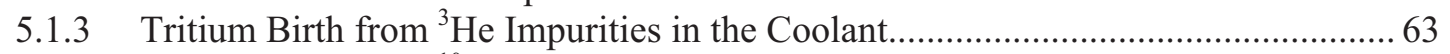

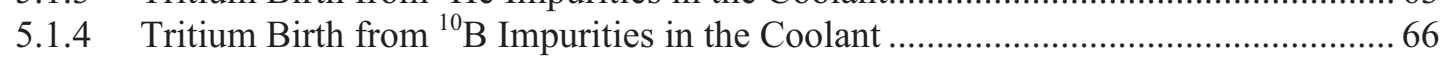

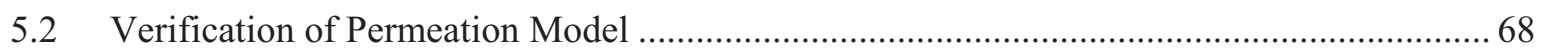

5.3 Verification of Leak Model............................................................................................ 71

5.4 Verification of Purification System Model ....................................................................... 73

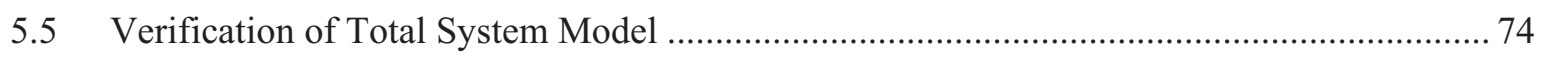

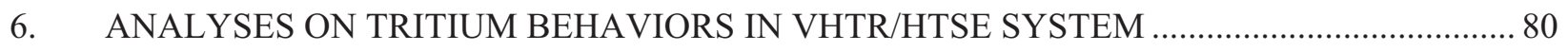

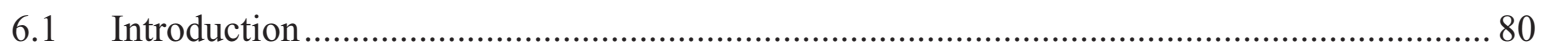

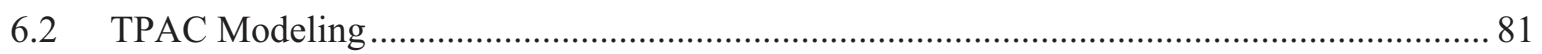

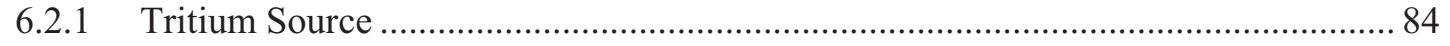

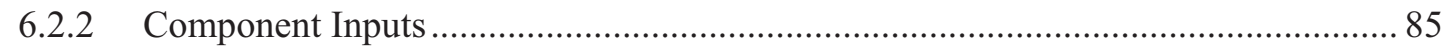

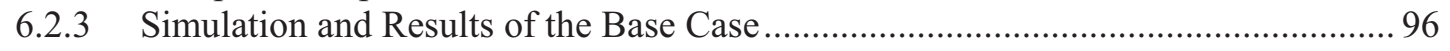

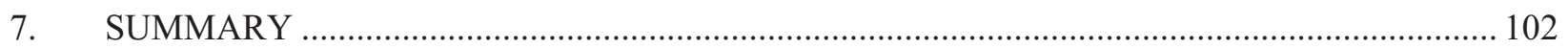

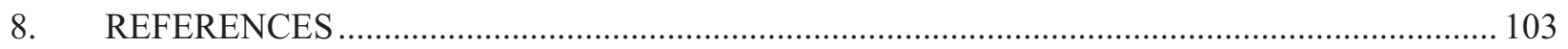

\section{FIGURES}

Figure 1-1. Diffusion, bulk transport, and permeation pathways of tritium in a heat transport loop

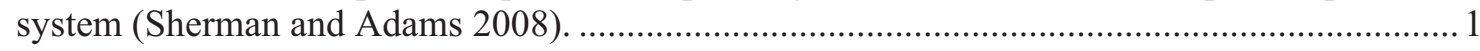

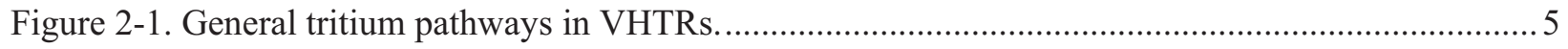

Figure 2-2. Tritium distribution in the VHTR system (Ohashi and Sherman 2007). ............................... 6

Figure 3-1. Cross-sectional picture of a PCHE (Dewson and Grady 2003). .......................................... 15

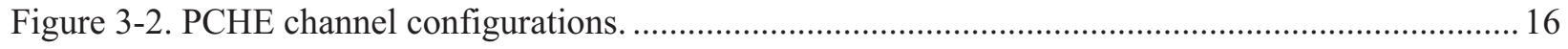

Figure 4-1. Basic TPAC user interface integrated into MATLAB SIMULINK......................................20

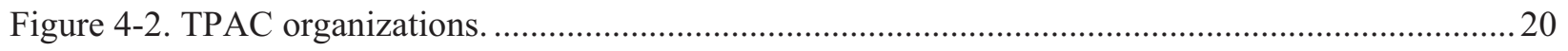

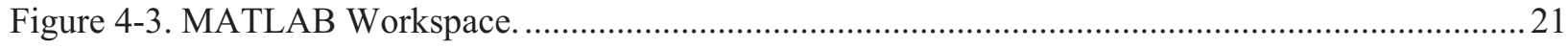

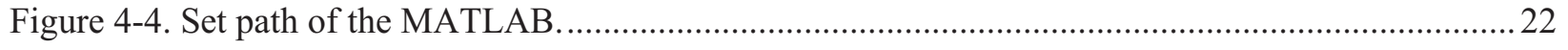

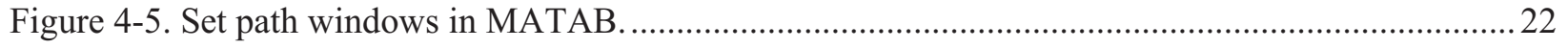

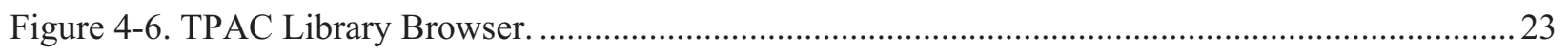

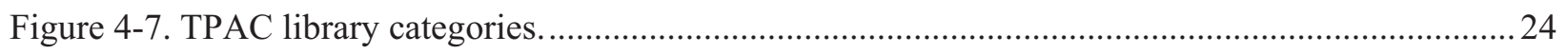

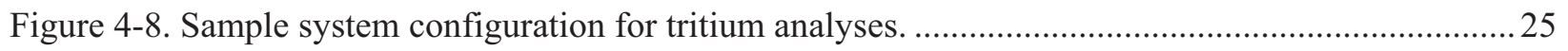




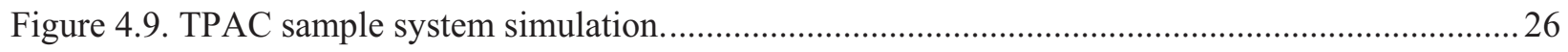

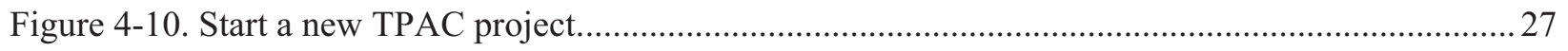

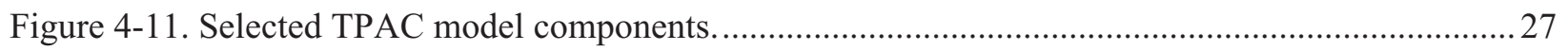

Figure 4-12. Connection of components (between Reactor and Pipe)..................................................2

Figure 4-13. Moving reactor component from library browser to editor...............................................29

Figure 4-14. Component arrangement for the sample configuration....................................................29

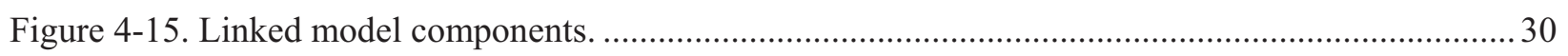

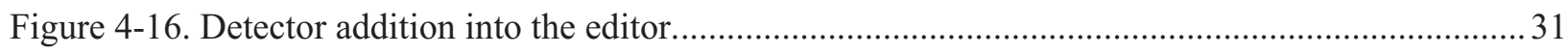

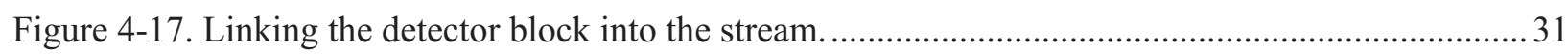

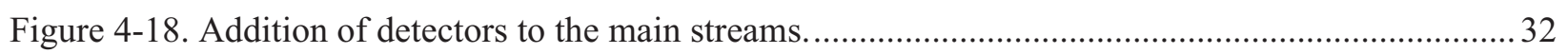

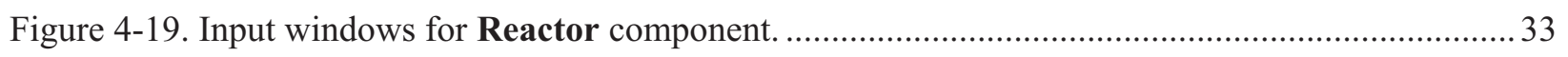

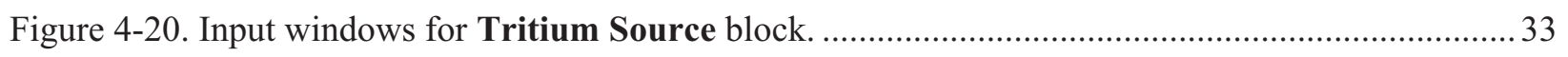

Figure 4-21. Input windows for Hot Leg component block............................................................. 34

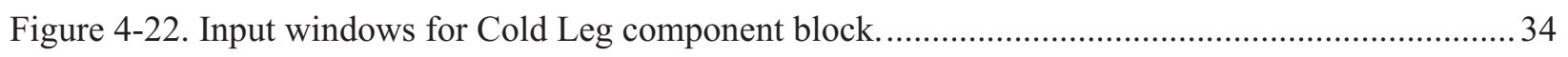

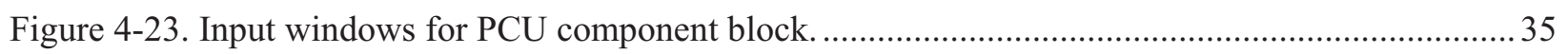

Figure 4-24. Input windows for Purification System 1 component block. ............................................... 35

Figure 4-25. Input windows for Purification System 2 component block. .............................................. 36

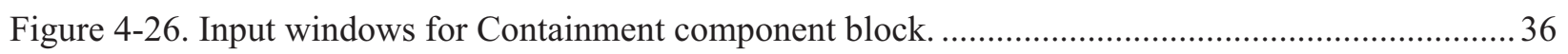

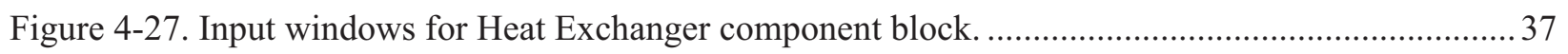

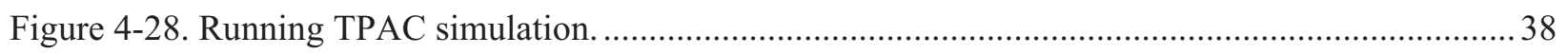

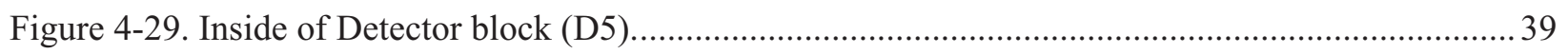

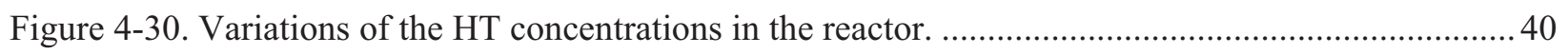

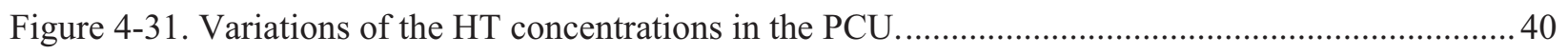

Figure 4-32. Variations of the HT concentrations in the containment................................................. 41

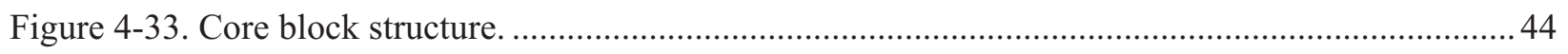

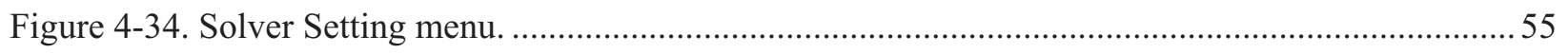

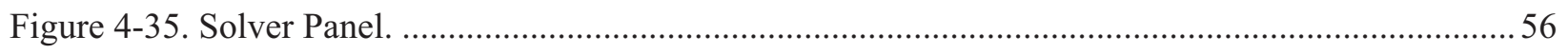

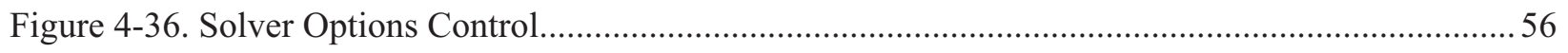

Figure 4-37. Variable-Step Continuous Solver Options. …….............................................................5 57

Figure 5-1. Primary coolant system of the Peach Bottom reactor (Wichner and Dyer 1979)...................59

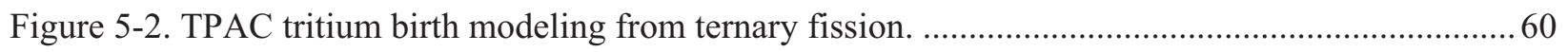

Figure 5-3. TPAC tritium birth modeling for neutron reaction with $\mathrm{Li}$ impurities................................... 61

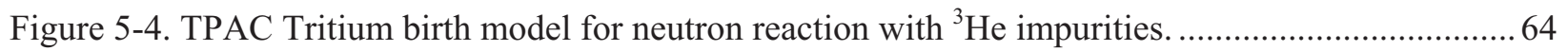

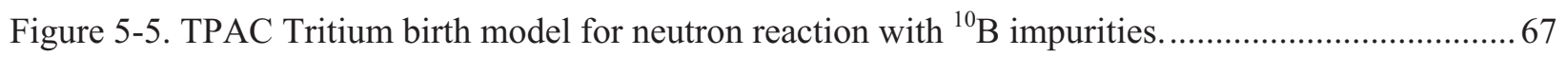

Figure 5-6. Tritium permeation modeling by INL Tritium code. ............................................................ 68 
Figure 5-7. Tritium leak modeling by INL Tritium code.

Figure 5-8. Comparison of tritium concentrations in the containment vessel of the Peach Bottom reactor. 73

Figure 5-9. Tritium purification modeling by INL Tritium code.. 73

Figure 5-10. Comparisons between analytical solution and TPAC solutions for verification of the purification system. 75

Figure 5-11. Simplified flow sheet of the Peach Bottom HTGR, illustrating tritium transport paths (Wichner and Dyer 1979). .75

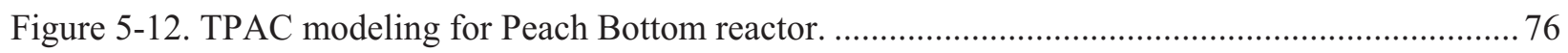

Figure 5-13. Steam generator submodel of the INL tritium code for Peach Bottom reactor...................... 77

Figure 5-14. Comparisons of tritium concentration, in the Peach Bottom reactor, between observed concentration (Wichner and Dyer 1979) and the computed solutions. ....................... 79

Figure 6-1. Indirect parallel configuration of VHTR/HTSE system (VHTR part) ................................... 80

Figure 6-2. Indirect parallel configuration of VHTR/HTSE system (HTSE part) .................................. 81

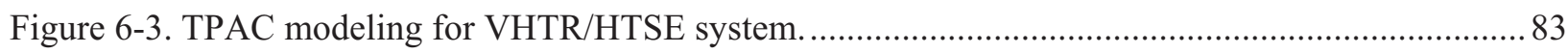

Figure 6-4. TPAC solver setting options for tritium analyses of the VHTR/HTSE system. .....................97

Figure 6-5. HT concentrations in the primary side (Reactor block). .................................................. 97

Figure 6-6. HT concentrations in the secondary side (PCU block). .....................................................98

Figure 6-7. HT concentrations in the IHTL side (IHTL block). ......................................................... 98

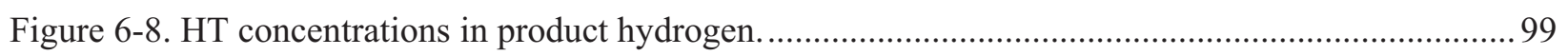

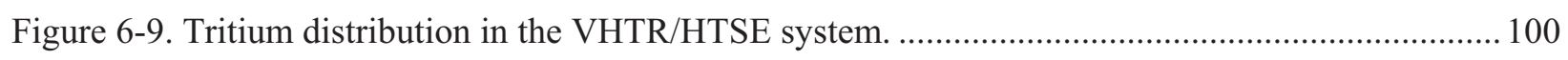

Figure 6-10. Effect of tritium release ratio on the tritium concentration in the hydrogen product........... 101

\section{TABLES}

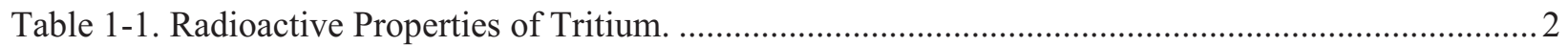

Table 1-2. Regulatory constraints on tritium in the U.S. (Ohashi and Sherman 2007). ........................... 2

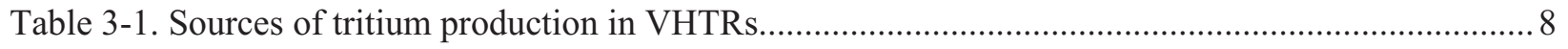

Table 3-2. Basic data for THYTAN evaluation of ternary fission............................................................ 9

Table 3-3. Tritium production reaction and cross section (Wichner and Dyer 1979). ................................ 9

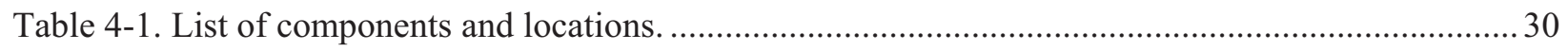

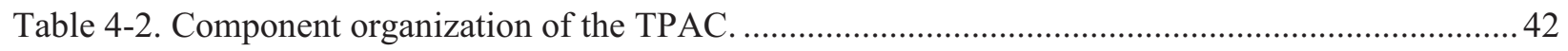

Table 4-3. Specifications of the Reactor Component block. .................................................................... 43

Table 4-4. Input parameters of the Reactor Component block. .............................................................. 43

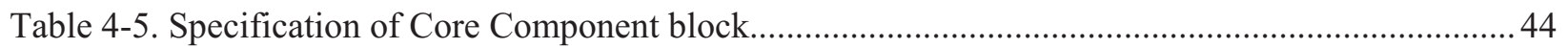

Table 4-6. Specification of Pipe-VHTR component block..................................................................... 45

Table 4-7. Specification of PipeII-VHTR component block. ...................................................................... 45 
Table 4-8. Input Parameters of Pipe-VHTR component block.............................................................. 46

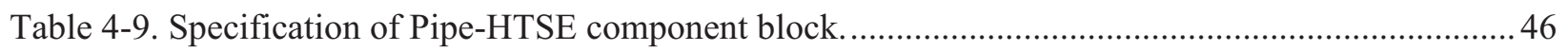

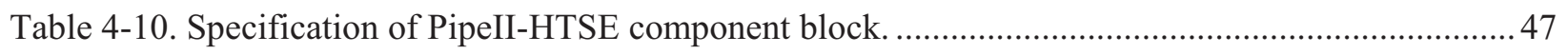

Table 4-11. Additional input parameters of Pipe-HTSE component block. ............................................ 47

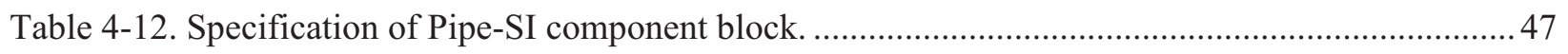

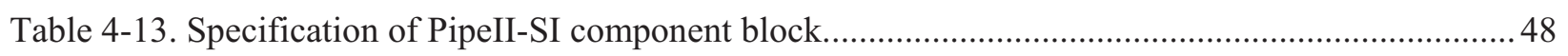

Table 4-14. Additional input parameters of Pipe-SI component block.................................................... 48

Table 4-15. Specification of Isotope Exchange component block............................................................ 48

Table 4-16. Input Parameters of Isotope Exchange Component Block. .................................................. 48

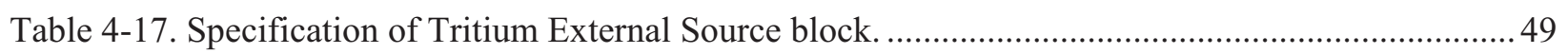

Table 4-18. Input parameters of Tritium External Source block. ........................................................... 49

Table 4-19. Specification of Heat Exchanger component block............................................................. 49

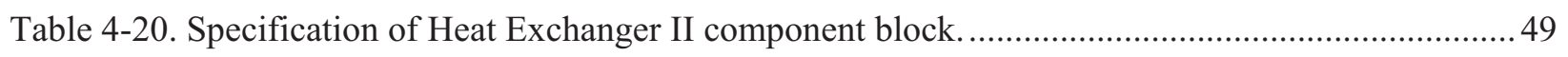

Table 4-21. Specification of Vessel-VHTR component block. ..........................................................50

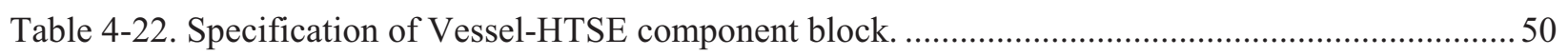

Table 4-23. Specification of Vessel-SI component block......................................................................... 51

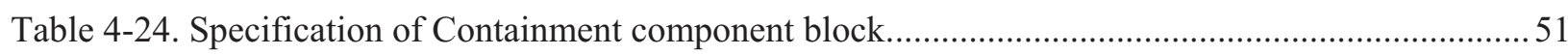

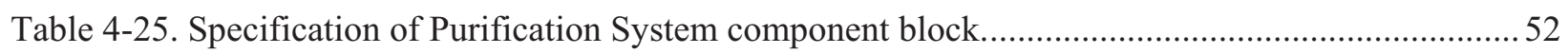

Table 4-26. Input parameters of Purification System component block...................................................52

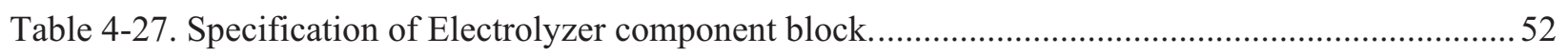

Table 4-28. Input parameters of Electrolyzer component block.............................................................52

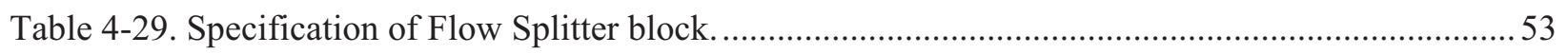

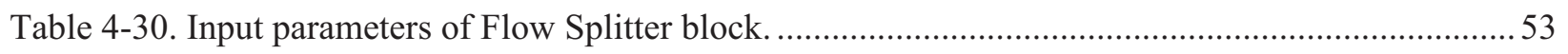

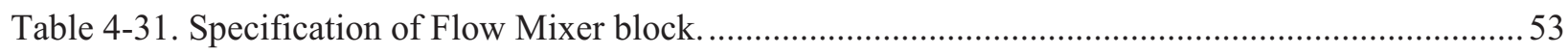

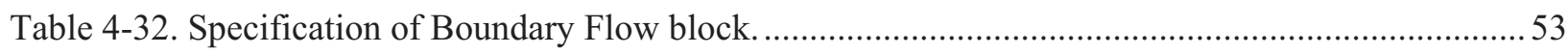

Table 4-33. Input parameters of Boundary Flow component block. ........................................................ 54

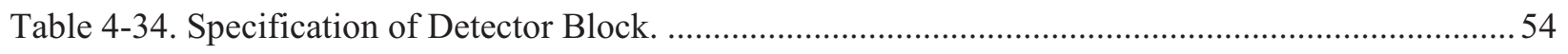

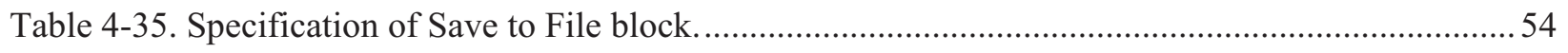

Table 4-36. Specification of Save to Workspace Block. ……............................................................... 55

Table 5-1. TPAC Input parameters for calculation of tritium birth from ternary fission............................ 60

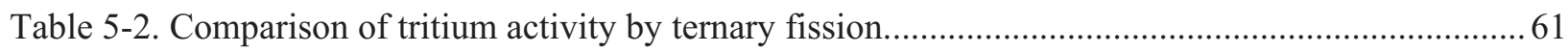

Table 5-3. Input parameters for validation of tritium birth model from ${ }^{6} \mathrm{Li}$ in the TPAC ........................ 62

Table 5-4. Comparison of tritium activity from ${ }^{6} \mathrm{Li}$ at the Core 2 operation of the Peach Bottom reactor. 
Table 5-5. Comparison of tritium activity from ${ }^{3} \mathrm{He}$ at the Core 2 operation of the Peach Bottom HTGR

Table 5-6. Input data for calculation of tritium birth from ${ }^{3} \mathrm{He}$ (Ohashi and Sherman 2007)..................66

Table 5-7. Input data for the calculation of tritium birth from ${ }^{3} \mathrm{He}$ (Ohashi and Sherman 2007).............. 66

Table 5-8. Comparison of tritium activity from ${ }^{10} \mathrm{~B}$ in the poisoned spine at the Core 2 operation

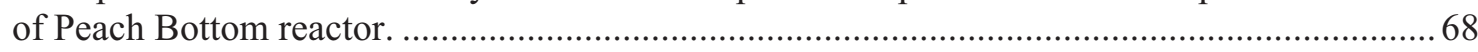

Table 5-9. The heat transfer tube dimensions of the steam generator in the Peach Bottom reactor

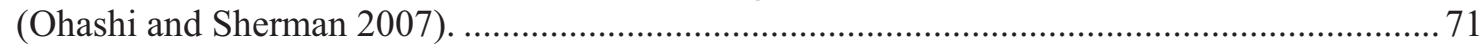

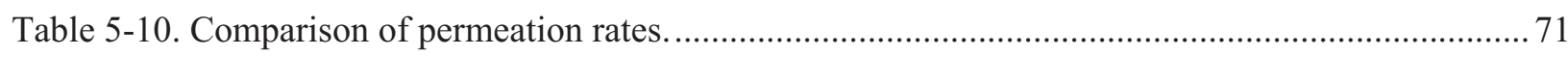

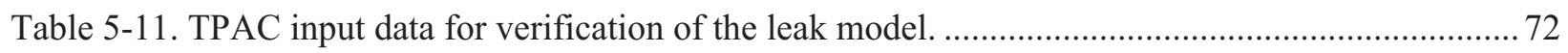

Table 5-12. THYTAN boundary conditions for verification of the purification system model

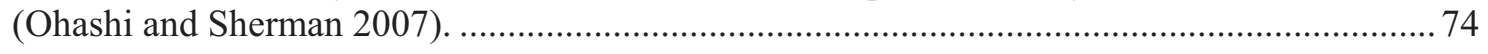

Table 5-13. Component sizes of the modeling (INL tritium code) for the Peach Bottom reactor.............. 76

Table 5-14. Dimensions of the steam generator for the Peach Bottom reactor (Ohashi and

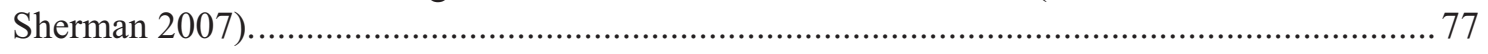

Table 5-15. Characteristics of the concentric duct for the Peach Bottom reactor (Ohashi and

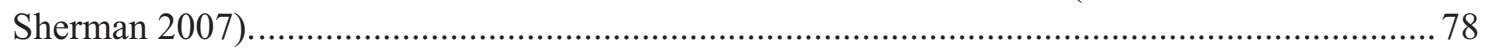

Table 6-1. Calculation results for the tritium birth rate in the high-temperature gas-cooled reactor

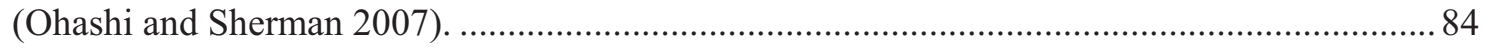

Table 6-2. Additional calculation results for the tritium birth rate in the high-temperature gas-

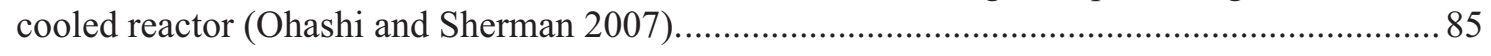

Table 6-3. TPAC input parameters in the primary side (Tritium Birth Block)........................................ 86

Table 6-4. TPAC input parameters in the primary side (Reactor Block)............................................... 86

Table 6-5. TPAC input parameters in the primary side (Hot Leg Block).............................................. 87

Table 6-6. TPAC input parameters in the primary side (Cold Leg Block). ............................................. 87

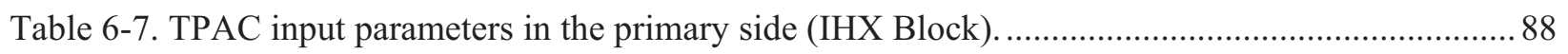

Table 6-8. TPAC input parameters in the primary side (Purification System Block)............................... 88

Table 6-9. TPAC input parameters in the secondary side (PCU Block) ................................................. 89

Table 6-10. TPAC input parameters in the secondary side (Purification System Block)......................... 89

Table 6-11. TPAC input parameters in the secondary side (Bypass Block). ........................................... 89

Table 6-12. TPAC input parameters in the secondary side (SHX Block).............................................. 90

Table 6-13. TPAC input parameters in the secondary side (Splitter Block)........................................... 90

Table 6-14. TPAC input parameters in the IHTL side (IHTL Block) .................................................... 91

Table 6-15. TPAC input parameters in the IHTL side (PHX-mod Block). ............................................. 91

Table 6-16. TPAC input parameters in the IHTL side (PHX-mod1 Block). ............................................ 92

Table 6-17. TPAC input parameters in the IHTL side (PHX-mod2 Block). ........................................... 93

Table 6-18. TPAC input parameters in the IHTL side (Flow Splitter1 Block)....................................... 93 
Table 6-19. TPAC input parameters in the IHTL side (Purification System2 Block).............................93

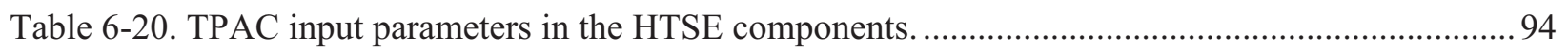

Table 6-21. TPAC input parameters in the HTSE components (Pipe-HTSE Block). ............................. 94

Table 6-22. TPAC input parameters in the HTSE components (Pipe-HTSE1 Block). ........................... 95

Table 6-23. TPAC input parameters in the HTSE components (Pipe-HTSE2 Block). ........................... 95

Table 6-24. TPAC input parameters in the HTSE components (Pipe-HTSE3 Block). ............................ 95

Table 6-25. TPAC input parameters in the HTSE components (Electrolyzer Block). ............................96

Table 6-26. TPAC input parameters in the HTSE components (Purge Flow Block). ..............................96

Table 6-27. Tritium concentration in the primary, secondary IHTL, and product hydrogen. .................. 100

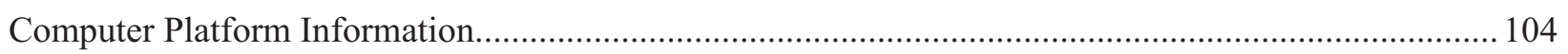




\section{ACRONYMS}

ASME American Society of Mechanical Engineers

AVR Arbeitsgemeinschaft Versuchsreaktor (Germany)

BDF backward differentiation formula

$\mathrm{Bq} \quad$ becquerel, the SI unit of radioactivity

CFD computational fluid dynamics

$\mathrm{Ci} \quad$ curie

EPA Environmental Protection Agency

FEM Finite Element Method

GCI grid convergence index

GUI graphical user interface

HT tritium gas

HTO tritiated water

HTE high-temperature electrolysis

HTR-10 High Temperature Reactor (10 MW) in China

HTGR high temperature gas-cooled reactor

HTSE high temperature steam electrolysis

HTTR high temperature test reactor

HTU heat transfer unit

IHTL intermediate heat transfer loop

IHX intermediate heat exchanger

LMTD $\quad \log$ mean temperature difference

NDF numerical differentiation formula

NGNP Next Generation Nuclear Plant

NRC Nuclear Regulatory Commission

PCU power conversion unit

PCHE printed circuit heat exchanger

PHX process heat exchanger

SHX secondary heat exchanger

SI sulfur-iodine 

very high temperature gas-cooled reactor 
xviii 


\section{Development and Verification of Tritium Analyses Code for a Very High Temperature Reactor}

\section{INTRODUCTION}

The very high temperature gas-cooled reactor (VHTR) is a helium-cooled, graphite moderated, thermal neutron spectrum nuclear reactor that will be operated at up to $9 \mathrm{MPa}$ and $950^{\circ} \mathrm{C}$. The VHTR is one of six reactor concepts recommended by the Generation IV Technology Roadmap for further development (DOE 2002). This reactor is currently envisioned as co-generation of electricity and process heat to many industries. It is regarded as one of the most promising future energy technologies because of its high efficiency, inherent passive safety features, and high temperature applications, including hydrogen production without $\mathrm{CO}_{2}$ emissions to atmosphere. Although a final reference configuration has not been established, the NGNP is expected to operate at $750-800^{\circ} \mathrm{C}$ and $5-9 \mathrm{MPa}$. The work presented here will be applicable to the NGNP Project as well as subsequent VHTR designs at higher temperatures and pressures. While specific configurations and components are assumed throughout this document, it should be understood that those assumptions are not final. Component and configuration changes - for example, use of steam generators instead of heat exchangers - may continue through the design process.

One potential problem of using VHTRs for hydrogen production applications is tritium permeation from the primary coolant to the hydrogen product through heat transfer surfaces. In VHTRs, tritium mostly comes from ternary fission of the fuel and neutron reactions with lithium impurities in the graphite, boron control materials in the reflector block, and ${ }^{3} \mathrm{He}$ naturally occurring in the helium coolant. Tritium that enters or is formed in the helium primary coolant will be circulated or permeated to the secondary coolant and the intermediate heat transfer loop. The permeated tritium enters the product hydrogen through heat exchanger surfaces. The mechanisms of tritium transport are diffusion, bulk transport, and permeation (See Figure 1-1).

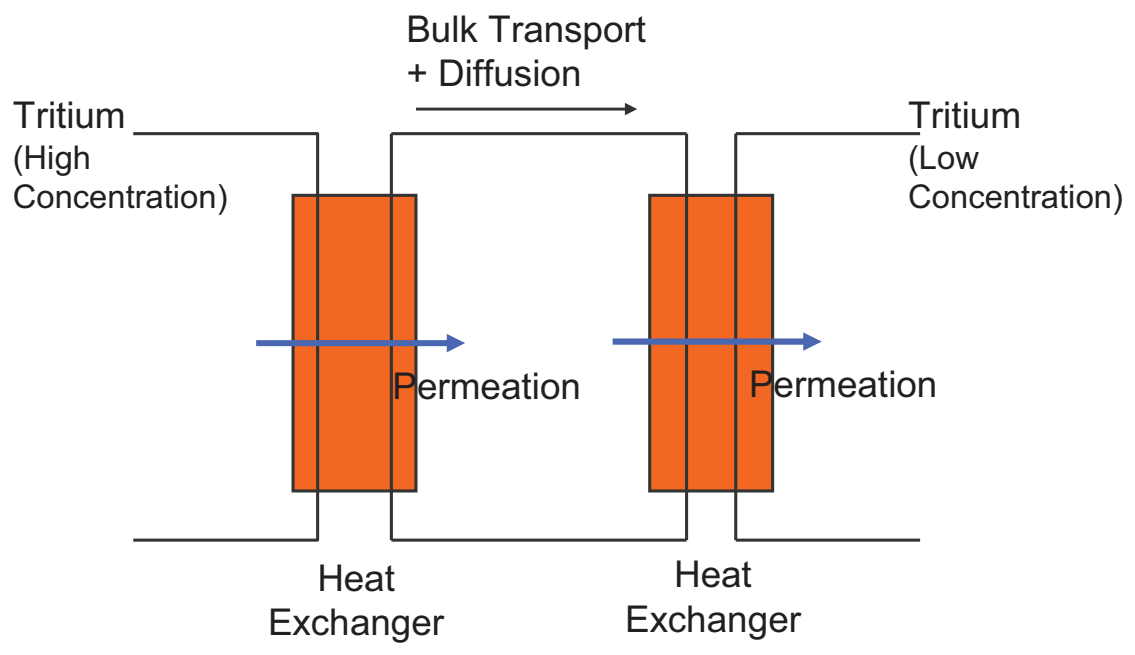

Figure 1-1. Diffusion, bulk transport, and permeation pathways of tritium in a notional heat transport loop system (Sherman and Adams 2008). 
Tritium is a radioactive isotope of hydrogen with the half life of 12.32 years, and mainly generated in the reactor core by ternary fissions and neutron reactions (Compare et al. 1974). Table 1-1 summarizes the radioactive properties of tritium. The nucleus of a tritium atom consists of a proton and two neutrons. This contrasts with the nucleus of an ordinary hydrogen atom and a deuterium atom. Ordinary hydrogen comprises over $99.9 \%$, deuterium comprises $0.02 \%$, and tritium comprises about a $10^{-16} \%$ of naturally occurring hydrogen. The chemical properties of tritium are essentially the same as ordinary hydrogen. Typically, tritium exists as a form of $\mathrm{HT}$, tritium gas $\left({ }^{1} \mathrm{H}-{ }^{3} \mathrm{H}\right)$, because of isotope exchange reactions between $\mathrm{T}_{2}\left({ }^{3} \mathrm{H}-{ }^{3} \mathrm{H}\right)$ and $\mathrm{H}_{2}$ (Wichner and Dyer 1979). Tritiated water, HTO, is another common form of tritium. In tritiated water, a tritium atom replaces one of the hydrogen atoms so the chemical form is HTO rather than $\mathrm{H}_{2} \mathrm{O}$.

Table 1-1. Radioactive Properties of Tritium.

\begin{tabular}{|c|c|c|c|c|c|c|c|}
\hline & & & & \multicolumn{3}{|c|}{ Radiation Energy (MeV) } \\
\cline { 6 - 8 } Isotope & $\begin{array}{c}\text { Half Life } \\
(\mathrm{yr})\end{array}$ & $\begin{array}{c}\text { Natural } \\
\text { Abundance }\end{array}$ & $\begin{array}{c}\text { Specific } \\
\text { Activity }\end{array}$ & $\begin{array}{c}\text { Decay } \\
\text { Mode }\end{array}$ & $\begin{array}{c}\text { Alpha } \\
(\alpha)\end{array}$ & $\begin{array}{c}\text { Beta } \\
(\beta)\end{array}$ & $\begin{array}{c}\text { Gamma } \\
(\gamma)\end{array}$ \\
\hline H-3 & 12 & $<<1$ & 9,800 & Beta $(\beta)$ & - & 0.0057 & - \\
\hline
\end{tabular}

The effect of radiation from tritium on health is relatively small and hazardous only if it is taken into the body because tritium decays by emitting a low-energy beta particle with no gamma radiation. This beta particle cannot penetrate deeply into tissue or travel far in air. The most likely form of uptake is as tritiated water. Uptake of tritium gas is typically very low (less than 1\%). The health hazard of tritium is associated with cell damages caused by the ionizing radiation that results from radioactive decay, with the potential for subsequent cancer induction. Nearly all (up to 99\%) inhaled tritium can be taken into the body from the lungs, where circulating blood then distributes it to all tissues. Ingested tritium oxide is almost completely absorbed, moving quickly from the gastrointestinal tract to the bloodstream. Within minutes it is found in varying concentrations in body fluids, organs, and other tissues. Generally, tritium is uniformly distributed through all biological fluids within one to two hours. Tritium is eliminated from the body with a biological half-life of 10 days, the same as for water.

In the U.S., tritium emissions are regulated by the U.S. Nuclear Regulatory Commission (NRC) and U.S. Environmental Protection Agency (EPA). Table 1-2 summaries the regulatory constraints on tritium.

Table 1-2. Regulatory constraints on tritium in the U.S. (Ohashi and Sherman 2007).

\begin{tabular}{llcc|cccc}
\hline & & \multicolumn{2}{c}{$\begin{array}{c}\text { Annual } \\
\text { Radiation Dose }\end{array}$} & \multicolumn{3}{c}{ Effluent Concentration } \\
& \multicolumn{1}{c}{ Regulation } & $(\mathbf{m r e m})$ & \multicolumn{3}{c}{ Air } & \multicolumn{2}{c}{ Water } \\
& & $(\mathbf{m S v})$ & $(\boldsymbol{\mu C i} / \mathbf{m l})$ & $(\mathbf{B q} / \mathbf{m l})$ & $(\boldsymbol{\mu C i} / \mathbf{m l})$ & $(\mathbf{B q} / \mathbf{m l})$ \\
\hline Limit & 10 CFR 20.1301(a) & 100 & 1 & - & - & - & - \\
& Table 2 of & 50 & 0.5 & $1 \times 10^{-7}$ & $3.7 \times 10^{-3}$ & $1 \times 10^{-3}$ & 37 \\
& Appendix B to & & & & & & \\
& 10 CFR 20 & & & & & & \\
Standard & 10 CFR 20.1301(e) & 25 & 0.25 & $\left(5 \times 10^{-8}\right)^{\mathrm{a}}$ & $\left(1.85 \times 10^{-3}\right)^{\mathrm{a}}$ & $\left(5 \times 10^{-4}\right)^{\mathrm{a}}$ & $(18.5)^{\mathrm{a}}$ \\
ALARA & Appendix I to & 15 & 0.15 & $\left(3 \times 10^{-8}\right)^{\mathrm{a}}$ & $\left(1.11 \times 10^{-3}\right)^{\mathrm{a}}$ & - & - \\
& 10 CFR 50 & 3 & 0.03 & - & - & $\left(6 \times 10^{-5}\right)^{\mathrm{a}}$ & $(2.22)^{\mathrm{a}}$ \\
Drinking & EPA standard & 4 & 0.04 & - & - & $2 \times 10^{-5}$ & 0.74 \\
Water & & & & & & & \\
\hline
\end{tabular}

a. Calculated by assuming the linear relationship between the annual dose of 50 mrem and the values in Table 2 of Appendix B of 10 CFR 20.

$\mathrm{ALARA}=$ as low as reasonably achievable 
CFR $=$ Code of Federal Regulations

$\mathrm{EPA}=$ U.S. Environmental Protection Agency

Because of its small size, the tritium atom can easily penetrate through metal by diffusion. Especially in VHTRs, large portions of tritium in the primary coolant permeate through the heat exchanger surfaces of the intermediate heat exchanger (IHX) and process heat exchanger (PHX). It then mixes into the process chemicals of the hydrogen plant eventually contaminating the hydrogen products (Ohashi and Sherman 2007).

Tritium behavior in high temperature gas-cooled reactors (HTGR) was evaluated in several countries in the 1970s, e.g., the Dragon reactor in England (Forsyth 1974), the Peach Bottom HTGR in the U.S. (Wichner and Dyer 1979), and Arbeitsgemeinschaft Versuchsreaktor (AVR) in Germany (Steinwarz, Rohrig, and Nieder 1980). Data from the operation of HTGRs and from laboratory experiments revealed the mechanism of tritium production, transport, and release to the environment. In his review of tritium behavior in an HTGR system, Gainey's (1976) calculations show that tritium releases should be well within current federal guidelines for the nuclear plant. For example, the estimated maximum dose to an average adult for a typical 3,000-MWt HTGR with a cooling tower is $0.38 \mathrm{mrem} / \mathrm{year}$, which is slightly more than one-tenth of the maximum annual dose allowed (Gainey 1976). For this reason, no further laboratory-scale work on tritium was required at that time. However, their tritium calculations were only concerned with general tritium release and did not examine questions related to nuclear hydrogen production. NGNP will use the HTGR as a heat source to produce hydrogen for industry or individual users.

Ohashi and Sherman (2007) recently estimated steady-state tritium movement and accumulation in an NGNP with a hydrogen plant using a high temperature electrolysis process and a thermochemical water splitting sulfur-iodine (SI) process using the THYTAN code. Estimated tritium concentrations in product hydrogen and in process chemicals in the hydrogen plant of the NGNP using the high temperature electrolysis process were slightly higher than the drinking water limit defined by the EPA and the limit in the effluent at the boundary of an unrestricted area of a nuclear plant as defined by the NRC. However, modified designs and operations could bring these concentrations within specified limits. Tritium concentrations in the NGNP using the SI process were calculated to be significantly higher and were affected by parameters with large uncertainties (tritium permeability of the PHX, the hydrogen concentration in the heat transfer and process fluids, and the equilibrium constant of the isotope exchange reaction between $\mathrm{HT}$ and $\mathrm{H}_{2} \mathrm{SO}_{4}$ ). These parameters, including tritium generation and the release rate in the reactor core, should be more accurately estimated in the near future to improve the calculations for the SI process. Decreasing the tritium permeation through the heat exchanger between the primary and secondary circuits by means of tritium permeation barriers, capture systems, and mitigation measures may be an effective method for decreasing tritium concentrations in product hydrogen, hydrogen plant, and tertiary coolant.

The main objective of the current research is to develop a computer code to analyze tritium behaviors in the VHTR systems as continuation of FY-08 work. The code is named "Tritium Permeation Analyses Code" (TPAC), and it is written in MATLAB SIMULINK Package. The TPAC was originally developed for analyses of tritium production and distribution in VHTRs and hydrogen production systems. However, the capability is not limited to only VHTR systems. Flexibility of the code can be extended by simple modifications to the general chemical systems that include tritium. The TPAC can solve the generations of tritium source and tritium transport equations, including the penetration of tritium through the heat exchanger wall. The details are described in this report. 


\section{SOURCES AND PATHWAYS OF TRITIUM IN VHTR}

\subsection{Tritium Source}

The tritium generation mechanism in VHTRs is well described by Gainey (1976), and Ohashi and Sherman (2007). The primary tritium birth mechanism is ternary fission of fuel (e.g. ${ }^{233} \mathrm{U},{ }^{235} \mathrm{U},{ }^{239} \mathrm{Pu}$, and ${ }^{241} \mathrm{Pu}$ ) because of thermal neutrons. Tritium is also generated in VHTR from ${ }^{6} \mathrm{Li},{ }^{7} \mathrm{Li},{ }^{3} \mathrm{He}$, and ${ }^{10} \mathrm{~B}$ by neutron capture reactions as:

${ }^{6} \mathrm{Li}(\mathrm{n}, \alpha){ }^{3} \mathrm{H}$,

${ }^{7} \mathrm{Li}(\mathrm{n}, \mathrm{n} \alpha){ }^{3} \mathrm{H}$

${ }^{3} \mathrm{He}(\mathrm{n}, \mathrm{p}){ }^{3} \mathrm{H}$

${ }^{10} \mathrm{~B}(\mathrm{n}, 2 \alpha){ }^{3} \mathrm{H}$

${ }^{10} \mathrm{~B}(\mathrm{n}, \alpha){ }^{7} \mathrm{Li}$.

${ }^{6} \mathrm{Li}$ and ${ }^{7} \mathrm{Li}$ are impurities in the core graphite material such as the sleeve, spine, reflector, and fuel matrix. ${ }^{3} \mathrm{He}$ is an impurity in the reactor coolant helium. Because helium coolant leaks from the primary loop to the containment vessel, helium is supplied to the primary coolant as a make-up with an impurity of ${ }^{3} \mathrm{He}$. ${ }^{10} \mathrm{~B}$ exists in control rods, burnable poisons, and reflectors. Tritium is produced directly from ${ }^{10} \mathrm{~B}$ via Equation (2-4) or via the chain reaction in Equations (2-2) and (2-5).

\subsection{Distribution of Tritium}

Tritium generated in the fuel particles by ternary fissions can escape into a primary coolant, permeating several barriers of the fuel particles. In addition, tritium born from ${ }^{10} \mathrm{~B}$ and ${ }^{6} \mathrm{Li}$ can pass into the primary coolant. The principal chemical form for tritium in the reactor coolant was reported as HT $\left({ }^{1} \mathrm{H}-{ }^{3} \mathrm{H}\right)$ because of the isotope exchange reaction between $\mathrm{T}_{2}\left({ }^{3} \mathrm{H}-{ }^{3} \mathrm{H}\right)$ and $\mathrm{H}_{2}$ (Wichner and Dyer 1979). Some of the tritium in the primary coolant is removed by a purification system installed in the primary loop. Some of the tritium can escape outside the coolant by permeation through the components and piping and by leakage with the primary helium coolant. The remaining tritium in the primary coolant permeates through the heat transfer tubes or surfaces of the IHX and gets mixed in with the secondary coolant.

In the secondary loop, some of the tritium is removed by the purification system or escapes outside, just as tritium behaves in the primary loop. The remainder of the tritium in the secondary coolant permeates through heat transfer surfaces and gets mixed into the tertiary coolant. Transportation of tritium into the tertiary coolant is the same as for the secondary coolant. It permeates through the heat transfer surfaces of PHXs and is mixed into the process chemicals of the hydrogen plant.

Tritium that has permeated the tertiary loop going to the hydrogen plant can react with hydrogen-containing process chemicals through isotopic exchange reactions. For example, the hightemperature electrolysis (HTE) process contains $\mathrm{H}_{2} \mathrm{O}$. Therefore, $\mathrm{HTO}$ (tritiated water) is produced by the isotope exchange reaction between $\mathrm{HT}$ and $\mathrm{H}_{2} \mathrm{O}$. Gaseous HTO and HT escape from the HTE process with the product hydrogen and oxygen. A portion of the liquid HTO flows out from the hydrogen plant with the drain water. The remainder of the liquid HTO is circulated into the plant with the recycling water and is accumulated in the water of the HTE process. The SI process used in hydrogen production also contains $\mathrm{H}_{2} \mathrm{O}, \mathrm{H}_{2} \mathrm{SO}_{4}$, and $\mathrm{HI}$ chemicals from which $\mathrm{HTO}, \mathrm{HTSO}_{4}$, and TI may be produced through isotope exchange reactions. These tritium-containing chemicals are circulated with and are accumulated 
in process the chemicals. Only gaseous HT and HTO can escape from the SI process with the product hydrogen and oxygen.

The above tritium pathways in VHTRs are illustrated in Figure 2-1. All of the production mechanisms lead to either retention in solids or entry into coolant systems. The tritium in the primary coolant can be adsorbed on graphite surfaces, leaked out of the primary circuit, removed from the purification system, or permeated to the process heat application system like hydrogen production.

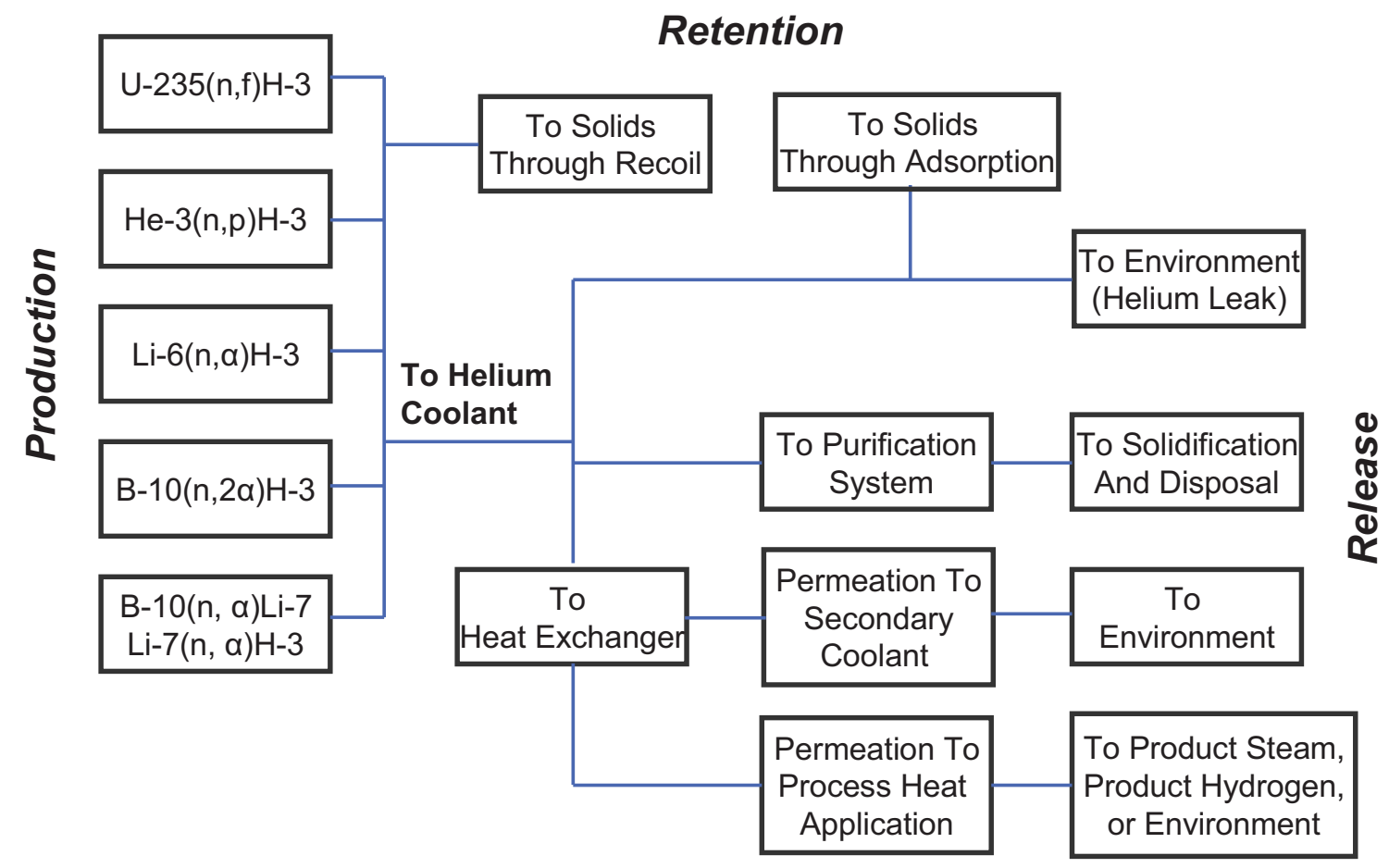

Figure 2-1. General tritium pathways in VHTRs.

Figure 2-2 shows the tritium distribution calculated by Ohashi and Sherman (2007) for a VHTR/HTE system at steady state. The calculation was performed with the THYTAN code developed in Japan and used by the Japan Atomic Energy Agency (JAEA) (Ohashi and Sherman 2007). According to their calculations, $30.7 \%$ of the tritium released from the core is removed by the purification system in the primary loop. A small portion of tritium $(\sim 0.11 \%)$ leaks to the outside from the primary loop with helium leakage. The remainder of the tritium $(69.1 \%)$ permeates into the secondary loop through a heat exchanger. For the secondary loop, $30.3 \%$ of the tritium, which is about one half of the permeated tritium from the primary loop, is removed by the purification system. Consequently, $38.7 \%$ of tritium permeates from the secondary helium loop to the tertiary loop through the SHX. In the tertiary loop, almost all of the tritium permeated from the secondary loop is removed by the purification system. Tritium permeation rates from the tertiary loop to the main line and to the sweep line of the HTE process are $0.946 \%$ and $2.499 \%$, respectively. However, depending on the system designs and operating conditions, the specified values can be completely different from their base calculations. 


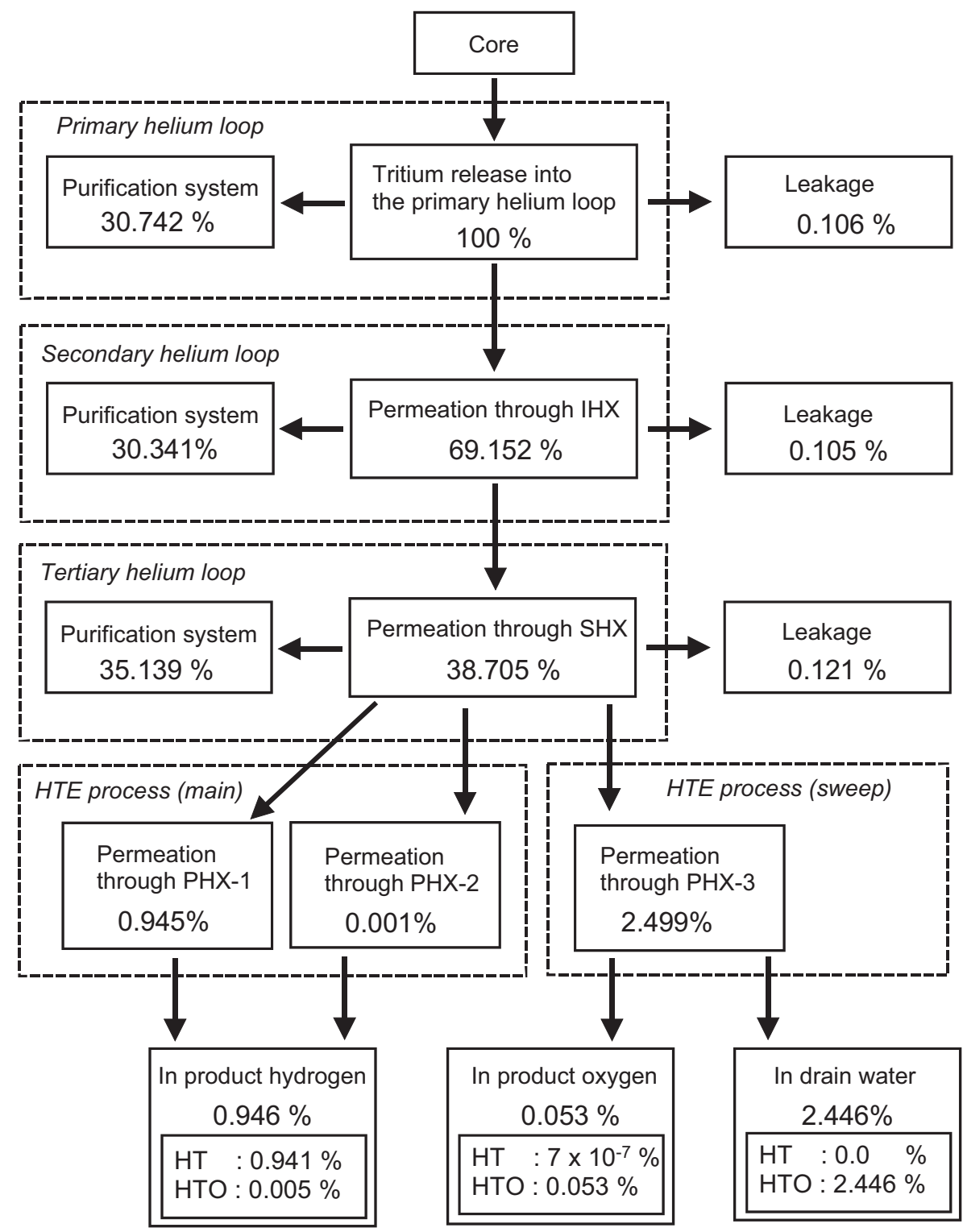

Figure 2-2. Tritium distribution in the VHTR system (Ohashi and Sherman 2007). 


\section{THEORY}

This section summarizes the theory adopted in the TPAC. The TPAC is capable of modeling tritium behaviors in the simplified representations of the VHTR, HTE, and SI processes. The following phenomena are taken into consideration in this code:

- Mass balance of the species $\left(\mathrm{H}_{2}, \mathrm{HT}, \mathrm{HTO}, \mathrm{HTSO}_{4}\right.$, and TI)

- Tritium and hydrogen permeation through the heat transfer surface

- Tritium and hydrogen permeation to outside through the pipe wall

- Tritium and hydrogen removal by the purification system

- Tritium and hydrogen leakage by helium leakage

- Isotope exchange between tritium containing and hydrogen containing chemicals

- Species movement in the electrolyzer.

\subsection{Mass Balance}

The TPAC basically solves the mass balance of tritium-containing chemicals and hydrogen in each component block as follows:

$$
\begin{aligned}
& V_{j} \frac{d C_{i, j}}{d t}=\sum\left(F_{\text {total }, j-1} \cdot C_{i, j-1}\right)-F_{\text {total }, j} \cdot C_{i, j}-S_{i, j} \\
& S_{i, j}=-R_{\text {core }, i, j}+R_{H X, i, j}+R_{\text {copipe }, i, j}+R_{\text {comp }, i, j}+R_{\text {leak }, i, j}+R_{P F, i, j}+R_{\text {reaction }, i, j}
\end{aligned}
$$

where

$$
\begin{array}{lll}
V_{j} & = & \text { the volume of block } \mathrm{j}[\mathrm{m} 3(\mathrm{STP})] \\
C_{i, j} & = & \text { the volume fraction of chemical i in block } \mathrm{j}[\mathrm{m} 3(\mathrm{STP}) / \mathrm{m} 3(\mathrm{STP})] \\
t & = & \text { time }[\mathrm{s}] \\
F_{\text {total }, j} & = & \text { the volumetric flow rate of all chemicals in block } \mathrm{j}[\mathrm{m} 3(\mathrm{STP}) / \mathrm{s}] \\
S_{i, j} & = & \text { the total amount of volume change rate of chemical } \mathrm{i} \text { in block } \mathrm{j} \text { by considering } \\
& & \text { generation, release, permeation, removal, leakage, and isotope exchange reactions } \\
R_{\text {core }, i, j}= & \text { volumetric release rate from the core to the primary coolant }[\mathrm{m} 3(\mathrm{STP}) / \mathrm{s}] \\
R_{H X, i, j}= & \text { volumetric permeation rate at heat exchanger }(\mathrm{i}=\mathrm{H} 2 \text { and } \mathrm{HT})[\mathrm{m} 3(\mathrm{STP}) / \mathrm{s}] \\
R_{\text {copipe }, i, j}= & \text { volumetric permeation rate at co-axial pipe }(\mathrm{i}=\mathrm{H} 2 \text { and } \mathrm{HT})[\mathrm{m} 3(\mathrm{STP}) / \mathrm{s}] \\
R_{\text {comp }, i, j}= & \text { volumetric permeation rate to outside }(\mathrm{i}=\mathrm{H} 2 \text { and } \mathrm{HT})[\mathrm{m} 3(\mathrm{STP}) / \mathrm{s}] \\
R_{\text {leak }, i, j}= & \text { volumetric leak rate with helium leakage }(\mathrm{i}=\mathrm{H} 2, \mathrm{HT} \text { and } \mathrm{HTO})[\mathrm{m} 3(\mathrm{STP}) / \mathrm{s}] \\
R_{P F, i, j}= & \text { volumetric removal rate by purification system }(\mathrm{i}=\mathrm{H} 2, \mathrm{HT} \text { and } \mathrm{HTO})[\mathrm{m} 3(\mathrm{STP}) / \mathrm{s}]
\end{array}
$$




$$
\begin{aligned}
R_{\text {reaction }, i, j=}= & \text { volumetric reaction rate by isotope exchange reactions }(\mathrm{i}=\mathrm{H} 2, \mathrm{HT}, \mathrm{HTO}, \mathrm{HTSO} 4 \\
& \text { and } \mathrm{TI})[\mathrm{m} 3(\mathrm{STP}) / \mathrm{s}] .
\end{aligned}
$$

\subsection{Tritium Source}

There are five different sources for tritium generation in the reactor core: ternary fission, birth from ${ }^{6} \mathrm{Li}$, birth from ${ }^{7} \mathrm{Li}$, birth from ${ }^{3} \mathrm{He}$, and birth from ${ }^{10} \mathrm{~B}$. Table $3-1$ summarizes the tritium production sources and total contributions. The detail equations for each source are described in the sections that follow.

Table 3-1. Sources of tritium production in VHTRs.

\begin{tabular}{|l|l|l|}
\hline Tritium Source & $\%$ total & Release Potential \\
\hline Ternary Fission & 62 & Time at temperature \\
\hline From ${ }^{3} \mathrm{He}$ & 18 & Produced in He coolant \\
\hline From ${ }^{6} \mathrm{Li}$ & & Partly retained in graphite; \\
- $\quad$ Core Graphite & 2 & Release during $\mathrm{H}_{2} \mathrm{O}$ ingress \\
- Core Matrix & 10 & \\
- Reflector (replaceable) & $<1$ & \\
- Reflector (permanent) & $<1$ & Apparently retained at Source \\
\hline From ${ }^{10} \mathrm{~B}$ & & \\
- Control Rod & 7 & \\
- Burnable Poisson & 1 & \\
- Reflector & $<1$ & \\
\hline
\end{tabular}

\subsubsection{Ternary Fission}

Tritium yields formed by ternary fission depend on the uranium isotope undergoing fission and the neutron flux.

$\frac{d\left(N_{T(T e r)}\right)}{d t}=K \cdot P \cdot Y-\lambda \cdot N_{T(T e r)}$

where

$N_{T(T e r)}=$ number of tritium atoms from ternary fission

$K=$ fission rate per thermal megawatt [fission/MW/s]

$P \quad=\quad$ reactor power $[\mathrm{MW}]$

$Y \quad=$ average yield per fission [1/fission]

$\lambda=$ tritium decay constant $[1 / \mathrm{s}]$.

Table 3-2 summarizes the necessary information for calculating tritium production by ternary fission. 
Table 3-2. Basic data for THYTAN evaluation of ternary fission.

\begin{tabular}{|c|c|c|}
\hline & Unit & Values \\
\hline Reactor Power (P) & MWth & 600 \\
\hline Fission Rate (K) & Fissions/MW sec & $3.12 \mathrm{e} 16$ \\
\hline Average Yield Per Fission (Y) & 1/fission & $1.0 \mathrm{e}-4$ \\
\hline Failure Fraction of Fuel Particles & - & 0.3 \\
\hline
\end{tabular}

\subsubsection{Birth from ${ }^{6} \mathrm{Li}$}

As described, tritium is produced in the VHTR by various sources such as ternary fissions and activation reactions with impurities and boron in the materials. Table 2-13 summarizes the tritium production reactions and cross sections (Wichner and Dyer 1979).

Table 3-3. Tritium production reaction and cross section (Wichner and Dyer 1979).

\begin{tabular}{|c|c|c|}
\hline Production Reaction & Cross section (barns) & Energy range (eV) \\
\hline${ }^{3} \mathrm{He}(\mathrm{n}, \mathrm{p}) \mathrm{T}$ & 2,280 & $0-2.38$ \\
\hline${ }^{6} \mathrm{Li}(\mathrm{n}, \mathrm{a}) \mathrm{T}$ & 408 & $0-2.38$ \\
\hline${ }^{10} \mathrm{~B}(\mathrm{n}, 2 \mathrm{a}) \mathrm{T}$ & 0.050 & $>0.18 \times 10^{6}$ \\
\hline${ }^{10} \mathrm{~B}(\mathrm{n}, \mathrm{a}){ }^{7} \mathrm{Li}$ & 1,630 & $0-2.38$ \\
\hline${ }^{7} \mathrm{Li}(\mathrm{n}, \mathrm{n}$ 'a) $\mathrm{T}$ & 0.153 & $>0.18 \times 10^{6}$ \\
\hline
\end{tabular}

The birth of tritium from ${ }^{6} \mathrm{Li}$, which is an impurity in the core and reflector graphite materials, is estimated by

$$
\begin{aligned}
& \frac{d\left(N_{L i 6}\right)}{d t}=-\phi_{t h} \cdot \sigma_{L i 6 T} \cdot N_{L i 6} \text { and } \\
& \frac{d\left(N_{T(L i 6)}\right)}{d t}=\phi_{t h} \cdot \sigma_{L i 6 T} \cdot N_{L i 6}-\lambda \cdot N_{T(L i 6)}
\end{aligned}
$$

where

$$
\begin{aligned}
& N_{L i 6}=\text { number of }{ }^{6} \mathrm{Li} \text { atoms } \\
& N_{T(L i 6)}=\text { number of tritium atoms from }{ }^{6} \mathrm{Li} \\
& \left.\phi_{t h}=\text { thermal neutron flux [neutrons } / \mathrm{cm}^{2} / \mathrm{s}\right] \\
& \sigma_{L i 6 T}=\text { effective cross section for }{ }^{6} \mathrm{Li}(\mathrm{n}, \alpha){ }^{3} \mathrm{H}\left[\mathrm{cm}^{2}\right] .
\end{aligned}
$$




\subsubsection{Birth from ${ }^{7} \mathrm{Li}$}

The birth of tritium from ${ }^{7} \mathrm{Li}$ is estimated by

$\frac{d\left(N_{L i 7}\right)}{d t}=-\phi_{f} \cdot \sigma_{L i 7 H 3} \cdot N_{L i 7}$ and

$\frac{d\left(N_{T(L i 7)}\right)}{d t}=\phi_{f} \cdot \sigma_{L i 7 T} \cdot N_{L i 7}-\lambda \cdot N_{T(L i 7)}$

where

$$
\begin{aligned}
& N_{L i 7}=\text { number of }{ }^{7} \mathrm{Li} \text { atoms, excluding }{ }^{10} \mathrm{~B} \text { source } \\
& N_{T(L i 7)}=\text { number of tritium atoms from }{ }^{7} \mathrm{Li} \text {, excluding birth from }{ }^{10} \mathrm{~B} \\
& \left.\phi_{f}=\text { fast neutron flux [neutrons } / \mathrm{cm}^{2} / \mathrm{s}\right] \\
& \sigma_{L i 7 T}=\text { effective cross section for }{ }^{7} \mathrm{Li}(\mathrm{n}, \mathrm{n} \alpha){ }^{3} \mathrm{H}\left[\mathrm{cm}^{2}\right] .
\end{aligned}
$$

\subsubsection{Birth from ${ }^{3} \mathrm{He}$}

Tritium is produced from ${ }^{3} \mathrm{He}$ via $\mathrm{n}(\mathrm{n}, \mathrm{p})$ reaction with thermal neutrons in the primary coolant. The natural abundance of ${ }^{3} \mathrm{He}$ in helium ranges from $1.3 \times 10^{-6}$ to $2 \times 10^{-7}$. The ${ }^{3} \mathrm{He}$ reaction has a relatively high thermal neutron cross section. The following equations express tritium birth from ${ }^{3} \mathrm{He}$.

$$
\begin{aligned}
& \frac{d\left(N_{H e 3}\right)}{d t}=f \cdot N_{H e 3}^{\circ}-f \cdot N_{H e 3}-\phi_{H e} \cdot \sigma_{H e 3 T} \cdot N_{H e 3} \\
& \frac{d\left(N_{T(H e 3)}\right)}{d t}=\phi_{H e} \cdot \sigma_{H e 3 T} \cdot N_{H e 3}-\lambda \cdot N_{T(H e 3)} \\
& \phi_{H e}=\frac{W_{\text {core }}}{W_{\text {total }}} \cdot \phi_{t h}
\end{aligned}
$$

where

$$
\begin{aligned}
& N_{H e 3}=\text { number of }{ }^{3} \mathrm{He} \text { atoms } \\
& N_{T(H e 3)}=\text { number of tritium atoms from }{ }^{3} \mathrm{He} \\
& f \quad=\text { fractional supply rate of helium coolant }[1 / \mathrm{s}] \\
& N_{H e 3}^{\circ}=\text { number of }{ }^{3} \mathrm{He} \text { atoms in the supply helium } \\
& \sigma_{H e 3 T}=\text { effective cross section for }{ }^{3} \mathrm{He}(\mathrm{n}, \mathrm{p}) \mathrm{T}\left[\mathrm{cm}^{2}\right] \\
& \phi_{H e}=\text { average thermal neutron flux experienced by the total primary helium inventory }\left[\mathrm{n} / \mathrm{cm}^{2} / \mathrm{s}\right] \\
& W_{\text {core }}=\text { helium inventory in core }[\mathrm{kg}] \\
& W_{\text {total }}=\text { total primary helium inventory }[\mathrm{kg}] .
\end{aligned}
$$




\subsubsection{Birth from ${ }^{10} \mathrm{~B}$}

Tritium birth from 10B can be expressed by

$$
\begin{aligned}
& \frac{d\left(N_{B 10}\right)}{d t}=-\left(\phi_{t h} \cdot \sigma_{B 10 L i 7}+\phi_{f} \cdot \sigma_{B 10 T}\right) \cdot N_{B 10} \\
& \frac{d\left(N_{L i 7(B 10)}\right)}{d t}=\phi_{t h} \cdot \sigma_{B 10 L i 7} \cdot N_{B 10}-\phi_{f} \cdot \sigma_{L i 7 T} \cdot N_{L i 7(B 10)} \\
& \frac{d\left(N_{T(B 10)}\right)}{d t}=\phi_{f} \cdot \sigma_{L i 7 T} \cdot N_{L i 7(B 10)}+\phi_{f} \cdot \sigma_{B 10 T} \cdot N_{B 10}-\lambda \cdot N_{T(B 10)}
\end{aligned}
$$

where

$$
\begin{array}{ll}
N_{B 10} & =\text { number of }{ }^{10} \mathrm{~B} \text { atoms } \\
N_{L i 7(B 10)} & =\text { number of }{ }^{7} \mathrm{Li} \text { atoms from }{ }^{10} \mathrm{~B} \\
N_{T(B 10)} & =\text { number of tritium from }{ }^{10} \mathrm{~B} \\
\sigma_{B 10 L i 7} & =\text { effective cross section for }{ }^{10} \mathrm{~B}(\mathrm{n}, \alpha){ }^{7} \mathrm{Li}\left[\mathrm{cm}^{2}\right] \\
\sigma_{B 10 T} & =\text { effective cross section for }{ }^{10} \mathrm{~B}(\mathrm{n}, 2 \alpha){ }^{3} \mathrm{H}\left[\mathrm{cm}^{2}\right] .
\end{array}
$$

\subsubsection{Tritium Release Rate}

After formation, tritium can rest in solids or circulate in the coolant. The retention of tritium in solids is well summarized in the GA report published in 2006 (GA-911081). The following description is the guideline for determining tritium retention fraction proposed by GA:

A steady-state retention fraction is assigned for each reaction chain. In the fuel, it is assumed that tritium formed in cracked particles or from contaminants on particles escapes readily while that formed within intact TRISO particles is strongly retained. Less than $1 \%$ of the particles are expected to be defective or fail during irradiation. Therefore, a tritium retention fraction of 0.99 is generally recommended. However, more investigation needs to be performed later.

The chains that involve reactions of nuclides in the solid phase to produce tritium depend on the content and location of possible boron and lithium impurities in graphite, which are not well known. The release rate of tritium, which is bound interstitially in graphite, is expected to be quite slow because a temperature of at least $1,200^{\circ} \mathrm{C}$ is required for tritium desorption from graphite. A retention fraction of 0.99 was recommended as an input to TRITGO (General Atomics 2006) for these reaction chains.

Each region solid is assumed to have uniform properties, but this is not necessarily a good assumption for reflector blocks containing localized boron pins. Treating these regions as if boron were uniformly dispersed throughout the graphite may cause the average reaction rate for this boron to be too high. In the case of control rods, the major lithium content is in the metal. The retention of tritium formed from this source may be over-predicted because tritium escapes more readily from metal than from graphite.

The control rods will not be fully inserted. An insertion fraction of about $11 \%$ is frequently cited. The relationship between extra gas space under rods, degree of rod insertion, etc., has not been treated as a variable. 
Tritium from the ${ }^{3} \mathrm{He}(\mathrm{n}, \mathrm{p}) \mathrm{T}$ reaction in the primary coolant will come to rest in solids as fractions, which vary from region to region depending on the space associated with channels and fabricated holes, clearance annuli, and pores. The following paragraphs summarize the method to calculate the average fraction of tritium that recoils into solids.

The recoil energy of a tritium $\left({ }^{3} \mathrm{H}\right)$ is about $0.2 \mathrm{MeV}$, leading to an estimated range of $0.05 \mathrm{~cm}$ in helium at $47.6 \mathrm{~atm}$ and $1,000^{\circ} \mathrm{C}$. In the case of pores, because they are generally smaller than $0.05 \mathrm{~cm}$, the fraction bound is taken as unity. A planar approximation is used for the clearance annuli (tolerances between graphite blocks or between the fuel rods and the graphite blocks containing them). If the width of the gap exceeds the recoil range,

Fraction Bound $=$ range $/(2 \cdot$ width $)$, range $<$ width,

If the width of the gap is less than the recoil range,

Fraction Bound $=($ range - width $/ 2) /$ range, range $>$ width

For large cylindrical channels or holes,

Fraction Bound = range/ channel diameter

Based on above guidelines, the tritium release rate from the core to the primary coolant, $R_{\text {core }, H T, j}\left[\mathrm{~m}^{3}\right.$ $(\mathrm{STP}) / \mathrm{s}]$, is calculated using the following equations:

$$
\begin{aligned}
\frac{N_{T(\text { total })}=}{d t}= & \sum\left\{\alpha_{T e r} \frac{d\left(N_{T(T e r)}\right)}{d t}\right\}+\sum\left[\alpha_{L i}\left\{\frac{d\left(N_{T(L i 6)}\right)}{d t}+\frac{d\left(N_{T(L i 7)}\right)}{d t}\right\}\right] \\
& +\sum\left\{\alpha_{H e 3} \frac{d\left(N_{T(H e 3)}\right)}{d t}\right\}+\sum\left\{\alpha_{B 10} \frac{d\left(N_{T(B 10)}\right)}{d t}\right\} \\
R_{\text {core }, H T, j}= & \frac{N_{T(t o t a l)}}{d t} \times \frac{1}{N_{A}} \times \frac{R \cdot T_{0}}{P_{0}}
\end{aligned}
$$

where

$$
\begin{array}{ll}
N_{T(\text { release })} & =\text { number of tritium atoms released to the primary coolant } \\
\alpha_{T e r} & =\text { fractional release ratio of tritium produced from ternary fission } \\
\alpha_{L i} & =\text { fractional release ratio of tritium produced from }{ }^{6} \mathrm{Li} \text { and }{ }^{7} \mathrm{Li} \\
\alpha_{H e 3} & =\text { fractional release ratio of tritium produced from }{ }^{3} \mathrm{He} \\
\alpha_{B 10} & =\text { fractional release ratio of tritium produced from }{ }^{10} \mathrm{~B} \\
N_{A} & =\text { Avogadro constant } \\
R & =\text { gas constant }(8.314) \\
T_{0} & =\text { standard temperature }(273.15 \mathrm{~K}) \\
P_{0} & =\text { standard pressure }\left(1.01325 \times 10^{5} \mathrm{~Pa}\right) .
\end{array}
$$




\subsection{Permeation}

In the VHTR system, heat exchangers are the main route of tritium permeation. It is therefore very important to predict accurate tritium penetration rates when estimating the tritium distributions and contamination levels in hydrogen from the hydrogen production plant. The permeation rate of $\mathrm{H}_{2}$ at the heat exchanger, $R_{H X, H 2}\left[\mathrm{~m}^{3}(\mathrm{STP}) / \mathrm{s}\right]$, and at the co-axial pipe, $R_{\text {copipe } H 2}\left[\mathrm{~m}^{3}(\mathrm{STP}) / \mathrm{s}\right]$, is generally estimated using

$$
R_{H X, H 2, j}\left(\text { or } \quad R_{\text {copipe }, H 2, j}\right)=\frac{A}{l} \cdot k_{p, H} \cdot\left(\sqrt{P_{H 2, h}}-\sqrt{P_{H 2, l}}\right)
$$

where

$A=$ heat transfer area or surface area $\left[\mathrm{m}^{2}\right]$

$l=$ thickness of heat transfer tube or component casing [m]

$k_{p, H}=$ permeability of hydrogen $\left[\mathrm{m}^{3}(\mathrm{STP}) / \mathrm{m} / \mathrm{s} / \mathrm{Pa}^{0.5}\right]$

$P_{H 2, h}=$ partial pressure of $\mathrm{H}_{2}$ at high pressure side $[\mathrm{Pa}]$

$P_{H 2, l}=$ partial pressure of $\mathrm{H}_{2}$ at low pressure side $[\mathrm{Pa}]$

$l$ is calculated by

$l=r_{o} \cdot \ln \left(\frac{r_{o}}{r_{i}}\right)$

where

$r_{o}=$ outer radius of heat transfer tube $[\mathrm{m}]$

$r_{i}=$ inner radius of heat transfer tube [m].

Permeability is calculated by the Arrhenius equation:

$k_{p}=f \cdot \exp \left(\frac{-E}{R T}\right)$

where

$$
\begin{aligned}
f & =\text { pre-exponential factor of permeability }\left[\mathrm{m}^{3}(\mathrm{STP}) / \mathrm{m} / \mathrm{s} / \mathrm{Pa}^{0.5}\right] \\
E & =\text { activation energy }[\mathrm{J} / \mathrm{mol}] \\
R & =\text { ideal gas constant }[\mathrm{J} / \mathrm{mol}-\mathrm{K}] \\
T & =\text { absolute temperature }[\mathrm{K}] .
\end{aligned}
$$


The permeation rate of $\mathrm{H}_{2}$ though the outer wall of the component and piping, $R_{\text {comp }, H 2}$, is calculated by excluding the $\mathrm{H}_{2}$ partial pressure at the low pressure side as

$$
R_{\text {comp }, H 2, j}=\frac{A}{l} \cdot k_{p, H} \cdot \sqrt{P_{H 2, h}} .
$$

The permeation rate of HT at the heat exchanger, $R_{H X, H 2}\left[\mathrm{~m}^{3}(\mathrm{STP}) / \mathrm{s}\right]$, and at the co-axial pipe, $R_{\text {copipe }, H 2}\left[\mathrm{~m}^{3}(\mathrm{STP}) / \mathrm{s}\right]$, is estimated by considering the effect of the existence of hydrogen on the adsorption-dissociation and recombination-desorption step as

$$
R_{H X, H T, j}\left(\text { or } \quad R_{\text {copipe }, H T, j}\right)=\frac{A}{l} \cdot k_{p, T} \cdot\left(1-\frac{P_{H 2, l}}{P_{\text {Total }, l}}\right)\left(\frac{P_{H T, h}}{\sqrt{P_{H 2, h}+P_{H T, h}}}-\frac{P_{H T, l}}{\sqrt{P_{H 2, l}+P_{H T, l}}}\right)
$$

where

$$
\begin{aligned}
& k_{p, T}=\text { permeability of tritium }\left[\mathrm{m}^{3}(\mathrm{STP}) / \mathrm{m} / \mathrm{s} / \mathrm{Pa}^{0.5}\right] \\
& P_{H T, h}=\text { partial pressure of } \mathrm{HT} \text { at high pressure side }[\mathrm{Pa}] \\
& P_{H T, l}=\text { partial pressure of } \mathrm{HT} \text { at low pressure side }[\mathrm{Pa}] \\
& P_{\text {Total }, l}=\text { total pressure at low pressure side }[\mathrm{Pa}] .
\end{aligned}
$$

The permeation rate of HT through the outer wall of the component and piping, $R_{\text {comp }, H T}$, is calculated by

$$
R_{\text {comp }, H T, j}=\frac{A}{l} \cdot k_{p, T} \cdot \frac{P_{H T, h}}{\sqrt{P_{H 2, h}+P_{H T, h}}} .
$$

As shown in Equations (3-16), (3-17), (3-20), and (3-21), a tube thickness is a very sensitive factor for the tritium permeation. The tritium permeation rate is inversely proportional to the tube thickness. In the typical tubular type heat exchangers, determination of the tube thickness is simple and straight forward. However, the determination is not simple in the printed circuit heat exchanger (PCHE), which is one of the strong candidates for VHTR heat exchangers. Figure 3-1 shows the cross-sectional configurations of a PCHE. A PCHE is a category of the compact heat exchanger manufactured by Heatric $^{\mathrm{TM}}$ (2003). It is manufactured by chemical etching and a diffusion bonding process, so it provides a large heat transfer surface area density - as high as $2,500 \mathrm{~m}^{2} / \mathrm{m}^{3}$. It allows operation at high temperatures and pressures up to $900^{\circ} \mathrm{C}$ and $50 \mathrm{MPa}$ and requires a correlation for metal thicknesses because the tritium permeation path in the PCHEs is two dimensional and the thickness varies along the channel surface. 


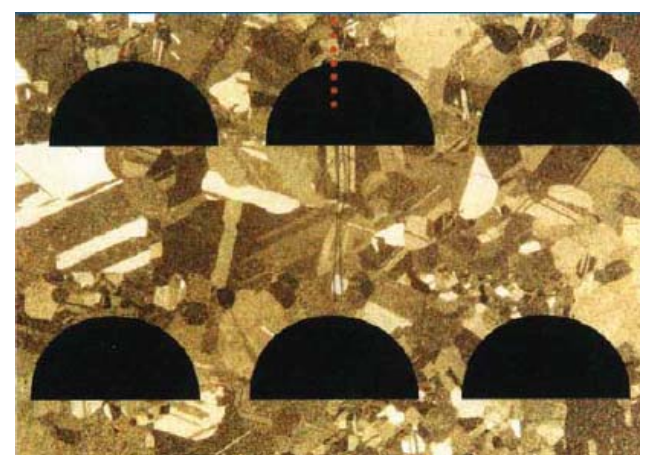

Figure 3-1. Cross-sectional picture of a PCHE (Dewson and Grady 2003).

Oh and Kim (2008) proposed the following correlations to determine the effective thickness $\left(t_{e f f}\right)$ of the PCHE channels based on two different configurations: standard configuration and offset configuration (See Figure 3-2).

1. Standard Configuration:

$$
\begin{array}{ll}
\frac{t_{\text {eff. }}}{d}=0.8 \cdot\left(\frac{t_{p}}{d}\right)^{2.92} \cdot\left(\frac{p}{d}\right)^{-0.19} & \left(\frac{t_{p}}{d}<0.8\right) \\
\frac{t_{\text {eff. }}}{d}=0.67 \cdot\left(\frac{t_{p}}{d}\right)^{1.51} \cdot\left(\frac{p}{d}\right)^{-0.61} & \left(\frac{t_{p}}{d}>0.8\right)
\end{array}
$$

2. Offset Configuration:

$$
\begin{array}{ll}
\frac{t_{\text {eff }} \cdot}{d}=0.48 \cdot\left(\frac{t_{p}}{d}\right)^{1.94} \cdot\left(\frac{p}{d}\right)^{-0.85} & \left(\frac{t_{p}}{d}<0.8\right) \\
\frac{t_{\text {eff. }}}{d}=0.65 \cdot\left(\frac{t_{p}}{d}\right)^{1.35} \cdot\left(\frac{p}{d}\right)^{-0.26} & \left(\frac{t_{p}}{d}>0.8\right)
\end{array}
$$

where

$$
\begin{aligned}
& d=\text { channel diameter }[\mathrm{m}] \\
& t_{p}=\text { plate thickness }[\mathrm{m}] \\
& p=\text { horizontal pitch }[\mathrm{m}]
\end{aligned}
$$



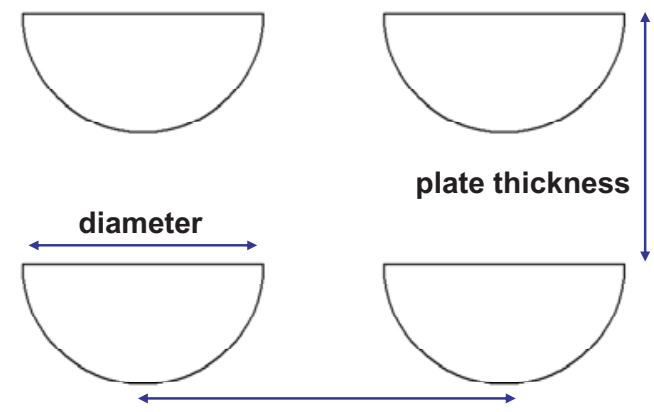

horizontal pitch

(a) Standard in-line configuration
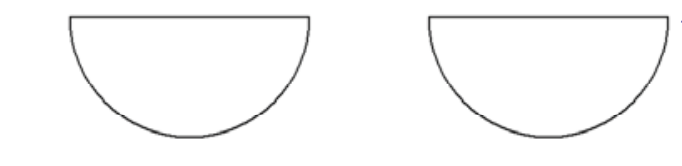

plate thickness

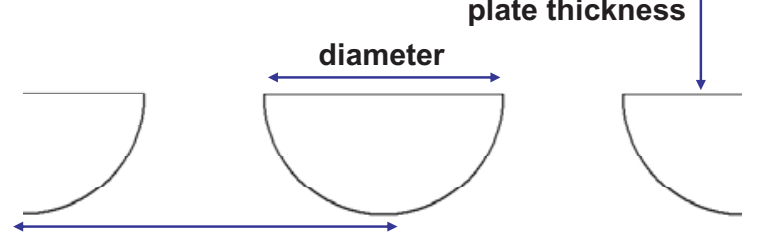

horizontal pitch

(b) Off-set configuration

Figure 3-2. PCHE channel configurations.

\subsection{Leakage}

The leak rate of helium from the loop, $R_{\text {leak }, H e}\left[\mathrm{~m}^{3}(\mathrm{STP}) / \mathrm{s}\right]$, can be expressed as

$R_{\text {leak }, \text { He }}=V_{\text {total }} \cdot L_{R}$

where

$V_{\text {total }}=$ total inventory in loop $\left[\mathrm{m}^{3}(\mathrm{STP})\right]$

$L_{R} \quad=$ helium leak rate $[1 / \mathrm{s}]$.

The leak rate of $\mathrm{H}_{2}, \mathrm{HT}$, and HTO with helium leakage in node $\mathrm{j}, R_{\text {leak }, i, j}$, is calculated as

$R_{\text {leak }, i, j}=V_{\text {total }} \cdot L_{R} \cdot \bar{C}_{i} \cdot \frac{V_{j}}{V_{\text {leak }}}\left(i=\mathrm{H}_{2}, \mathrm{HT}\right.$ and HTO $)$

where

$\bar{C}_{i} \quad=$ average concentration of chemical $\mathrm{i}$ in nodes with helium leak

$V_{\text {leak }}=$ sum of the inventory of nodes with helium leak.

\subsection{Purification}

The removal rate, $R_{P F}$, of hydrogen and tritium-containing chemicals in the primary and intermediate loop by the purification system is expressed as

$R_{P F, i, j}=F_{P F, H e} \cdot \eta_{i} \cdot C_{i, j}\left(i=\mathrm{H}_{2}, \mathrm{HT}\right.$, and $\left.\mathrm{HTO}\right)$

where

$F_{P F, H e}=$ helium flow rate at purification system $\left[\mathrm{m}^{3}(\mathrm{STP}) / \mathrm{s}\right]$

$\eta_{i} \quad=\quad$ fractional efficiency of purification system for removing component $\mathrm{i}$. 


\subsection{Electrolyzer}

A very simple electrolyzer model has been implemented in TPAC in order to match the species conservation in the following chemical reaction:

$\mathrm{H}_{2} \mathrm{O}=\mathrm{H}_{2}+0.5 \mathrm{O}_{2}$

In this model, a complicated electrochemistry model has not been applied. Decomposition of $\mathrm{H}_{2} \mathrm{O}$ into $\mathrm{H}_{2}$ and $\mathrm{O}_{2}$ were simply considered by conversion ratios. HTO was considered to be chemically identical to $\mathrm{H}_{2} \mathrm{O}$, so the same conversion correlation was applied to $\mathrm{HTO}$ decomposition. Produced $\mathrm{O}_{2}$ in the cathode was considered to be directly transferred to the anode.

\subsection{Isotope Exchange}

The SI process contains $\mathrm{H}_{2}, \mathrm{H}_{2} \mathrm{O}, \mathrm{H}_{2} \mathrm{SO}_{4}$, and $\mathrm{HI}$ and the $\mathrm{HTE}$ process contains $\mathrm{H}_{2}$ and $\mathrm{H}_{2} \mathrm{O}$ as hydrogen-containing chemicals. The primary and intermediate coolants also contain $\mathrm{H}_{2}$ and $\mathrm{H}_{2} \mathrm{O}$ as impurities. To analyze the tritium behaviors in the VHTR/hydrogen production system, we need some additional models that can handle isotope exchange reactions between some chemicals. The TPAC takes into account the following isotope exchange reactions between tritium containing chemicals and hydrogen containing chemicals:

- Reaction-1: $\mathrm{HT}+\mathrm{H}_{2} \mathrm{O}=\mathrm{H}_{2}+\mathrm{HTO}$

- Reaction-2: $\mathrm{HT}+\mathrm{H}_{2} \mathrm{SO}_{4}=\mathrm{H}_{2}+\mathrm{HTSO}_{4}$

- $\quad$ Reaction-3: $\mathrm{HT}+\mathrm{HI}=\mathrm{H}_{2}+\mathrm{TI}$

- Reaction-4: $\mathrm{HTO}+\mathrm{H}_{2} \mathrm{SO}_{4}=\mathrm{H}_{2} \mathrm{O}+\mathrm{HTSO}_{4}$

- $\quad$ Reaction-5: $\mathrm{HTO}+\mathrm{HI}=\mathrm{H}_{2} \mathrm{O}+\mathrm{TI}$.

Chemical equilibrium of the isotope exchange reaction from Reaction-1 through Reaction- 5 can be expressed by the following equations.

$$
\begin{aligned}
& K_{1}=\frac{F_{H 2, e q} \cdot F_{H T O, e q}}{F_{H T, e q} \cdot F_{H 2 O, e q}} \\
& K_{2}=\frac{F_{H 2, e q} \cdot F_{H T S O 4, e q}}{F_{H T, e q} \cdot F_{H 2 S O 4, e q}} \\
& K_{3}=\frac{F_{H 2, e q} \cdot F_{T I, e q}}{F_{H T, e q} \cdot F_{H I, e q}} \\
& K_{4}=\frac{K_{2}}{K_{1}}=\frac{F_{H 2 O, e q} \cdot F_{H T S O 4, e q}}{F_{H T O, e q} \cdot F_{H 2 S O 4, e q}} \\
& K_{5}=\frac{K_{3}}{K_{1}}=\frac{F_{H 2 O, e q} \cdot F_{T I, e q}}{F_{H T O, e q} \cdot F_{H I, e q}}
\end{aligned}
$$

where

$K=$ equilibrium constant of each isotope exchange reaction 
$F_{i, e q}=$ volumetric flow rate of each chemical at equilibrium $\left[\mathrm{m}^{3}(\mathrm{STP}) / \mathrm{s}\right]$

In the above equations, Reaction- 4 and Reaction- 5 can be expressed by combinations of Reaction- 1 through Reaction-3. Therefore, equations (3-33) and (3-34) do not need to be solved. To solve Equations (3-30), (3-31), and (3-32), the equilibrium (the values of $\mathrm{F}_{\mathrm{i}, \mathrm{eq}} \mathrm{s}$ were expressed as:

$$
\begin{aligned}
& F_{H T, e q}=F_{H T, I N}-\Delta_{1}-\Delta_{2}-\Delta_{3} \\
& F_{H 2, e q}=F_{H 2, I N}+\Delta_{1}+\Delta_{2}+\Delta_{3} \\
& F_{H 2 O, e q}=F_{H 2 O, I N}-\Delta_{1} \\
& F_{H T O, e q}=F_{H T O, I N}+\Delta_{1} \\
& F_{H 2 S O 4, e q}=F_{H 2 S O 4, I N}-\Delta_{2} \\
& F_{H T S O 4, e q}=F_{H T S O 4, I N}+\Delta_{2} \\
& F_{H I, e q}=F_{H I, I N}-\Delta_{3} \\
& F_{T I, e q}=F_{T I, I N}+\Delta_{3}
\end{aligned}
$$

where

$F_{i, I N}=$ inlet volumetric flow rate of each chemical species $\left[\mathrm{m}^{3}(\mathrm{STP}) / \mathrm{s}\right]$

$\Delta_{n} \quad=$ amount of HT conversion rate by Reaction-n $\left[\mathrm{m}^{3}(\mathrm{STP}) / \mathrm{s}\right]$.

From the above set-up, we can solve three unknowns $\left(\Delta_{1}, \Delta_{2}, \Delta_{3}\right)$ from three equations (Equations (3-30), (3-31) and (3-32)).

The equilibrium constants of Reaction-1 through Reaction-3 can be expressed in the following equation (Atomic Energy Society of Japan 1982):

$\log K_{1}=0.292 \log T+(336.5 / T)-1.055$

$\log K_{2}:$ unknown

$\ln K_{3}=-1.13+1.07 \times 10^{-2} T-2.26 \times 10^{-5} T^{2}+2.10 \times 10^{-8} T^{3}-7.25 \times 10^{-12} T^{4}$ 


\section{TRITIUM PERMEATION ANALYSES CODE (TPAC)}

\subsection{Program Overview}

The Tritium Permeation Analyses Code (TPAC) is the computer code developed by Idaho National Laboratory (INL) for the purpose of analyses of tritium behaviors and distributions in the VHTR systems including integrated hydrogen production systems such as HTE and SI processes. The TPAC is based on the mass conservation equations of various tritium-containing species (HT, HTO, $\mathrm{HTSO}_{4}$, and $\mathrm{TI}$ ) and hydrogen $\left(\mathrm{H}_{2}\right)$ coupled with a variety of tritium source and sink models. The models include tritium sources from ternary fission and neutron reactions, leakage, permeation through solid walls, purification, isotope exchange reactions, and electrolysis. The detailed models are well described in Section 3. The TPAC provides large flexibility for system configurations and very convenient graphical user interface (GUI). The system can be configured (not only for VHTR but also general components) using easy dragand-drops on the screen.

The TPAC has been developed using MATLAB SIMULINK Packages (MathWorks, 2009), a world famous numerical computing environment and language. Currently, more than one million people are reportedly using this software across many industries and universities. MATLAB is a high-level technical computing program language created by MathWorks. It provides easy matrix manipulation, algorithms implementation, user interface creation, and numerous built-in numerical libraries. SIMULINK is a builtin package integrated into MATLAB that specializes in modeling, simulating, and analyzing multidomain dynamic systems. Its primary interface is a graphical block diagramming tool and a customizable set of block libraries. It offers tight integration with the rest of the MATLAB environment. It supports linear and nonlinear system modeling in continuous time, sampled time, or a hybrid of both.

The TPAC has been developed based on the SIMULINK user interface. All TPAC component libraries were built in the SIMULINK model library so the TPAC component blocks can be easily integrated with preexisting SIMULINK model blocks. It provides enormous capabilities for code flexibility and extensibility. Figure 4-1 shows the basic TPAC user interface integrated in MATLAB SIMULINK. Therefore, the TPAC interface is exactly the same as MATLAB SIMULINK interface except for the TPAC process component library, which was developed and designed for tritium analyses in this work. Symbol 1 in Figure 4-1, is the default MATLAB Workspace where the entire status of the simulation can be checked. The data calculated in the SIMULINK Workspace can be interacted and postprocessed. Symbol 2 is the SIMULINK Workspace where all the component blocks were arranged from the TPAC libraries for submitting the job with some detailed user settings. Symbol 3 is the SIMULINK Library Browser in which the TPAC libraries are implemented and integrated. Users can easily find the TPAC components in this browser and move them to the SIMULINK Workspace for making block models. The following sections will describe the TPAC structures and how to develop and run the model.

\subsection{TPAC Structures}

This section describes the TPAC code structures and how to install and start the program. Figure 4-2 shows the TPAC organization. In the TPAC folder, there are two files and two folders. The file, 'TPAC_BETA_Lib.mld.' is the main program containing all the component blocks. The file, "slblocks.m" is the file for linking the TPAC program and the MATLAB SIMULINK; without this file, the TPAC component blocks do not show in the SIMULINK Library Browser. The folder 'functions'

includes some function libraries related to tritium-related models such as isotope exchange reaction. The folder 'Icons' includes all the icons used in the TPAC GUI. 


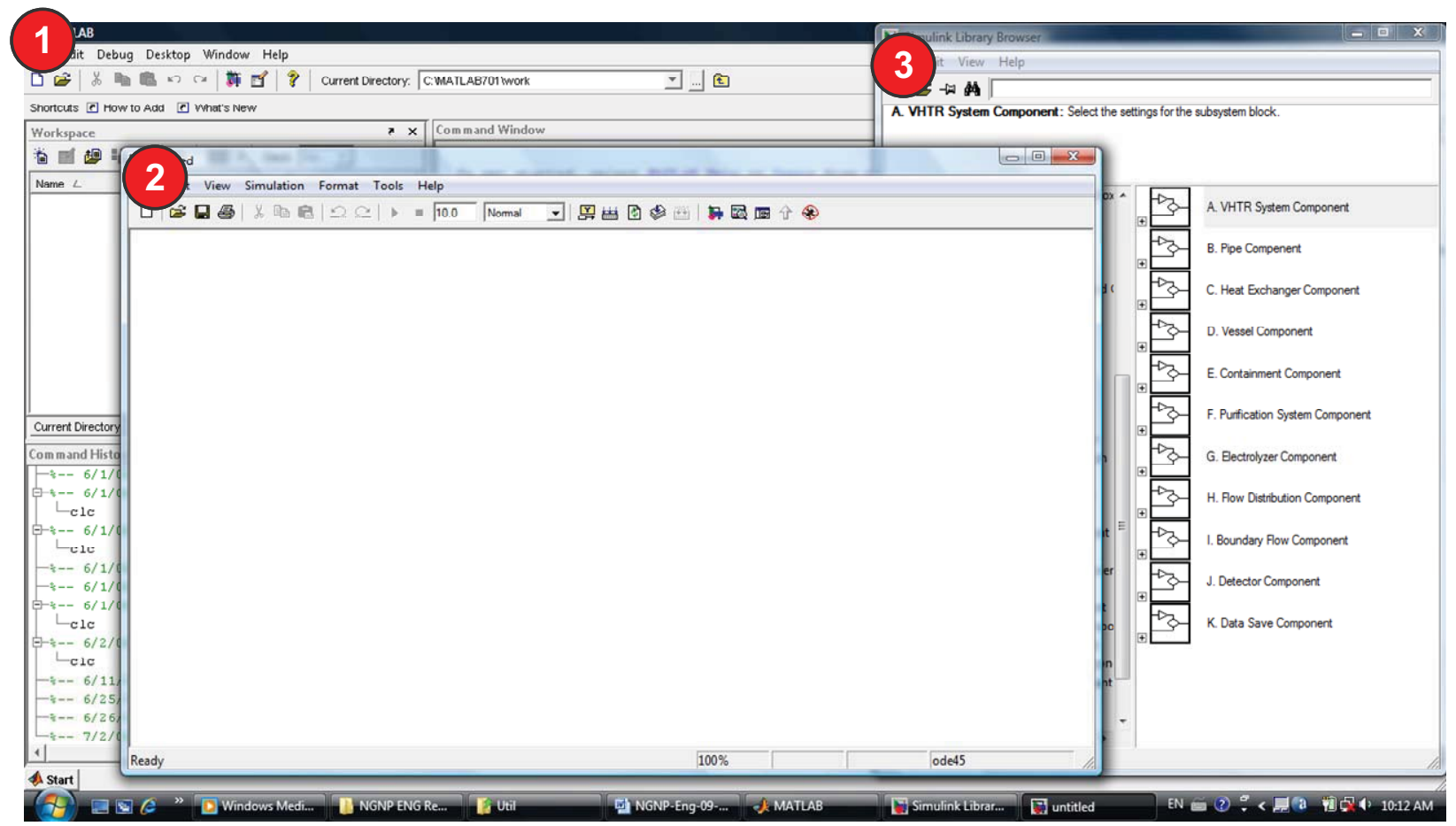

Figure 4-1. Basic TPAC user interface integrated into MATLAB SIMULINK.
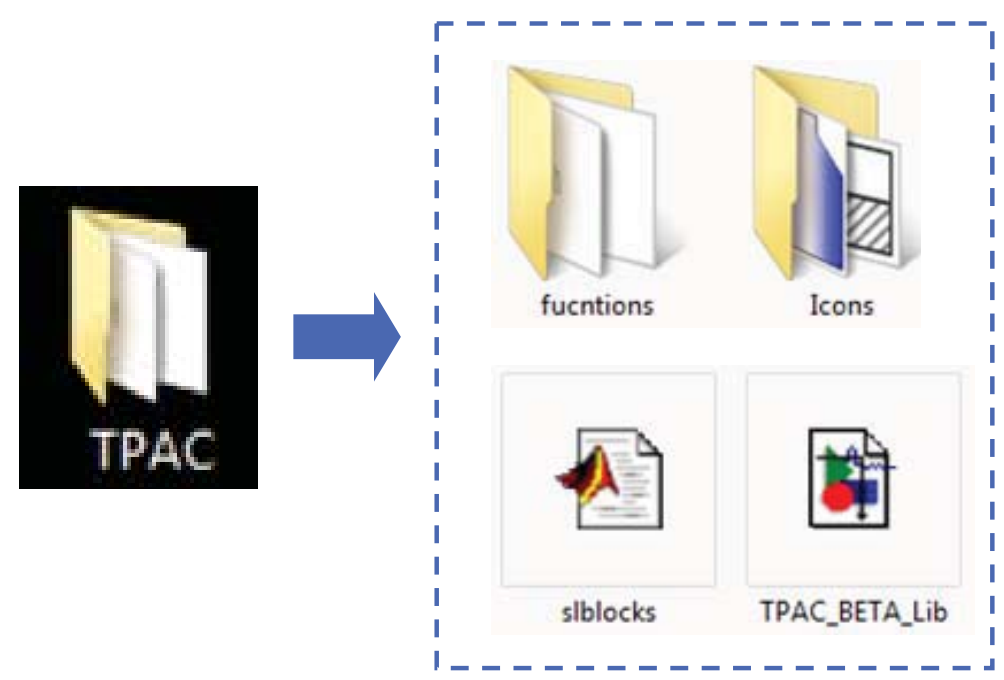

Figure 4-2. TPAC organizations.

Installation of the TPAC is very user-friendly, but because the code is developed based on sharing the SIMULINK interface, MATLAB SIMULINK Package should be installed first. The basic MATLAB SIMULINK package (student edition) is sufficient to install and run the TPAC. The following instruction directs how to install the TPAC in the MATLAB SIMULINK environment.

\section{TPAC Installation}

3. Copy 'TPAC' Folder in any location where the user wants to place it.

4. Run MATLAB 
Just double-clicking the MATLAB icons can make the MATLAB program start. Figure 4-3 shows the default Workspace of MATLAB.

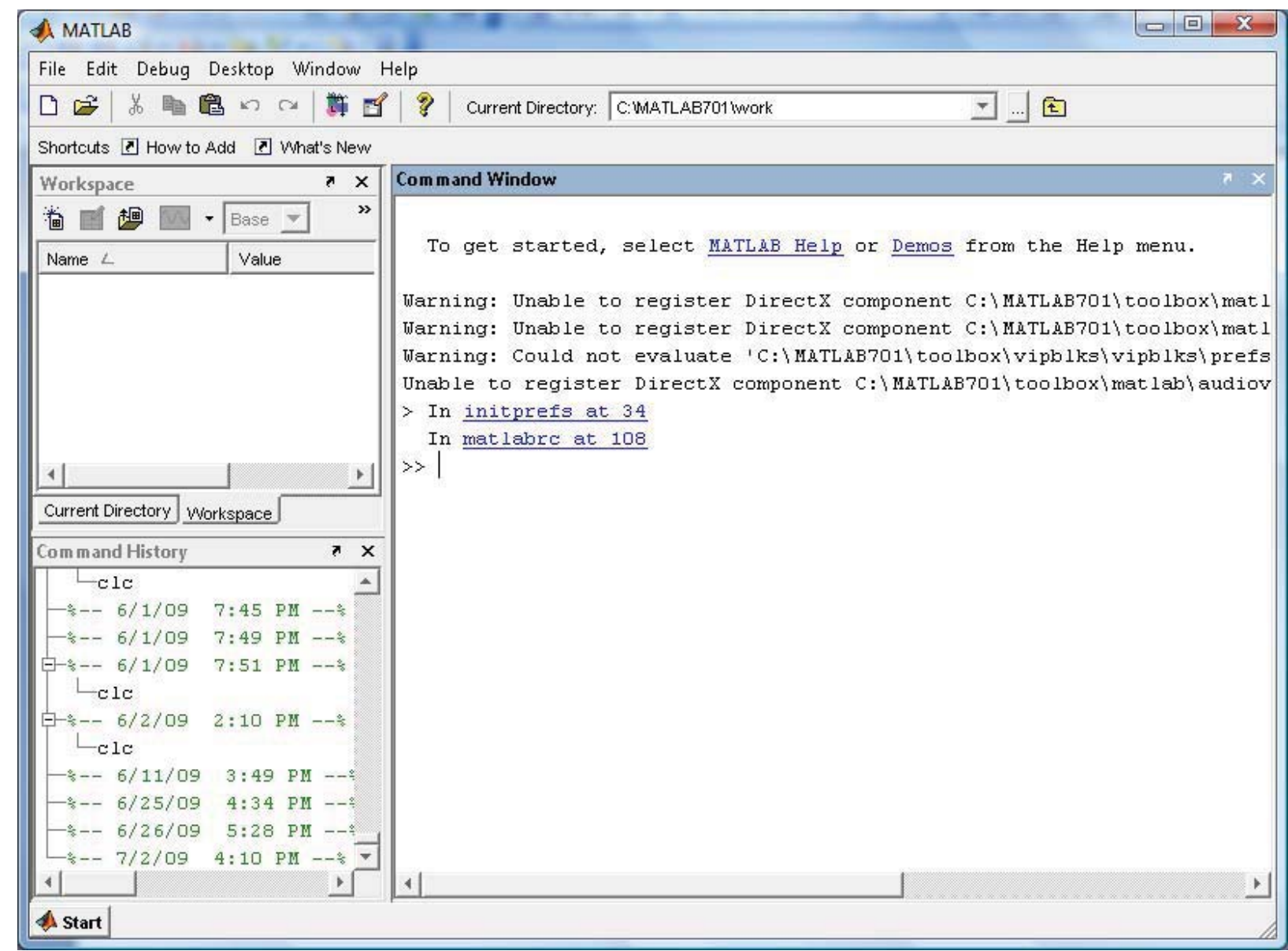

Figure 4-3. MATLAB Workspace.

5. Set Path of the TPAC Folder

To use the TPAC in the MATLAB, users should set the path of the TPAC so that the MATLAB program recognizes that the TPAC is integrated into the MATLAB environment. To add the path of the TPAC, click File/Set path in the main menu (See Figure 4-4) to open the set path window (See Figure 45). The TPAC folder can be added by clicking the 'Add with subfolders ...' button and including the TPAC folder that includes all the related files as shown in Figure 4-5. Adding the TPAC folder in the path automatically integrates the TPAC into the MATLAB Library. 


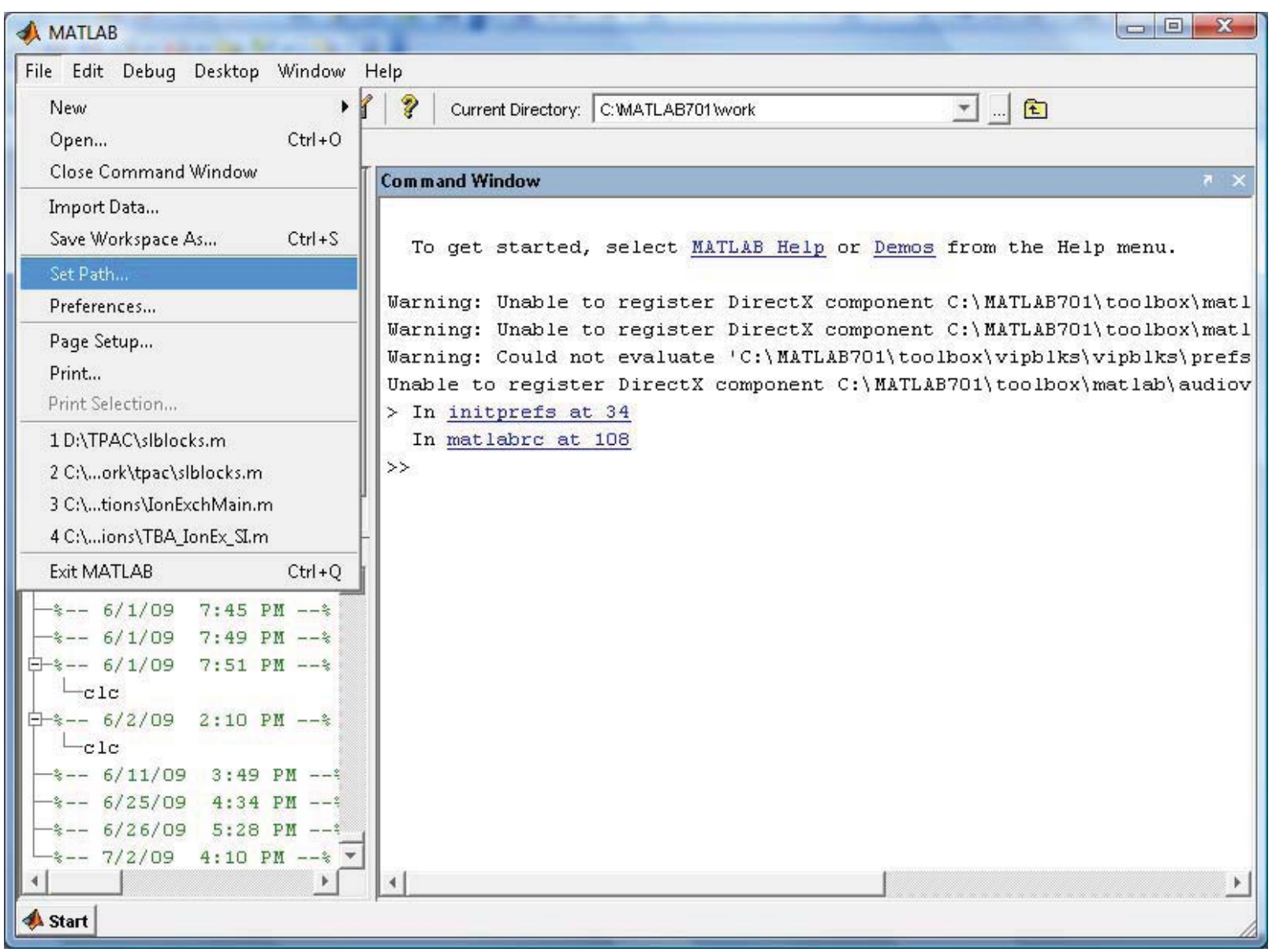

Figure 4-4. Set path of the MATLAB.

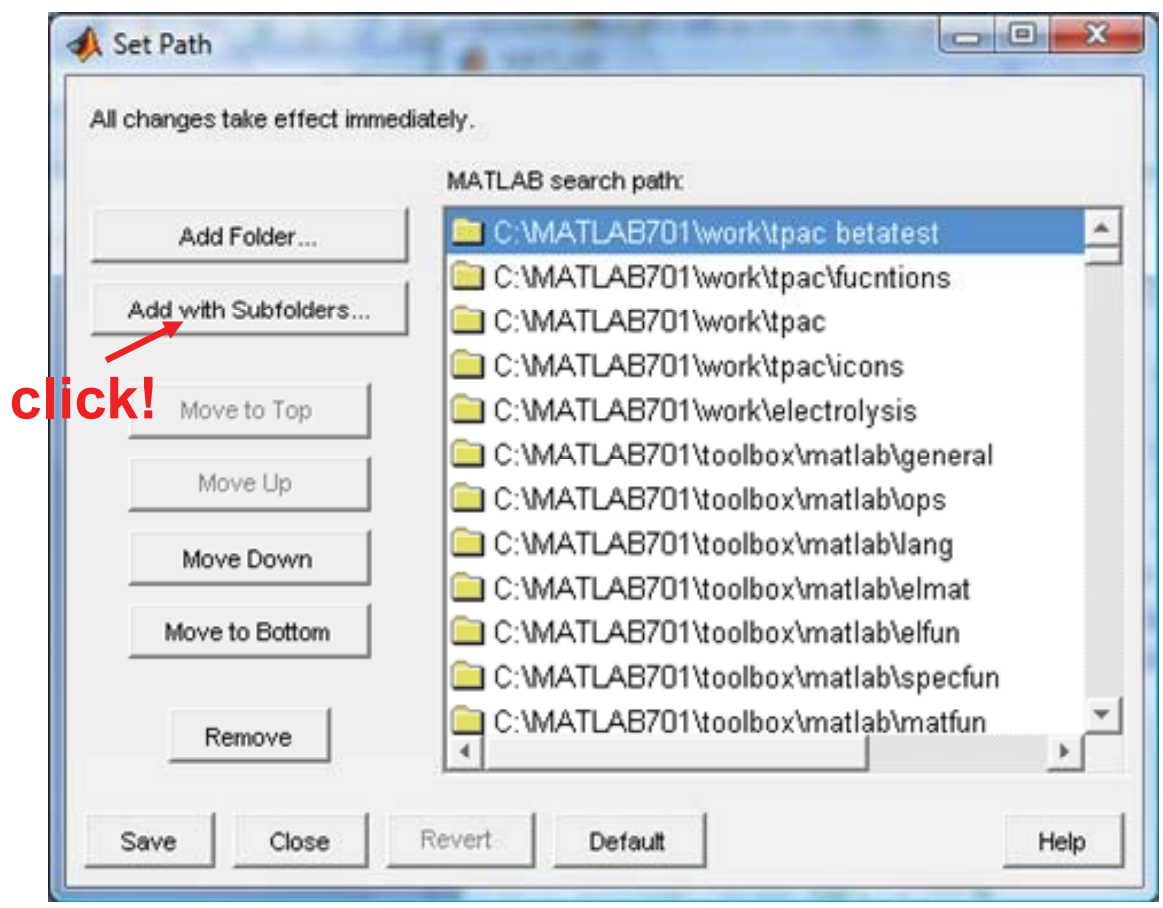

Figure 4-5. Set path windows in MATAB. 
6. Check the Linkage. The linkage can be easily checked if the TPAC is successfully integrated into the MATLAB by running SIMULINK. The SIMULINK can be started by clicking the following button in the MATLAB toolbar.

\section{: Starting SIMULINK in MATLAB}

When the above button is clicked, the SIMULINK Library Browser will pop up as shown in Figure 46. The TPAC can be seen in the Model List on the left-hand side, and the TPAC components can be seen in the Component List on the right-hand side. As shown in this figure, the current version is TPAC $1.5 \mathrm{~b}$.

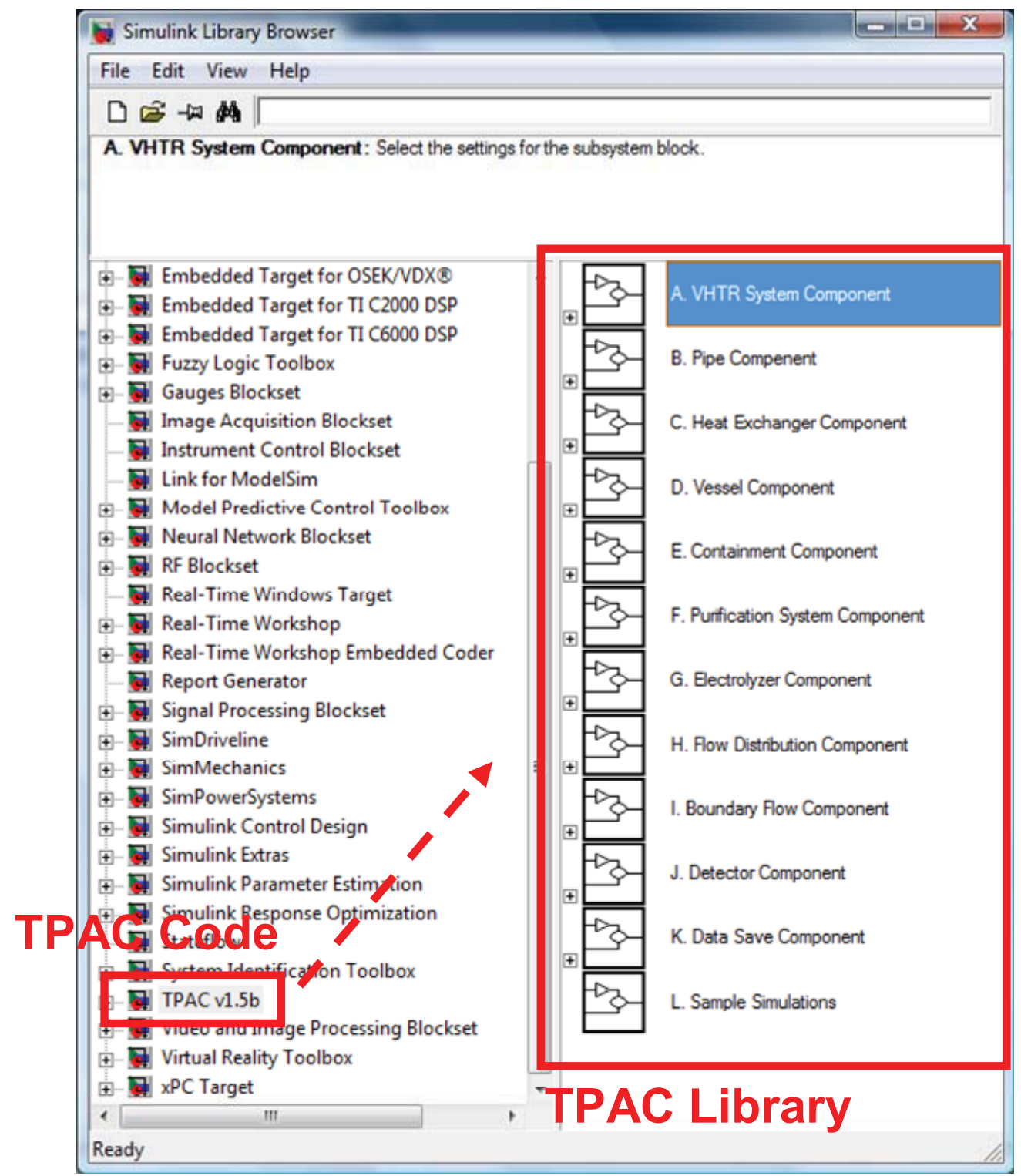

Figure 4-6. TPAC Library Browser. 


\section{TPAC Structures}

As shown in Figure 4-7, the TPAC has a variety of library categories. Each category has different sets of component block models. Figure 4-7 shows the structure of the TPAC component libraries. TPAC 1.5b consists of 12 different categories. VHTR System Component contains the component blocks related to the VHTR systems such as core and vessel. Pipe Component contains various types of pipe component blocks including VHTR, HTSE, and SI systems. Heat Exchanger Component contains two different heat exchanger component blocks. Vessel Component contains various vessel components related to VHTR, HTSE, and SI systems. Containment Component contains the reactor containment block. Purification System Component contains a tritium purification system block. Electrolyzer Component contains an electrolyzer block. Flow Distributions Component contains flow distributor and mixer blocks. Boundary Flow Component contains a bound flow block that can be used for open-flow or fixed flows. Detector Component contains a detector block that can display the flow conditions during or after simulation. Data Save Component contains data save blocks that export calculated results to MATLAB Workspace or external files. Sample Simulation contains some sample simulation cases, including those used for code verification works. Details on the each component in the TPAC are will described in Section 4.4.

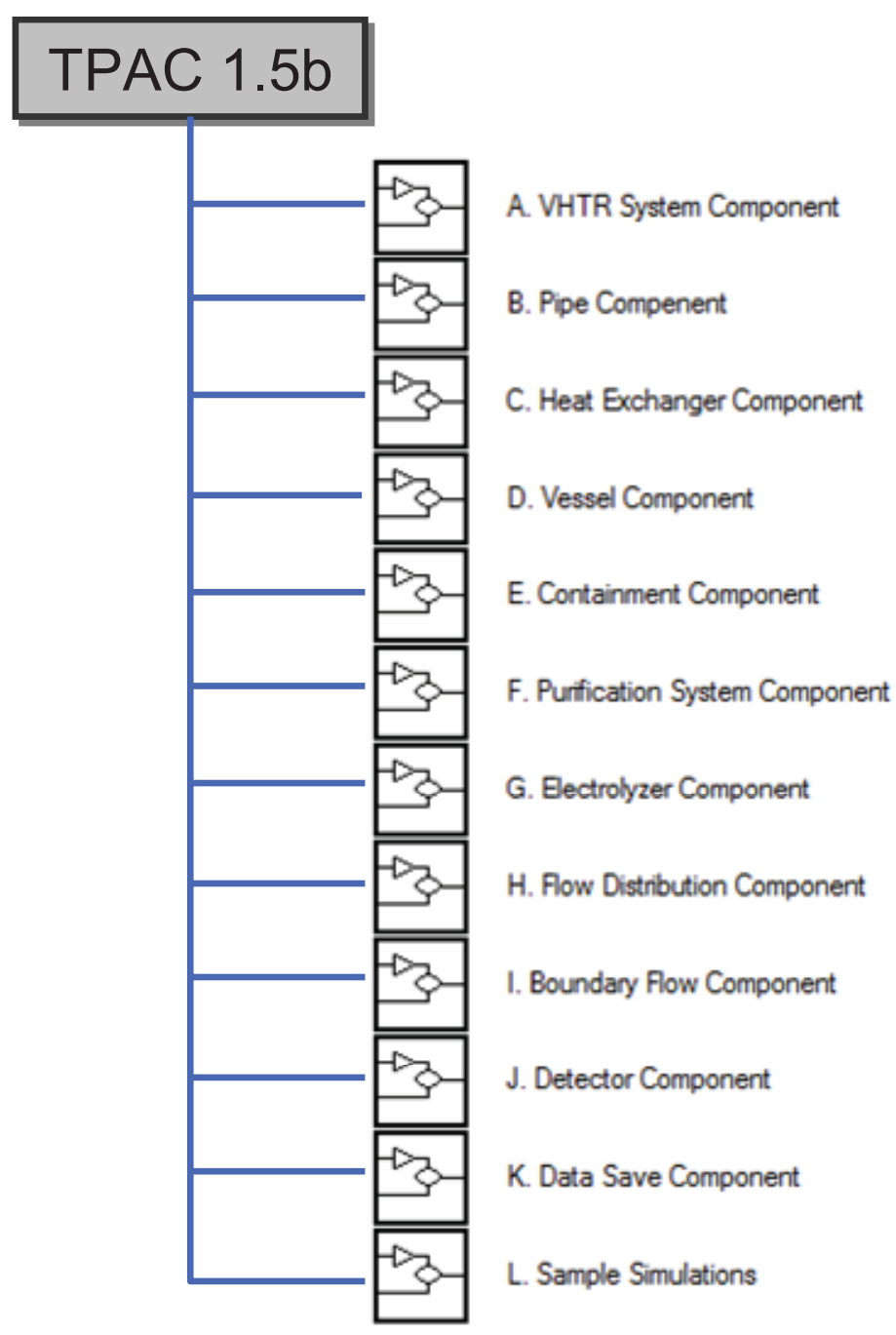

Figure 4-7. TPAC library categories. 


\subsection{Starting TPAC for Tritium Analyses}

This section shows a simple application of the TPAC into VHTR tritium analyses to understand how to develop a TPAC model and analyze it. This modeling application includes (1) starting TPAC, (2) manipulating TPAC components, (3) linking components, (4) implementing input data, (5) setting solver and running, and (6) post-processing results. Figure 4-8 shows the sample system configuration for tritium analyses. This system consists of primary and secondary coolant loops. The primary loop has a reactor, pipes (hot leg and cold leg), a compressor, and a purifier. The secondary loop has a power conversion unit and a secondary purifier. The primary and the secondary loops are connected by an IHX. All the systems are enclosed in the containment building. Tritium in the primary side was assumed to have penetrated through the IHX. Leakage of coolant from the primary side to the containment has been assumed through the cold leg and the reactor vessel. No leakage has been considered in the secondary side. Purifications were located at the coldest positions for both primary and the secondary loops. This system does not represent any specific reactor designs and therefore the parameters and the input data were arbitrarily chosen. Therefore, the results obtained in this sample simulation have no practical meaning for the actual reactor analyses. Figure 4-9 shows the final TPAC modeling for the sample configuration developed in this section.

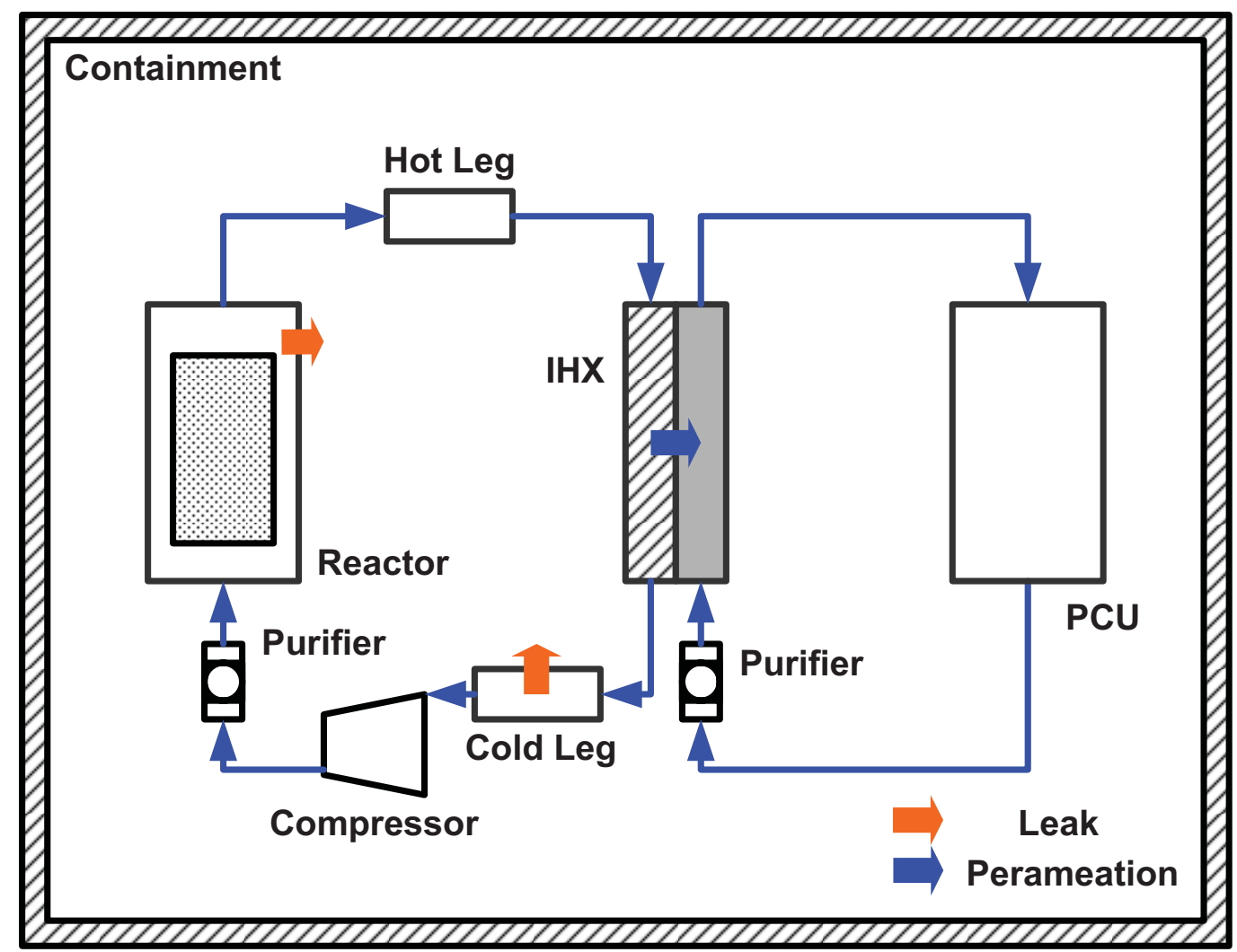

Figure 4-8. Sample system configuration for tritium analyses. 


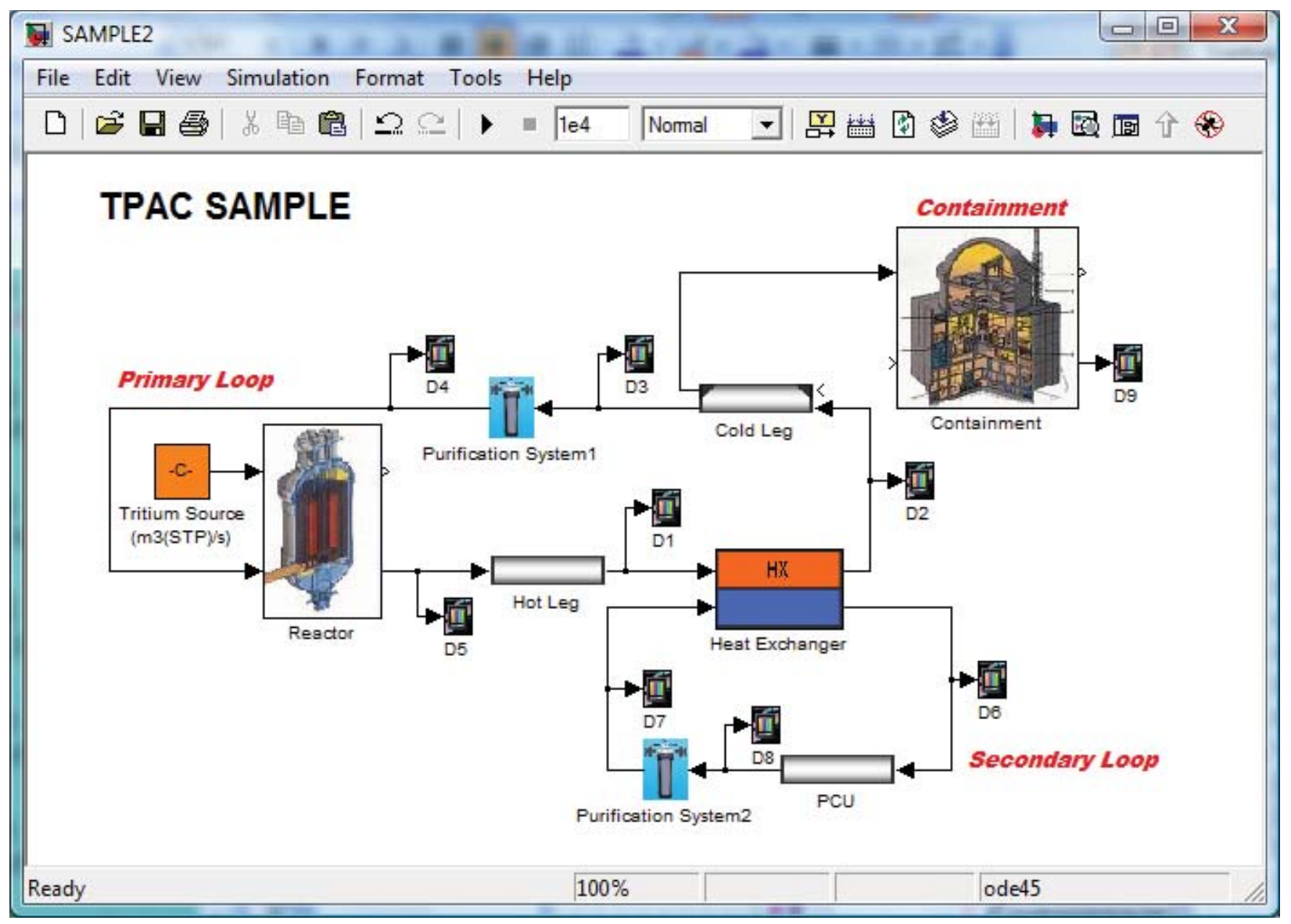

Figure 4.9. TPAC sample system simulation.

\subsubsection{Starting TPAC}

Starting the TPAC is also very user-friendly. The following is the procedure to start a new project of the TPAC.

1. Run MATLAB. Double-clicking MATLAB icon on the window desktop will start the MATLAB program and show up the MATLAB workspace.

2. Run SIMULINK. Clicking SIMULINK button on the MATLAB toolbar will show up the SIMULINK Library Browser (See Figure 4-10).

3. Start a New TPAC Project (SIMULINK Editor). By clicking the New button on the Library Browser, a new TPAC project (SIMULINK Editor) can be started (See Figure 4-10).

4. Save a File Name. The new project can be saved from 'File/Save' on the Menu. 


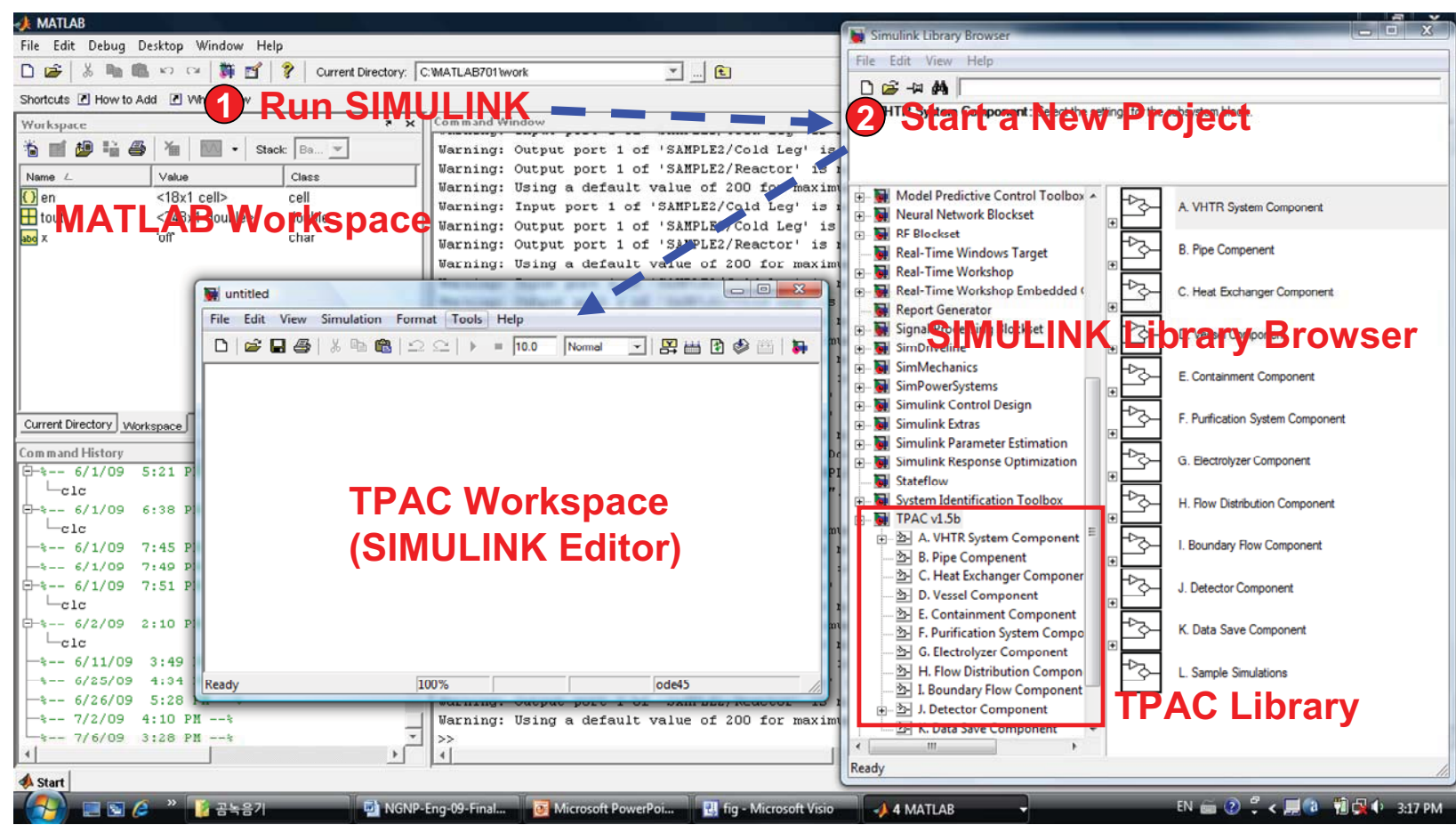

Figure 4-10. Start a new TPAC project.

\subsubsection{Developing Input Diagram}

To simulate the tritium behaviors in the VHTR systems, the input file that consists of block diagrams should be developed first. The TPAC is based on the GUI which provides easy drag-and-drop features for developing a model diagram. This section describes how to manipulate the model components and how to develop the input model diagram with those components.

\section{Basic Manipulation of the Component Blocks}

Select an object by clicking it. Small black square "handles" appear at the corners of a selected block and near the end points of a selected line. For example, Figure 4-11 shows a selected reactor component, containment component, and pipe component. When users select an object by clicking it, any other selected objects are deselected.

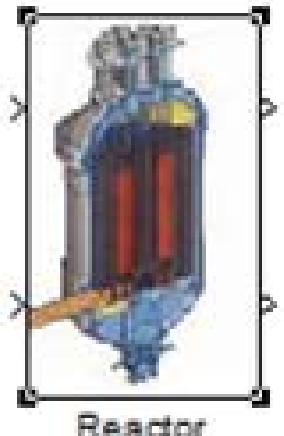

Figure 4-11. Selected TPAC model components.
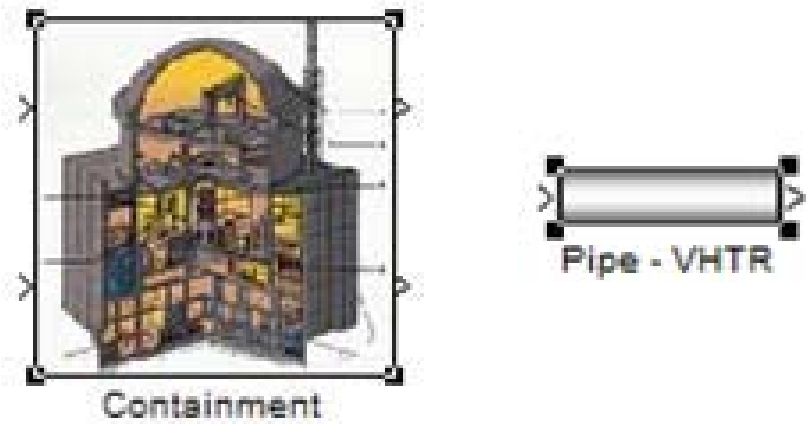
More than one object can be selected either by selecting objects one at a time, by selecting objects located near each other using a bounding box, or by selecting the entire model. To select more than one object by selecting each object individually, hold down the Shift key and click each object to be selected. To deselect a selected object, click the object again while holding down the Shift key. To select all objects in the active window, choose Select All from the Edit menu.

TPAC component or SIMULINK block diagrams use lines to represent pathways for signals among blocks in a model. TPAC (or SIMULINK) can connect blocks by drawing lines from their output ports to their input ports. Figure 4-12 shows a simple example of connecting Reactor and Pipe components. First, click the output port of the reactor, and then drag the line to the input port of the pipe. Figure 4-12 indicates that the reactor outflow is coming into the pipe inflow.

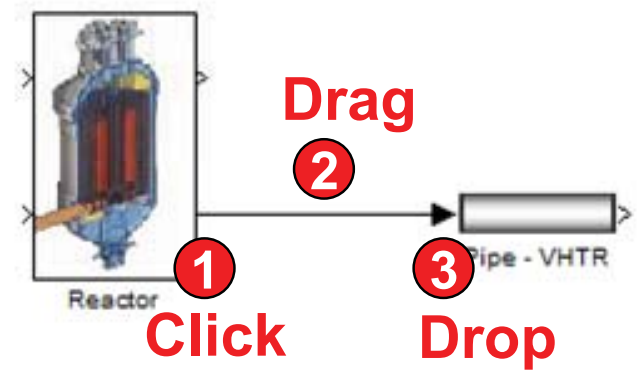

Figure 4-12. Connection of components (between Reactor and Pipe).

\section{Input Diagram Development for Sample Configuration}

The input diagram shown in Figure 4-9 will be developed through this section. The following is the procedure for developing the input diagram.

1. Place Reactor Component in the SIMULINK Editor. The Reactor component block (TPAC 1.5b/A. VHTR System Component/Reactor) can be moved from the library browser to the editor by drag-anddrop. First, click and hold Reactor block in the library browser (mouse left button), and then drag mouse to the editor. When the mouse pointer is located where the users wants, drop the component by releasing mouse button. Figure 4-13 shows the procedure.

2. Place all other components into the editor. As shown above, the other components can also be placed in the editor by the same methods. Place and arrange all the components as shown in Figure 4-14. Table 4-1 summarizes the components and their locations. The name of the component can be easily changed in the editor.

3. Link all the components. After placing the components, users should link all the components to interchange their information and signal; the linking method was already explained in Figure 4-12. By using the linking method, the model components can be linked as shown in Figure 4-15).

4. Add detector components. To read or plot the data after simulation, detector components should be connected to the streams. The detector component can be found in TPAC $\mathbf{1 . 5 b} / \mathbf{J}$. Detector Component/ Detector of the library browser. Figure 4-16 shows how to add a detector component into the editor. Like the other components, the detector block can be added using the drag-and-drop feature. After placing the block in the editor, the size of the detector can be adjusted easily. To link the detector and the stream, users need a different method as shown in Figure 4-17. First, click the stream of interest with ctrl button, another branch line is then created that is connected to the main stream. This line can be connected to the detector block. Using the same method, detector blocks can be added to all the streams as shown in Figure 4-18. The detector blocks allow the user to access the data in the connected streams during or after simulation. 


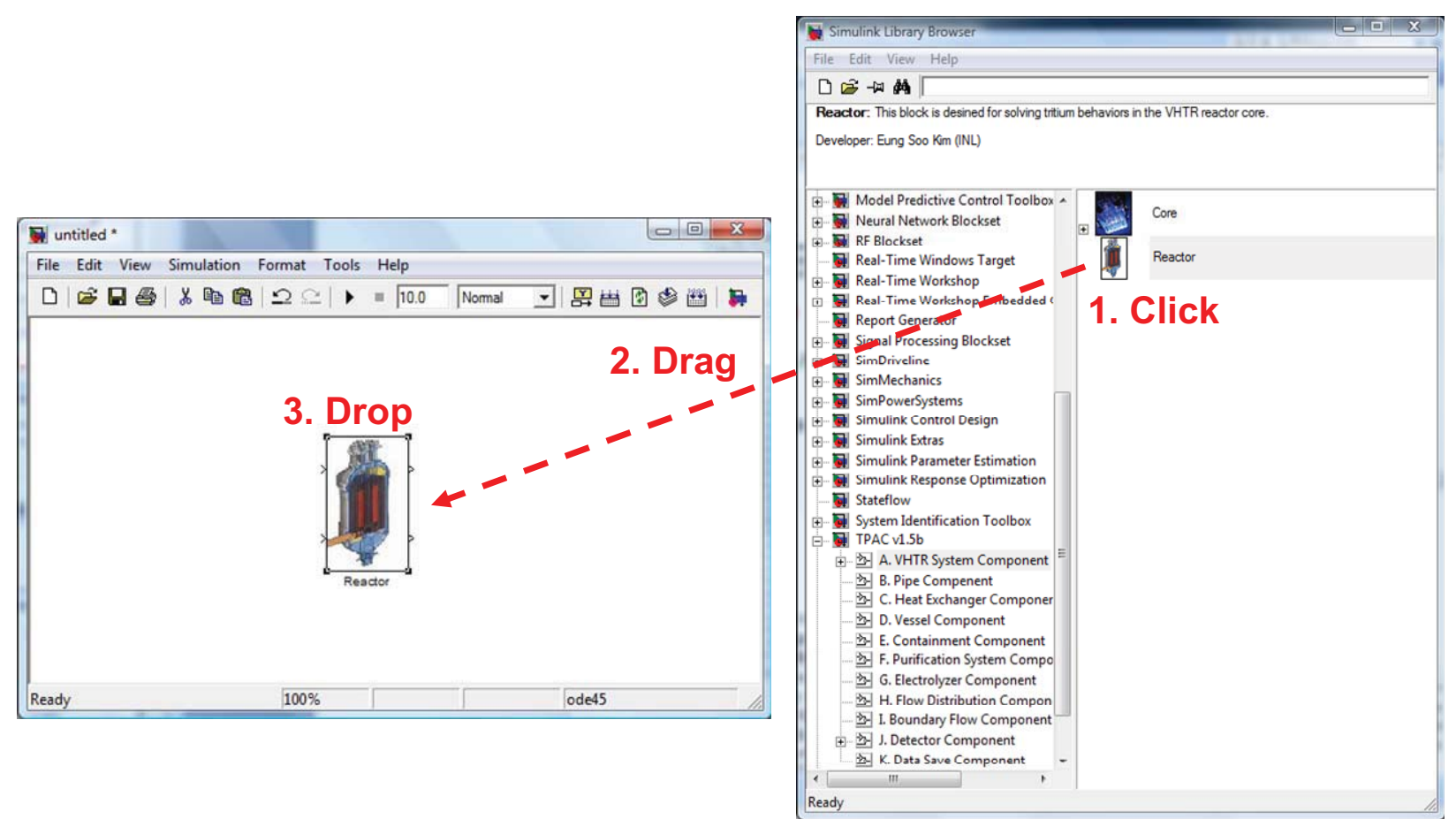

Figure 4-13. Moving reactor component from library browser to editor.

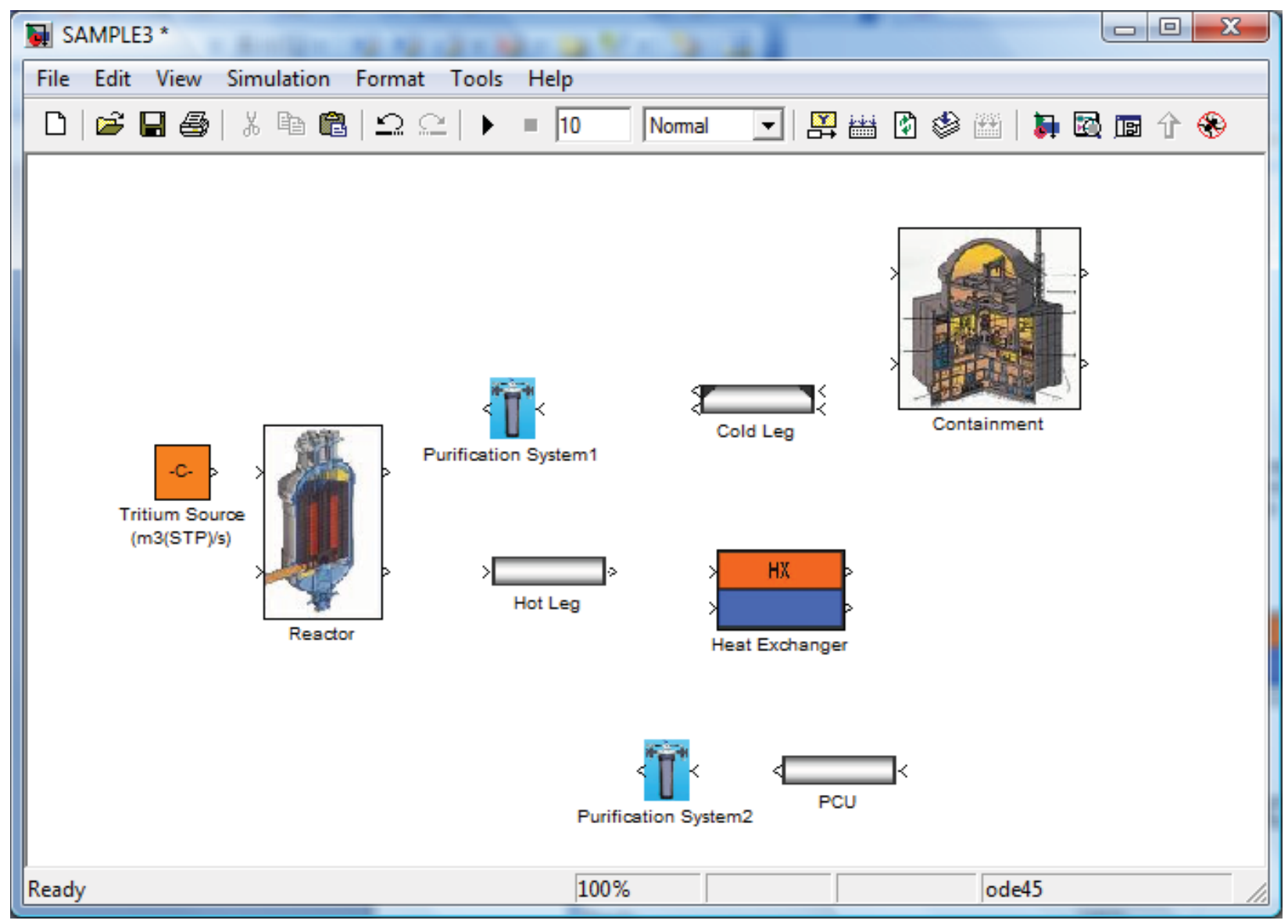

Figure 4-14. Component arrangement for the sample configuration. 
Table 4-1. List of components and locations.

\begin{tabular}{|l|l|}
\multicolumn{1}{|c|}{ Component Name } & \multicolumn{1}{c|}{ Locations in Library Browser } \\
\hline Reactor & TPAC 1.5b/A. VHTR System Component/ Reactor \\
\hline Tritium Source & SIMULINK/Source/ Constant \\
\hline Hot Leg & TPAC 1.5b/B. Pipe Component/ Pipe-VHTR \\
\hline Cold Leg & TPAC 1.5b/B. Pipe Component/ PipeII-VHTR \\
\hline Heat Exchanger & TPAC 1.5b/C. Heat Exchanger Component/Heat Exchanger \\
\hline PCU & TPAC 1.5b/B. Pipe Component/ Pipe-VHTR \\
\hline Containment & TPAC 1.5b/E. Containment Component/ Containment \\
\hline Purification System 1 & TPAC 1.5b/F. Purification System Component/ Purification System \\
\hline Purification System 1 & TPAC 1.5b/F. Purification System Component/ Purification System \\
\hline
\end{tabular}

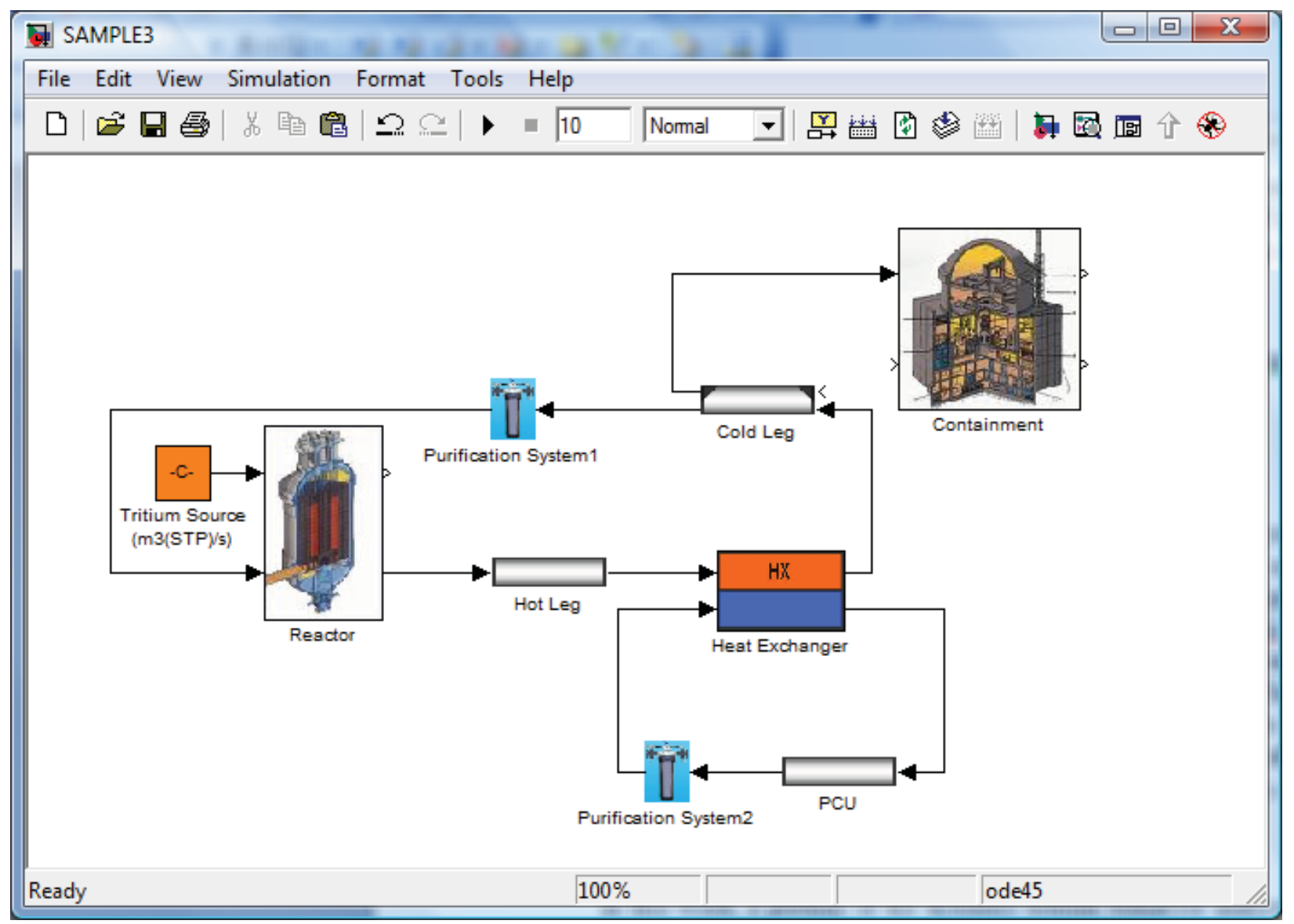

Figure 4-15. Linked model components. 


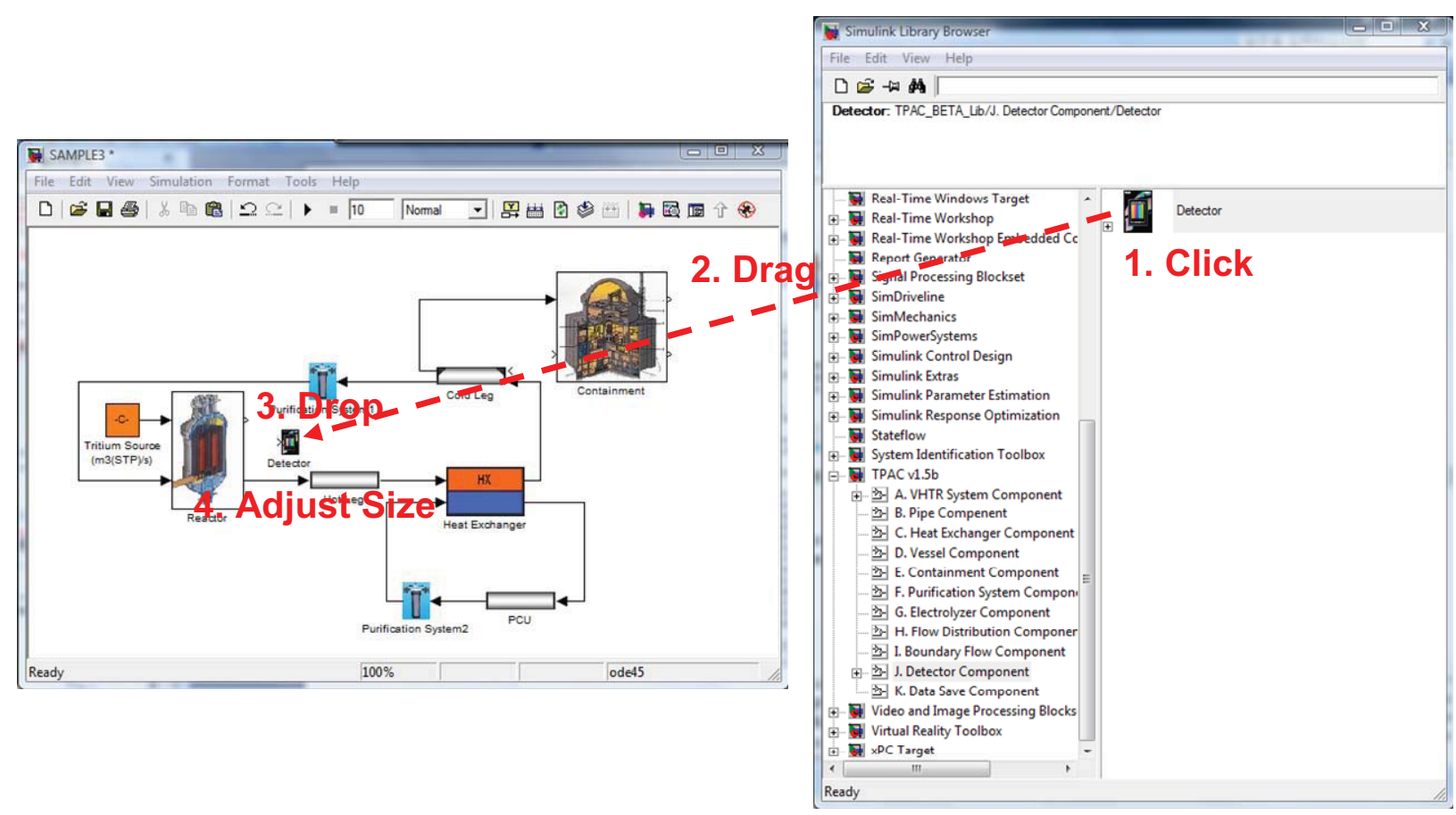

Figure 4-16. Detector addition into the editor.

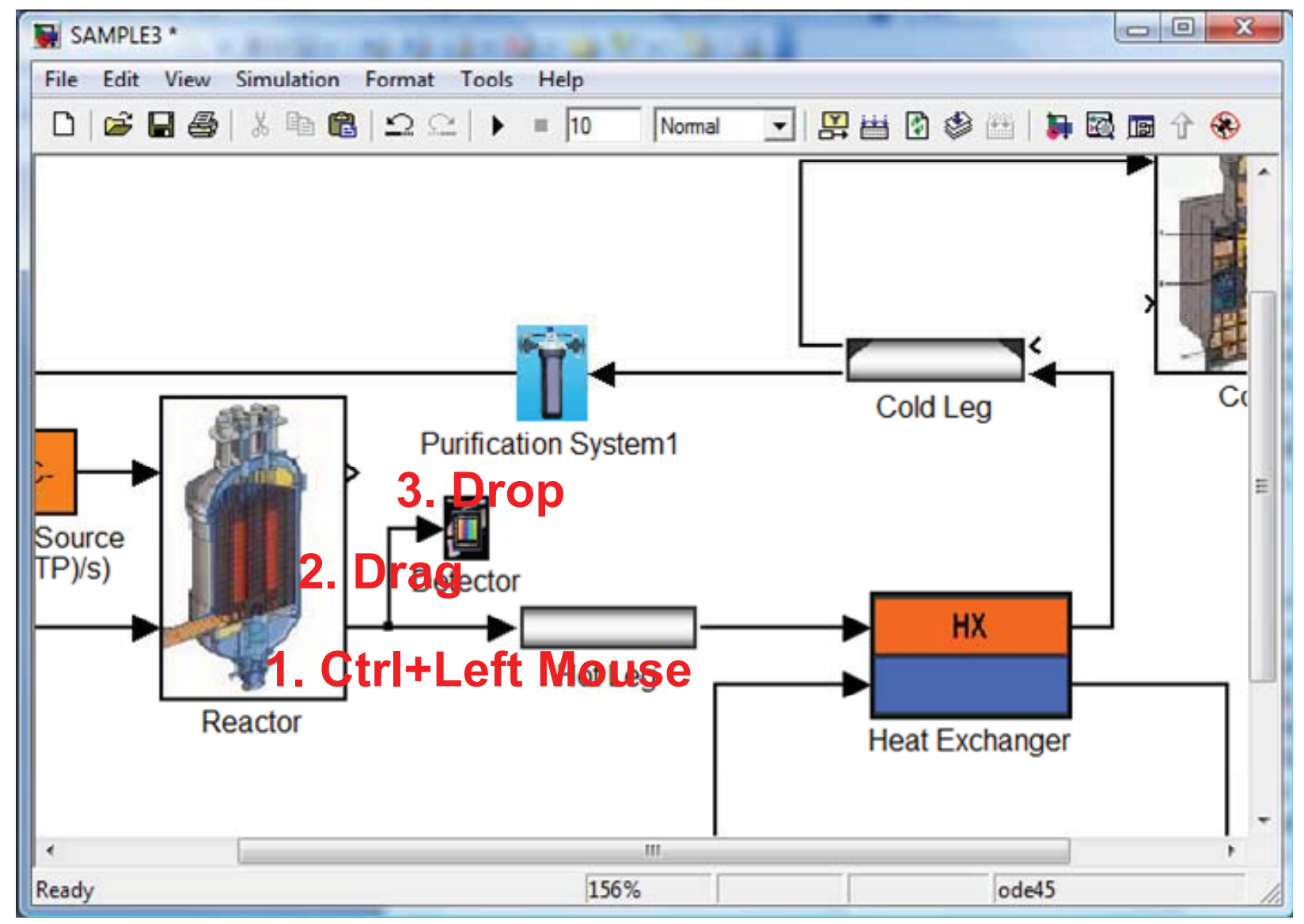

Figure 4-17. Linking the detector block into the stream. 


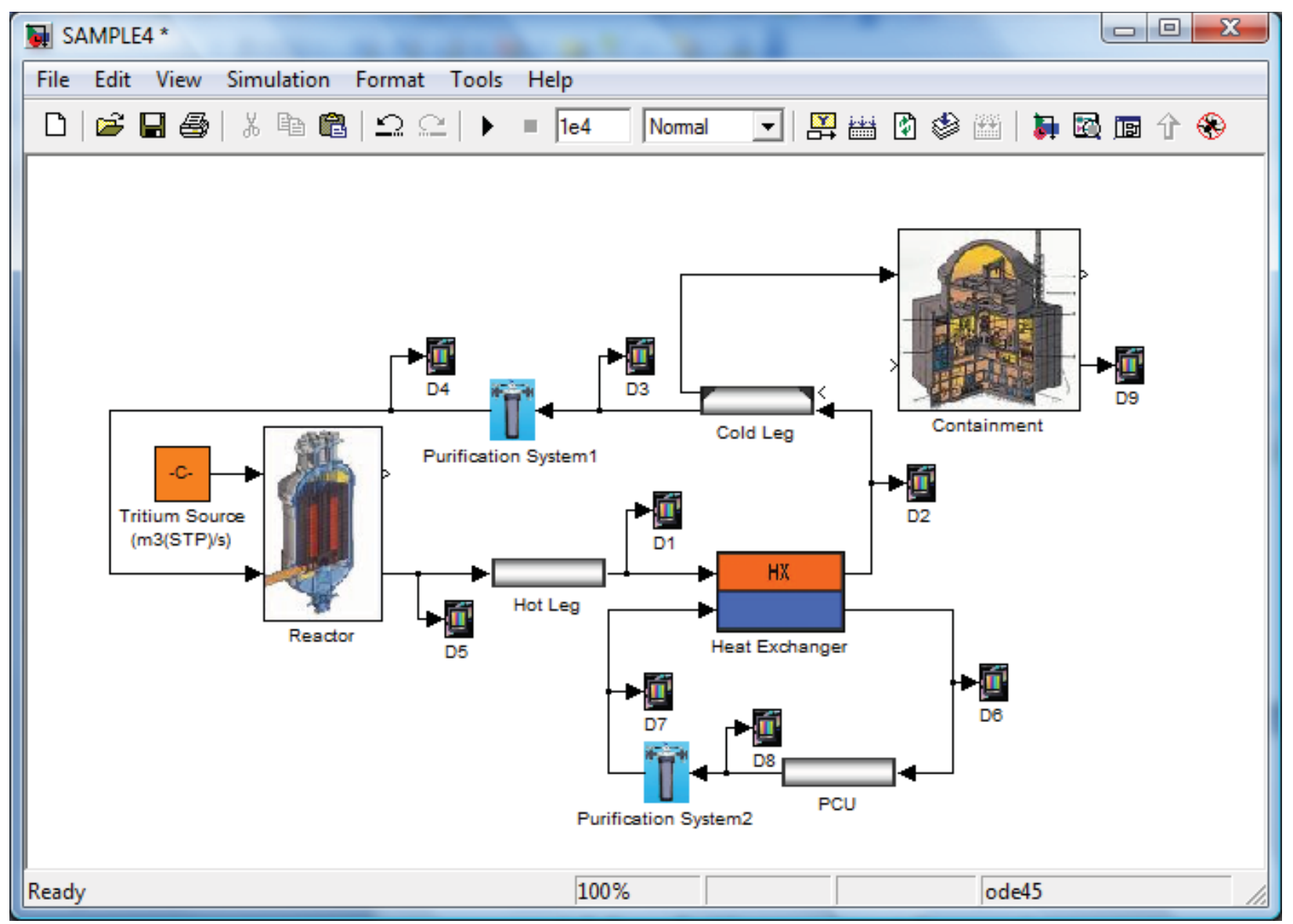

Figure 4-18. Addition of detectors to the main streams.

\subsubsection{Setting Up Input Parameters}

Once users develop the input diagram of the simulation, the input parameters should be defined for each component block. The current section summarizes the parameters defined in this simulation. The input data used in this simulation were arbitrarily chosen, so it does not represent any specific reactor designs such as gas turbine modular helium reactor or High Temperature Test Reactor. To access the input parameters, users can double-click the component blocks. Each block has its own input windows that represent its component types. The following summarizes the input data defined in the components.

\section{Reactor}

Figure 4-19 shows the input windows for the Reactor component. Specify each parameter as shown in this figure. 


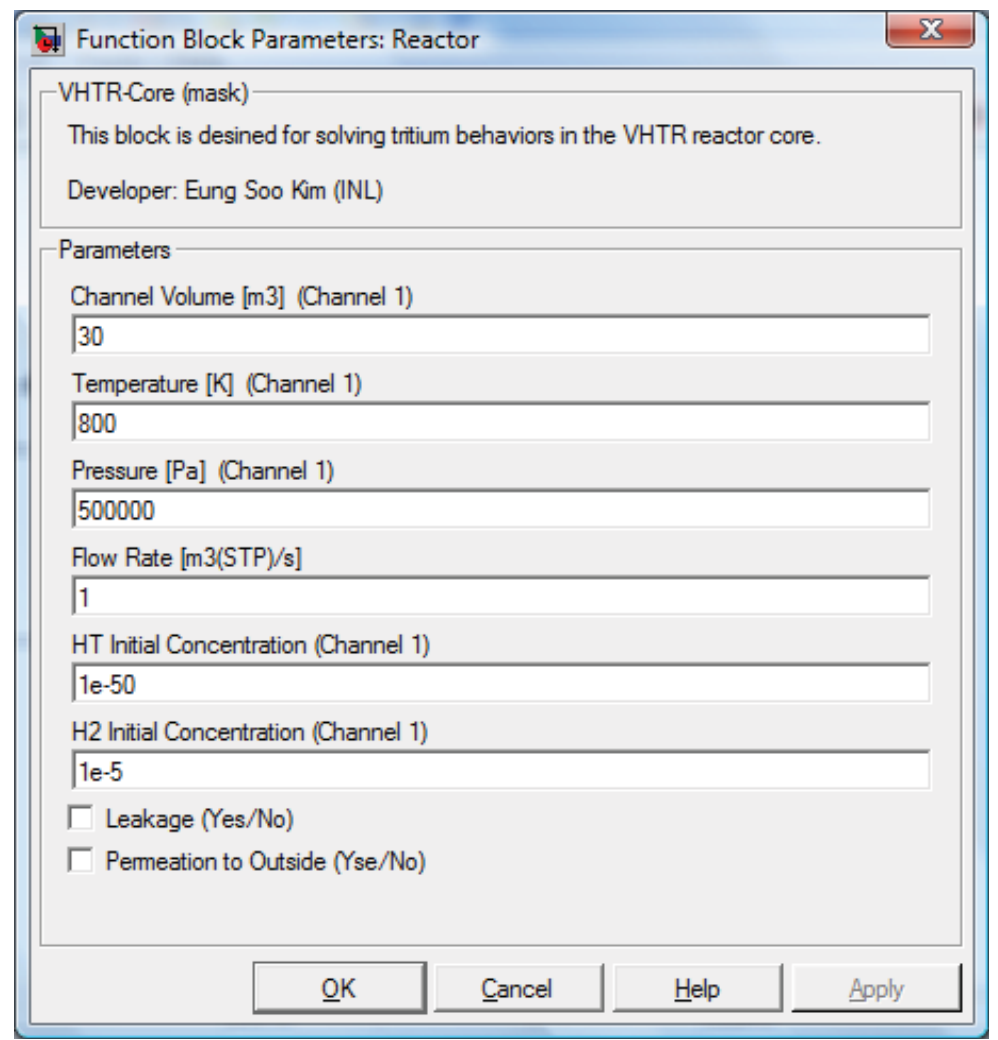

Figure 4-19. Input windows for Reactor component.

\section{Tritium Source}

Figure 4-20 shows the input windows for the tritium source block. Specify each parameter as shown in this figure.

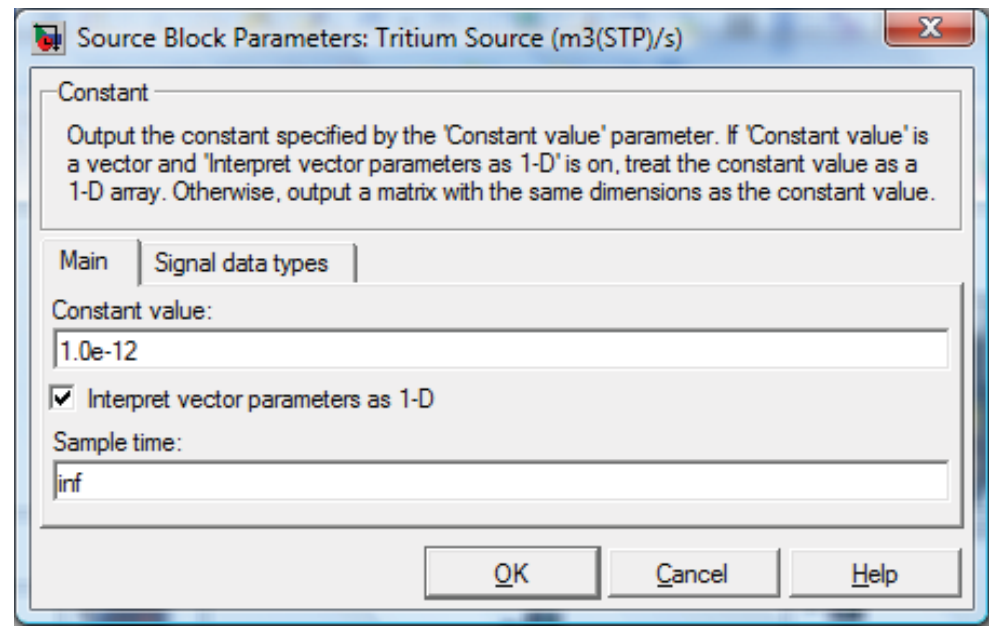

Figure 4-20. Input windows for Tritium Source block.

\section{Hot Leg}

Figure 4-21 shows the input windows for the Hot Leg component. Specify each parameter as shown in this figure. 


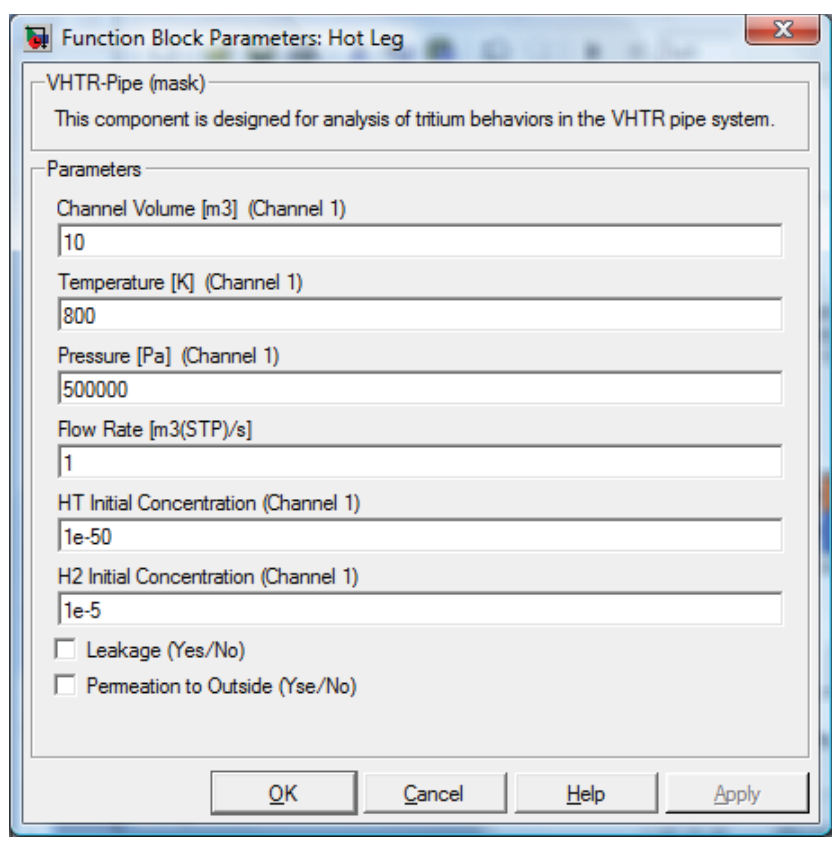

Figure 4-21. Input windows for Hot Leg component block.

\section{Cold Leg}

Figure 4-22 shows the input windows for the Cold Leg component. Specify each parameter as shown in this figure.

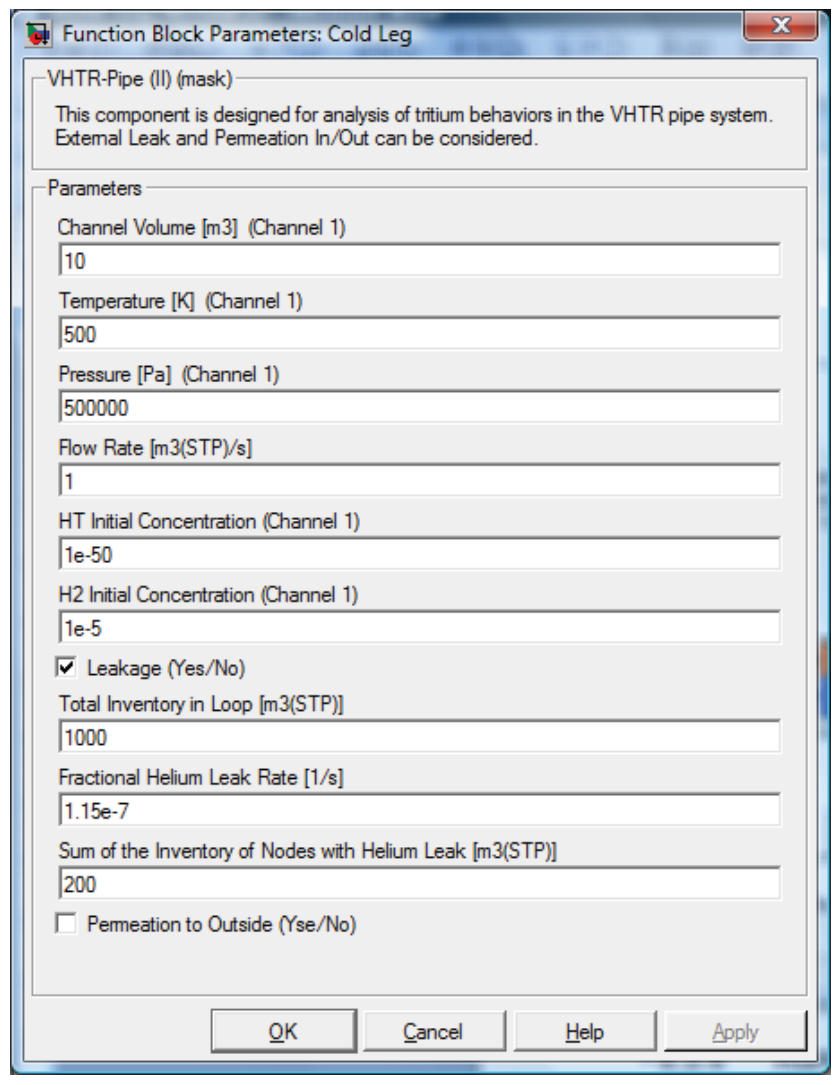

Figure 4-22. Input windows for Cold Leg component block. 


\section{$P C U$}

Figure 4-23 shows the input windows for the PCU component. Specify each parameter as shown in this figure.

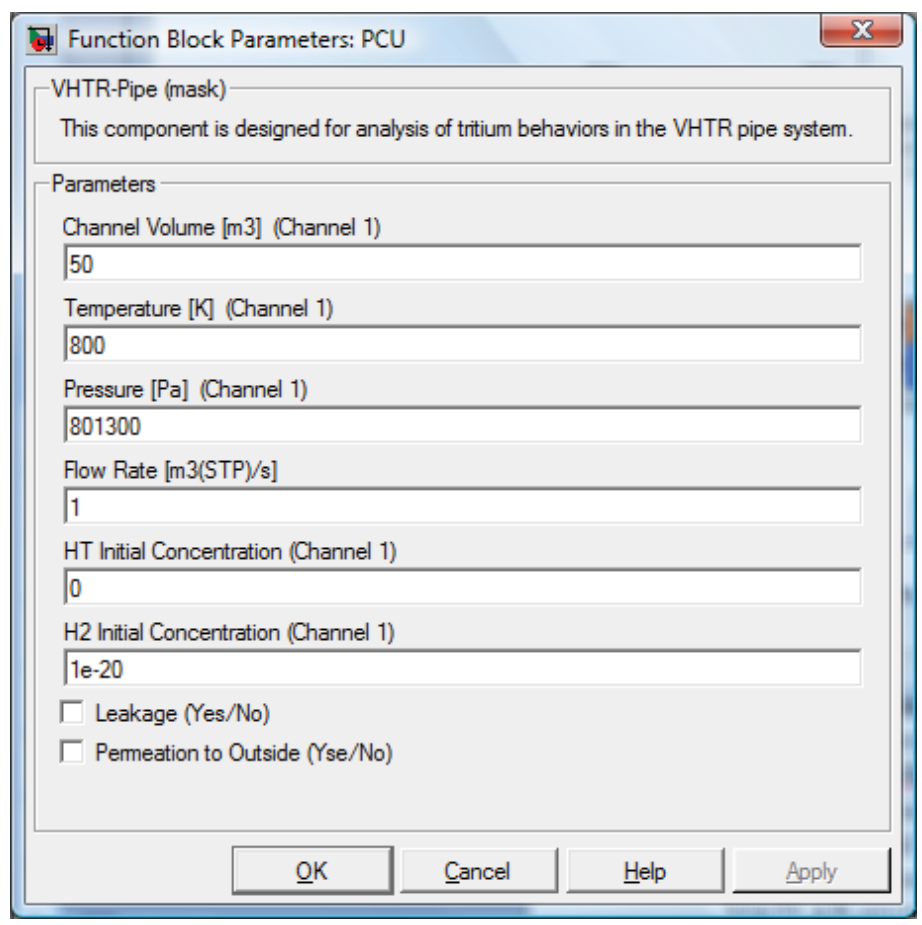

Figure 4-23. Input windows for PCU component block.

\section{Purification System 1}

Figure 4-24 shows the input windows for the Purification System 1 component. Specify each parameter as shown in this figure.

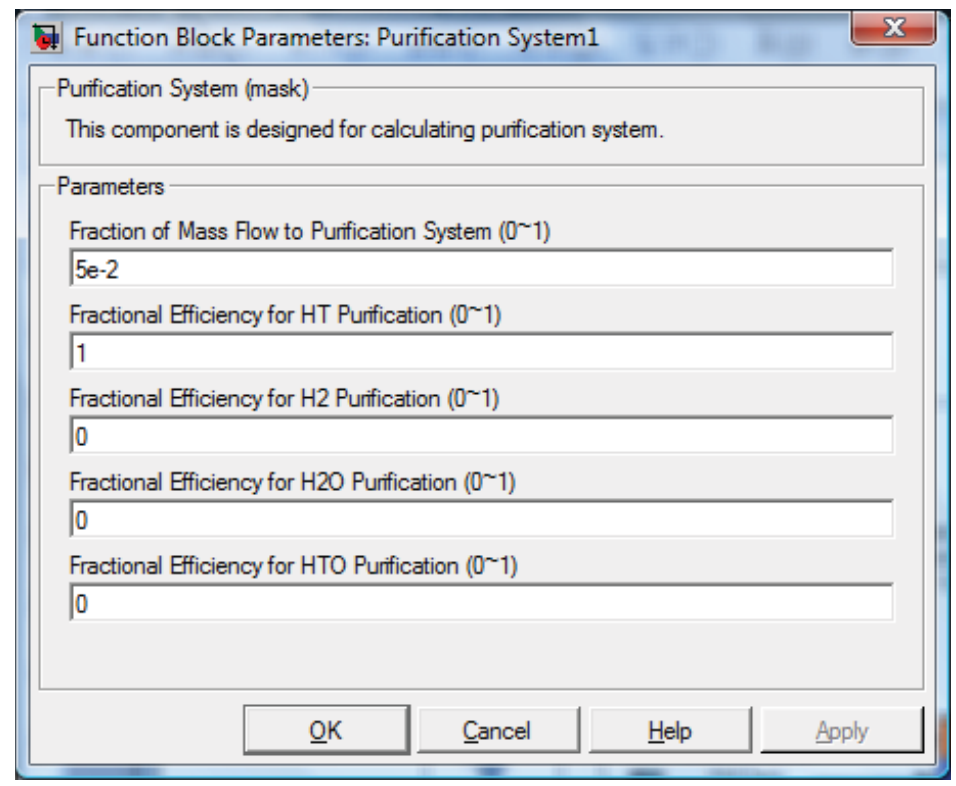

Figure 4-24. Input windows for Purification System 1 component block. 


\section{Purification System 2}

Figure 4-25 shows the input windows for the Purification System 2 component. Specify each parameter as shown in this figure.

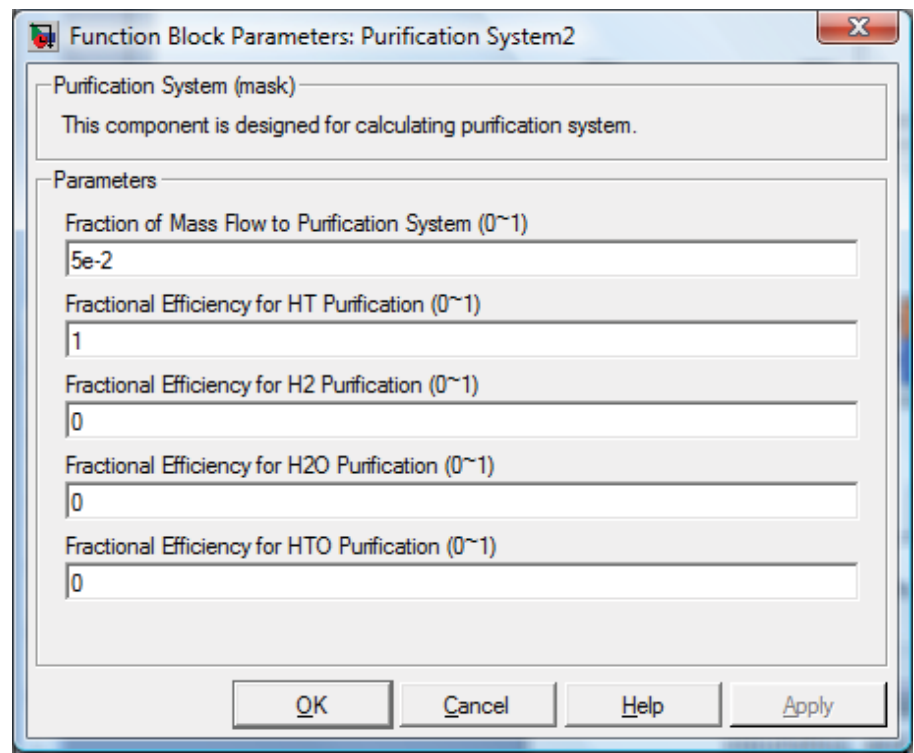

Figure 4-25. Input windows for Purification System 2 component block.

\section{Containment}

Figure 4-26 shows the input windows for the Containment component. Specify each parameter as shown in this figure.

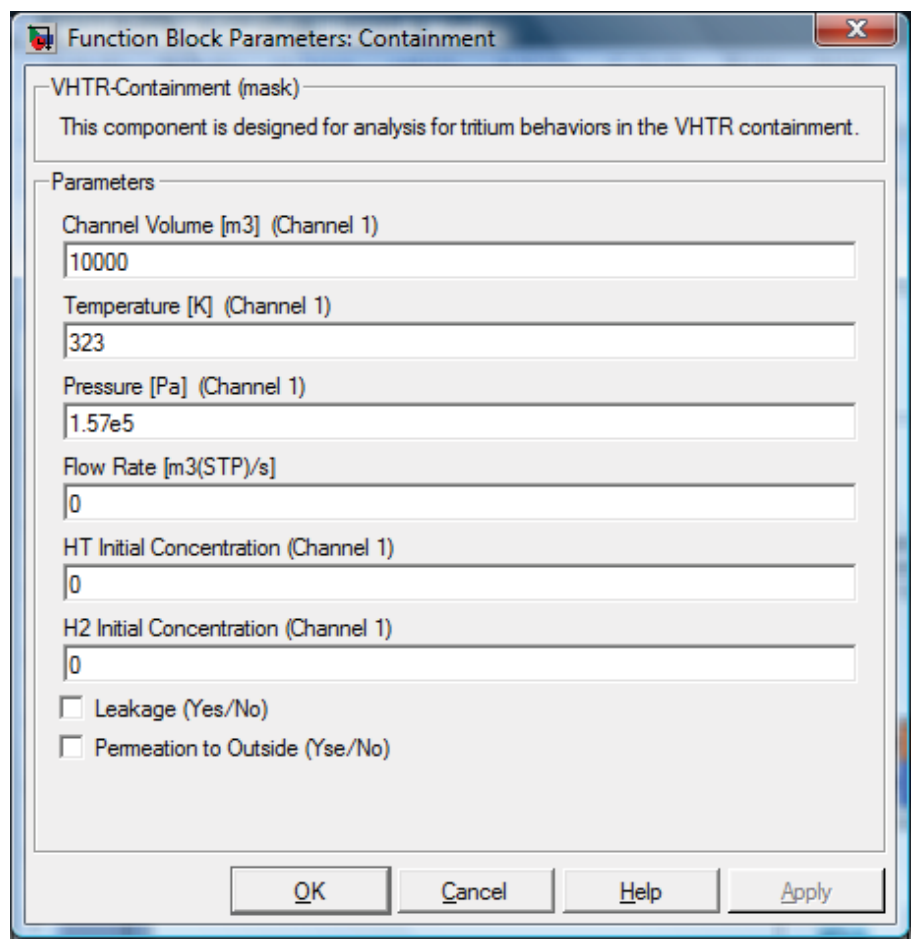

Figure 4-26. Input windows for Containment component block. 


\section{Heat Exchanger}

Figure 4-27 shows the input windows for the Heat Exchanger component. Specify each parameter as shown in this figure.

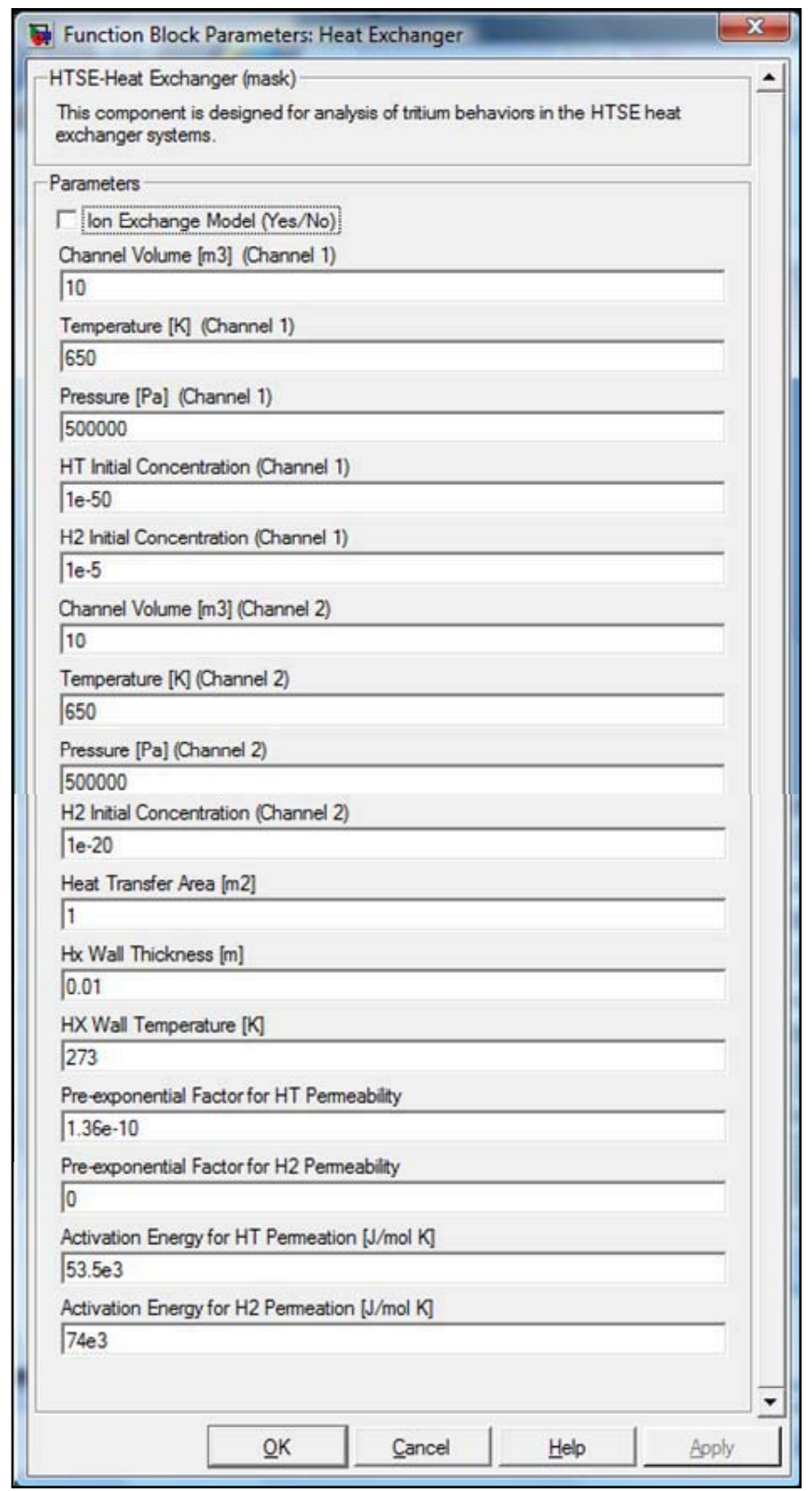

Figure 4-27. Input windows for Heat Exchanger component block.

\subsubsection{Running Job}

In the previous section, the input diagram has been developed and the input parameters have been specified. So the model is now ready for running. Before running the simulation, several parameters related to the solver should be predefined. The parameters include solver type, maximum/minimum time step, and initial time step. In this simulation, the default setting has been used so that any changes of the 
setting are not required. The details for the solver setting are described Section 4.5. Figure 4-28 shows the input diagram of the sample simulation. Running the TPAC simulation involves the following steps:

1. Enter the calculation time into the box in the toolbar, which is specified in Figure 4-28 as 1e4 sec.

2. Click the Run button on the toolbar; the simulation will now perform from 0 to $1 \mathrm{e} 4 \mathrm{sec}$.

3. Click the Stop button to terminate the simulation.

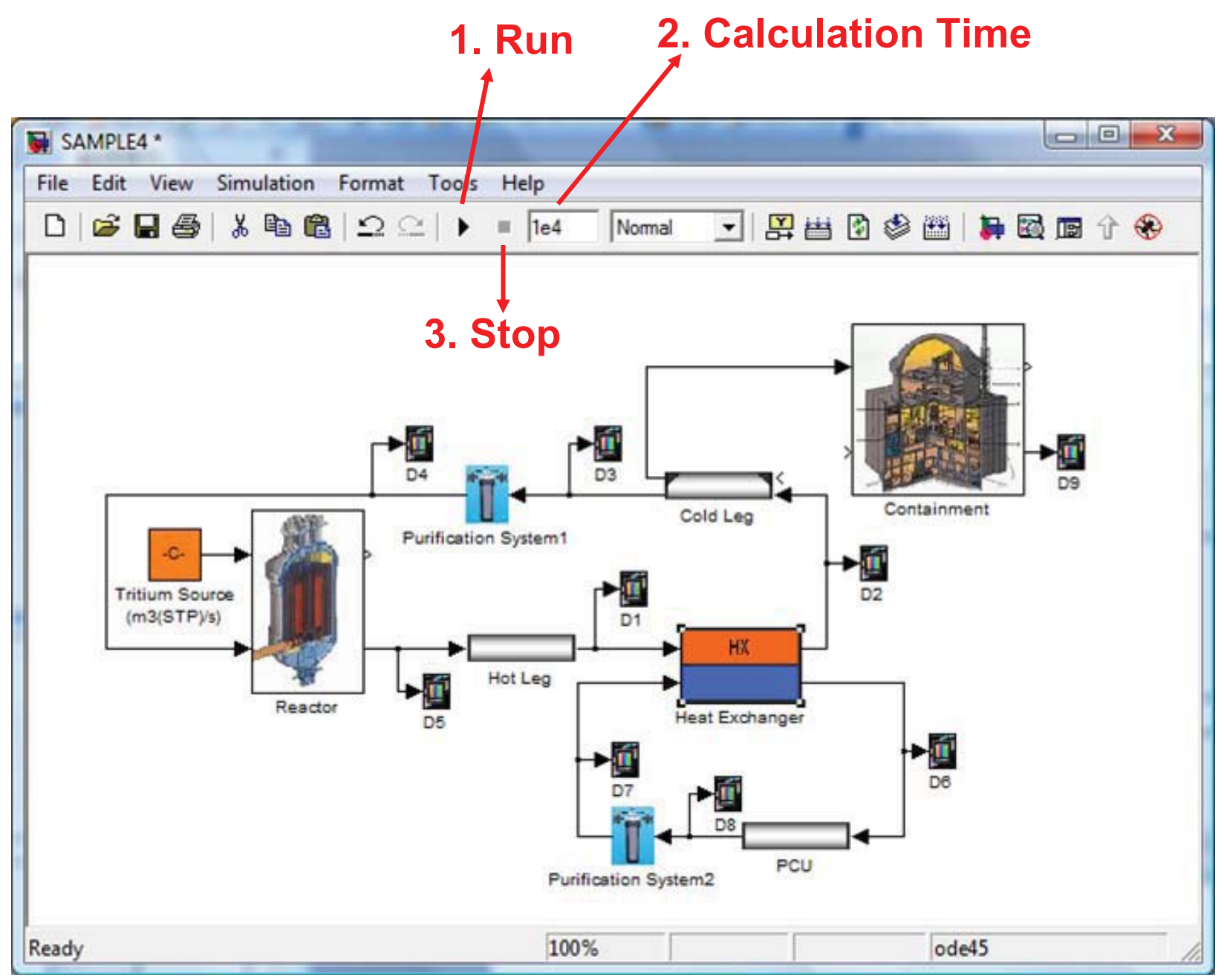

Figure 4-28. Running TPAC simulation.

\subsubsection{Analyses on the Results}

After simulation, the results can be easily checked by detector blocks that have been already linked to the streams. The detector block shows the upstream flow conditions. For example, the D1 detector block contains the information of the Hot Leg component. The data of the detector can be accessed by doubleclicking the icons. Figure 4-29 shows the D5 detector data which contains the Reactor component information. The detector block consists of two parts; display and plot. Display region shows the data of the stream at the end of calculations. Plot region displays the graph of time vs. specific data. The data are arranged in the following sequence from top to bottom.

- $\quad$ Flow Rate $\left[\mathrm{m}^{3}(\mathrm{STP}) / \mathrm{s}\right]$

- $\quad$ HT Concentration [mole fraction] 
- Temperature [K]

- Pressure $[\mathrm{Pa}]$

- $\mathrm{H}_{2}$ Concentration [mole fraction]

- $\mathrm{H}_{2} \mathrm{O}$ Concentration [mole fraction]

- HTO Concentration [mole fraction]

- $\mathrm{H}_{2} \mathrm{SO}_{4}$ Concentration [mole fraction]

- $\mathrm{HTSO}_{4}$ Concentration [mole fraction]

- HI Concentration [mole fraction]

- TI Concentration [mole fraction]

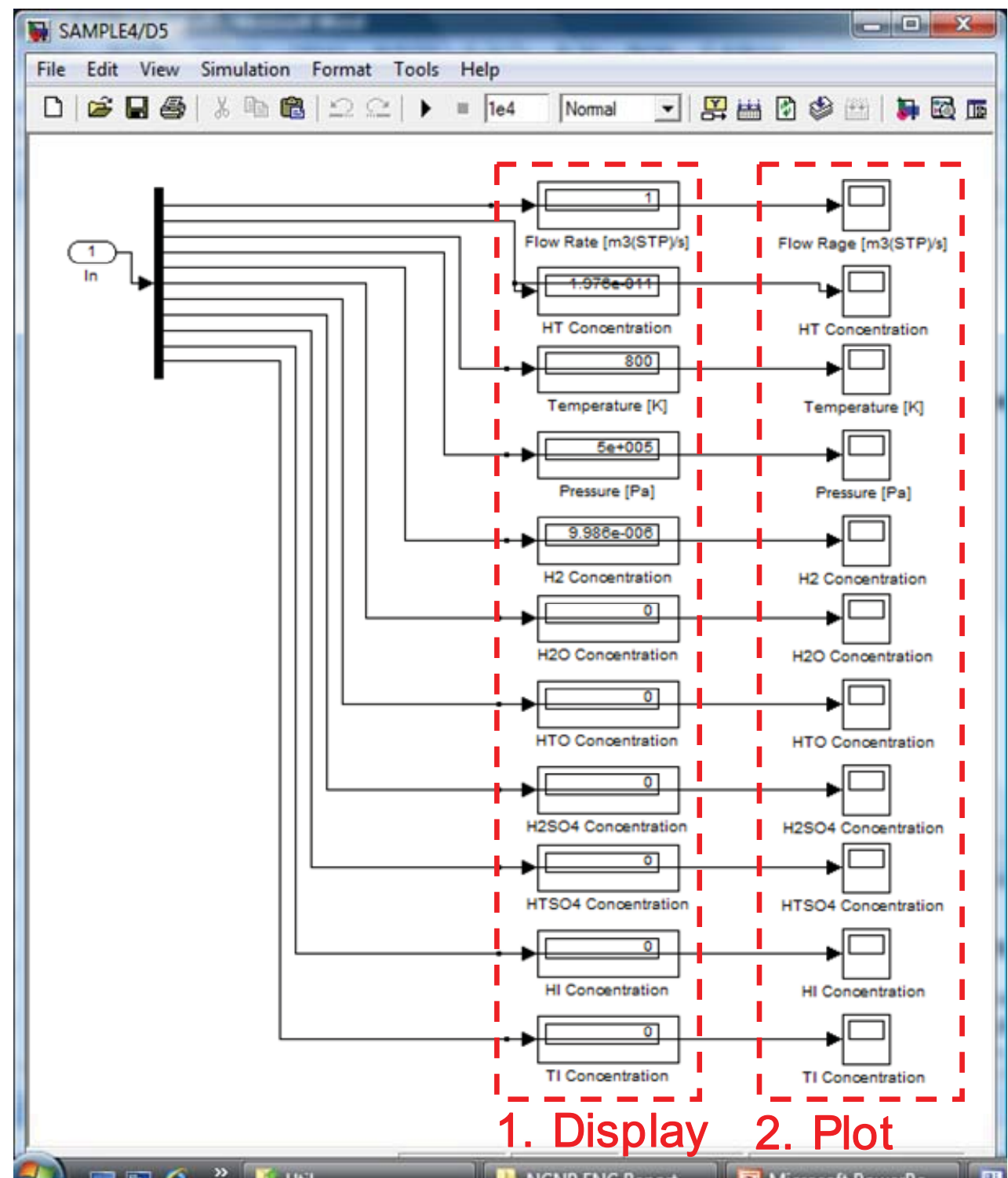

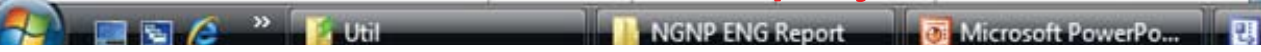

Figure 4-29. Inside of Detector block (D5). 
According to the simulation results, the HT concentration in the Reactor is $1.976 \times 10^{-11}$ mole fraction $(=0.01976 \mathrm{ppb})$ after $1 \times 10^{4} \mathrm{sec}(=2.8 \mathrm{hrs})$. Figure $4-30$ shows the variations of the HT concentrations. This plot can be popped up by double-clicking the Plot icons. Initially, the HT concentration rapidly increases, it then becomes saturated by the balance of generation (tritium source) and removal (purification system, leakage, and permeation).

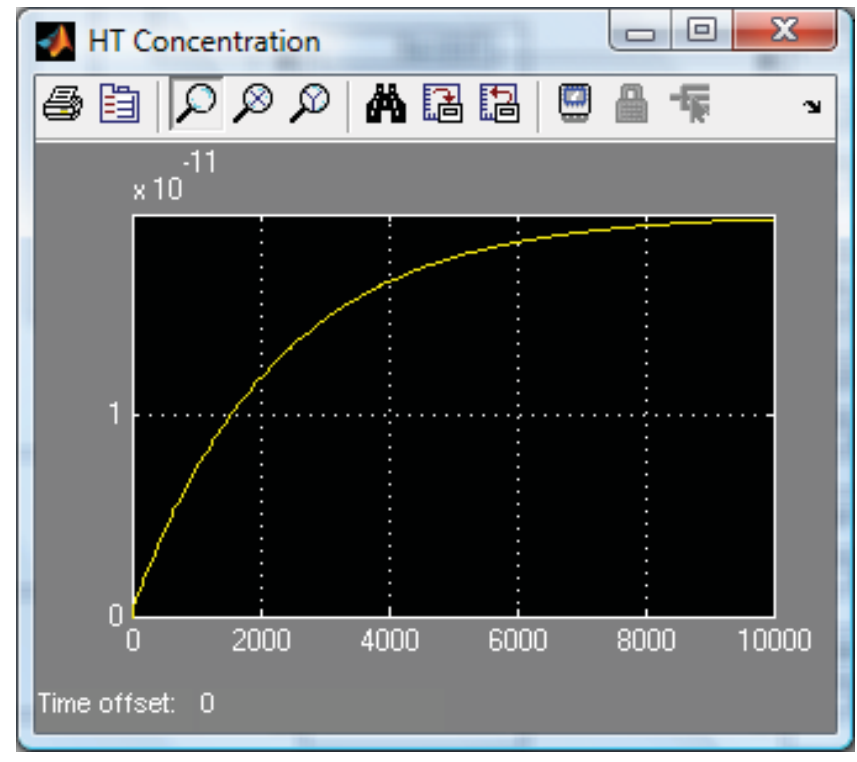

Figure 4-30. Variations of the HT concentrations in the reactor.

Figures 4-31 and 4-32 show the HT concentrations in the PCU (D8 detector) and the containment (D9 detector), respectively. The HT concentrations in the PCU are initially increased by permeation of the tritium through the heat exchanger (See Figure 4-31). They are then getting saturated by purification of the HT. In the containment, the HT concentrations are continuously increased by leakage of coolant from the primary loop (See Figure 4-32). No leakage, permeation, or purification was considered in the containment and therefore HT concentrations are continuously increased. For the other components or streams, users can also access the data as described above.

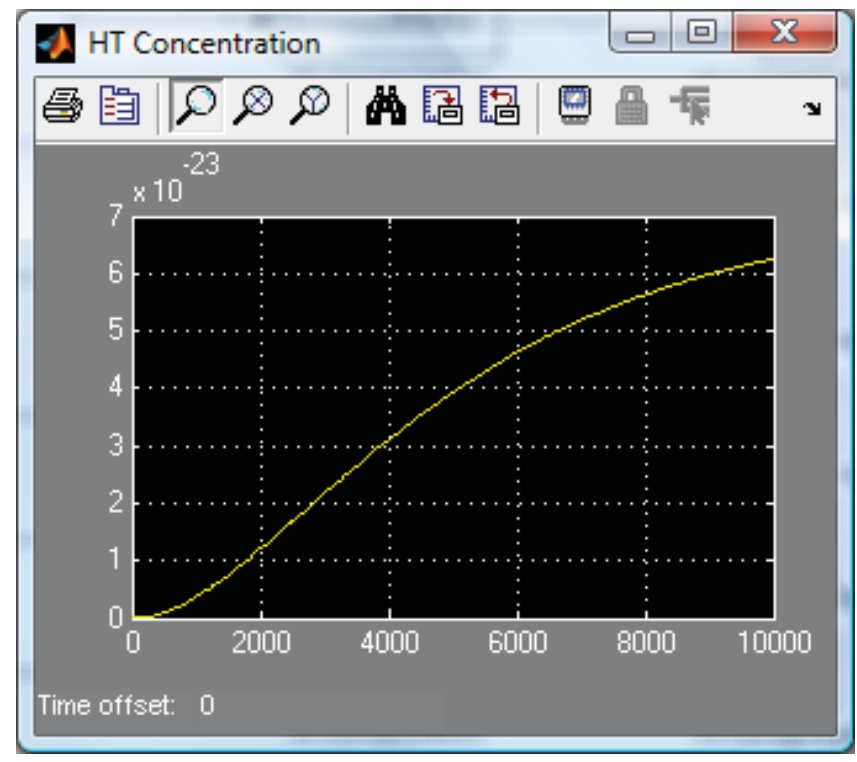

Figure 4-31. Variations of the HT concentrations in the PCU. 


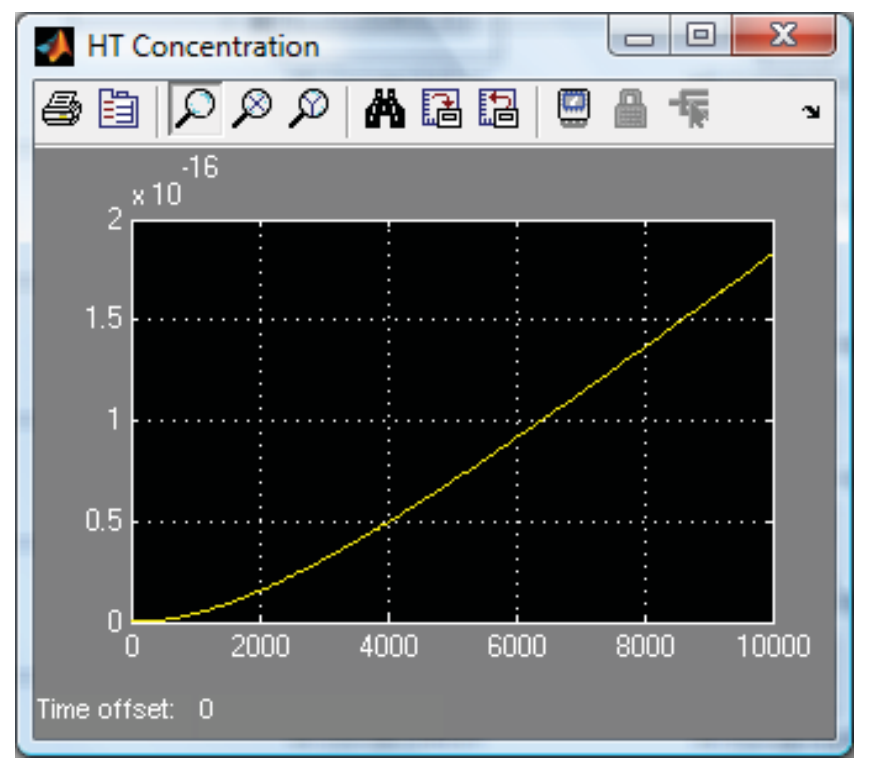

Figure 4-32. Variations of the HT concentrations in the containment.

\subsection{Component Summary}

The TPAC consists of a variety of model blocks that represent VHTR or hydrogen production system components. This section summarizes the type of component blocks and how to use them. Table 4-2 lists the component organizations in the TPAC. The TPAC has 11 categories, each consisting of its own component blocks that represent reactor components, hydrogen production system components, or other subsystems. The details about these components are described in the following subsections.

\subsubsection{VHTR System Component}

VHTR System Component category has two component blocks; Reactor and Core. These two components are used to model the VHTR core and the pressure vessel.

\section{Reactor Component}

Table 4-3 summarizes the specifications of the Reactor block. This table shows the governing equations and models used in this block. It also shows port information needed for actual modeling in the SIMULINK editor. The Reactor block solves two species conservation equations $\left(\mathrm{HT}, \mathrm{H}_{2}\right)$ with leakage and permeation models. This block has four ports that exchange information with other component blocks. Table 4-4 lists the input parameters that should be defined in the reactor model.

\section{Core}

Table 4-5 shows the specifications of the Core block. This block calculates various tritium generations from the core such as ternary fission and neutron reactions. Figure 4-33 shows the inside of the core block. It basically consists of five different tritium source calculation blocks. However, depending on the user's choice, it can be very flexibly modified to represent various designs by simply adding or deleting components. 
Table 4-2. Component organization of the TPAC.

\begin{tabular}{|c|c|c|}
\hline Category & \multicolumn{2}{|c|}{ Component Blocks } \\
\hline \multirow{8}{*}{ A. VHTR System Component } & \multirow{7}{*}{ Core } & Ternary Fission \\
\hline & & Birth from $6 \mathrm{Li}$ \\
\hline & & Birth from $7 \mathrm{Li}$ \\
\hline & & Birth from $3 \mathrm{He}$ \\
\hline & & Birth from 10B \\
\hline & & Convert dNT/dt to Rcore \\
\hline & & Mux \\
\hline & React & \\
\hline & Pipe-I & \\
\hline & Pipe-I & \\
\hline & Pipe-s & \\
\hline & Pipe I & \\
\hline B. Pipe Component & Pipe I & \\
\hline & Pipe I & \\
\hline & Isotop & \\
\hline & Extern & Source \\
\hline & Termi & \\
\hline$C$ Hent Eychonger Comnonent & Heat & \\
\hline C. Heat Exchanger Component & Heat & \\
\hline & Vesse & \\
\hline & Vesse & \\
\hline D Voul Cammonat & Vesse & \\
\hline D. vesser component & Isotor & \\
\hline & Exter & Source \\
\hline & Term & \\
\hline E. Containment Component & Conta & \\
\hline F. Purification System Component & Purifi & \\
\hline G. Electrolyzer Component & Electr & \\
\hline H Flow Distribution Comnonent & Flow & \\
\hline 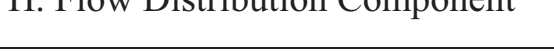 & Flow & \\
\hline I. Boundary Flow Component & Boun & \\
\hline J. Detector Component & Detec & \\
\hline K Data Save Comnonent & Save & \\
\hline R. Data Dave Componemt & Save & \\
\hline
\end{tabular}


Table 4-3. Specifications of the Reactor Component block.

\begin{tabular}{|c|c|c|c|}
\hline \multicolumn{2}{|l|}{ Icon } & \multicolumn{2}{|r|}{ Specifications } \\
\hline & & \multicolumn{2}{|c|}{ HT Species Conservation } \\
\hline & Governing & \multicolumn{2}{|c|}{$\mathrm{H}_{2}$ Species Conservation } \\
\hline & $\begin{array}{l}\text { Equations and } \\
\text { Models }\end{array}$ & \multicolumn{2}{|c|}{ Leakage Model } \\
\hline & & \multicolumn{2}{|c|}{ Permeations Model } \\
\hline & \multirow{4}{*}{ Port Information } & (1) & Flow In \\
\hline & & (2) & Flow Out \\
\hline \multirow[t]{2}{*}{ Reactor } & & 3 & Tritium Source (Core Model) In \\
\hline & & (4) & Tritium Leak and Permeation Out \\
\hline
\end{tabular}

Table 4-4. Input parameters of the Reactor Component block.

\begin{tabular}{|c|c|c|}
\hline Input Parameter & Unit & Description \\
\hline Channel volume & $\mathrm{m}^{3}$ & Volume of the reactor \\
\hline Temperature & $\mathrm{K}$ & Average temperature in the reactor \\
\hline Pressure & $\mathrm{Pa}$ & Average pressure in the reactor \\
\hline Flow rate & $\mathrm{m}^{3}(\mathrm{STP}) / \mathrm{s}$ & Flow rate of the reactor outlet \\
\hline HT initial concentration & mole fraction & Average initial HT mole fraction in the reactor \\
\hline $\mathrm{H}_{2}$ initial concentration & mole fraction & Average initial $\mathrm{H}_{2}$ mole fraction in the reactor \\
\hline Leakage & \# & Check box for activating leakage model \\
\hline Total inventory in loop & $\mathrm{m}^{3}(\mathrm{STP})$ & Total inventory of the loop including the reactor \\
\hline Fractional helium leak rate & $1 / \mathrm{s}$ & Fraction helium leak rate \\
\hline $\begin{array}{l}\text { Sum of the inventory of the nodes with } \\
\text { helium leak }\end{array}$ & $\mathrm{m}^{3}(\mathrm{STP})$ & Sum of the inventory of the loop with helium leak \\
\hline Permeation to outside & \# & Check box for activating permeation model \\
\hline Surface area for permeation & $\mathrm{m}^{2}$ & Surface area for permeation in the reactor \\
\hline Thickness of the wall & $\mathrm{m}$ & Wall thickness for the permeation in the reactor \\
\hline Permeation temperature & $\mathrm{K}$ & Temperature for permeation \\
\hline $\begin{array}{l}\text { Pre-exponential factor for HT } \\
\text { permeation }\end{array}$ & $\mathrm{m}^{3}(\mathrm{STP}) / \mathrm{m} / \mathrm{s}$ & Pre-exponential factor for HT permeation \\
\hline Activation energy for HT permeation & $\mathrm{J} / \mathrm{mol}$ & Activation energy for HT permeation \\
\hline $\begin{array}{l}\text { Pre-exponential factor for } \mathrm{H}_{2} \\
\text { permeation }\end{array}$ & $\mathrm{m}^{3}(\mathrm{STP}) / \mathrm{m} / \mathrm{s}$ & Pre-exponential factor for $\mathrm{H}_{2}$ permeation \\
\hline Activation energy for $\mathrm{H}_{2}$ permeation & $\mathrm{J} / \mathrm{mol}$ & Activation energy for $\mathrm{H}_{2}$ permeation \\
\hline
\end{tabular}


Table 4-5. Specification of Core Component block.

\begin{tabular}{|c|c|c|}
\hline Icon & & Specifications \\
\hline \multirow{6}{*}{ Core } & \multirow{5}{*}{$\begin{array}{l}\text { Governing } \\
\text { Equations and } \\
\text { Models }\end{array}$} & Ternary Fission \\
\hline & & Tritium Birth from ${ }^{6} \mathrm{Li}$ \\
\hline & & Tritium Birth from ${ }^{7} \mathrm{Li}$ \\
\hline & & Tritium Birth from ${ }^{3} \mathrm{He}$ \\
\hline & & Tritium Birth from ${ }^{10} \mathrm{~B}$ \\
\hline & Port Information & (1) Tritium Generation in the Core \\
\hline
\end{tabular}
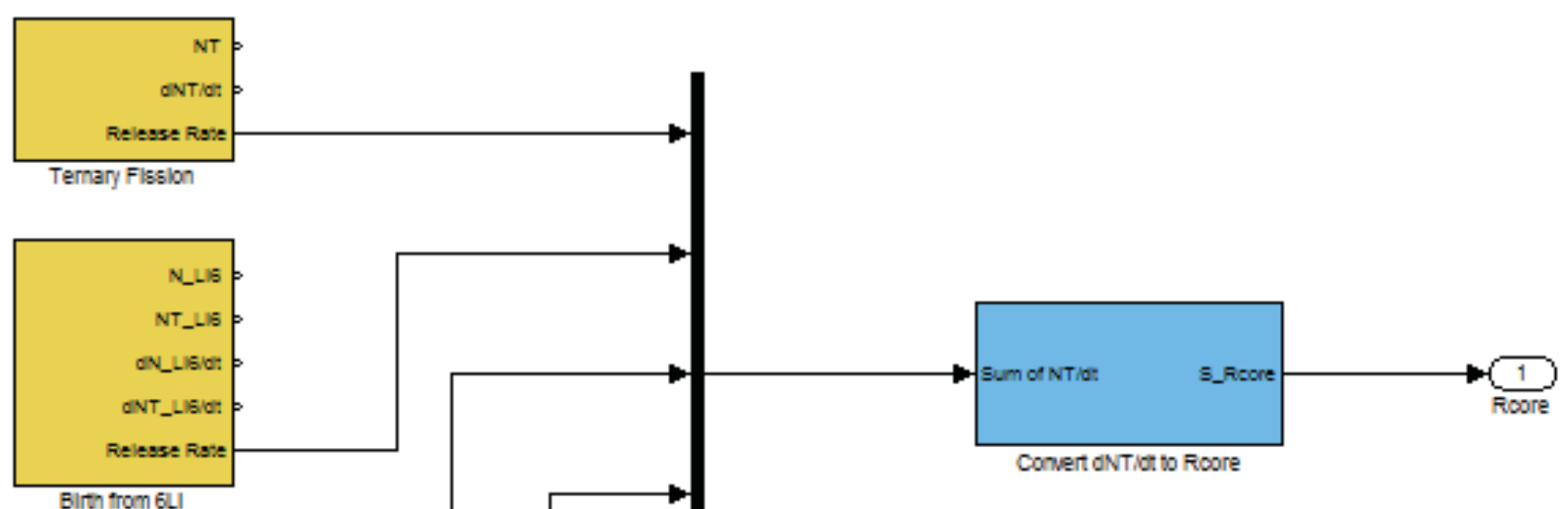

Birth from 6LI
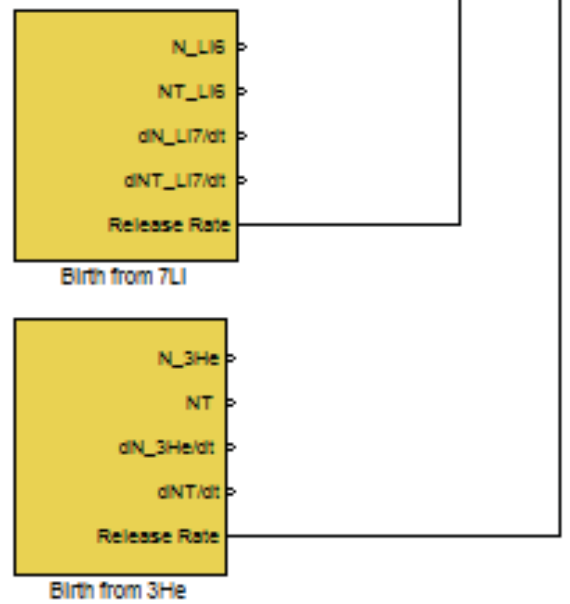

Birth from 3 He

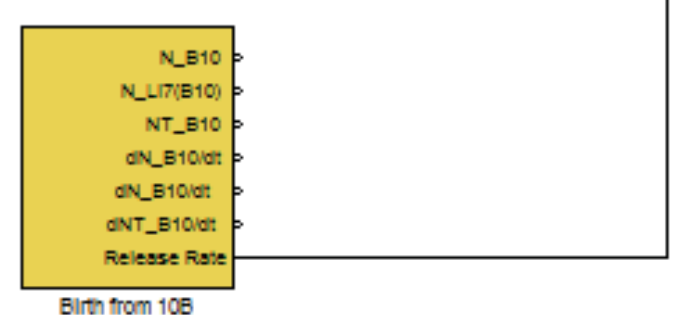

Birth from 108

Figure 4-33. Core block structure. 


\subsubsection{Pipe Component}

The Pipe Component category has nine component blocks as shown in Table 4-2. Tables 4-6 through 4-18 summarize specifications and input parameters of the components related to this category.

Tables 4-6 and 4-7 show the specifications of two VHTR-Pipe components. The two components are composed of the same equation sets, but they have different user interfaces. Pipe-VHTR has only Flow In and Flow Out ports in the block while PipeII-VHTR has two additional ports: Tritium Leak and Permeation In/Out ports. The Tritium Leak and Permeation Out port of a pipe component can be connected to the Tritium Leak and Permeation in the port of another pipe, vessel, or containment block. Tables 4-9, 4-10, and 4-11 summarize the HTSE-Pipe related component blocks. These blocks solve two additional species conservation equations $\left(\mathrm{H}_{2} \mathrm{O}, \mathrm{HTO}\right)$ than the VHTR-Pipe blocks. Tables 4-12, 4-13, and 4-14 summarize the SI-Pipe blocks. These blocks solve six more species conservation equations $\left(\mathrm{H}_{2} \mathrm{O}, \mathrm{HTO}, \mathrm{H}_{2} \mathrm{SO}_{4}, \mathrm{HTSO}_{4}\right.$, HI, and TI) compared to the VHTR-Pipe blocks. Tables 4-16 and 4-17 summarize the Isotope Exchange block, which provides three isotope exchange reactions. Tables 4-18 and 4-19 summarize the External Tritium Source block, which provides external user input for tritium source. This block can be easily connected to the Tritium Leak and Permeation In port in the pipe blocks.

Table 4-6. Specification of Pipe-VHTR component block.

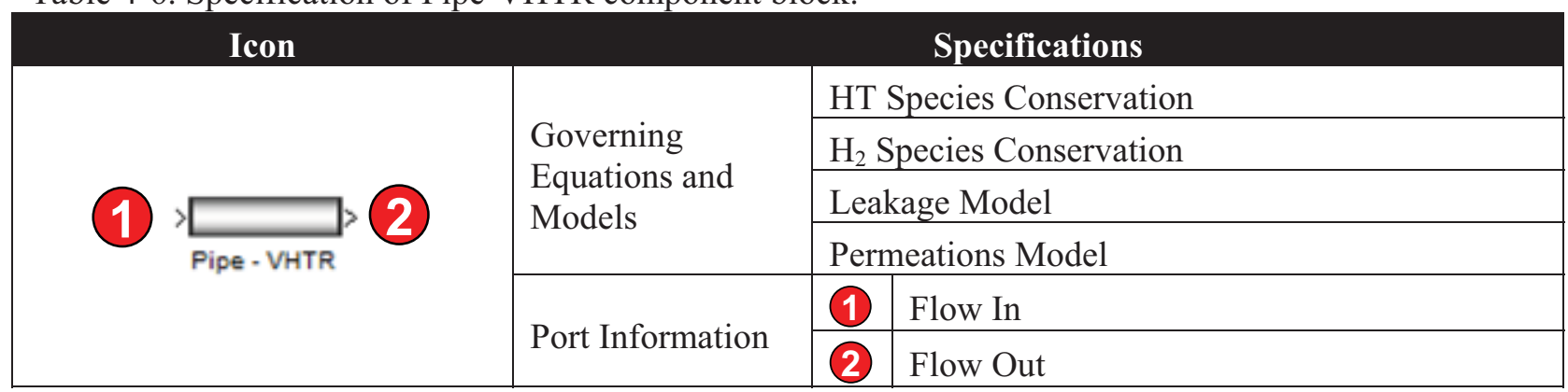

Table 4-7. Specification of PipeII-VHTR component block.

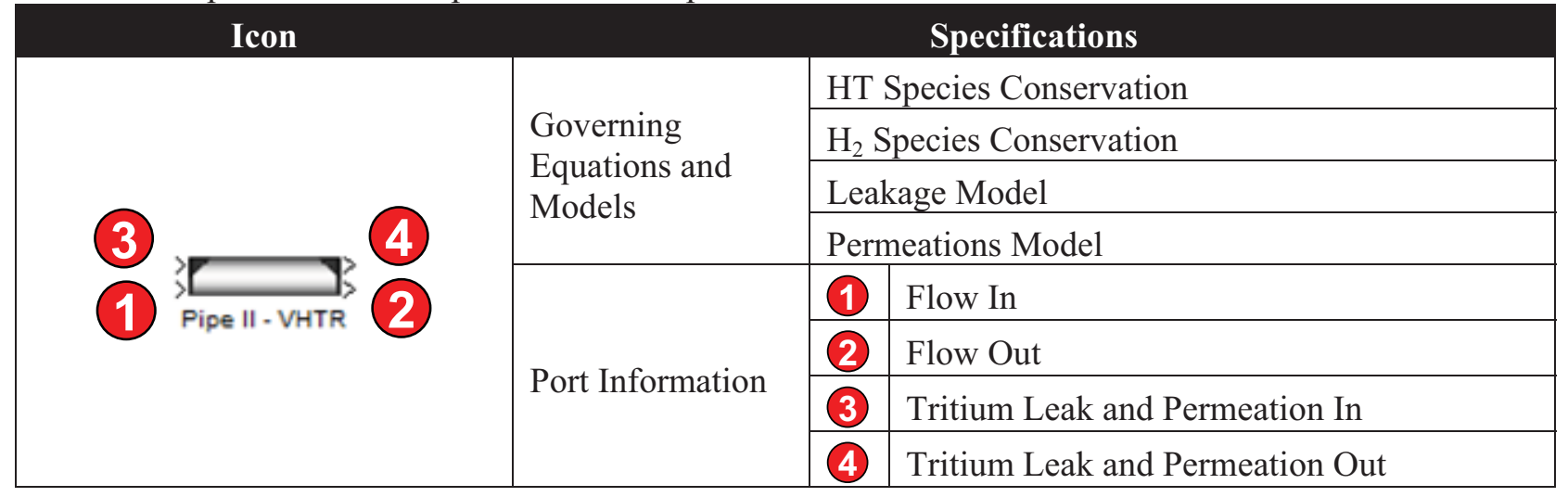


Table 4-8. Input Parameters of Pipe-VHTR component block.

\begin{tabular}{|c|c|c|}
\hline Input Parameter & Unit & Description \\
\hline Channel Volume & $\mathrm{m}^{3}$ & Volume of the pipe \\
\hline Temperature & K & Average temperature in the pipe \\
\hline Pressure & $\mathrm{Pa}$ & Average pressure in the pipe \\
\hline Flow Rate & $\mathrm{m}^{3}(\mathrm{STP}) / \mathrm{s}$ & Flow rate of the pipe outlet \\
\hline HT Initial Concentration & mole fraction & Average initial HT mole fraction in the pipe \\
\hline $\mathrm{H}_{2}$ Initial Concentration & mole fraction & Average initial $\mathrm{H}_{2}$ mole fraction in the pipe \\
\hline Leakage & \# & Check box for activating leakage model \\
\hline Total Inventory in Loop & $\mathrm{m}^{3}(\mathrm{STP})$ & Total inventory of the loop including the pipe \\
\hline Fractional Helium Leak Rate & $1 / \mathrm{s}$ & Fraction helium leak rate \\
\hline $\begin{array}{l}\text { Sum of the inventory of the nodes } \\
\text { with helium leak }\end{array}$ & $\mathrm{m}^{3}(\mathrm{STP})$ & Sum of the inventory of the loop with helium leak \\
\hline Permeation to Outside & \# & Check box for activating permeation model \\
\hline Surface Area for Permeation & $\mathrm{m}^{2}$ & Surface area for permeation in the pipe \\
\hline Thickness of the Wall & $\mathrm{m}$ & Wall thickness for the permeation in the pipe \\
\hline Permeation Temperature & K & Temperature for permeation \\
\hline $\begin{array}{l}\text { Pre-exponential Factor for HT } \\
\text { Permeation }\end{array}$ & $\mathrm{m}^{3}(\mathrm{STP}) / \mathrm{m} / \mathrm{s}$ & Pre-exponential factor for HT permeation \\
\hline Activation Energy for HT Permeation & $\mathrm{J} / \mathrm{mol}$ & Activation energy for HT permeation \\
\hline $\begin{array}{l}\text { Pre-exponential Factor for } \mathrm{H}_{2} \\
\text { Permeation }\end{array}$ & $\mathrm{m}^{3}(\mathrm{STP}) / \mathrm{m} / \mathrm{s}$ & Pre-exponential factor for $\mathrm{H}_{2}$ permeation \\
\hline Activation Energy for $\mathrm{H}_{2}$ Permeation & $\mathrm{J} / \mathrm{mol}$ & Activation energy for $\mathrm{H}_{2}$ permeation \\
\hline
\end{tabular}

Table 4-9. Specification of Pipe-HTSE component block.

\begin{tabular}{|c|c|c|c|}
\hline \multicolumn{2}{|l|}{ Icon } & \multicolumn{2}{|r|}{ Specifications } \\
\hline \multirow{8}{*}{ Pipe-HTSE } & \multirow{6}{*}{$\begin{array}{l}\text { Governing } \\
\text { Equations and } \\
\text { Models }\end{array}$} & \multicolumn{2}{|c|}{ HT Species Conservation } \\
\hline & & \multicolumn{2}{|c|}{$\mathrm{H}_{2}$ Species Conservation } \\
\hline & & \multicolumn{2}{|c|}{$\mathrm{H}_{2} \mathrm{O}$ Species Conservation } \\
\hline & & \multicolumn{2}{|c|}{ HTO Species Conservation } \\
\hline & & \multicolumn{2}{|c|}{ Leakage Model } \\
\hline & & \multicolumn{2}{|c|}{ Permeations Model } \\
\hline & \multirow{2}{*}{ Port Information } & (1) & Flow In \\
\hline & & (2) & Flow Out \\
\hline
\end{tabular}


Table 4-10. Specification of PipeII-HTSE component block.

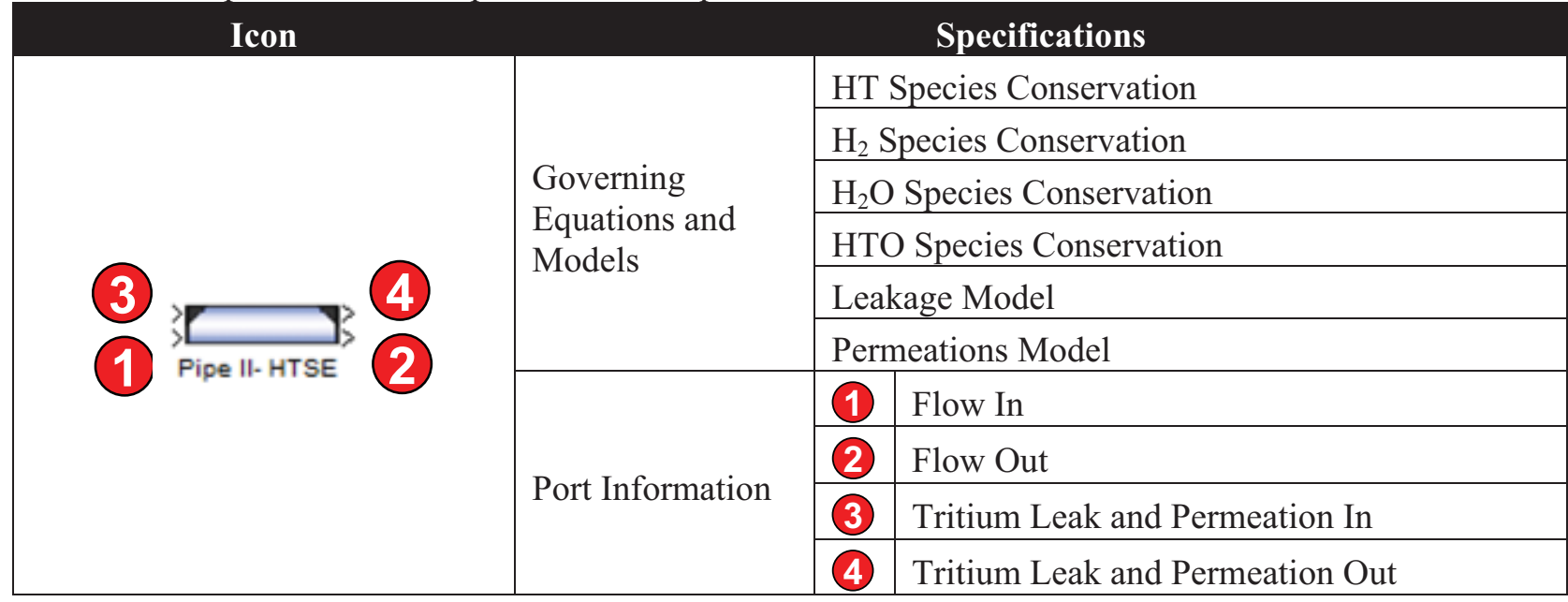

Table 4-11. Additional input parameters of Pipe-HTSE component block.

\begin{tabular}{|l|l|l|}
\multicolumn{1}{|c|}{ Input Parameter } & \multicolumn{1}{c|}{ Unit } & Description \\
\hline $\mathrm{H}_{2} \mathrm{O}$ Initial Concentration & mole fraction & Average initial $\mathrm{H}_{2} \mathrm{O}$ mole fraction in the pipe \\
\hline HTO Initial Concentration & mole fraction & Average initial HTO mole fraction in the pipe \\
\hline
\end{tabular}

Table 4-12. Specification of Pipe-SI component block.

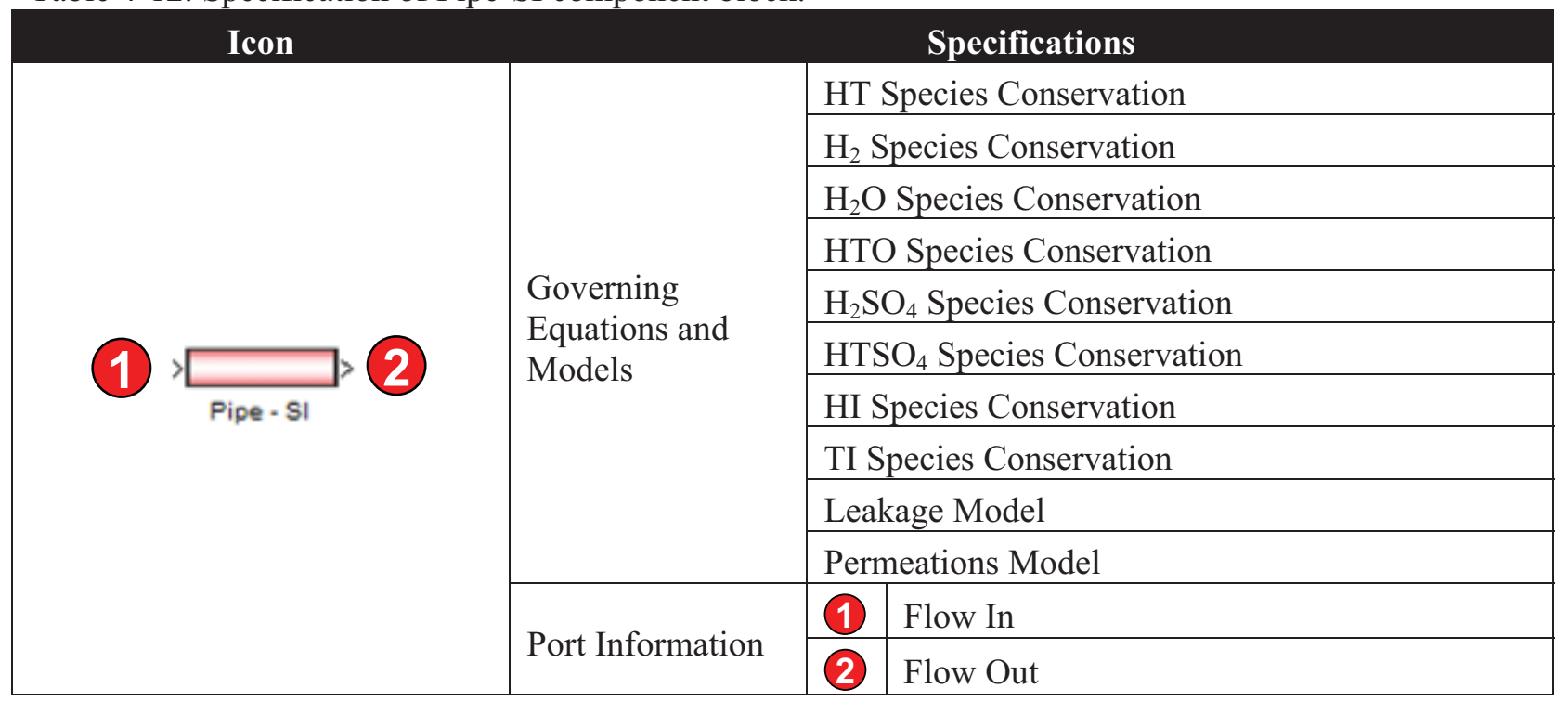


Table 4-13. Specification of PipeII-SI component block.

\begin{tabular}{|c|c|c|c|}
\hline Icon & & & Specifications \\
\hline \multirow{14}{*}{ Pipe II- SI } & \multirow{10}{*}{$\begin{array}{l}\text { Governing } \\
\text { Equations and } \\
\text { Models }\end{array}$} & \multicolumn{2}{|c|}{ HT Species Conservation } \\
\hline & & \multicolumn{2}{|c|}{$\mathrm{H}_{2}$ Species Conservation } \\
\hline & & \multicolumn{2}{|c|}{$\mathrm{H}_{2} \mathrm{O}$ Species Conservation } \\
\hline & & \multicolumn{2}{|c|}{ HTO Species Conservation } \\
\hline & & \multicolumn{2}{|c|}{$\mathrm{H}_{2} \mathrm{SO}_{4}$ Species Conservation } \\
\hline & & \multicolumn{2}{|c|}{$\mathrm{HTSO}_{4}$ Species Conservation } \\
\hline & & \multicolumn{2}{|c|}{ HI Species Conservation } \\
\hline & & \multicolumn{2}{|c|}{ TI Species Conservation } \\
\hline & & \multicolumn{2}{|c|}{ Leakage Model } \\
\hline & & \multicolumn{2}{|c|}{ Permeations Model } \\
\hline & \multirow{4}{*}{ Port Information } & (1) & Flow In \\
\hline & & (2) & Flow Out \\
\hline & & (3) & Tritium Leak and Permeation In \\
\hline & & (4) & Tritium Leak and Permeation Out \\
\hline
\end{tabular}

Table 4-14. Additional input parameters of Pipe-SI component block.

\begin{tabular}{|l|l|l|}
\multicolumn{1}{c|}{ Input Parameter } & \multicolumn{1}{c|}{ Unit } & \multicolumn{1}{c|}{ Description } \\
\hline $\mathrm{H}_{2} \mathrm{O}$ Initial Concentration & mole fraction & Average initial $\mathrm{H}_{2} \mathrm{O}$ mole fraction in the pipe \\
\hline $\mathrm{HTO}$ Initial Concentration & mole fraction & Average initial $\mathrm{HTO}$ mole fraction in the pipe \\
\hline $\mathrm{H}_{2} \mathrm{SO}_{4}$ Initial Concentration & mole fraction & Average initial $\mathrm{H}_{2} \mathrm{SO}_{4}$ mole fraction in the pipe \\
\hline $\mathrm{HTSO}_{4}$ Initial Concentration & mole fraction & Average initial $\mathrm{HTSO}_{4}$ mole fraction in the pipe \\
\hline $\mathrm{HI}$ Initial Concentration & mole fraction & Average initial $\mathrm{HI}$ mole fraction in the pipe \\
\hline HT Initial Concentration & mole fraction & Average initial $\mathrm{HT}$ mole fraction in the pipe \\
\hline
\end{tabular}

Table 4-15. Specification of Isotope Exchange component block.

\begin{tabular}{|c|c|c|c|}
\hline Icon & & & Specifications \\
\hline \multirow{5}{*}{ Isotope Exchange } & \multirow{3}{*}{$\begin{array}{l}\text { Governing } \\
\text { Equations and } \\
\text { Models }\end{array}$} & \multicolumn{2}{|c|}{$\mathrm{HT}+\mathrm{H}_{2} \mathrm{O}=\mathrm{H}_{2}+\mathrm{HTO}$ Equilibrium } \\
\hline & & \multicolumn{2}{|c|}{$\mathrm{HT}+\mathrm{H}_{2} \mathrm{SO}_{4}=\mathrm{H}_{2}+\mathrm{HTSO}_{4}$ Equilibrium } \\
\hline & & \multicolumn{2}{|c|}{$\mathrm{HT}+\mathrm{HI}=\mathrm{H}_{2}+\mathrm{TI}$ Equilibrium } \\
\hline & \multirow{2}{*}{ Port Information } & (1) & Flow In \\
\hline & & (2) & Flow Out \\
\hline
\end{tabular}

Table 4-16. Input Parameters of Isotope Exchange Component Block.

\begin{tabular}{|l|l|l|}
\hline \multicolumn{2}{|c|}{ Unit } & \multicolumn{1}{c|}{ Description } \\
\hline Isotope Exchange Model & $\#$ & $\begin{array}{l}\text { Selection of Isotope Exchange Model for VHTR, } \\
\text { HTSE, and SI Process }\end{array}$ \\
\hline
\end{tabular}


Table 4-17. Specification of Tritium External Source block.

\begin{tabular}{|c|l|l|l|}
\hline \multicolumn{2}{|c|}{ Icon } & \multicolumn{2}{|c|}{ Specifications } \\
\hline \multirow{2}{*}{ Tritium External Souroe } & $\begin{array}{l}\text { Governing } \\
\text { Equations and } \\
\text { Models }\end{array}$ & \multicolumn{2}{|c|}{ NONE } \\
\cline { 2 - 4 } & Port Information & (1) & Tritium External Source Out \\
\hline
\end{tabular}

Table 4-18. Input parameters of Tritium External Source block.

\begin{tabular}{|l|l|l|}
\multicolumn{1}{c}{ Input Parameter } & \multicolumn{1}{c|}{ Unit } & \multicolumn{1}{c|}{ Description } \\
\hline External HT Source & $\mathrm{m}^{3}(\mathrm{STP}) / \mathrm{s}$ & External HT Source into Pipe \\
\hline External $\mathrm{H}_{2}$ Source & $\mathrm{m}^{3}(\mathrm{STP}) / \mathrm{s}$ & External $\mathrm{H}_{2}$ Source into Pipe \\
\hline
\end{tabular}

\subsubsection{Heat Exchanger Component}

The Heat Exchanger Component category has two component blocks as shown in Table 4-2. Table 4-19 summarize the general Heat Exchanger component block which solves two species conservation for each side of the channel with the permeation model. On the other hand, Table 4-20 summarizes the Heat Exchanger II component model which solves only permeation model without species conservation in the component.

Table 4-19. Specification of Heat Exchanger component block.

\begin{tabular}{|c|c|c|c|}
\hline Icon & & & Specifications \\
\hline \multirow{5}{*}{$H X$} & \multirow{5}{*}{$\begin{array}{l}\text { Governing } \\
\text { Equations and } \\
\text { Models }\end{array}$} & \multicolumn{2}{|c|}{ HT Species Conservation (Primary) } \\
\hline & & \multicolumn{2}{|c|}{$\mathrm{H}_{2}$ Species Conservation (Primary) } \\
\hline & & \multicolumn{2}{|c|}{ HT Species Conservation (Secondary) } \\
\hline & & \multicolumn{2}{|c|}{$\mathrm{H}_{2}$ Species Conservation (Secondary) } \\
\hline & & \multicolumn{2}{|c|}{ Permeations Model } \\
\hline \multirow{4}{*}{ Heat Exchanger } & \multirow{4}{*}{ Port Information } & (1) & Flow In (Primary) \\
\hline & & 2 & Flow Out (Primary) \\
\hline & & (3) & Flow In (Secondary) \\
\hline & & (4) & Flow Out (Secondary) \\
\hline
\end{tabular}

Table 4-20. Specification of Heat Exchanger II component block.

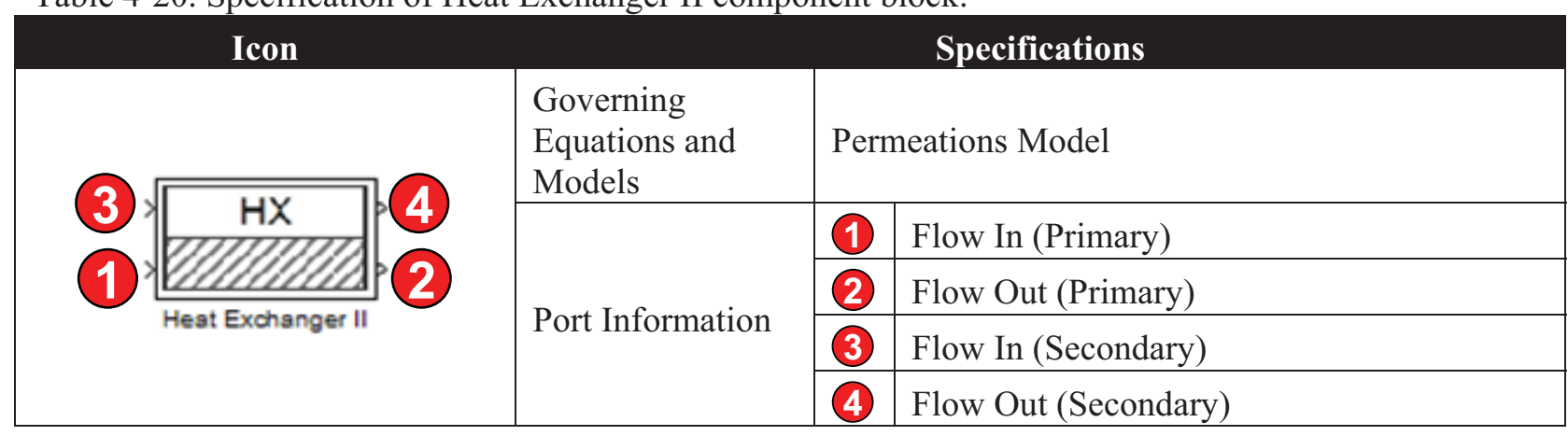




\subsubsection{Vessel Component}

The Vessel Component category has three different types of vessel component blocks; VHTR, HTSE, and SI. Tables 4-21, 4-22, and 4-23 summarize the block specification s for Vessel-VHTR, Vessel-HTSE, and Vessel-SI blocks, respectively. The basic input parameters are the same as those of pipe components (See Tables 4-8, 4-11, 4-14).

Table 4-21. Specification of Vessel-VHTR component block.

\begin{tabular}{|c|c|c|c|}
\hline Icon & \multicolumn{3}{|r|}{ Specifications } \\
\hline & & \multicolumn{2}{|c|}{ HT Species Conservation } \\
\hline & Governing & \multicolumn{2}{|c|}{$\mathrm{H}_{2}$ Species Conservation } \\
\hline & Models & \multicolumn{2}{|c|}{ Leakage Model } \\
\hline & & \multicolumn{2}{|c|}{ Permeations Model } \\
\hline \multirow{4}{*}{ Vessel - VHTR } & \multirow{4}{*}{ Port Information } & (1) & Flow In \\
\hline & & (2) & Flow Out \\
\hline & & (3) & Tritium Leak and Permeation In \\
\hline & & (4) & Tritium Leak and Permeation Out \\
\hline
\end{tabular}

Table 4-22. Specification of Vessel-HTSE component block.

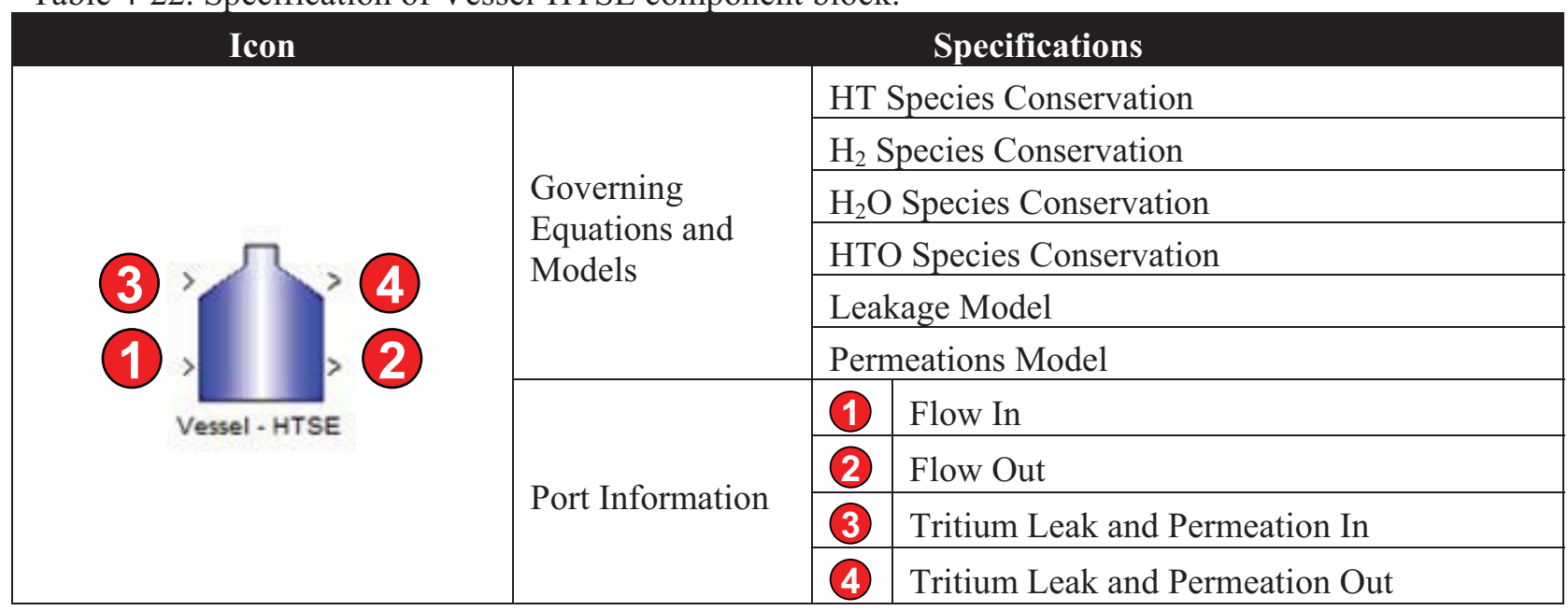


Table 4-23. Specification of Vessel-SI component block.

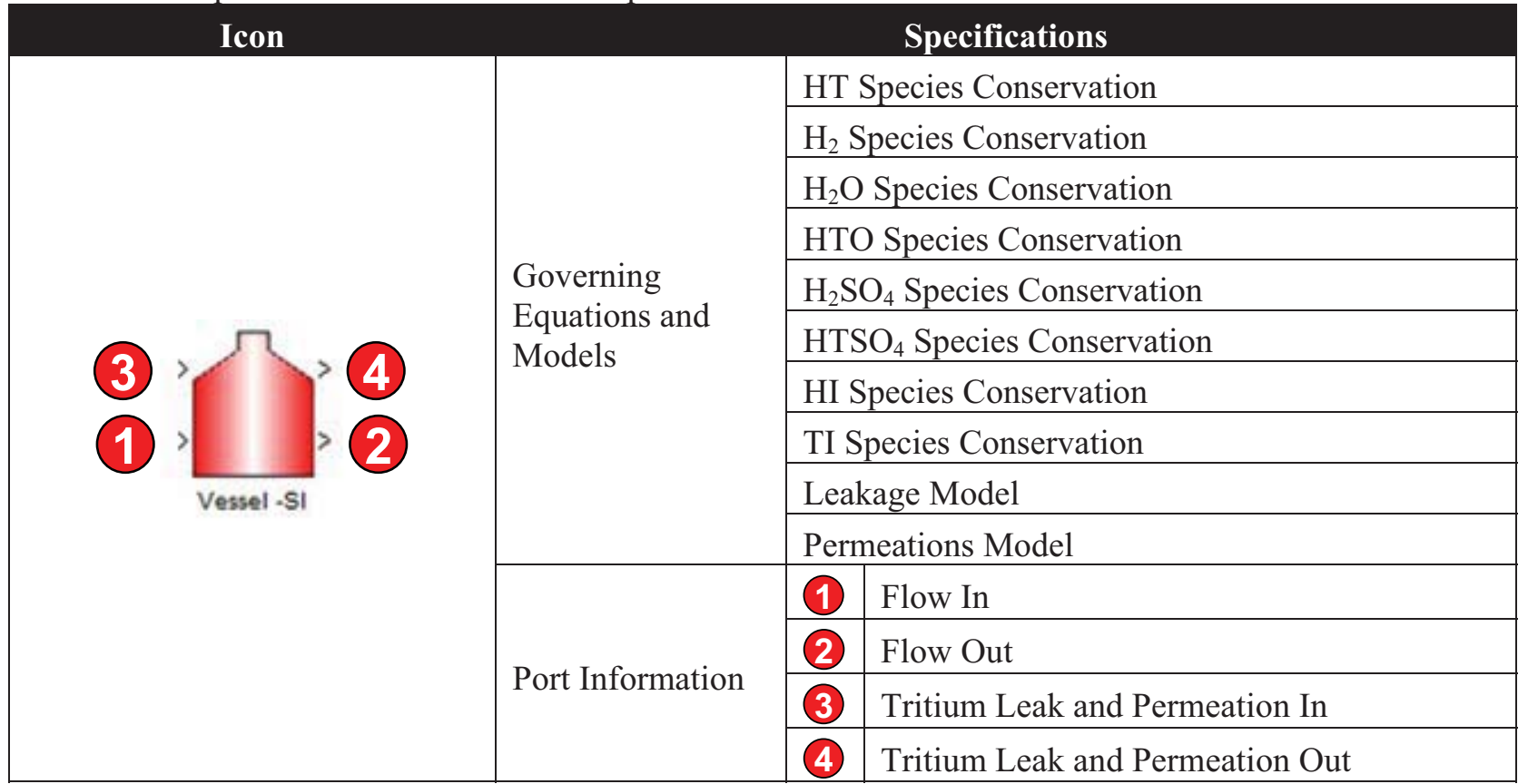

\subsubsection{Containment Component}

Table 4-24 summarizes the specifications of the Containment component block. This block is similar to the VHTR-pipe components and therefore the same input parameters are used here (See Table 4-8).

Table 4-24. Specification of Containment component block.

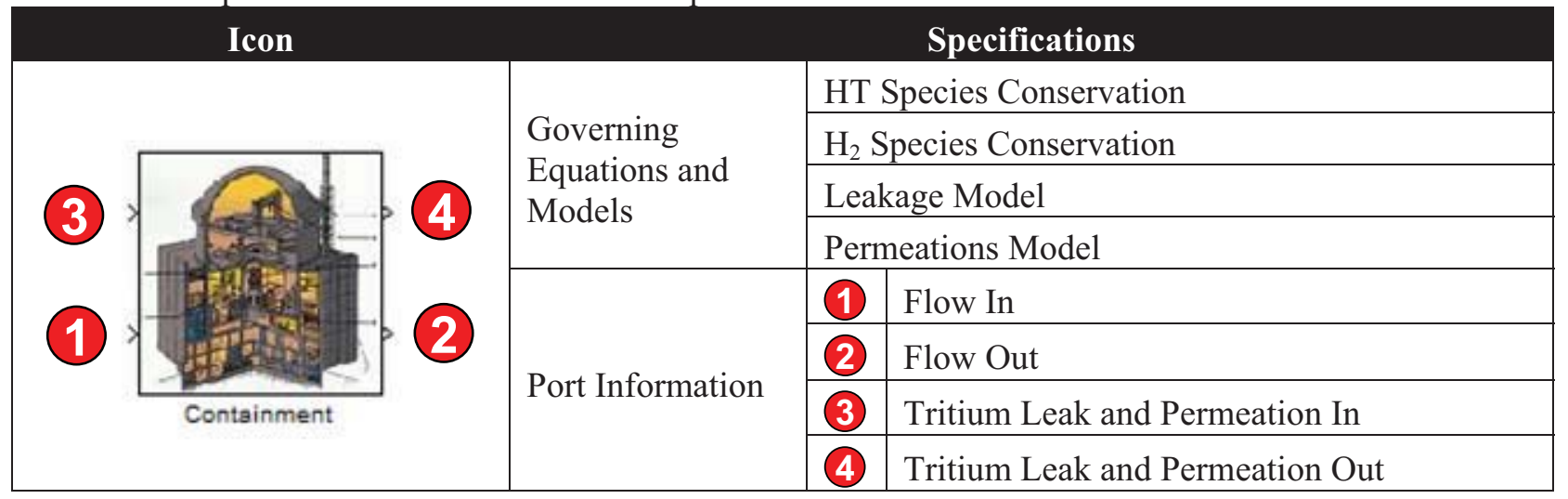

\subsubsection{Purification System Component}

Tables 4-25 and 4-26 summarize the specifications and the input parameters in the Purification System component block. This block does not solve any species conservation equations but solves the purification system model. 
Table 4-25. Specification of Purification System component block.

\begin{tabular}{|l|l|l|l|}
\hline \multicolumn{2}{|c|}{ Icon } & \multicolumn{2}{|c|}{ Specifications } \\
\hline \multirow{2}{*}{$(1)$} & $\begin{array}{l}\text { Governing } \\
\text { Equations and } \\
\text { Models }\end{array}$ & \multicolumn{2}{|c|}{ Purification System Model } \\
\cline { 2 - 5 } & Port Information & (1) & Flow In \\
\cline { 3 - 5 } & 2 & Flow Out \\
\hline
\end{tabular}

Table 4-26. Input parameters of Purification System component block.

\begin{tabular}{|l|l|l|}
\hline \multicolumn{2}{|c|}{ Input Parameter } & Unit \\
\hline $\begin{array}{l}\text { Fraction of Mass Flow to Purification } \\
\text { System }\end{array}$ & - & Fraction of flow to Purification System $(0 \sim 1)$ \\
\hline Fractional Efficiency of HT Purification & - & Efficiency of HT Purification $(0 \sim 1)$ \\
\hline Fractional Efficiency of $\mathrm{H}_{2}$ Purification & - & Efficiency of $\mathrm{H}_{2}$ Purification $(0 \sim 1)$ \\
\hline Fractional Efficiency of $\mathrm{H}_{2} \mathrm{O}$ Purification & - & Efficiency of $\mathrm{H}_{2} \mathrm{O}$ Purification $(0 \sim 1)$ \\
\hline Fractional Efficiency of HTO Purification & - & Efficiency of HTO Purification $(0 \sim 1)$ \\
\hline
\end{tabular}

\subsubsection{Electrolyzer Component}

Tables 4-27 and 4-28 summarize the specifications and the input parameters for the Electrolyzer component block. This block does not solve any species conservation equations, but solves the electrolyzer model that is based on the conversion ratio.

Table 4-27. Specification of Electrolyzer component block.

\begin{tabular}{|l|l|l|l|}
\hline \multicolumn{2}{|c|}{ Icon } & \multicolumn{3}{|c|}{ Specifications } \\
\hline
\end{tabular}

Table 4-28. Input parameters of Electrolyzer component block.

\begin{tabular}{|l|c|l|}
\hline \multicolumn{1}{|c|}{ Input Parameter } & Unit & \multicolumn{1}{c|}{ Description } \\
\hline System Conversion Ratio & - & $\mathrm{H}_{2} \mathrm{O}$ conversion ratio by electrolysis $(0 \sim 100 \%)$ \\
\hline
\end{tabular}

\subsubsection{Flow Distribution Component}

Tables 4-29, 4-30, and 4-31 summarize the Flow Splitter and Flow Mixer blocks which are related to the flow distributions. These blocks are not solving any physical equations or models, but are very important blocks when users develop complicated system configurations. 
Table 4-29. Specification of Flow Splitter block.

\begin{tabular}{|l|l|l|l|}
\hline \multicolumn{2}{|c|}{ Icon } & \multicolumn{2}{|l|}{ Specifications } \\
\hline & $\begin{array}{l}\text { Governing } \\
\text { Equations and } \\
\text { Models }\end{array}$ & \multicolumn{2}{|l|}{ NONE } \\
\cline { 2 - 4 } & & 1 & Flow In \\
\hline \multirow{2}{*}{$(2)$} & Port Information & 2 & Flow Out-1 \\
\cline { 3 - 5 } & & 3 & Flow Out-2 \\
\hline
\end{tabular}

Table 4-30. Input parameters of Flow Splitter block.

\begin{tabular}{|l|c|l|}
\hline \multicolumn{1}{|c|}{ Input Parameter } & Unit & Description \\
\hline Separation Ratio & - & Separation Ratio of Flow Out-1 to Flow In $(0 \sim 1)$ \\
\hline
\end{tabular}

Table 4-31. Specification of Flow Mixer block.

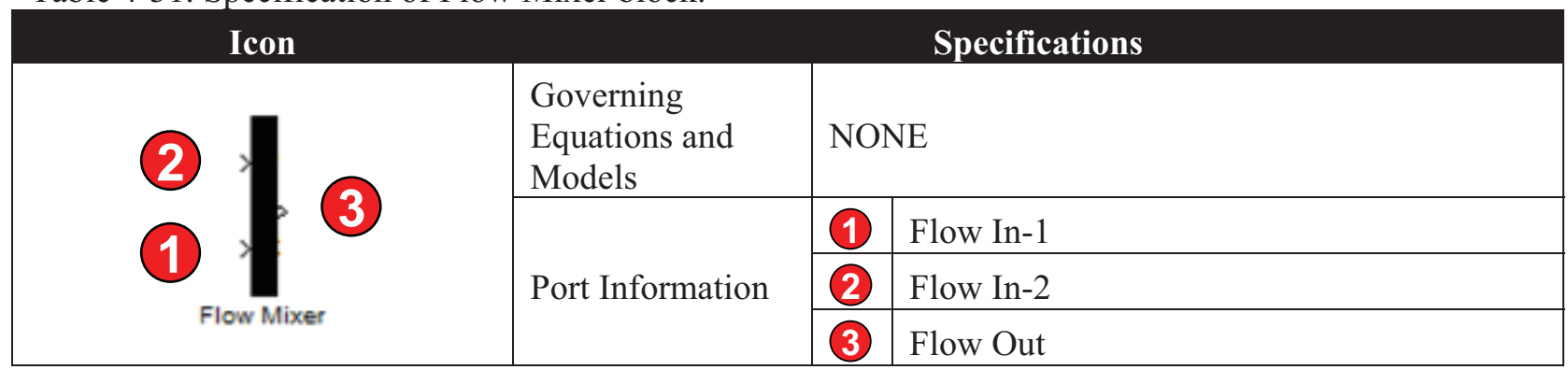

\subsubsection{Boundary Flow Component}

Tables 4-32 and 4-33 summarize the specifications and the input parameters of the Boundary Flow block which is used for providing flow sources in the open system (once-through).

Table 4-32. Specification of Boundary Flow block.

\begin{tabular}{|l|l|l|l|}
\hline \multicolumn{2}{|c|}{ Icon } \\
\hline \multirow{2}{*}{\begin{tabular}{|l|l|l|}
\hline \\
boundary inflow
\end{tabular}} & $\begin{array}{l}\text { Governing } \\
\text { Equations and } \\
\text { Models }\end{array}$ & \multicolumn{2}{|c|}{ NONE } \\
\cline { 2 - 4 } & Port Information & (1) & Flow Out \\
\hline
\end{tabular}


Table 4-33. Input parameters of Boundary Flow component block.

\begin{tabular}{|c|c|c|}
\hline Input Parameter & Unit & Description \\
\hline Flow Rate & $\mathrm{m}^{3}(\mathrm{STP}) / \mathrm{s}$ & Flow rate of the boundary flow \\
\hline Temperature & $\mathrm{K}$ & Average temperature of the boundary flow \\
\hline Pressure & $\mathrm{Pa}$ & Average pressure of the boundary flow \\
\hline HT Concentration & mole fraction & HT mole fraction of the boundary flow \\
\hline $\mathrm{H}_{2}$ Concentration & mole fraction & $\mathrm{H}_{2}$ mole fraction of the boundary flow \\
\hline $\mathrm{H}_{2} \mathrm{O}$ Concentration & mole fraction & $\mathrm{H}_{2} \mathrm{O}$ mole fraction of the boundary flow \\
\hline HTO Concentration & mole fraction & HTO mole fraction of the boundary flow \\
\hline $\mathrm{H}_{2} \mathrm{SO}_{4}$ Concentration & mole fraction & $\mathrm{H}_{2} \mathrm{SO}_{4}$ mole fraction of the boundary flow \\
\hline $\mathrm{HTSO}_{4}$ Concentration & mole fraction & $\mathrm{HTSO}_{4}$ mole fraction of the boundary flow \\
\hline HI Concentration & mole fraction & HI mole fraction of the boundary flow \\
\hline HT Concentration & mole fraction & HT mole fraction of the boundary flow \\
\hline
\end{tabular}

\subsubsection{Detector Component}

Table 4-34 summarizes the specification of the Detector block which allows the user to access the flow or component information during or after simulation.

Table 4-34. Specification of Detector Block.

\begin{tabular}{|l|l|l|l|}
\hline \multicolumn{2}{|c|}{ Icon } & \multicolumn{2}{|c|}{ Specifications } \\
\hline & $\begin{array}{l}\text { Governing } \\
\text { Equations and } \\
\text { Models }\end{array}$ & \multicolumn{2}{|c|}{ NONE } \\
\cline { 2 - 4 } & Port Information & (1) & Flow In (Signal) \\
\hline
\end{tabular}

\subsubsection{Data Save Component}

Tables 4-35 and 4-36 summarize the specifications of the two data save blocks; Save to File and Save to Workspace. The Save to File block allows the user to save the flow conditions into file while the Save to Workspace block allows the user to save the file in the MATLAB Workspace.

Table 4-35. Specification of Save to File block.

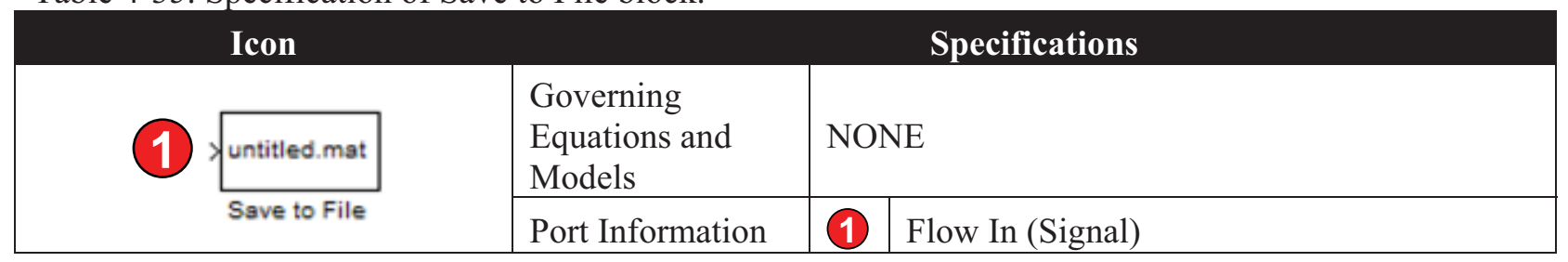


Table 4-36. Specification of Save to Workspace Block.

\begin{tabular}{|c|l|l|l|}
\hline \multicolumn{2}{|c|}{ Icon } & \multicolumn{2}{|c|}{ Specifications } \\
\hline \multirow{2}{*}{\begin{tabular}{|l|l|l|}
\hline simout \\
Save to Workspace
\end{tabular}} & $\begin{array}{l}\text { Governing } \\
\text { Equations and } \\
\text { Models }\end{array}$ & \multicolumn{2}{|l|}{ NONE } \\
\cline { 2 - 4 } & Port Information & Flow In (Signal) \\
\hline
\end{tabular}

\subsection{Solver Setting}

The TPAC is using the solver embedded in the MATLAB SIMULINK. The Solver Setting window can be opened by selecting Simulation/Configuration Parameters... in the Main Menu (See Figure 4-34).

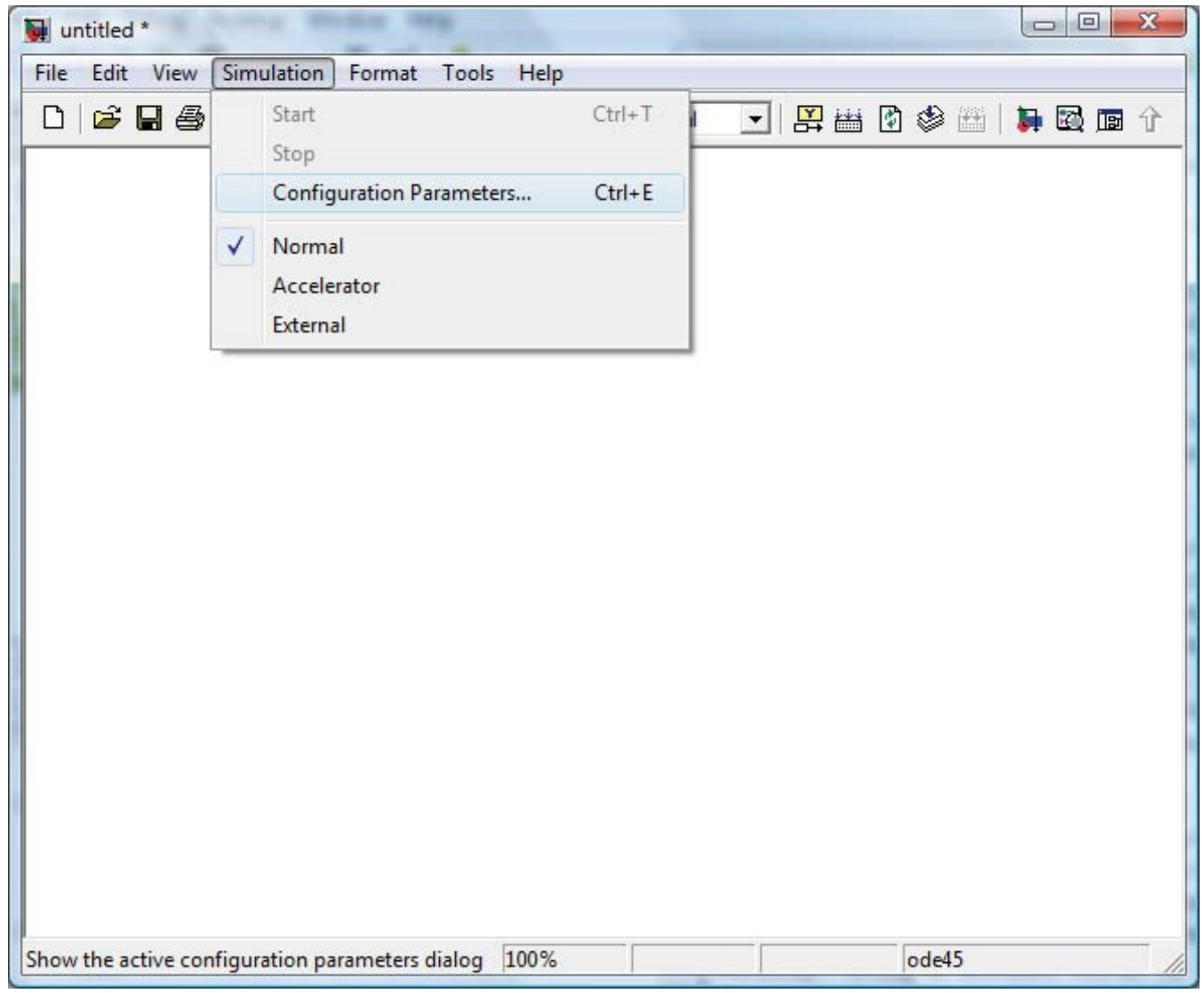

Figure 4-34. Solver Setting menu.

The following is the description about the Solver Setting Panel documented in the MATLAB SIMULINK user manual (Mathworks 2009). For more details about the solver setting, the MATLAB user manual is recommended.

The Solver configuration parameters pane allows the user to specify a simulation start and stop time and select and configure a solver for a particular simulation configuration (See Figure 4-35). 


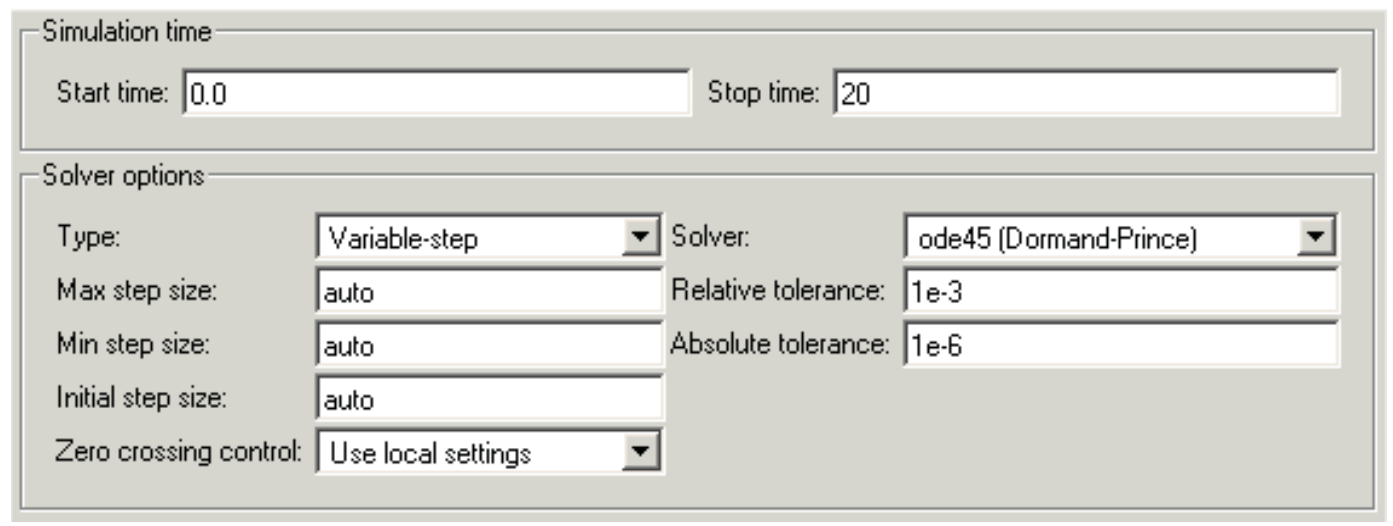

Figure 4-35. Solver Panel.

The Solver pane contains the following control groups:

- Simulation time. This control group enables us to specify the simulation start and stop time. It contains the following controls.

- Start time. Specifies the simulation start time. The default start time is 0.0 seconds.

- Stop time. Specifies the simulation stop time. The default stop time is 10.0 seconds. Specify "inf" to cause the simulation to run until users pause or stop it.

Simulation time and actual clock time are not the same. For example, running a simulation for 10 seconds usually does not take 10 seconds. The amount of time it takes to run a simulation depends on many factors, including the model's complexity, the solver's step sizes, and the computer's speed.

- Solver Options. The Solver options controls group allows us to specify the type of solver to be used and simulation options specific to that solver (See Figure 4-36).

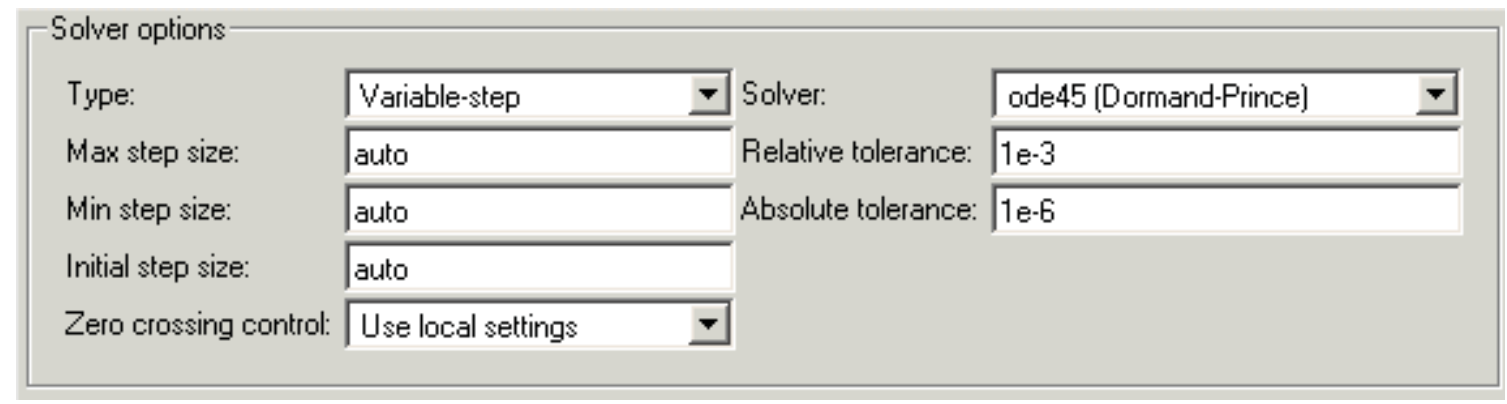

Figure 4-36. Solver Options Control.

The contents of the group depend on the solver type.

- General Solver Options. The follow options always appear:

- $\quad$ Type. Specifies the type of solver to be used to solve the currently selected model, either Fixedstep or Variable-step.

- Solver. Specifies the solver used to simulate this configuration of the current model. The associated pull-down list displays available solvers of the type specified by the Type control. To specify another solver of the specified type, select the solver from the pull-down list.

The other controls that appear in this group depend on the type of solver users have selected. 
- Variable-Step Continuous Solver Options. The following options appear when users select any of the SIMULINK variable-step continuous solvers.

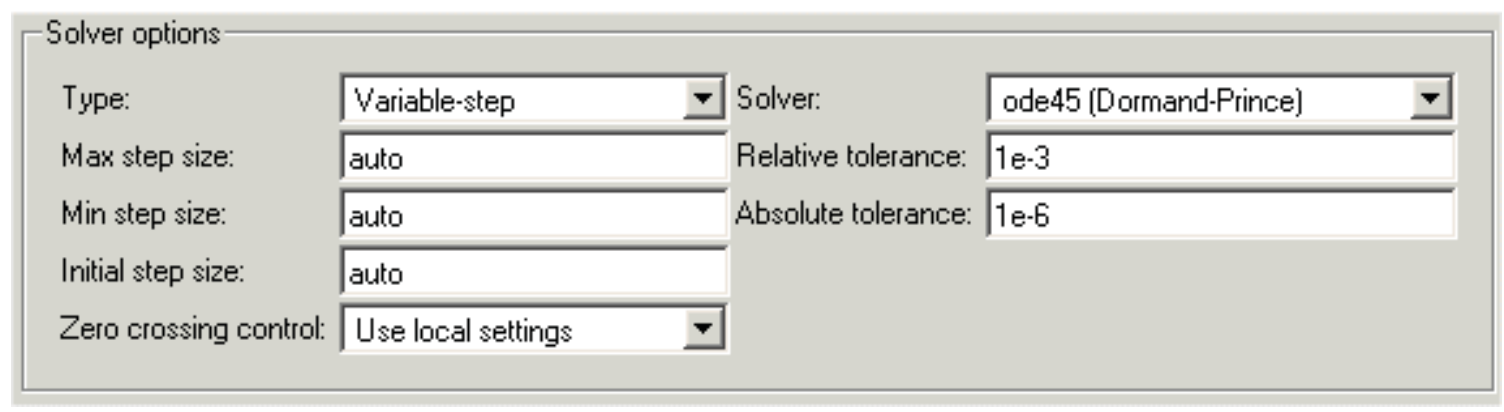

Figure 4-37. Variable-Step Continuous Solver Options.

- Max step size. Specifies the largest time step the solver can take. The default is determined from the start and stop times. If the stop time equals the start time or is inf, SIMULINK chooses 0.2 sec. as the maximum step size. Otherwise, it sets the maximum step size to

$$
h_{\max }=\frac{t_{\text {stop }}-t_{\text {start }}}{50}
$$

Generally, the default maximum step size is sufficient. If users are concerned about the solver missing a significant behavior, change the parameter to prevent the solver from taking too large a step. If the time span of the simulation is very long, the default step size might be too large for the solver to find the solution. Also, if our model contains periodic or nearly periodic behavior and users know the period, set the maximum step size to some fraction (such as 1/4) of that period.

- Initial step size. By default, the solver selects an initial step size by examining the derivatives of the states at the start time. If the first step size is too large, the solver might step over important behavior. The initial step size parameter is a suggested first step size. The solver tries this step size but reduces it if error criteria are not satisfied.

- Min step size. This option appears only for variable-step continuous solvers. Specifies the smallest time step the selected variable-step solver can take. If the solver needs to take a smaller step to meet error tolerances, it issues a warning indicating the current effective relative tolerance. This parameter can be either a real number greater than zero or a two-element vector where the first element is the minimum step size and the second element is the maximum number of minimum step size warnings to be issued before issuing an error. Setting the second element to zero results in an error the first time the solver must take a step smaller than the specified minimum. This is equivalent to changing the minimum step size violation diagnostic to error on the Diagnostics pane. Setting the second element to -1 results in an unlimited number of warnings. This is also the default if the input is a scalar. The default values for this parameter are a minimum step size on the order of machine precision and an unlimited number of warnings.

- Relative tolerance. Relative tolerance for this solver.

- Absolute tolerance. Absolute tolerance for this solver.

- Maximum order. This option appears only if users select the ode15s solver, which is based on numerical differentiation formulas (NDFs) of orders 1-5. Although the higher order formulas are more accurate, they are less stable. If our model is stiff and requires more stability, reduce the maximum order to 2 (the highest order for which the NDF is A-stable). As an alternative, users can try using the ode23s solver, which is a lower order (and A-stable) solver. 


\section{VERIFICATION OF THE CODE}

TPAC is a dynamic simulation code developed at INL for tritium behaviors analyses in the VHTR system (named as TPAC) as described in detail in the previous sections. The TPAC was designed to solve (1) mass conservations of tritium and hydrogen, (2) core tritium generation, (3) tritium permeation through the pipe walls or heat exchanger walls, (4) leakage, (5) purification systems, (6) isotope-exchange, and (7) electrolyzer.

To achieve code reliability, the TPAC was verified based on analytical solutions and experimental data. The main focus of verification work was to determine if:

- The equations and models are correctly implemented into the code to represents the phenomena of interest.

- There is any bug in the code.

- The code needs any improvements or modifications.

The Peach Bottom data and analytical solutions were used as the reference data for the verification. The Peach Bottom reactor was a helium-cooled graphite-moderated reactor built in the United States in 1958. Figure 5-1 shows the schematics of the Peach Bottom Reactor. The primary circuit consisted of two loops, each containing a helium compressor and steam generator. The total helium flow of $210,000 \mathrm{~kg} / \mathrm{h}$ was divided equally between the two loops. Coolant temperatures at the core inlet and outlet of the reactor vessel were 345 and $714^{\circ} \mathrm{C}$, respectively, and the primary loop pressure was approximately $2.4 \mathrm{MPa}(335$ psig). The reactor and steam generator were connected by a concentric duct. Coolant exiting the reactor flows in the inner pipe of the concentric duct. The steam generators were forced recirculation, drum type boilers that have pendant U-tube economizer, evaporator, and super-heater sections.

In the process of verifying the Peach Bottom reactor, Core 2 operation data was evaluated by Wichner and Dyer (1979). Core 1 fuel particles were coated with a single layer of pyrolytic graphite, solely to prevent hydrolysis during manufacture. The Core 2 fuel particles were designed to be BISO (fuel coated with two ceramic layers) in order to retain gaseous fission products during the life (from July 1970 to October 1974). 


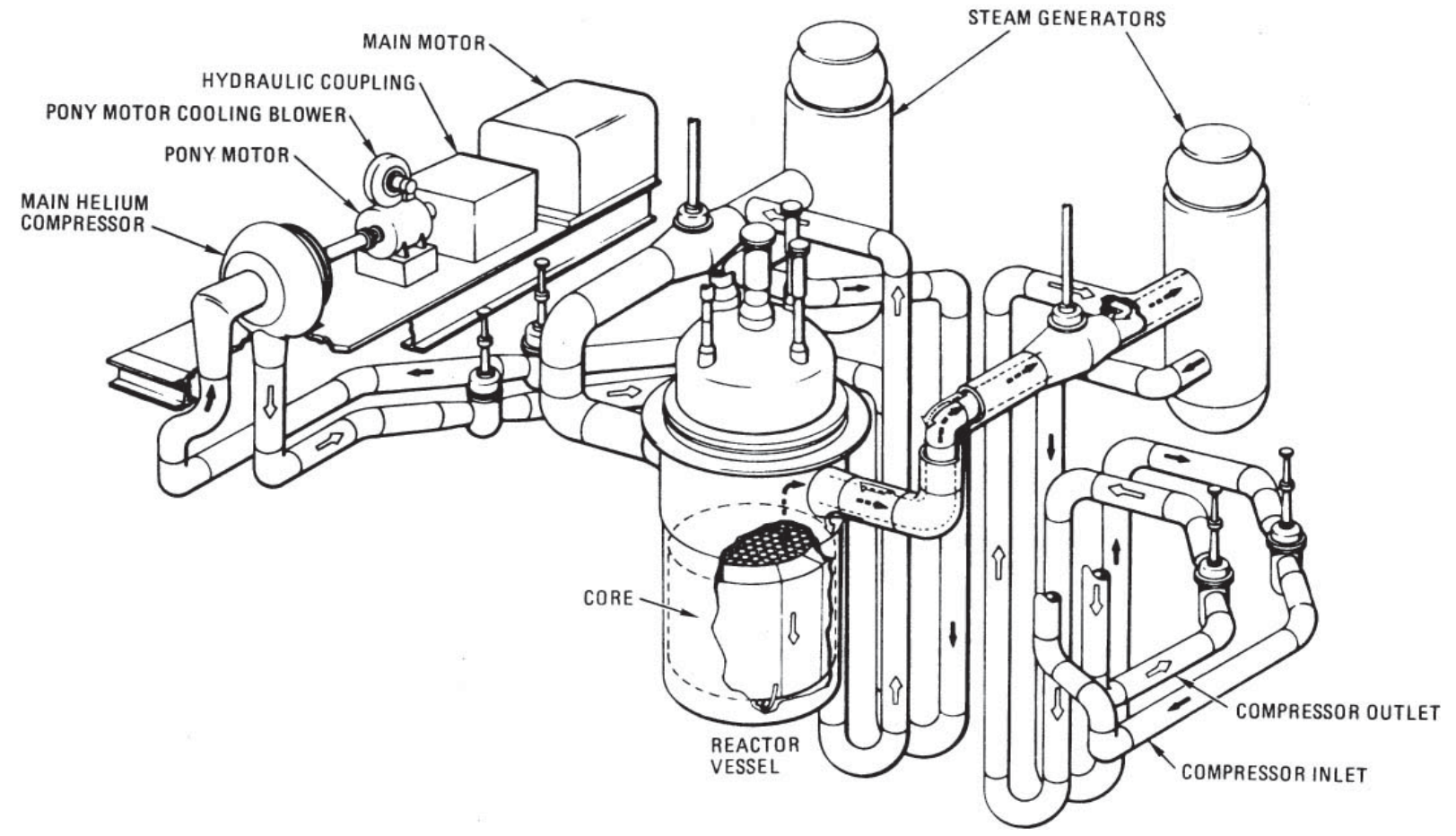

Figure 5-1. Primary coolant system of the Peach Bottom reactor (Wichner and Dyer 1979).

Analytical solutions and the THYTAN code results, previously verified in FY-07 and FY-08, were also used in verifying the TPAC. The following models were taken into considerations in the verification process:

- Mass conservation equations (governing equations).

- Reactor core model for tritium generation.

- Tritium and hydrogen permeation model through the metal.

- Leak model of the reactor system.

- Purification system model.

- System coupling and integration model.

\subsection{Verification of Core Model}

The core model for the tritium birth was verified first. The core model involves various tritium birth models from different sources, and therefore it generally affects total tritium distributions and behaviors the most. The core model in the TPAC consists of the following tritium sources:

- Tritium birth from ternary fission

- Tritium birth from neutron reaction with lithium $\left({ }^{6} \mathrm{Li},{ }^{7} \mathrm{Li}\right)$

- Tritium birth from neutron reaction with ${ }^{3} \mathrm{He}$ in the coolant

- Tritium birth from neutron reaction with ${ }^{10} \mathrm{~B}$. 


\subsubsection{Tritium Birth from Ternary Fission}

Figure 5-2 shows the tritium birth modeling of the TPAC for Ternary fission. Table 5-1 summarizes the input parameters used for verification for this ternary fission model. In the ternary fission block, the following tritium source equation has been implemented.

$\frac{d\left(N_{T(T e r)}\right)}{d t}=K \cdot P \cdot Y-\lambda \cdot N_{T(T e r)}$

where

$$
\begin{array}{ll}
N_{T(\text { Ter })} & =\text { number of tritium atoms from ternary fission } \\
K & =\text { fission rate per thermal megawatt }[\text { fission } / \mathrm{MW} / \mathrm{s}] \\
P & =\text { reactor power }[\mathrm{MW}] \\
Y & =\text { average yield per fission }[1 / \text { fission }] \\
\lambda & =\text { tritium decay constant }[1 / \mathrm{s}] .
\end{array}
$$

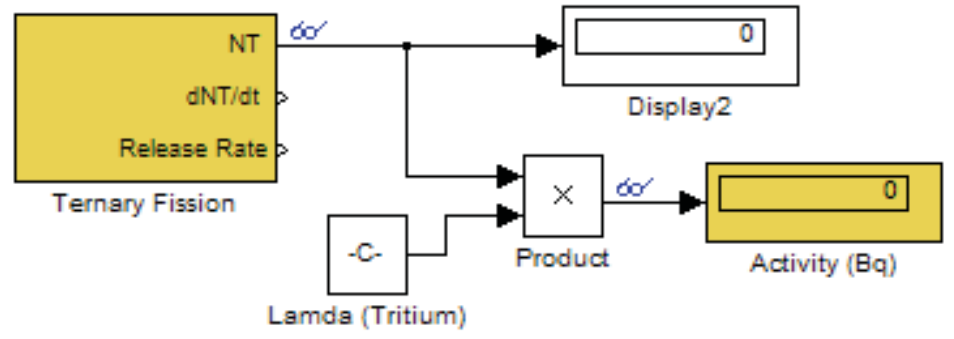

Figure 5-2. TPAC tritium birth modeling from ternary fission.

Table 5-1. TPAC Input parameters for calculation of tritium birth from ternary fission.

\begin{tabular}{|l|l|}
\hline \multicolumn{1}{|c|}{ Input Parameters } & \multicolumn{1}{c|}{ Values } \\
\hline Reactor Power (MWth) & 66.55 \\
\hline Fission Rate per Thermal Power (Fission/MWth/s) & $3.12 \mathrm{e} 16$ \\
\hline Average Fission per Fission (1/s) & $1 \mathrm{e}-4$ \\
\hline Initial Amount of Tritium (\#) & 0 \\
\hline Calculation Time (s) & $1.34 \mathrm{e} 8$ \\
\hline
\end{tabular}

The following analytical solution was used for validation of the ternary fission model in the TPAC.

$$
N_{T}\left(t_{f}\right)=K \cdot \bar{P} \cdot Y\left(\frac{1-\exp \left(-\lambda \cdot t_{f}\right)}{\lambda}\right)
$$

where

$$
\begin{aligned}
& N_{T}\left(t_{f}\right)=\text { atoms of tritium at time } t_{f} \\
& K \quad=\text { fission rate per thermal megawatt }\left(3.121 \times 10^{16} \text { fissions } / \mathrm{MW} / \mathrm{s}\right)
\end{aligned}
$$


$Y=$ average yield per fission $\left(1 \times 10^{-4}\right)$

$\lambda=$ tritium decay constant $\left(1.793 \times 10^{-19} \mathrm{~s}^{-1}\right)$.

An average power, $\bar{P}$ was calculated using the following equation.

$\bar{P}=P_{\text {rated }}\left(E F P D / t_{f}\right)$

where

$P_{\text {rated }}=$ rated power $(115 \mathrm{MWth})$

$E F P=$ equivalent full power days at $\mathrm{EOL}$ (897 days)

$t_{f}=$ duration of Core 2 operation, including shutdown $\left(1.34 \times 10^{8} \mathrm{~s}\right.$ or 1,550 days $)$.

Table 5-2 summarizes the computed and reported results. The reported tritium birth by ternary fission during 1,550 days was $1,210 \mathrm{Ci}(=4.43 \mathrm{e} 13 \mathrm{~Bq})$. The TPAC results show very good agreement with the reported value and the analytical solution. They are also in good agreement with the THYTAN solution.

Table 5-2. Comparison of tritium activity by ternary fission.

\begin{tabular}{|c|c|c|c|c|}
\hline \multicolumn{5}{|c|}{ Activity } \\
\hline $\begin{array}{c}\text { Reported Value - Peach } \\
\text { Bottom } \\
\text { (Wichner and Dyer 1979) }\end{array}$ & $\begin{array}{c}\text { Analytical } \\
\text { Solution }\end{array}$ & $\begin{array}{c}\text { Computed Solution from } \\
\text { THYTAN (Ohashi and } \\
\text { Sherman 2007) }\end{array}$ & $\begin{array}{c}\text { Computed Solution } \\
\text { by TPAC }\end{array}$ \\
\hline$(\mathrm{Ci})$ & $(\mathrm{Bq})$ & $(\mathrm{Bq})$ & $(\mathrm{Bq})$ & $(\mathrm{Bq})$ \\
\hline 1,210 & $4.43 \times 10^{13}$ & $4.43 \times 10^{13}$ & $4.42 \times 10^{13}$ & $4.436 \times 10^{13}$ \\
\hline
\end{tabular}

\subsubsection{Tritium Birth from Li Impurities}

Figure 5-3 shows the TPAC tritium birth modeling from Li impurities. For verification, the tritium birth from the $\mathrm{Li}$ has been converted to radioactivity.

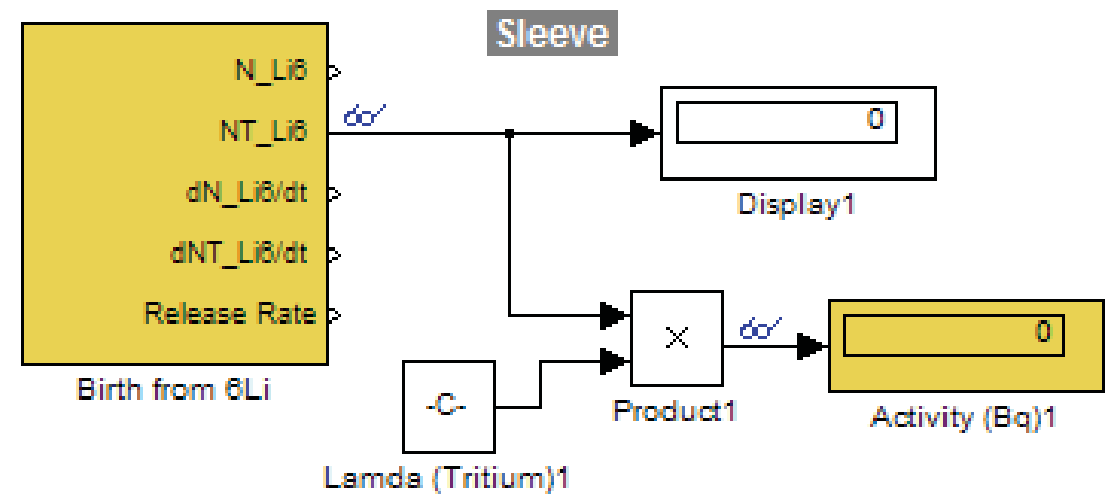

Figure 5-3. TPAC tritium birth modeling for neutron reaction with Li impurities. 
The TPAC tritium source block from Li impurities, which was specified as 'Birth from 6Li' in Figure 5-3, was designed to solve the following equations:

$$
\begin{aligned}
& \frac{d\left(N_{L i 7}\right)}{d t}=-\phi_{f} \cdot \sigma_{L i 7 H 3} \cdot N_{L i 7} \\
& \frac{d\left(N_{T(L i 7)}\right)}{d t}=\phi_{f} \cdot \sigma_{L i 7 T} \cdot N_{L i 7}-\lambda \cdot N_{T(L i 7)}
\end{aligned}
$$

where

$$
\begin{aligned}
& N_{L i 7}=\text { number of }{ }^{7} \mathrm{Li} \text { atoms, excluding }{ }^{10} \mathrm{~B} \text { source } \\
& N_{T(L i 7)}=\text { number of tritium atoms from }{ }^{7} \mathrm{Li} \text {, excluding birth from }{ }^{10} \mathrm{~B} \\
& \left.\phi_{f}=\text { fast neutron flux [neutrons } / \mathrm{cm}^{2} / \mathrm{s}\right] \\
& \sigma_{L i 7 T}=\text { effective cross section for }{ }^{7} \mathrm{Li}(\mathrm{n}, \mathrm{n} \alpha){ }^{3} \mathrm{H}\left[\mathrm{cm}^{2}\right] .
\end{aligned}
$$

Table 5-3 summarizes the input parameters used for verification of the ${ }^{6} \mathrm{Li}$ neutron reaction model in the TPAC.

Table 5-3. Input parameters for validation of tritium birth model from ${ }^{6} \mathrm{Li}$ in the TPAC.

\begin{tabular}{llc}
\hline \multicolumn{1}{c}{ Component } & \multicolumn{1}{c}{$\begin{array}{c}\text { Thermal Neutron Flux } \\
(\text { neutrons/cm } / \mathbf{s})\end{array}$} & $\begin{array}{c}\text { Initial Amount of }{ }^{6} \mathbf{L i} \\
(\mathbf{m o l e s})\end{array}$ \\
\hline Sleeve & $2.82 \times 10^{13}$ & $6.99 \times 10^{-4}$ \\
Spine & $2.82 \times 10^{13}$ & $5.17 \times 10^{-5}$ \\
Removal radial reflector & Core $1: 2.57 \times 10^{13}$ & $7.56 \times 10^{-4}$ \\
& Core $2: 2.82 \times 10^{13}$ & \\
Permanent radial reflector & Core $1: 1.28 \times 10^{13}$ & $1.12 \times 10^{-3}$ \\
Axial reflector & Core $2: 1.41 \times 10^{13}$ & $6.74 \times 10^{-4}$ \\
Fuel matrix & $1.41 \times 10^{13}$ & $7.76 \times 10^{-4}$ \\
${ }^{*}$ Effective Cross-section for ${ }^{6} \mathrm{Li}(\mathrm{n}, \alpha)^{3} \mathrm{H}=2.82 \mathrm{e} 13 \mathrm{~cm}^{2}$ & \\
\hline
\end{tabular}

The reference birth of tritium from ${ }^{6} \mathrm{Li}$ for verification was estimated by the following analytical solution:

$$
N_{T}\left(t_{f}\right)=\left(\frac{\phi_{t h} \cdot \sigma_{L i 6 T} \cdot N_{6}(0)}{\lambda-\phi_{t h} \cdot \sigma_{L i 6 T}}\right) \cdot\left[\exp \left(-\phi_{t h} \cdot \sigma_{L i 6 T} \cdot t_{f}\right)-\exp \left(-\lambda \cdot t_{f}\right)\right]
$$

where

$$
\begin{aligned}
& N_{T}\left(t_{f}\right)=\text { atoms of tritium from }{ }^{6} \mathrm{Li} \text { at time } t_{f} \\
& \sigma_{L i 6 T}=\text { effective cross section for }{ }^{6} \mathrm{Li}(\mathrm{n}, \alpha) \mathrm{T}\left(4.08 \times 10^{-22} \mathrm{~cm}^{2}\right)
\end{aligned}
$$




$$
N_{6}(0)=\text { initial amount of }{ }^{6} \mathrm{Li} \text { atoms. }
$$

Table 5-4 summarizes the reported and computed tritium activity. As reported by Ohashi and Sherman (2007), there were some unknown discrepancies between reported values and analytical solutions that have not yet been revealed. However, their THYTAN solutions showed good agreement with the analytical solutions. The TPAC also showed very good agreement with the analytical solutions and THYTAN results for various regions of the core. It verifies that the TPAC solves Equations (5-4) and (5-5) correctly.

Table 5-4. Comparison of tritium activity from ${ }^{6} \mathrm{Li}$ at the Core 2 operation of the Peach Bottom reactor.

\begin{tabular}{|c|c|c|c|c|c|}
\hline \multirow{3}{*}{$\begin{array}{c}\text { Graphite } \\
\text { Component }\end{array}$} & \multicolumn{5}{|c|}{ Activity } \\
\hline & \multicolumn{2}{|c|}{$\begin{array}{l}\text { Reported Value } \\
\text { (Peach Bottom) }\end{array}$} & \multirow{2}{*}{$\begin{array}{c}\begin{array}{c}\text { Analytical } \\
\text { Solution }\end{array} \\
(\mathrm{Bq}) \\
\end{array}$} & \multirow{2}{*}{$\begin{array}{c}\text { THYTAN } \\
\text { (Ohashi and } \\
\text { Sherman 2007) }\end{array}$} & \multirow{2}{*}{$\frac{\text { TPAC Solution }}{(\mathrm{Bq})}$} \\
\hline & $(\mathrm{Ci})$ & $(\mathrm{Bq})$ & & & \\
\hline Sleeve & 14.0 & $5.13 \times 10^{11}$ & $5.12 \times 10^{11}$ & $5.12 \times 10^{11}$ & $5.12 \times 10^{11}$ \\
\hline Spine & 1.0 & $3.66 \times 10^{10}$ & $3.78 \times 10^{10}$ & $3.78 \times 10^{10}$ & $3.78 \times 10^{11}$ \\
\hline $\begin{array}{l}\text { Removal radial } \\
\text { reflector }\end{array}$ & 16.4 & $6.01 \times 10^{11}$ & $5.76 \times 10^{11}$ & $5.75 \times 10^{11}$ & $5.76 \times 10^{11}$ \\
\hline $\begin{array}{l}\text { Permanent radial } \\
\text { reflector }\end{array}$ & 18.8 & $6.89 \times 10^{11}$ & $6.72 \times 10^{11}$ & $6.69 \times 10^{11}$ & $6.68 \times 10^{11}$ \\
\hline Axial reflector & 9.2 & $3.37 \times 10^{11}$ & $3.42 \times 10^{11}$ & $3.42 \times 10^{11}$ & $3.42 \times 10^{11}$ \\
\hline Fuel matrix & 13.1 & $4.80 \times 10^{11}$ & $5.68 \times 10^{11}$ & $5.68 \times 10^{11}$ & $5.68 \times 10^{11}$ \\
\hline
\end{tabular}

\subsubsection{Tritium Birth from ${ }^{3} \mathrm{He}$ Impurities in the Coolant}

Figure 5-4 shows the TPAC tritium birth modeling for neutron reaction of ${ }^{3} \mathrm{He}$ impurities in the coolant. The tritium source block by ${ }^{3} \mathrm{He}$ neutron reaction was designed to solve the following equations:

$$
\begin{aligned}
& \frac{d\left(N_{H e 3}\right)}{d t}=f \cdot N_{H e 3}^{\circ}-f \cdot N_{H e 3}-\phi_{H e} \cdot \sigma_{H e 3 T} \cdot N_{H e 3} \\
& \frac{d\left(N_{T(H e 3)}\right)}{d t}=\phi_{H e} \cdot \sigma_{H e 3 T} \cdot N_{H e 3}-\lambda \cdot N_{T(H e 3)} \\
& \phi_{H e}=\frac{W_{\text {core }}}{W_{\text {total }}} \cdot \phi_{t h}
\end{aligned}
$$

where

$$
\begin{aligned}
& N_{H e 3}=\text { number of }{ }^{3} \mathrm{He} \text { atoms } \\
& N_{T(H e 3)}=\text { number of tritium atoms from }{ }^{3} \mathrm{He} \\
& f \quad=\text { fractional supply rate of helium coolant }[1 / \mathrm{s}] \\
& N_{\mathrm{He3}}^{\circ}=\text { number of }{ }^{3} \mathrm{He} \text { atoms in the supply helium }
\end{aligned}
$$


$\sigma_{H e 3 T}=$ effective cross section for ${ }^{3} \mathrm{He}(\mathrm{n}, \mathrm{p}) \mathrm{T}\left[\mathrm{cm}^{2}\right]$

$\phi_{\mathrm{He}}=$ average thermal neutron flux experienced by the total primary helium inventory $\left[\mathrm{n} / \mathrm{cm}^{2} / \mathrm{s}\right]$

$W_{\text {core }}=$ helium inventory in core $[\mathrm{kg}]$

$W_{\text {total }}=$ total primary helium inventory $[\mathrm{kg}]$.

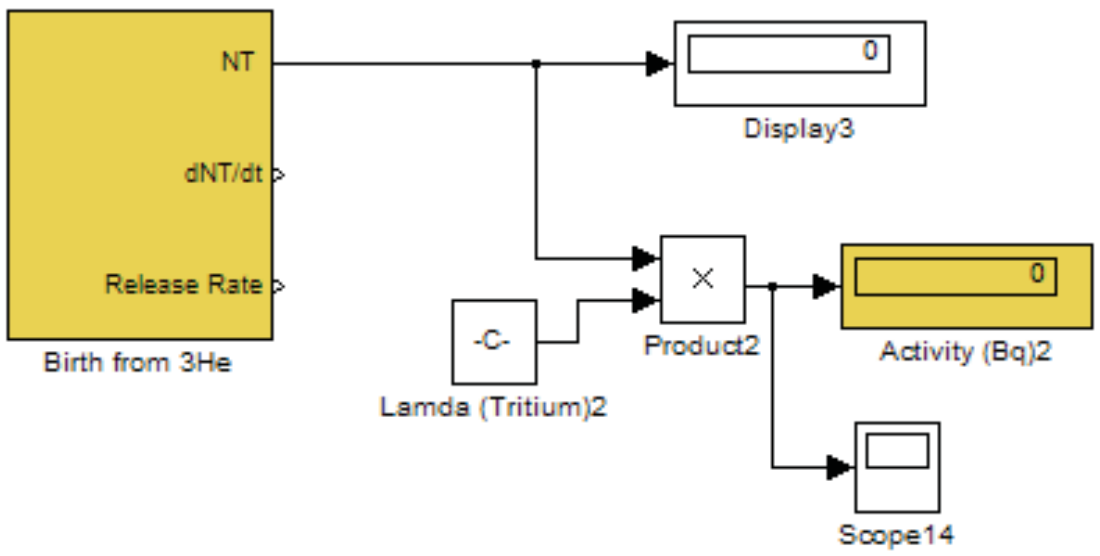

Figure 5-4. TPAC Tritium birth model for neutron reaction with ${ }^{3} \mathrm{He}$ impurities.

For obtaining the reference data, the birth of tritium from ${ }^{3} \mathrm{He}$ was estimated by the following analytical equations (Wichner and Dyer [1979]).

$N_{T 1}=\frac{\left(V_{1}+V_{7}\right) \cdot \phi_{t h} \cdot \sigma_{H e 3 T} \cdot N_{3}}{Q+\lambda \cdot V}$,

for the sleeve graphite

$$
N_{T 2}\left(t_{f}\right)=\frac{V_{3}}{V} \cdot \phi_{t h} \cdot \sigma_{H e 3 T} \cdot N_{3}\left[\frac{1-\exp \left(-\lambda \cdot t_{f}\right)}{\lambda}\right],
$$

for the removal radial reflector

$N_{T 3}\left(t_{f}\right)=\frac{V_{4}}{V} \cdot \phi_{t h} \cdot \sigma_{H e 3 T} \cdot N_{3}\left[\frac{1-\exp \left(-\lambda \cdot t_{f}\right)}{\lambda}\right]$,

for the permanent radial reflector

$N_{T 4}\left(t_{f}\right)=\frac{V_{6}}{V} \cdot \phi_{t h, 3} \cdot \sigma_{H e 3 T} \cdot N_{3}\left[\frac{1-\exp \left(-\lambda \cdot t_{f}\right)}{\lambda}\right]$,

and for the axial reflector

$N_{T 5}\left(t_{f}\right)=\frac{V_{5}}{V} \cdot \phi_{t h, 2} \cdot \sigma_{H e 3 T} \cdot N_{3}\left[\frac{1-\exp \left(-\lambda \cdot t_{f}\right)}{\lambda}\right]$ 
where

$$
\begin{aligned}
& N_{T 1}=\text { total moles of tritium circulating in the reactor with the coolant } \\
& N_{T 2}=\text { total moles of tritium born in the sleeve graphite from }{ }^{3} \mathrm{He} \\
& N_{T 3}=\text { total moles of tritium born in the removal radial reflector from }{ }^{3} \mathrm{He} \\
& N_{T 4}=\text { total moles of tritium born in the permanent reflector from }{ }^{3} \mathrm{He} \\
& N_{T 5}=\text { total moles of tritium born in the axial reflector from }{ }^{3} \mathrm{He} \\
& V_{1}=\text { volume of coolant passage in core }\left(1.77 \times 10^{6} \mathrm{~cm}^{3}\right) \\
& V_{2}=\text { ex-core primary system volume }\left(1.88 \times 10^{8} \mathrm{~cm}^{3}\right) \\
& V_{3}=\text { connected porosity in sleeve graphite }\left(3.44 \times 10^{5} \mathrm{~cm}^{3}\right) \\
& V_{4}=\text { connected porosity in removal radial reflector }\left(8.46 \times 10^{5} \mathrm{~cm}^{3}\right) \\
& V_{5}=\text { connected porosity in axial reflector }\left(3.92 \times 10^{5} \mathrm{~cm}^{3}\right) \\
& V_{6}=\text { connected porosity in permanent radial reflector }\left(2.32 \times 10^{6} \mathrm{~cm}^{3}\right) \\
& V_{7}=\text { purge flow volume within the fuel elements }\left(6.32 \times 10^{5} \mathrm{~cm}^{3}\right) \\
& V \quad=\text { effective helium volume of the primary system } \\
& \left(V_{1}+V_{2}+V_{3}+V_{4}+V_{5}+V_{6}\left[1.94 \times 10^{8} \mathrm{~cm}^{3}\right]\right) \\
& \phi_{t h}=\text { average thermal neutron flux in core and removal radial reflector, } \\
& \text { Core } 2\left(2.82 \times 10^{13} \text { neutrons } / \mathrm{cm}^{2} / \mathrm{s}\right) \\
& \phi_{t h, 2}=\text { average thermal neutron flux in axial reflector }\left(1.41 \times 10^{13} \text { neutrons } / \mathrm{cm}^{2} / \mathrm{s}\right) \\
& \phi_{t h, 3}=\text { average thermal neutron flux in permanent radial reflector }\left(1.41 \times 10^{13} \text { neutrons } / \mathrm{cm}^{2} / \mathrm{s}\right) \\
& \sigma_{\text {He3T }}=\text { effective cross section for }{ }^{3} \mathrm{He}(\mathrm{n}, \mathrm{p}) \mathrm{T}\left(2.28 \times 10^{-21} \mathrm{~cm}^{2}\right) \\
& Q \quad=\quad \text { flow to chemical cleanup system plus } 10 \% \text { of fuel element purge flow } \\
& \left(Q_{1}\left(2.40 \times 10^{4} \mathrm{~cm}^{3} / \mathrm{s}\right)\right)+\text { leakage flow rate from primary system }\left(Q_{2}\left[25.5 \mathrm{~cm}^{3} / \mathrm{s}\right]\right) \text {. }
\end{aligned}
$$

The total moles of ${ }^{3} \mathrm{He}$ in the primary system, $N_{3}$, is governed by the relation in the following equation:

$$
\frac{d N_{3}}{d t}=-\sigma_{H e 3 T} \cdot N_{3}\left\{\left(\frac{V_{1}+V_{3}+V_{4}+V_{7}}{V}\right) \cdot \phi_{t h}+\left(\frac{V_{5}+V_{6}}{V}\right) \cdot \phi_{t h, 2}\right\}+Q_{2}\left(\left[{ }^{3} \mathrm{He}\right]_{i}-\left[{ }^{3} \mathrm{He}\right]\right)
$$

where

$$
\begin{aligned}
& {\left[{ }^{3} \mathrm{He}\right]_{i}=} \begin{array}{l}
{ }^{3} \mathrm{He} \text { concentration in makeup helium }\left(5.78 \times 10^{-11} \mathrm{moles} / \mathrm{cm}^{3} \text { based on } 0.16 \mathrm{ppm}{ }^{3} \mathrm{He}\right. \text { in } \\
\text { helium })
\end{array} \\
& {\left[{ }^{3} \mathrm{He}\right]={ }^{3} \mathrm{He} \text { concentration in primary system }\left(=N_{3} / V\right) . }
\end{aligned}
$$


Table 5-5 summarizes the calculated tritium birth from ${ }^{3} \mathrm{He}$ in the Core 2 operation in the Peach Bottom reactor. The input parameters are summarized in Tables 5-6 and 5-7. Ohashi and Sherman (2007) reported that the values are larger than both analytical and computed solutions within $10-60 \%$. However, the reason is still unknown. The TPAC solutions show good agreement with analytical solutions and THYTAN results. It verifies that the TPAC solves Equations (5-7), (5-8), and (5-9), correctly.

Table 5-5. Comparison of tritium activity from ${ }^{3} \mathrm{He}$ at the Core 2 operation of the Peach Bottom HTGR.

\begin{tabular}{|l|c|c|c|c|c|}
\hline & \multicolumn{5}{c|}{ Activity } \\
\hline \multirow{2}{*}{\multicolumn{1}{|c|}{ Region }} & $\begin{array}{c}\text { Reported Value } \\
\text { (Peach Bottom) }\end{array}$ & $\begin{array}{c}\text { Analytical } \\
\text { Solution }\end{array}$ & $\begin{array}{c}\text { THYTAN } \\
\text { (Ohashi and } \\
\text { Sherman 2007) }\end{array}$ & $\begin{array}{c}\text { TPAC } \\
\text { Solution }\end{array}$ \\
\cline { 2 - 6 }$(\mathrm{Ci})$ & $(\mathrm{Bq})$ & $(\mathrm{Bq})$ & $(\mathrm{Bq})$ & $(\mathrm{Bq})$ \\
\hline In sleeve graphite & 5.4 & $1.98 \times 10^{11}$ & $1.31 \times 10^{11}$ & $1.26 \times 10^{11}$ & $1.28 \times 10^{11}$ \\
\hline $\begin{array}{l}\text { In removable radial } \\
\text { reflector }\end{array}$ & 13.5 & $4.95 \times 10^{11}$ & $3.20 \times 10^{11}$ & $3.09 \times 10^{11}$ & $3.12 \times 10^{11}$ \\
\hline $\begin{array}{l}\text { In permanent radial } \\
\text { reflector }\end{array}$ & 15.5 & $5.68 \times 10^{11}$ & $5.43 \times 10^{11}$ & $5.24 \times 10^{11}$ & $5.31 \times 10^{11}$ \\
\hline In axial reflector & 3.1 & $1.14 \times 10^{12}$ & $9.17 \times 10^{11}$ & $8.86 \times 10^{11}$ & $8.98 \times 10^{11}$ \\
\hline
\end{tabular}

Table 5-6. Input data for calculation of tritium birth from ${ }^{3} \mathrm{He}$ (Ohashi and Sherman 2007).

\begin{tabular}{c|l|l}
\multicolumn{1}{c|}{ Parameter } & \multicolumn{1}{c}{ Unit } & \multicolumn{1}{c}{ Value } \\
\hline Effective cross section for ${ }^{3} \mathrm{He}(\mathrm{n}, \mathrm{p}) \mathrm{T}$ & $\mathrm{cm}$ & $2.28 \times 10^{-21}$ \\
\hline${ }^{3} \mathrm{He}$ concentration in makeup helium & $\mathrm{ppm}$ & 0.16 \\
\hline Helium inventory in primary system & $\mathrm{kg}$ & 269 \\
\hline
\end{tabular}

Table 5-7. Input data for the calculation of tritium birth from ${ }^{3} \mathrm{He}$ (Ohashi and Sherman 2007).

\begin{tabular}{l|c|c}
\hline \multicolumn{1}{c|}{ Subnode } & $\begin{array}{c}\text { Thermal Neutron Flux } \\
(\text { neutrons/cm } / \mathbf{s})\end{array}$ & $\begin{array}{c}\text { Helium Inventory } \\
\text { (kg) }\end{array}$ \\
\hline In circulating coolant & $2.82 \times 10^{13}$ & 3.33 \\
\hline In sleeve graphite & $2.82 \times 10^{13}$ & 0.477 \\
\hline In removal radial reflector & $2.82 \times 10^{13}$ & 1.17 \\
\hline In permanent radial reflector & $1.41 \times 10^{13}$ & 3.22 \\
\hline In axial reflector & $1.41 \times 10^{13}$ & 0.543 \\
\hline
\end{tabular}

\subsubsection{Tritium Birth from ${ }^{10} \mathrm{~B}$ Impurities in the Coolant}

Figure 5-5 shows the TPAC tritium birth modeling for neutron reaction of ${ }^{10} \mathrm{~B}$ impurities in the coolant. The tritium source block by ${ }^{10} \mathrm{~B}$ neutron reaction was designed to solve the following equations.

$$
\begin{aligned}
& \frac{d\left(N_{B 10}\right)}{d t}=-\left(\phi_{t h} \cdot \sigma_{B 10 L i 7}+\phi_{f} \cdot \sigma_{B 10 T}\right) \cdot N_{B 10} \\
& \frac{d\left(N_{L i 7(B 10)}\right)}{d t}=\phi_{t h} \cdot \sigma_{B 10 L i 7} \cdot N_{B 10}-\phi_{f} \cdot \sigma_{L i 7 T} \cdot N_{L i 7(B 10)}
\end{aligned}
$$


$\frac{d\left(N_{T(B 10)}\right)}{d t}=\phi_{f} \cdot \sigma_{L i 7 T} \cdot N_{L i 7(B 10)}+\phi_{f} \cdot \sigma_{B 10 T} \cdot N_{B 10}-\lambda \cdot N_{T(B 10)}$

where

$$
\begin{array}{ll}
N_{B 10} & =\text { number of }{ }^{10} \mathrm{~B} \text { atoms } \\
N_{L i 7(B 10)} & =\text { number of }{ }^{7} \mathrm{Li} \text { atoms from }{ }^{10} \mathrm{~B} \\
N_{T(B 10)} & =\text { number of tritium from }{ }^{10} \mathrm{~B} \\
\sigma_{B 10 L i 7} & =\text { effective cross section for }{ }^{10} \mathrm{~B}(\mathrm{n}, \alpha){ }^{7} \mathrm{Li}\left[\mathrm{cm}^{2}\right] \\
\sigma_{B 10 T} & =\text { effective cross section for }{ }^{10} \mathrm{~B}(\mathrm{n}, 2 \alpha){ }^{3} \mathrm{H}\left[\mathrm{cm}^{2}\right] .
\end{array}
$$

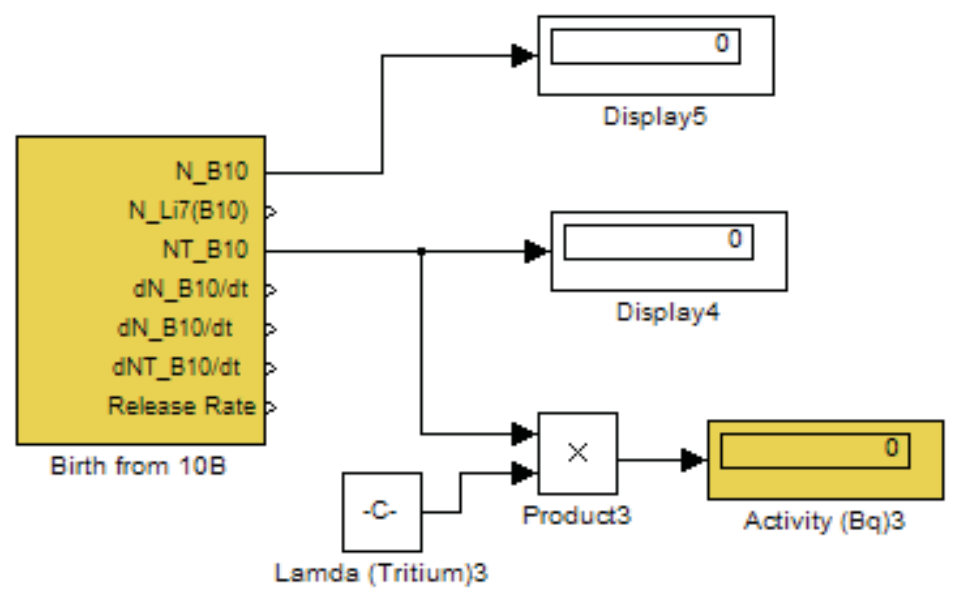

Figure 5-5. TPAC Tritium birth model for neutron reaction with ${ }^{10} \mathrm{~B}$ impurities.

For the reference data, the tritium birth from ${ }^{10} \mathrm{~B}$ was evaluated by the following equation:

$$
\begin{aligned}
\frac{N_{T}\left(t_{f}\right)}{N_{10}(0)}= & \frac{b \cdot a}{(b-a) \cdot(\lambda-a)}\left(\exp \left(-a \cdot t_{f}\right)-\exp \left(-\lambda \cdot t_{f}\right)\right) \\
& -\frac{b \cdot a}{(b-a) \cdot(\lambda-b)}\left(\exp \left(-b \cdot t_{f}\right)-\exp \left(-\lambda \cdot t_{f}\right)\right) \\
& +\frac{c}{(\lambda-a)}\left(\exp \left(-a \cdot t_{f}\right)-\exp \left(-\lambda \cdot t_{f}\right)\right)
\end{aligned}
$$

where

$$
\begin{aligned}
a & =\beta \phi t h \sigma \mathrm{B}^{10} \mathrm{Li}^{7} \\
b & =\phi \mathrm{f} \sigma \mathrm{Li}^{7} \mathrm{~T} \\
c & =\phi \mathrm{f} \sigma \mathrm{B}^{10} \mathrm{~T} \\
\beta & =\text { self-shielding factor }(0.0141) \\
\phi_{t h} & =\text { average thermal neutron flux }\left(2.82 \times 1,013 \text { neutrons } / \mathrm{cm}^{2} / \mathrm{s}\right)
\end{aligned}
$$


$\phi_{f} \quad=$ average fast neutron flux $\left(2.26 \times 1,013\right.$ neutrons $\left./ \mathrm{cm}^{2} / \mathrm{s}\right)$

$\sigma_{B 10 L i 7}=$ effective cross section for ${ }^{10} \mathrm{~B}(\mathrm{n}, \alpha){ }^{7} \mathrm{Li}\left(1.63 \times 10^{-21} \mathrm{~cm}^{2}\right)$

$\sigma_{\text {Li7T }}=$ effective cross section for ${ }^{7} \mathrm{Li}(\mathrm{n}, \mathrm{n} \alpha){ }^{3} \mathrm{H}\left(1.53 \times 10^{-25} \mathrm{~cm}^{2}\right)$

$\sigma_{B 10 T}=$ effective cross section for ${ }^{10} \mathrm{~B}(\mathrm{n}, 2 \alpha){ }^{3} \mathrm{H}\left(5.00 \times 10^{-26} \mathrm{~cm}^{2}\right)$

$N_{10}(0)=$ initial amount of ${ }^{10} \mathrm{~B}$ atoms (20.15 moles).

Tritium from ${ }^{10} \mathrm{~B}$ is produced in the poisoned spine and in the control rod. However, because the boron level and control rod position varies with time in the control rod, only the poisoned spine was taken into consideration here. Table 5-8 shows the calculation result and reported values. Computed values by the TPAC show good agreement with the analytical solutions.

Table 5-8. Comparison of tritium activity from ${ }^{10} \mathrm{~B}$ in the poisoned spine at the Core 2 operation of Peach Bottom reactor.

\begin{tabular}{|c|c|c|c|c|}
\hline \multicolumn{2}{|c|}{ Activity } & \multicolumn{1}{|c|}{$\begin{array}{c}\text { THYTAN } \\
\text { (Ohashi and } \\
\text { Reported Value } \\
\text { (Peach Bottom) }\end{array}$} & $\begin{array}{c}\text { Analytical } \\
\text { Solution }\end{array}$ & TPAC Solution \\
\hline$(\mathrm{Ci})$ & $(\mathrm{Bq})$ & $(\mathrm{Bq})$ & $(\mathrm{Bq})$ & $(\mathrm{Bq})$ \\
\hline 85.7 & $3.14 \times 10^{12}$ & $3.19 \times 10^{12}$ & $3.18 \times 10^{12}$ & $3.19 \times 10^{12}$ \\
\hline
\end{tabular}

\subsection{Verification of Permeation Model}

In this section, the TPAC tritium permeation model has been verified. Figure 5-6 shows two modeling for verification. Figure 5-6 (a) is the modeling of tritium permeation through the vessel or pipe walls out of the components. Figure 5-6 (b) is the modeling of tritium permeation through the heat exchanger walls.

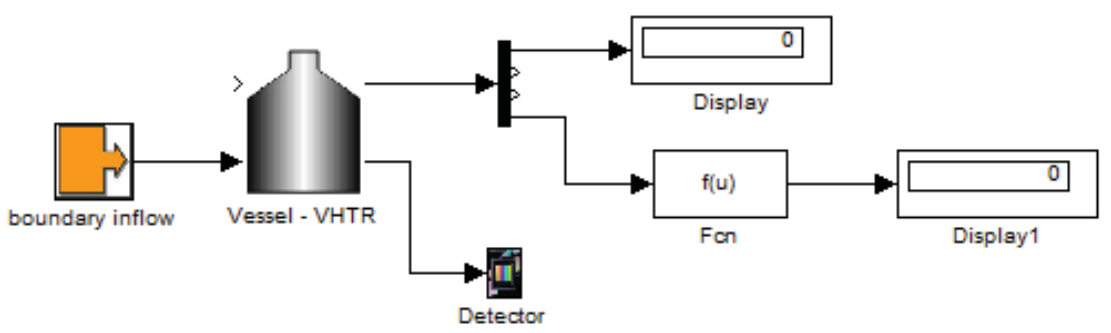

(a) Tritium permeation modeling in the vessel or pipe walls to outside.

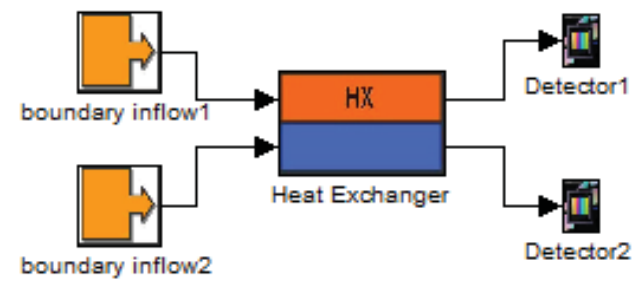

(b) Tritium permeation modeling in the heat exchanger walls.

Figure 5-6. Tritium permeation modeling by INL Tritium code. 
Two species permeations in the TPAC were taken into consideration; (1) hydrogen and (2) tritium. The TPAC was designed to solve the forms of general tritium permeation equations described below.

The permeation rate of $\mathrm{H}_{2}$ at the heat exchanger, $R_{H X, H 2}\left[\mathrm{~m}^{3}(\mathrm{STP}) / \mathrm{s}\right]$, and at the co-axial pipe, $R_{\text {copipe }, H 2}\left[\mathrm{~m}^{3}(\mathrm{STP}) / \mathrm{s}\right]$, is estimated using

$$
R_{H X, H 2, j}\left(\text { or } \quad R_{\text {copipe }, H 2, j}\right)=\frac{A}{l} \cdot k_{p, H} \cdot\left(\sqrt{P_{H 2, h}}-\sqrt{P_{H 2, l}}\right)
$$

where

$$
\begin{aligned}
& A=\text { heat transfer area or surface area }\left[\mathrm{m}^{2}\right] \\
& l=\text { thickness of heat transfer tube or component casing }[\mathrm{m}] \\
& k_{p, H}=\text { permeability of hydrogen }\left[\mathrm{m}^{3}(\mathrm{STP}) / \mathrm{m} / \mathrm{s} / \mathrm{Pa}^{0.5}\right] \\
& P_{H 2, h}=\text { partial pressure of } \mathrm{H}_{2} \text { at high pressure side }[\mathrm{Pa}] \\
& P_{H 2, l}=\text { partial pressure of } \mathrm{H}_{2} \text { at low pressure side }[\mathrm{Pa}] .
\end{aligned}
$$

$l$ is calculated by

$$
l=r_{o} \cdot \ln \left(\frac{r_{o}}{r_{i}}\right)
$$

where

$r_{o}=$ outer radius of heat transfer tube $[\mathrm{m}]$

$r_{i}=$ inner radius of heat transfer tube $[\mathrm{m}]$.

Permeability is calculated by using the Arrhenius equation:

$$
k_{p}=f \cdot \exp \left(\frac{-E}{R T}\right)
$$

where

$$
\begin{aligned}
f & =\text { pre-exponential factor of permeability }\left[\mathrm{m}^{3}(\mathrm{STP}) / \mathrm{m} / \mathrm{s} / \mathrm{Pa}^{0.5}\right] \\
E & =\text { activation energy }[\mathrm{J} / \mathrm{mol}] \\
R & =\text { ideal gas constant }[\mathrm{J} / \mathrm{mol}-\mathrm{K}] \\
T & =\text { temperature }[\mathrm{K}] .
\end{aligned}
$$

The permeation rate of $\mathrm{H}_{2}$ though the outer wall of the component and piping, $R_{\text {comp }, H 2}$, is calculated by excluding the $\mathrm{H}_{2}$ partial pressure at the low pressure side as follows:

$$
R_{\text {comp }, H 2, j}=\frac{A}{l} \cdot k_{p, H} \cdot \sqrt{P_{H 2, h}} .
$$


The permeation rate of HT at the heat exchanger, $R_{H X, H 2}\left[\mathrm{~m}^{3}(\mathrm{STP}) / \mathrm{s}\right]$, and at the co-axial pipe,

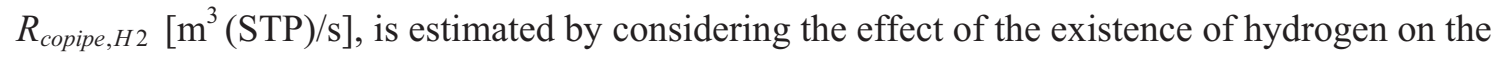
adsorption-dissociation and recombination-desorption step as follows:

$$
R_{H X, H T, j}\left(\text { or } \quad R_{\text {copipe }, H T, j}\right)=\frac{A}{l} \cdot k_{p, T} \cdot\left(1-\frac{P_{H 2, l}}{P_{T o t a l, l}}\right)\left(\frac{P_{H T, h}}{\sqrt{P_{H 2, h}+P_{H T, h}}}-\frac{P_{H T, l}}{\sqrt{P_{H 2, l}+P_{H T, l}}}\right)
$$

where

$$
\begin{aligned}
& k_{p, T}=\text { permeability of tritium }\left[\mathrm{m}^{3}(\mathrm{STP}) / \mathrm{m} / \mathrm{s} / \mathrm{Pa}^{0.5}\right] \\
& P_{H T, h}=\text { partial pressure of } \mathrm{HT} \text { at high pressure side }[\mathrm{Pa}] \\
& P_{H T, l}=\text { partial pressure of } \mathrm{HT} \text { at low pressure side }[\mathrm{Pa}] \\
& P_{T o t a l, l}=\text { total pressure at low pressure side }[\mathrm{Pa}]
\end{aligned}
$$

The permeation rate of HT through the outer wall of the component and piping, $R_{c o m p, H T}$, is calculated by using the following equation:

$$
R_{\text {comp }, H T, j}=\frac{A}{l} \cdot k_{p, T} \cdot \frac{P_{H T, h}}{\sqrt{P_{H 2, h}+P_{H T, h}}} \text {. }
$$

For verification of tritium permeation models, the permeation rates of the heat transfer tubing obtained from the Peach Bottom HTGR steam generator at the end of life (Yang, Baugh, and Baldwin 1977) has been selected to be used. The reported permeation rate, J, of the Incoloy 800 super-heater tubing, steel evaporator tubing, and low-carbon steel economizer are as follows:

for the economizer

$$
J=7.78 \times 10^{1} \cdot \exp (-4500 / T)(493 \mathrm{~K}-623 \mathrm{~K})\left[\mu \mathrm{Ci} / \mathrm{m}^{2} / \mathrm{h}\right]
$$

for the evaporator

$$
J=6.97 \times 10^{3} \cdot \exp (-6830 / T)(573 \mathrm{~K}-693 \mathrm{~K})\left[\mu \mathrm{Ci} / \mathrm{m}^{2} / \mathrm{h}\right]
$$

for the super-heater

$$
J=1.72 \times 10^{3} \cdot \exp (-6440 / T)(673 \mathrm{~K}-973 \mathrm{~K})\left[\mu \mathrm{Ci} / \mathrm{m}^{2} / \mathrm{h}\right]
$$

Calculation of the tritium permeation rate for the super-heater, evaporator, and economizer was carried out. Table 5-9 shows the size and dimension of the heat exchangers. The experimental conditions - tritium concentration in the feed side of $0.461 \mathrm{ppb}$, feed helium pressure of $0.1013 \times 10^{5} \mathrm{~Pa}$, and the permeation chamber pressure of $1.33 \times 10^{-3} \mathrm{~Pa}$-were employed as boundary conditions. The effect of impurity hydrogen was ignored. The hydrogen concentration of $199 \mathrm{ppm}$ was assumed for the boundary condition for the primary side. 
Table 5-9. The heat transfer tube dimensions of the steam generator in the Peach Bottom reactor (Ohashi and Sherman 2007).

\begin{tabular}{l|c|c|c}
\hline \multicolumn{1}{c|}{ Sample } & $\begin{array}{c}\text { Effective Area } \\
\left(\mathbf{m}^{\mathbf{2}}\right)\end{array}$ & $\begin{array}{c}\text { Outer Radius } \\
(\mathbf{m})\end{array}$ & $\begin{array}{c}\text { Inner Radius } \\
(\mathbf{m})\end{array}$ \\
\hline Economizer (inlet) & $103.47 \times 10^{-4}$ & $6.350 \times 10^{-3}$ & $4.775 \times 10^{-3}$ \\
\hline Evaporator (inlet) & $68.34 \times 10^{-4}$ & $9.525 \times 10^{-3}$ & $7.300 \times 10^{-3}$ \\
\hline Super-heater (inlet) & $90.16 \times 10^{-4}$ & $9.525 \times 10^{-3}$ & $6.350 \times 10^{-3}$ \\
\hline
\end{tabular}

Table 5-10 summarizes the analytical solutions of Equations (5-26) through (5-28), THYTAN results (Ohashi and Sherman 2007), and the TPAC solutions. In this table, the TPAC solutions are in good agreement with analytical solutions and reported THYTAN results.

Table 5-10. Comparison of permeation rates.

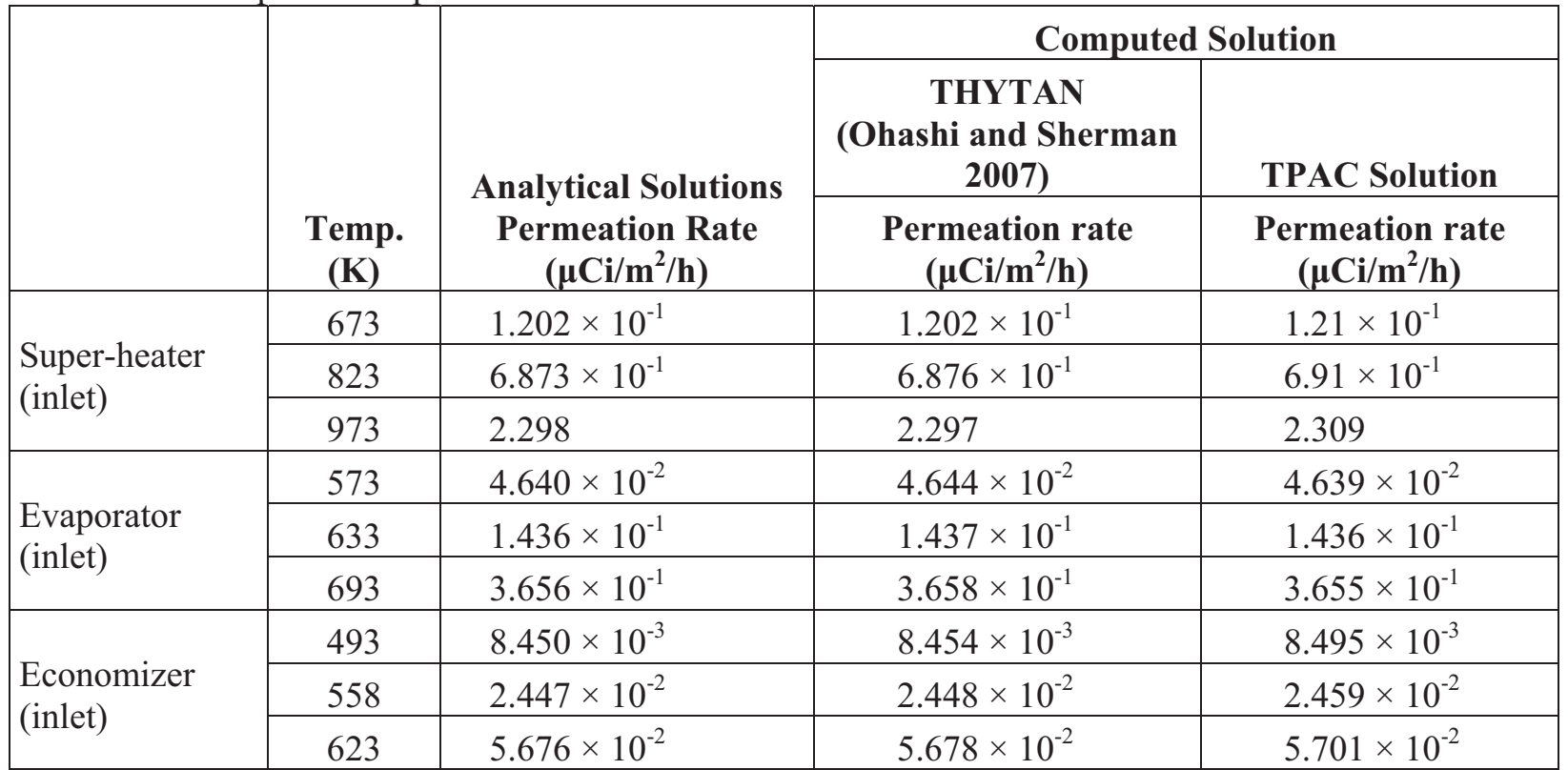

\subsection{Verification of Leak Model}

The verification of the leak model in the TPAC is described in this section. Figure 5-7 shows two different modeling for verification. In Figure 5-7(a), the primary and the containment were considered to be single components. To maintain the primary tritium concentration constant, the same amount of leakage from the primary side has been re-injected back to the primary side. In Figure 5-7(b), the primary side and the secondary side have been modeled to be two different loops with convective flows. In this model, leakage and mass conservation are verified together.

The TPAC input data is summarized in Table 5-11. Since the information on the containment vessel temperature is not available, the average containment vessel temperature is assumed to be $323 \mathrm{~K}$. The tritium concentration in the primary loop of $2 \times 10^{5} \mu \mathrm{Ci} / \mathrm{cm}^{3}$ corresponds to $1.98 \times 10^{3} \mathrm{ppb}$ under the reported average temperature of $809 \mathrm{~K}$ and a pressure of $23 \mathrm{~atm}$ in the primary coolant. In order to keep the tritium concentration in the primary coolant $1.98 \times 10^{3} \mathrm{ppb}$, the tritium release rate to the primary coolant was adjusted by the core model. The initial concentration of tritium in the containment vessel was set to zero. 


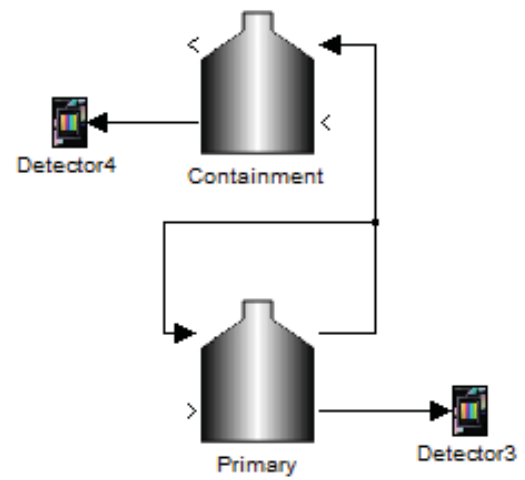

(a) Tritium leakage modeling for single primary and single containment system.

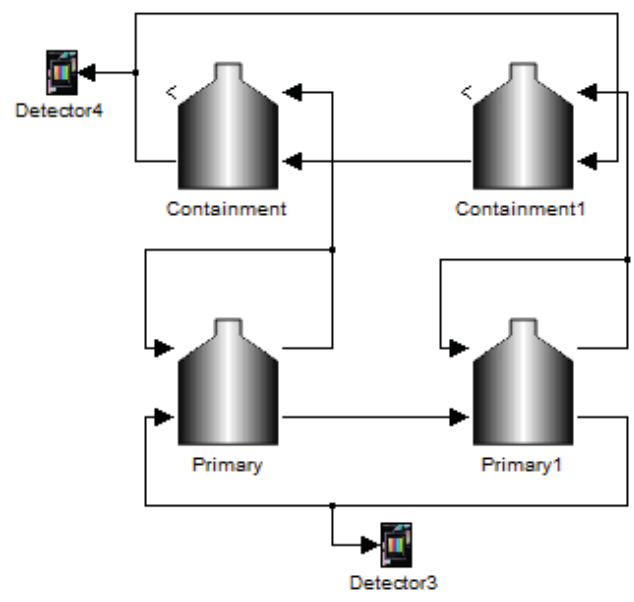

(b) Tritium leakage modeling for duel primary and dual containment system.

Figure 5-7. Tritium leak modeling by INL Tritium code.

Table 5-11. TPAC input data for verification of the leak model.

\begin{tabular}{|c|c|c|}
\hline Parameter & Unit & Value \\
\hline Leak rate from primary to containment vessel & $1 / \mathrm{h}$ & $4.15 \times 10^{-4} \mathrm{a}$ \\
\hline Primary loop volume & $\mathrm{m}^{3}$ & 232 \\
\hline Primary loop pressure & $\mathrm{Pa}$ & $2.33 \times 10^{6 \mathrm{~b}}$ \\
\hline Primary loop temperature & $\mathrm{K}$ & 809 \\
\hline Leak rate from containment vessel to atmosphere & $1 / \mathrm{h}$ & $4.17 \times 10^{-4 c}$ \\
\hline Containment vessel volume & $\mathrm{m}^{3}$ & $1.56 \times 10^{4 \mathrm{~d}}$ \\
\hline Containment vessel pressure & $\mathrm{Pa}$ & $1.57 \times 10^{5 \mathrm{e}}$ \\
\hline Containment vessel temperature & $\mathrm{K}$ & $323^{f}$ \\
\hline \multicolumn{3}{|c|}{$\begin{array}{l}\text { a. Based on } 3.2 \mathrm{~kg} / \text { day. } \\
\text { b. Based on } 23 \mathrm{~atm} \text {. } \\
\text { c. Based on } 0.1 \% / \text { day. } \\
\text { d. Based on a nitrogen volume of } 2.04 \times 104 \mathrm{~m}^{3} \text { at a pressure of } 1.57 \times 10^{5} \mathrm{~Pa} \text { and assumed temperature of } 323 \mathrm{~K} \text {. } \\
\text { e. Based on } 8 \text { psig. } \\
\text { f. Assumed. }\end{array}$} \\
\hline
\end{tabular}


In order to verify the TPAC leak model, the tritium concentration in the containment vessel was estimated using the reported leak rate and the tritium concentration in the primary loop as Ohashi and Sherman (2007) did by using the THYTAN code. The TPAC solutions for the tritium concentration in the containment vessel were compared with the experimental result, the reported analytical solution, and THYTAN results.

The containment vessel's deinerting operation was carried out approximately every 127 days. The reported analytic solution for the tritium concentration in the containment vessel at the end of 127 days was $2.1 \times 10^{-7} \mu \mathrm{Ci} / \mathrm{cm}^{3}$, which is equivalent to $2.1 \times 10^{-4} \mathrm{ppb}$ at the containment vessel pressure of $1.57 \times$ $10^{5} \mathrm{~Pa}$ and the assumed temperature of $323 \mathrm{~K}$. This is shown in Figure 5-8 as a solid circle. As a result, the computed tritium concentration by the TPAC showed good agreement with analytical solutions and THYTAN results. However, the computed solutions were less than the reported experimental data observed in 1971 during the special tritium survey.

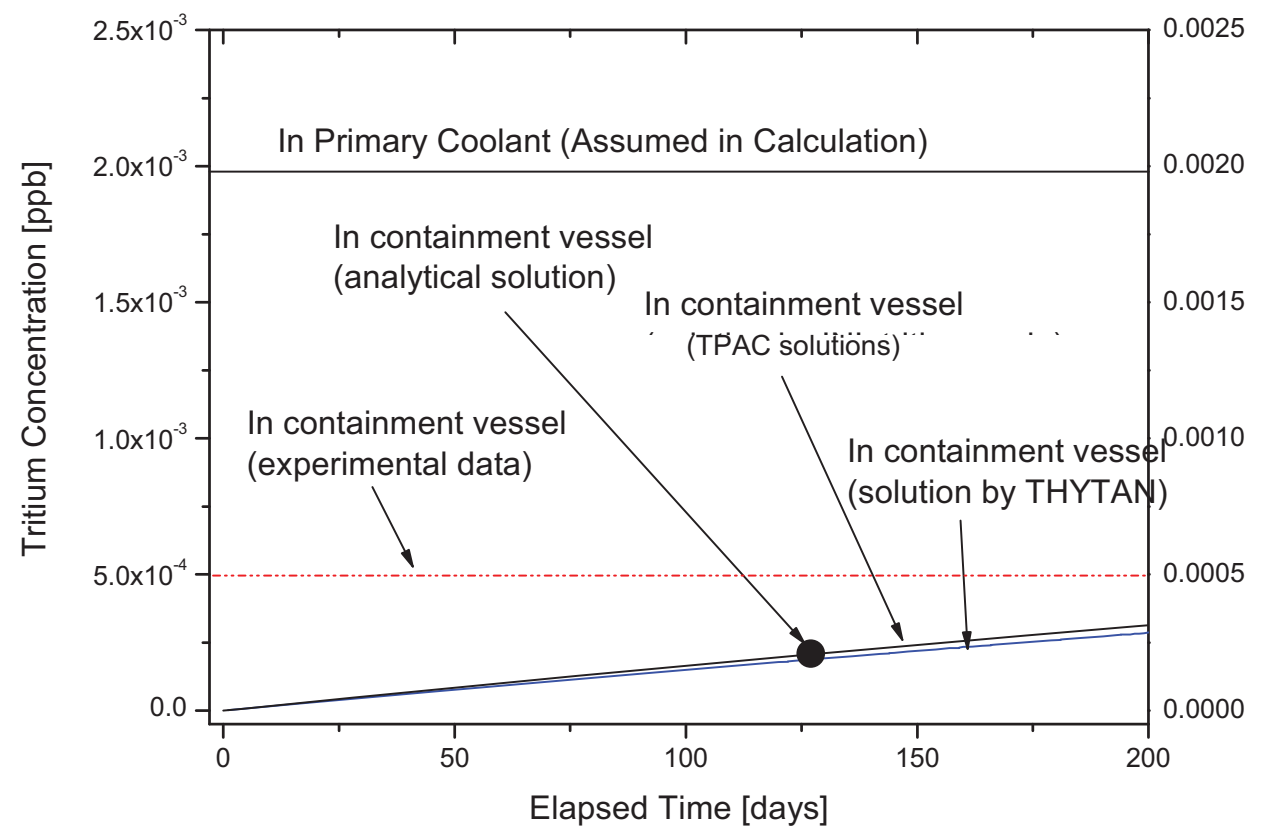

Figure 5-8. Comparison of tritium concentrations in the containment vessel of the Peach Bottom reactor.

\subsection{Verification of Purification System Model}

Verification of purification model in the TPAC is described in this section. Figure 5-9 shows the TPAC modeling for verification.

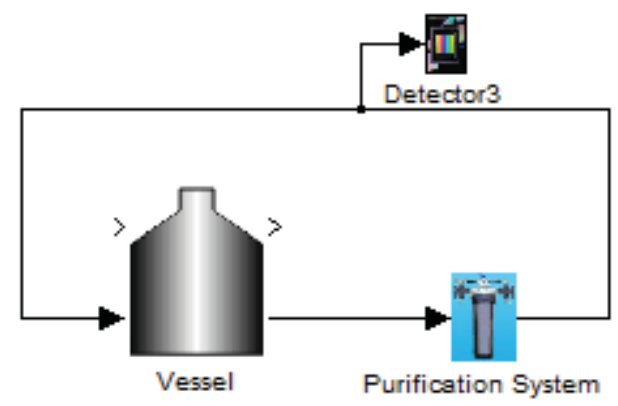

Figure 5-9. Tritium purification modeling by INL Tritium code. 
The TPAC purification system model was verified by

$$
\begin{aligned}
V_{j} \frac{d C_{i, j}}{d t} & =-R_{P F, i, j} \\
& =-F_{P F, H e} \cdot \eta_{i} \cdot C_{i, j}
\end{aligned}
$$

The solution for $C_{i, j}$ is found in

$$
C_{i, j}(t)=C_{0, i, j} \cdot \exp \left(-\frac{F_{P F, H e} \cdot \eta_{i}}{V_{j}} \cdot t\right)
$$

where

$$
C_{0, i, j}=\text { initial concentration of chemical } \mathrm{i} \text { in node } \mathrm{j}\left[\mathrm{m}^{3}(\mathrm{STP}) / \mathrm{m}^{3}(\mathrm{STP})\right] .
$$

Table 5-12 summarizes the boundary conditions for verification of the purification system model. The HT concentration was calculated during $3,000 \mathrm{sec}$.

Table 5-12. THYTAN boundary conditions for verification of the purification system model (Ohashi and Sherman 2007).

\begin{tabular}{l|c|c|c}
\hline \multicolumn{1}{c|}{ Parameter } & Symbol & Unit & Value \\
\hline Inventory & $V_{j}$ & $\mathrm{~m}^{3}(\mathrm{STP})$ & 1 \\
\hline Helium flow rate at purification system & $F_{P F, H e}$ & $\mathrm{~m}^{3}(\mathrm{STP})$ & $1.0 \times 10^{-3}$ \\
\hline $\begin{array}{l}\text { Fractional efficiency of purification system } \\
\text { for HT }\end{array}$ & $\eta_{H T}$ & - & 0.9 \\
\hline Initial concentration of HT & $C_{0, H T, j}$ & $\mathrm{~m}^{3}(\mathrm{STP}) / \mathrm{m}^{3}(\mathrm{STP})$ & $1.0 \times 10^{-9}$ \\
\hline
\end{tabular}

Figure 5-10 shows the comparisons between analytical solution and computational results by the TPAC. As shown in this figure, both the analytical solution and the TPAC solutions are in good agreement.

\subsection{Verification of Total System Model}

In this part, verification of the TPAC has been carried out against Peach Bottom reactor Core 2 operation. The simplified flow sheet of the reactor primary circuit and cleanup systems of the Peach Bottom HTGR are shown in Figure 5-11. A small portion of the tritium picked up by the fuel element purge flow (i.e., $454 \mathrm{~kg} / \mathrm{h}[1,000 \mathrm{lb} / \mathrm{h}]$ ) was permanently retained in the fission product traps that are located within the base of each fuel element. However, a major portion of the tritium left the core in the purge stream and entered the fission product trapping system. It was concluded that the water and Freoncooled delay beds in the fission product trapping system did not play a significant role in the disposition of tritium in the reactor. About $10 \%$ of the purified helium leaving the Freon-cooled bed was diverted to a liquid nitrogen trap and (liquid nitrogen-cooled charcoal beds). It was confirmed that tritium was effectively captured in these traps. A smaller helium purge flow (i.e., $91 \mathrm{~kg} / \mathrm{h}[200 \mathrm{lb} / \mathrm{h}]$ ) was drawn from the steam generator to the chemical cleanup system, which consisted of an oxidizer unit and a molecularsieve dehydrator. Gaseous HT was converted to HTO in the oxidizer and drawn off the waste disposal drain tank from the condenser downstream from the unit. Additional HTO was removed by the molecularsieve dehydrator downstream from the oxidizer. Purified helium that exited from the chemical cleanup system entered the fission product trapping system upstream from the liquid nitrogen trap. 


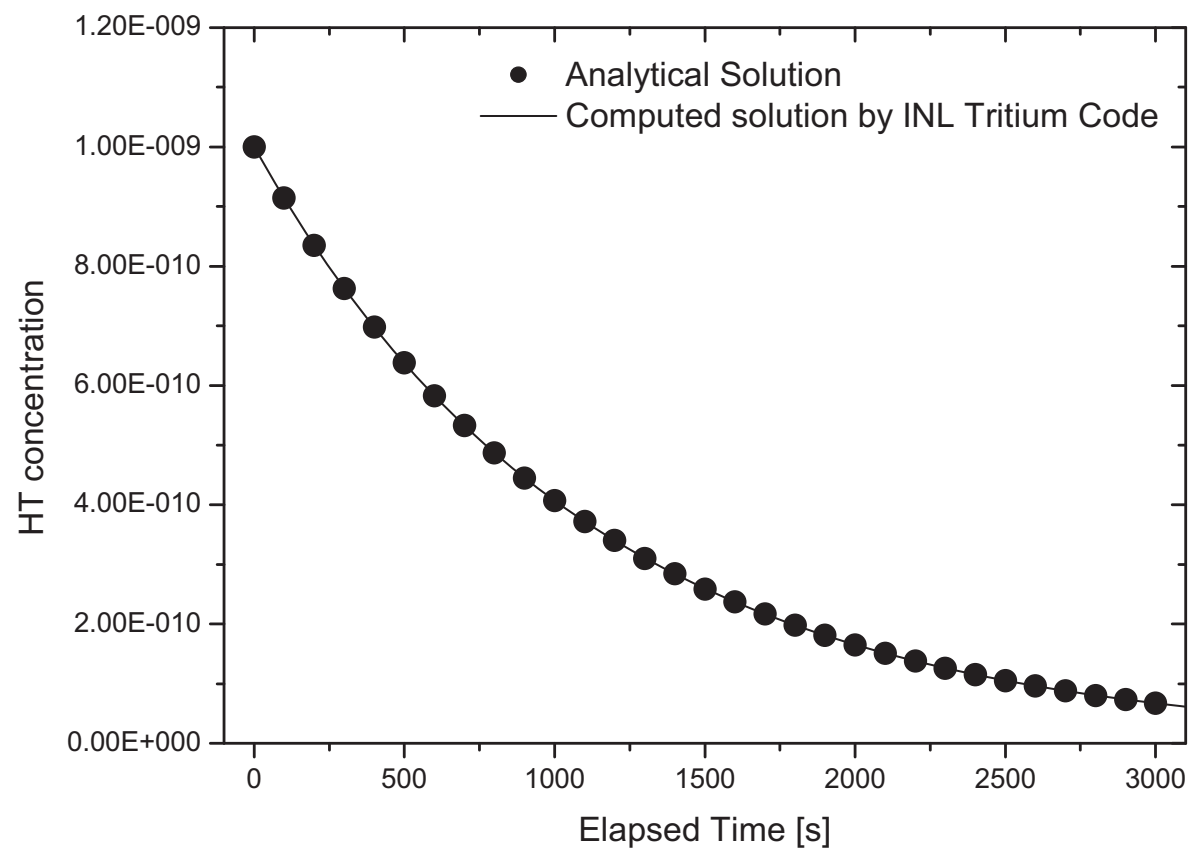

Figure 5-10. Comparisons between analytical solution and TPAC solutions for verification of the purification system.

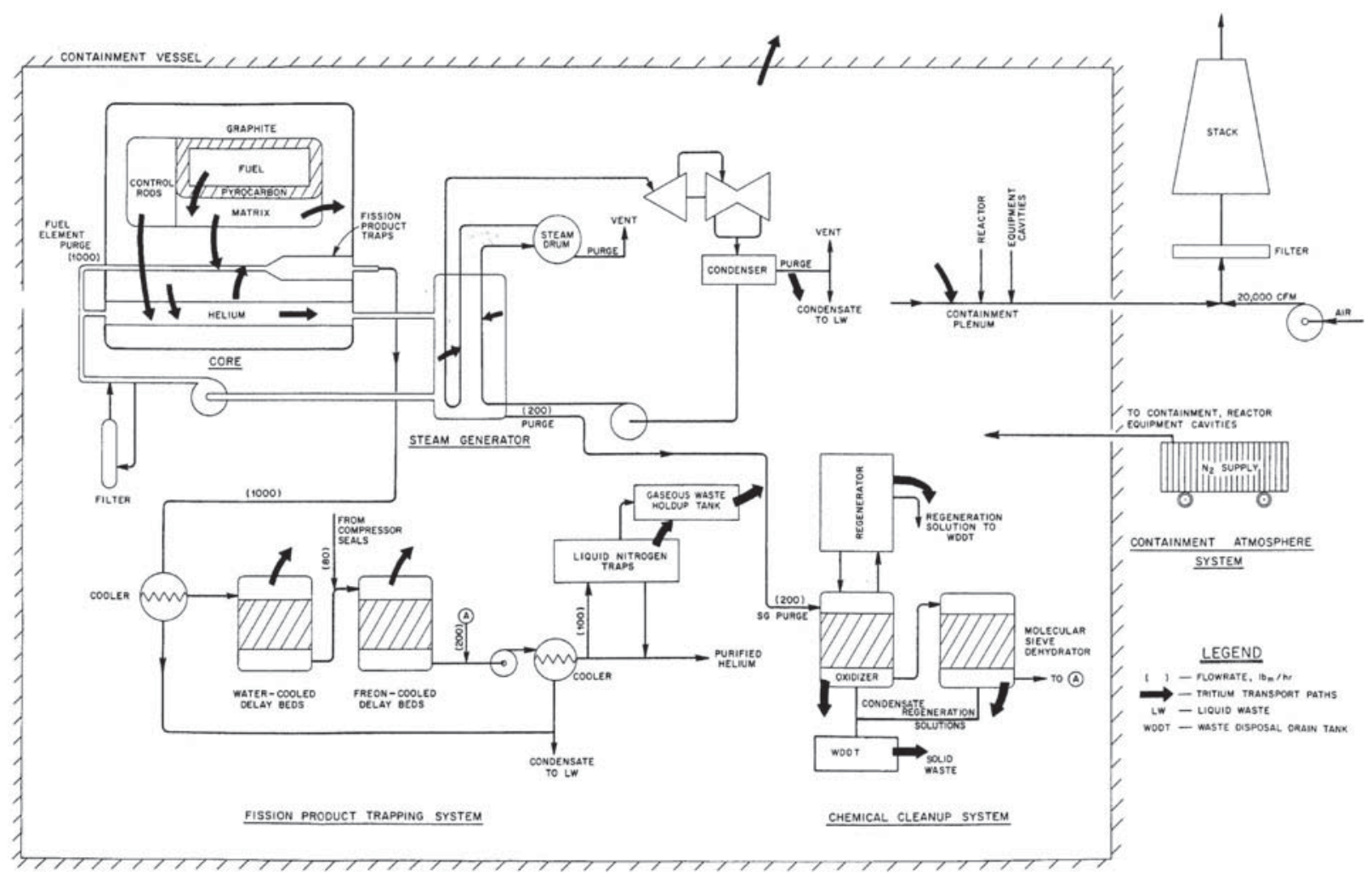

Figure 5-11. Simplified flow sheet of the Peach Bottom HTGR, illustrating tritium transport paths (Wichner and Dyer 1979). 
Figure 5-12 shows the TPAC modeling for the Peach Bottom reactor. The system is composed of reactor, steam generator, concentric pipe, containment, and purification system. For simplicity, two steam generator loops have been simplified to a single steam generator loop in the modeling. The tritium flow path in this system is as follows: The tritium is generated in the reactor core and released; majority of the released tritium enters into the main flow distributed in the whole system; the rest of the tritium from core is purged to the purification system for removing tritium from the primary loop; some of the tritium in the main flow is permeated to secondary side through the steam generator walls or leaked to the containment through the pipe lines; and a small portion of main flow is purged to another purification system.

The total volume of the system was set to be $232 \mathrm{~m}^{3}$, and the size of the each component was assumed based on the THYTAN code input developed by Ohashi and Sherman (2007). Table 5-13 summarizes the sizes of the modeling components. The temperature and the pressure of all the components were set as $809 \mathrm{~K}$ and $23 \mathrm{~atm}$, which are the average temperature and pressure in the system.

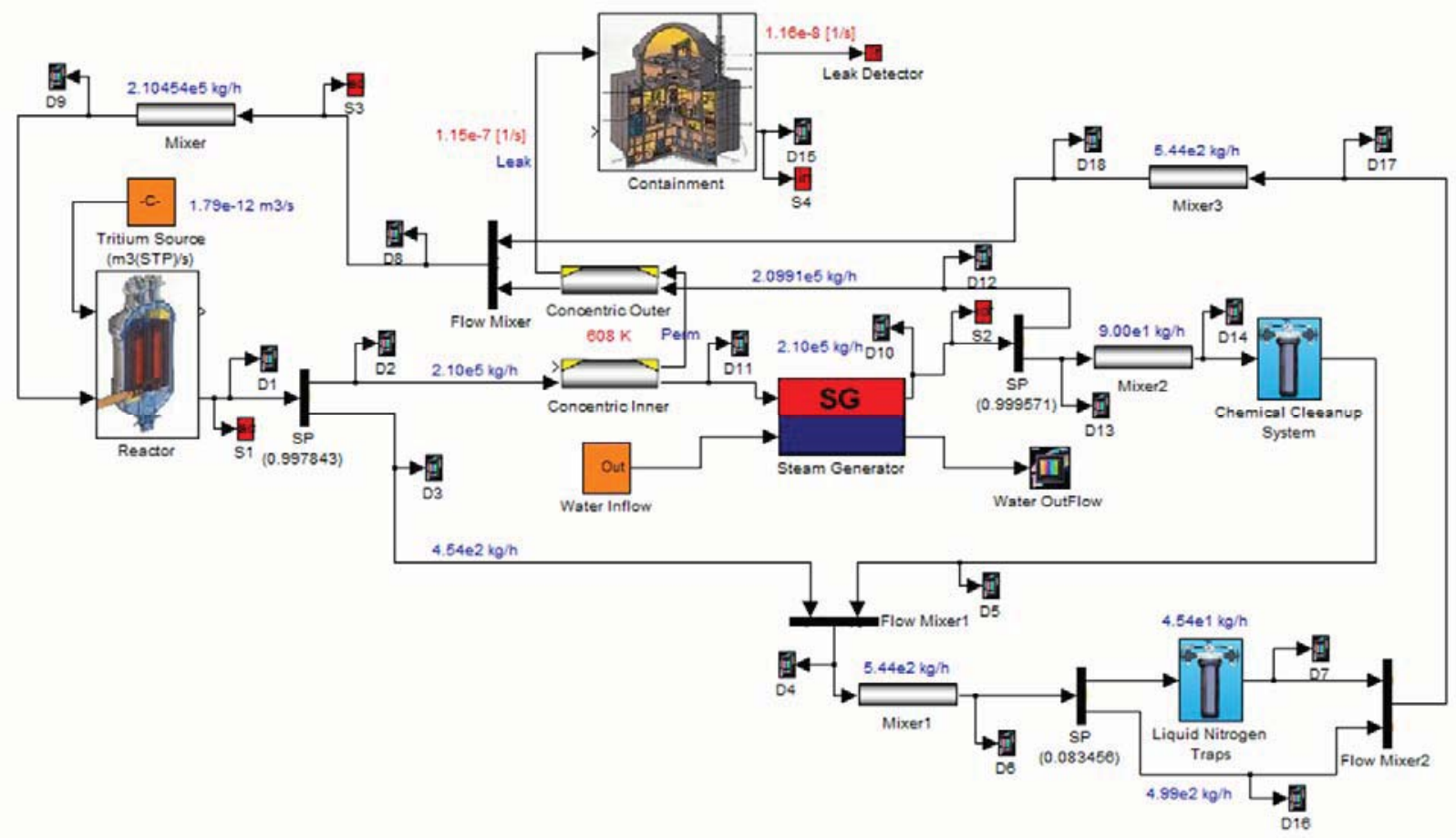

Figure 5-12. TPAC modeling for Peach Bottom reactor.

Table 5-13. Component sizes of the modeling (INL tritium code) for the Peach Bottom reactor.

\begin{tabular}{lc} 
& Volume \\
& {$\left[\mathrm{m}^{3}\right]$} \\
\hline Reactor & 10.5 \\
Concentric Inner & 10.5 \\
Concentric Outer & 10.5 \\
S/G & 158.2 \\
Mixer & 5.3 \\
Mixer 1 & 10.5 \\
Mixer 2 & 21.2 \\
Mixer 3 & 5.3 \\
Total System & 232.0 \\
\hline
\end{tabular}


The tritium birth rate of the core was determined between $310 \mathrm{Ci}\left(1.15 \times 10^{13} \mathrm{~Bq}\right)$ as a minimum and $1,203 \mathrm{Ci}\left(4.45 \times 10^{13} \mathrm{~Bq}\right)$ as a maximum for 1,550 days of Core 2 operation. The tritium birth rate, $310 \mathrm{Ci}$ is the leakage to the fission product trapping system via the fuel element purge flow, and the value of $1,203 \mathrm{Ci}$ is the maximum available release rate of tritium from the core. The tritium birth rate was assumed to be constant during the operating time.

The steam generator was modeled to be a single loop by merging two steam generators into one. The steam generator model consisted of three components: super heater, evaporator, and economizer. Each component was modeled by five nodes. Figure 5-13 shows the submodel of the steam generator. The metal temperatures of the steam generator were determined based on the reactor operating conditions (see Table 5-14). The parameters for the permeation models were chosen from the Equations (5-26), (5-27), and (5-28).

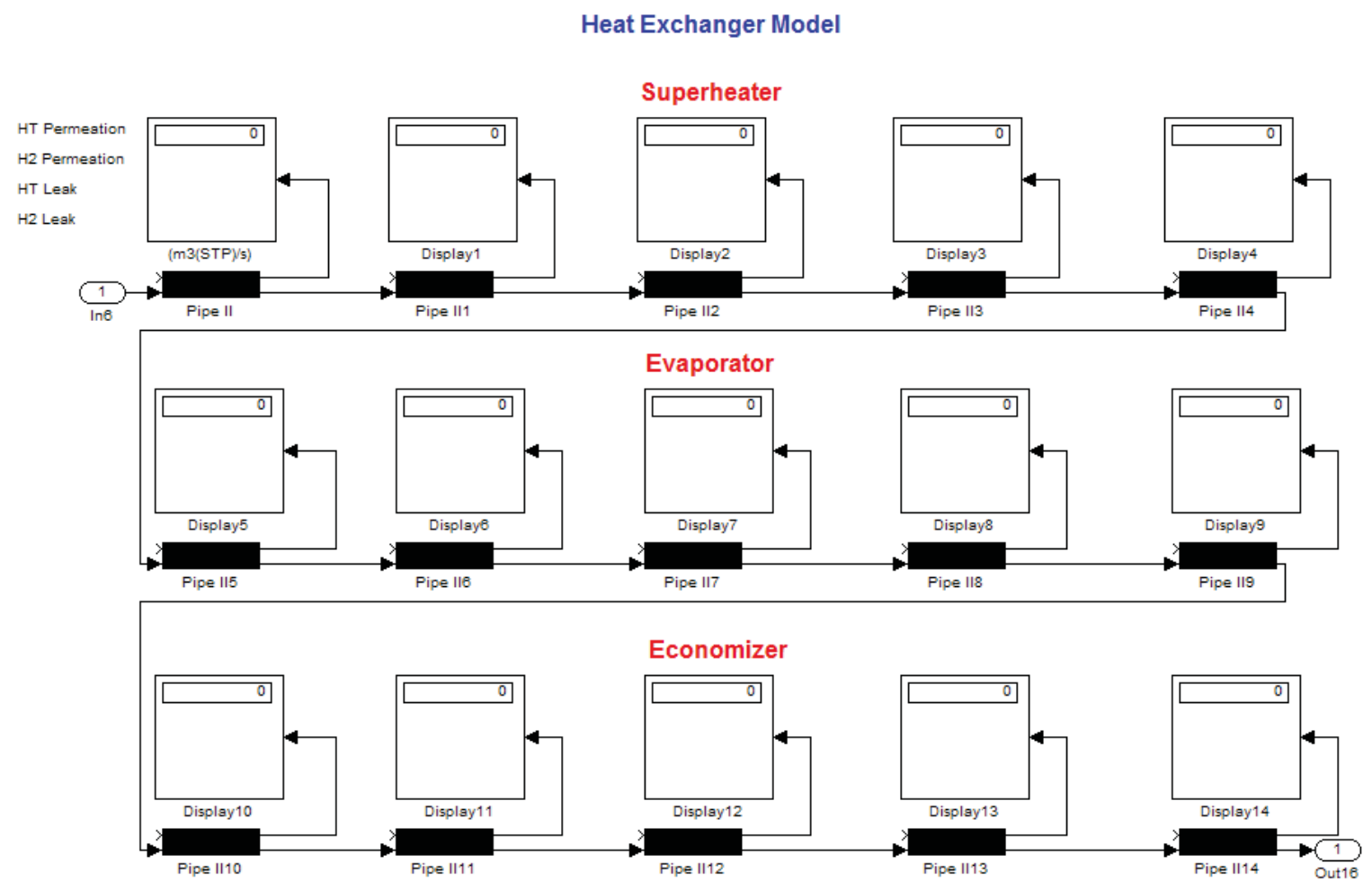

Figure 5-13. Steam generator submodel of the INL tritium code for Peach Bottom reactor.

Table 5-14. Dimensions of the steam generator for the Peach Bottom reactor (Ohashi and Sherman 2007). Metal Temperature

$(\mathrm{K})$

\begin{tabular}{lccccc}
\multicolumn{1}{c}{ Section } & $\begin{array}{c}\text { Surface Area } \\
\left(\mathrm{m}^{2}\right)\end{array}$ & $\begin{array}{c}\text { Outer Radius } \\
(\mathrm{m})\end{array}$ & $\begin{array}{c}\text { Inner Radius } \\
(\mathrm{m})\end{array}$ & $\begin{array}{c}\text { Helium Side } \\
\text { Outlet }\end{array}$ & $\begin{array}{c}\text { Helium Side } \\
\text { Inlet }\end{array}$ \\
\hline Economizer & 212 & $6.350 \times 10-3$ & $4.775 \times 10-3$ & 513 & 593 \\
Evaporator & 474 & $9.525 \times 10-3$ & $7.305 \times 10-3$ & 593 & 618 \\
Super-heater & 275 & $9.525 \times 10-3$ & $6.350 \times 10-3$ & 693 & 853 \\
\multicolumn{2}{l}{} & & & & \\
\multicolumn{2}{l}{ a. For two steam generators. } & & & & \\
\hline
\end{tabular}


The concentric pipe has been modeled by two pipe components of the TPAC. To model the permeation through the concentric pipe walls, the inner pipe permeation-out port was linked to the outer pipe permeation-in port. Table 5-15 shows the dimensions of the concentric pipes. The pipe wall temperature was assumed to be $616 \mathrm{~K}$, and the materials were assumed to be carbon-silicon steel, A-212 (General Atomics 1978).

Table 5-15. Characteristics of the concentric duct for the Peach Bottom reactor (Ohashi and Sherman 2007).

\begin{tabular}{|c|c|}
\hline Parameter & Value \\
\hline Length (m) & $7.65 \mathrm{a}$ \\
\hline Outer diameter of inner pipe (m) & 0.8064 \\
\hline Inner diameter of inner pipe (m) & $0.7430 \mathrm{~b}$ \\
\hline
\end{tabular}

The two purification systems considered in the modeling were nitrogen trap and chemical cleanup system. The efficiencies for the systems were assumed to be $100 \%$ (Wichner and Dyer 1979). The mass flow-rates for the nitrogen trap and chemical clean-up system were set as 45.4 and $90.7 \mathrm{~kg} / \mathrm{h}$, respectively. The leakage was modeled at the outer pipe of the concentric pipe, so all the tritium was assumed to be leaked to the containment through the concentric pipe. The parameters used for the leakage model are determined based on the Table 5-11 in the previous section.

Tritium concentration in the primary coolant, based on the activity of $310 \mathrm{Ci}$ to the purge loop and $0 \mathrm{Ci}$ to the main flow channel (case of minimum release rate) was calculated by the TPAC to be $8.91 \times 10^{-12} \mathrm{~m}^{3} / \mathrm{m}^{3}$, which corresponds to $8.88 \times 10^{-5} \mu \mathrm{Ci} / \mathrm{cm}^{3}$ based on the average temperature and pressure of the primary coolant. As for the case based on the tritium activity of $310 \mathrm{Ci}$ to the purge flow and $893 \mathrm{Ci}$ to the main flow channel (case of maximum release rate), tritium concentration in the primary coolant was calculated to be $3.46 \times 10^{-11} \mathrm{~m}^{3} / \mathrm{m}^{3}\left(3.44 \times 10^{-4} \mu \mathrm{Ci} / \mathrm{cm}^{3}\right)$. The above results are all in good agreement with the THYTAN solutions, which considered two steam generator loops and two core regions. The reported THYTAN results are $8.16 \times 10^{-5} \mu \mathrm{Ci} / \mathrm{cm}^{3}$ for the minimum, and $3.38 \times 10^{-4} \mu$ $\mathrm{Ci} / \mathrm{cm}^{3}$ for the maximum based on the average temperature and pressure of the primary coolant.

Figure 5-14 compares the reported experimental results (Wichner and Dyer 1979), THYTAN results (Ohashi and Sherman 2007), and the TPAC. Reported experimental data on tritium in the primary coolant were obtained in 1974 by Wichner and Dyer (1979). Tritium activity in the primary coolant (main loop HT and HTO) fluctuated in a range from about $2 \times 10^{-6} \mu \mathrm{Ci} / \mathrm{cm}^{3}$ to about $3 \times 10^{-4} \mu \mathrm{Ci} / \mathrm{cm}^{3}$ during operation in 1974. Figure 5-14 shows that the computed solutions are in the range of the experimental data. However, the computed solutions are located at the higher ranges of experimental data. It can be concluded that the computed solution from the codes (THYTAN and TPAC) is slightly conservative; however, the codes could calculate tritium concentrations at the same level as the experimental results of the Peach Bottom reactor. The calculated TPAC solutions showed good agreement with the THYTAN results, even though they used different nodalizations. 


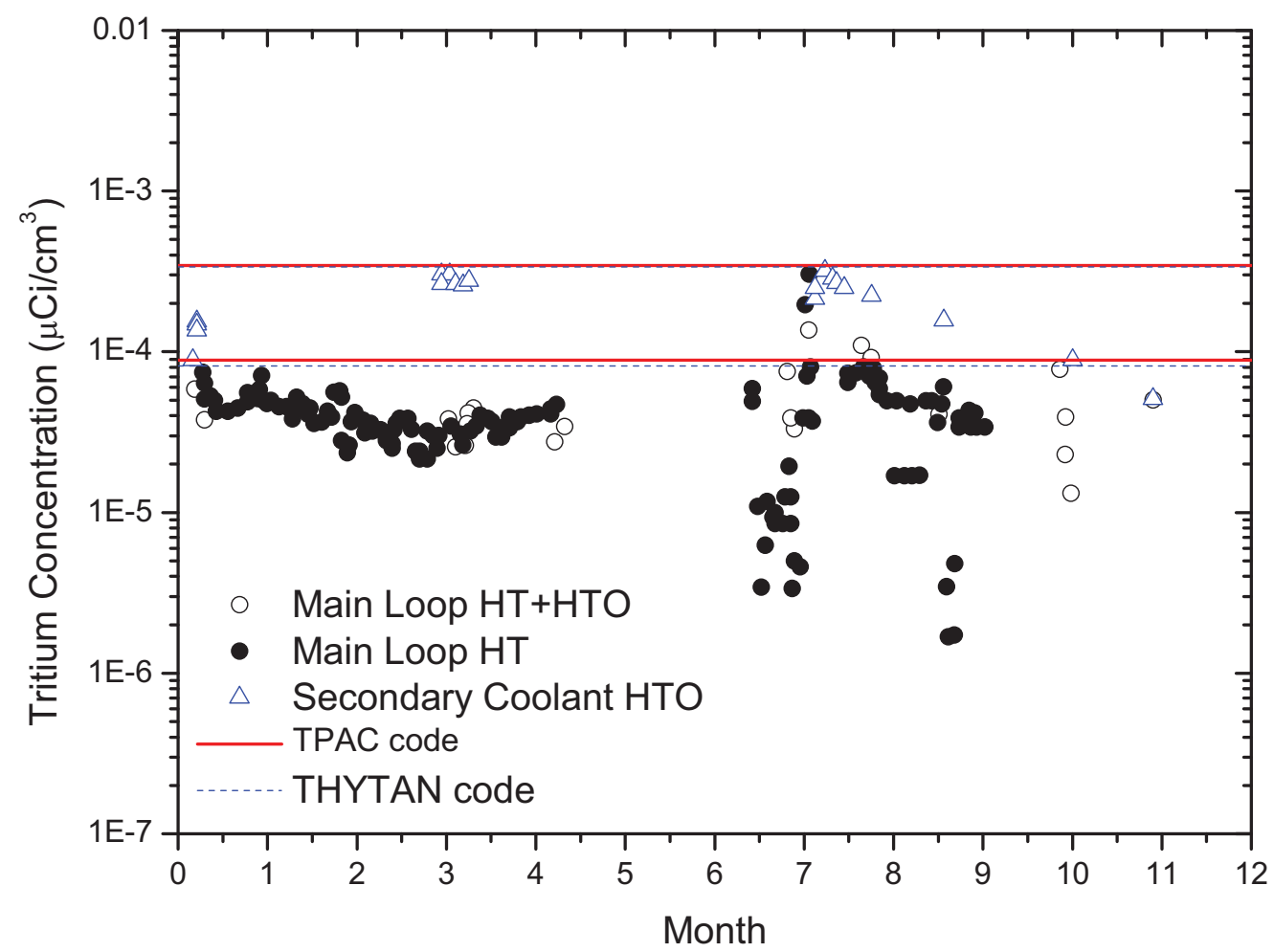

Figure 5-14. Comparisons of tritium concentration, in the Peach Bottom reactor, between observed concentration (Wichner and Dyer 1979) and the computed solutions. 


\section{ANALYSES ON TRITIUM BEHAVIORS IN VHTR/HTSE SYSTEM}

\subsection{Introduction}

In the VHTR hydrogen production system, tritium permeation from the core into the produced hydrogen is a significant issue because hydrogen isotopes can easily permeate through the high temperature heat exchanger tubes and contaminate product hydrogen. If the hydrogen produced in this system is used as a product, that tritium could potentially expose individuals or be released to the environment, depending on the application. Because of this potential, tritium contamination of hydrogen was considered in this study.

Figure 6-1 illustrates a schematic of the indirect parallel system configuration between a VHTR and a HTSE system, which has been proposed by Oh et al. (2007) from their system optimization studies. In this configuration, the flow in the secondary coolant system is divided, with most of the flow going towards the PCU and the remainder going through a secondary heat exchanger (SHX) that directs heat towards the HTSE plant. The flow through the hot side of the SHX is then mixed with the flow from the PCU to feed the cold side of the IHX. However, some of the flow is diverted away from the PCU, which acts to decrease the efficiency of the cycle. There are three coolant loops. The primary coolant system contains the nuclear reactor, the hot side of the IHX, and a compressor. The secondary coolant system contains the cold side of the IHX, the hot side of the SHX, the PCU, and connecting piping, which is assumed to be short. The intermediate heat transport loop connects the secondary coolant system to the HTSE plant through several PHXs.

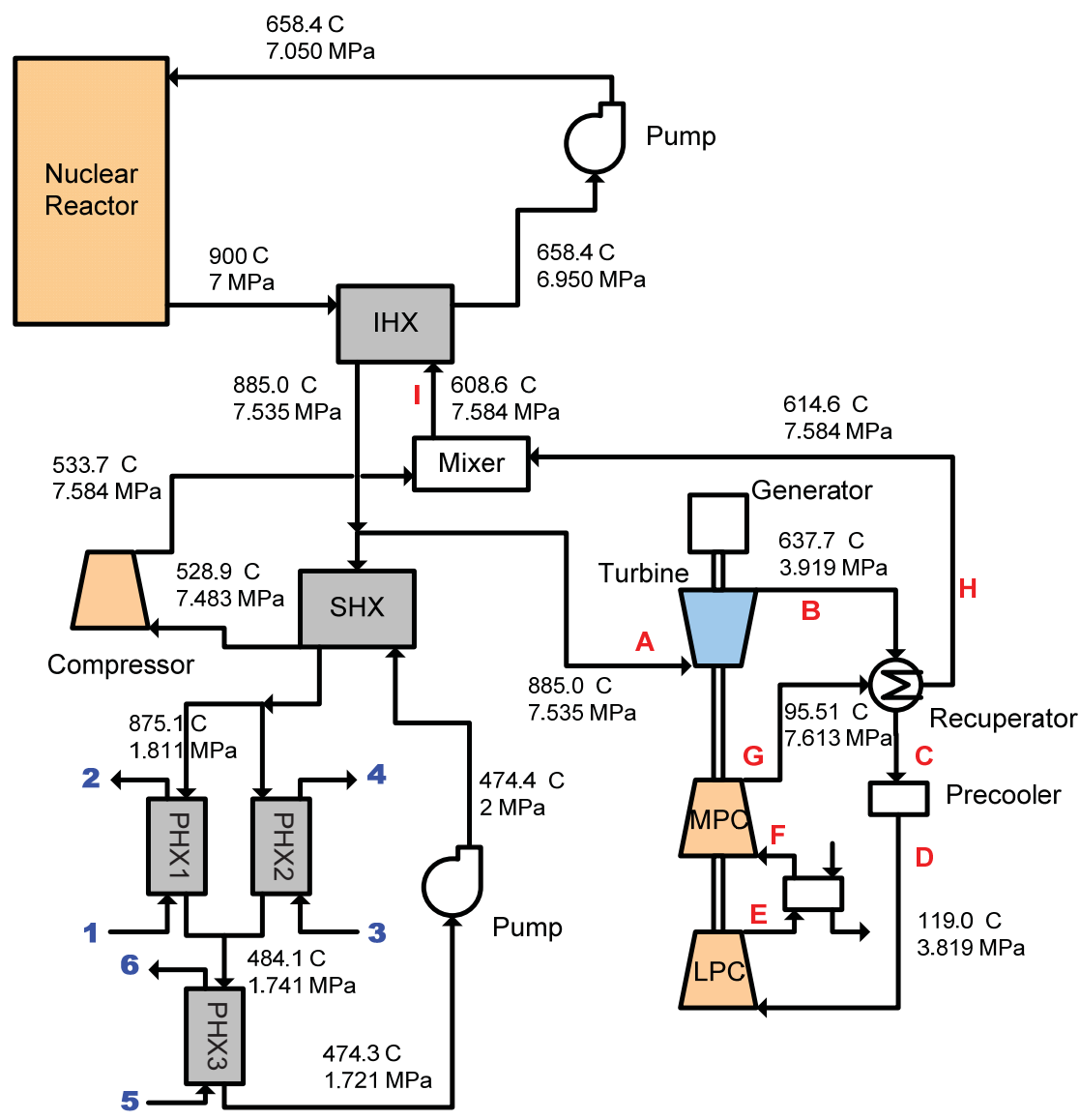

Figure 6-1. Indirect parallel configuration of VHTR/HTSE system (VHTR part). 
For electrolysis, the steam is heated to about $800^{\circ} \mathrm{C}$ by the heat from SHX. The heated steam is converted into hydrogen and oxygen in the electrolyzer and discharged through the fuel and oxidizer outlet, respectively as shown in Figure 6-2. The heat of the discharged gases is recovered through three recuperators. Finally, the product gas in the fuel side contains hydrogen and steam, and the oxidizer outlet gas contains oxygen and steam. As shown in Figure 6-2, the discharged fuel steam is recycled to the inlet fuel stream, and the hydrogen gas is separated and collected in the separator. In the oxidizer outlet stream, heat is first recuperated and then the stream is run through an expander to recover work. The oxygen and water components of the stream are then separated.

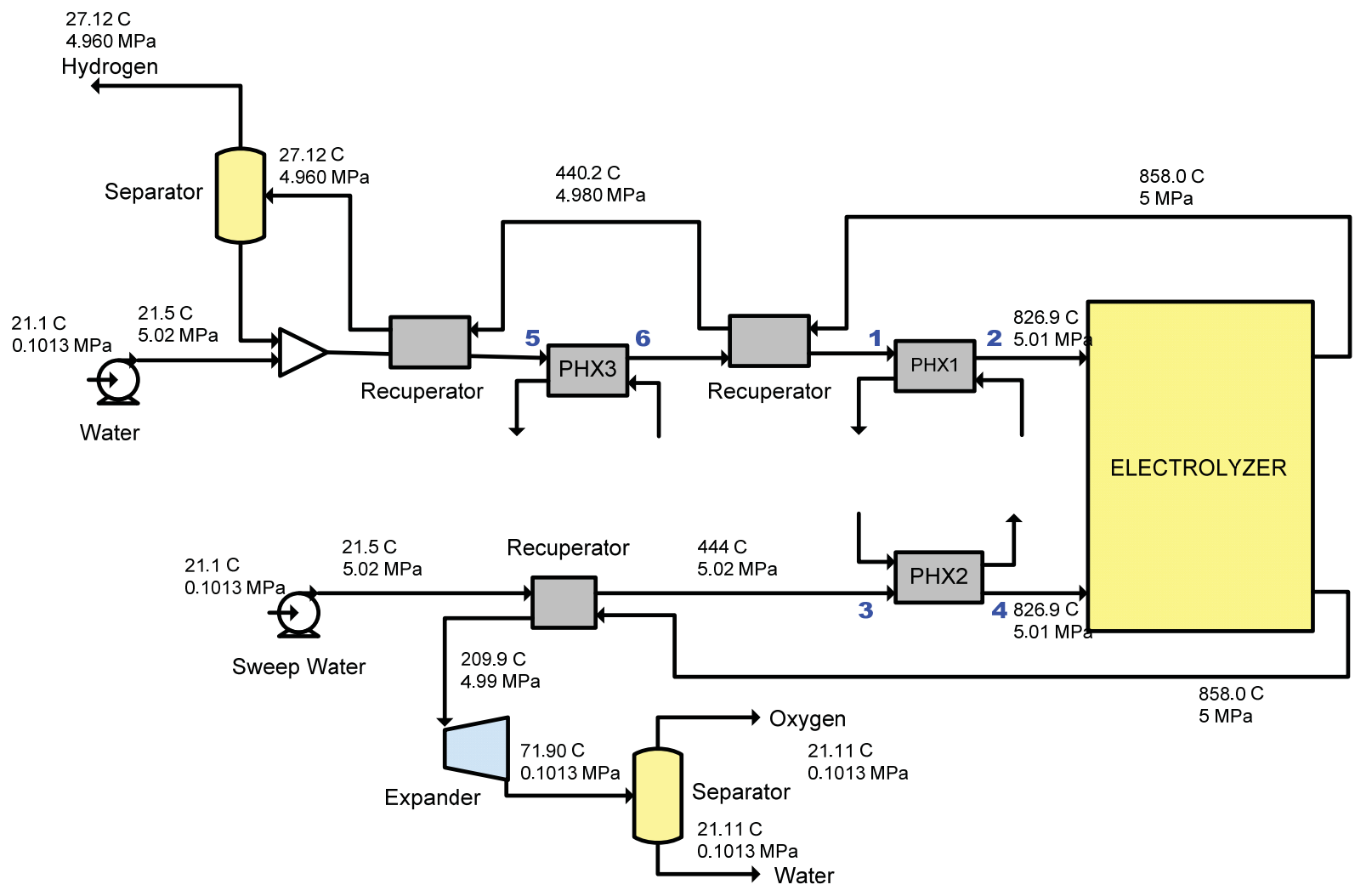

Figure 6-2. Indirect parallel configuration of VHTR/HTSE system (HTSE part).

\subsection{TPAC Modeling}

The VHTR/HTSE system described in Figure 6-1 and Figure 6-2 has been modeled by the TPAC. Figure 6-3 shows the TPAC model for this system. In this modeling, the system has been divided into five separate loops; (1) primary side, (2) secondary side (PCU), (3) intermediate heat transfer loop, (4) HTSE (water supplier), and (5) HTSE (purge flow). The primary side model is composed of the five component blocks:

- Reactor

- Hot-leg

- Cold-leg

- IHX

- Purification system (modeled by a TPAC reactor component block) (modeled by a TPAC VHTR pipe component block) (modeled by a TPAC VHTR pipe component block) (modeled by a TPAC heat exchanger block) (modeled by a TPAC purification system component block) 
The secondary side (PCU) was modeled by the following seven component blocks:

- $\mathrm{PCU}$

- Bypass

- IHX

- SHX

- Flow Splitter

- Flow Mixer

- Purification system1 (modeled by a TPAC VHTR pipe component block)

(modeled by a TPAC VHTR pipe component block)

(modeled by a TPAC heat exchanger block)

(modeled by a TPAC heat exchanger block)

(modeled by a TPAC flow splitter component block)

(modeled by a TPAC flow mixer component block)

(modeled by a TPAC purification system component block)

The intermediate heat transfer loop was modeled by the following eight component blocks:

- IHTL

- SHX1

- PHX-mod

- $\quad$ PHX-mod1

- $\quad$ PHX-mod3

- Flow Splitter 1

- Flow Mixer1

- Purification system2 (modeled by a TPAC VHTR pipe component block)

(modeled by a TPAC heat exchanger block)

(modeled by a modified TPAC heat exchanger block)

(modeled by a modified TPAC heat exchanger block)

(modeled by a modified TPAC heat exchanger block)

(modeled by a TPAC flow splitter component block)

(modeled by a TPAC flow mixer component block)

(modeled by a TPAC purification system component block)

The HTSE system has been simplified from the original system shown in Figure 6.2. In the TPAC model, recycling and recuperating cycles have been eliminated. This simplification is expected to be more conservative than the original configuration, providing more HT permeation from the PHXs. In the TPAC model, the HTSE (water supplier) consists of the following seven component blocks:

- $\mathrm{H}_{2} \mathrm{O}$ Flow

- Pipe-HTSE

- Pipe-HTSE1

- Pipe-HTSE2

- $\quad$ PHX-mod

- PHX-mod1

- Isotope Exchange

- Electrolyzer (modeled by a TPAC boundary component block)

(modeled by a TPAC HTSE pipe component block)

(modeled by a TPAC HTSE pipe component block)

(modeled by a TPAC HTSE pipe component block)

(modeled by a modified TPAC heat exchanger block)

(modeled by a modified TPAC heat exchanger block)

(modeled by a TPAC isotope exchange component block)

(modeled by a TPAC electrolyzer component block)

The HTSE (purge flow) was modeled by the following four component blocks:

- Purge Flow

- Pipe-HTSE3

- Electrolyzer

- $\quad$ PHX-mod3 (modeled by a TPAC boundary component block)

(modeled by a TPAC HTSE pipe component block)

(modeled by a TPAC electrolyzer component block)

(modeled by a modified TPAC heat exchanger block) 


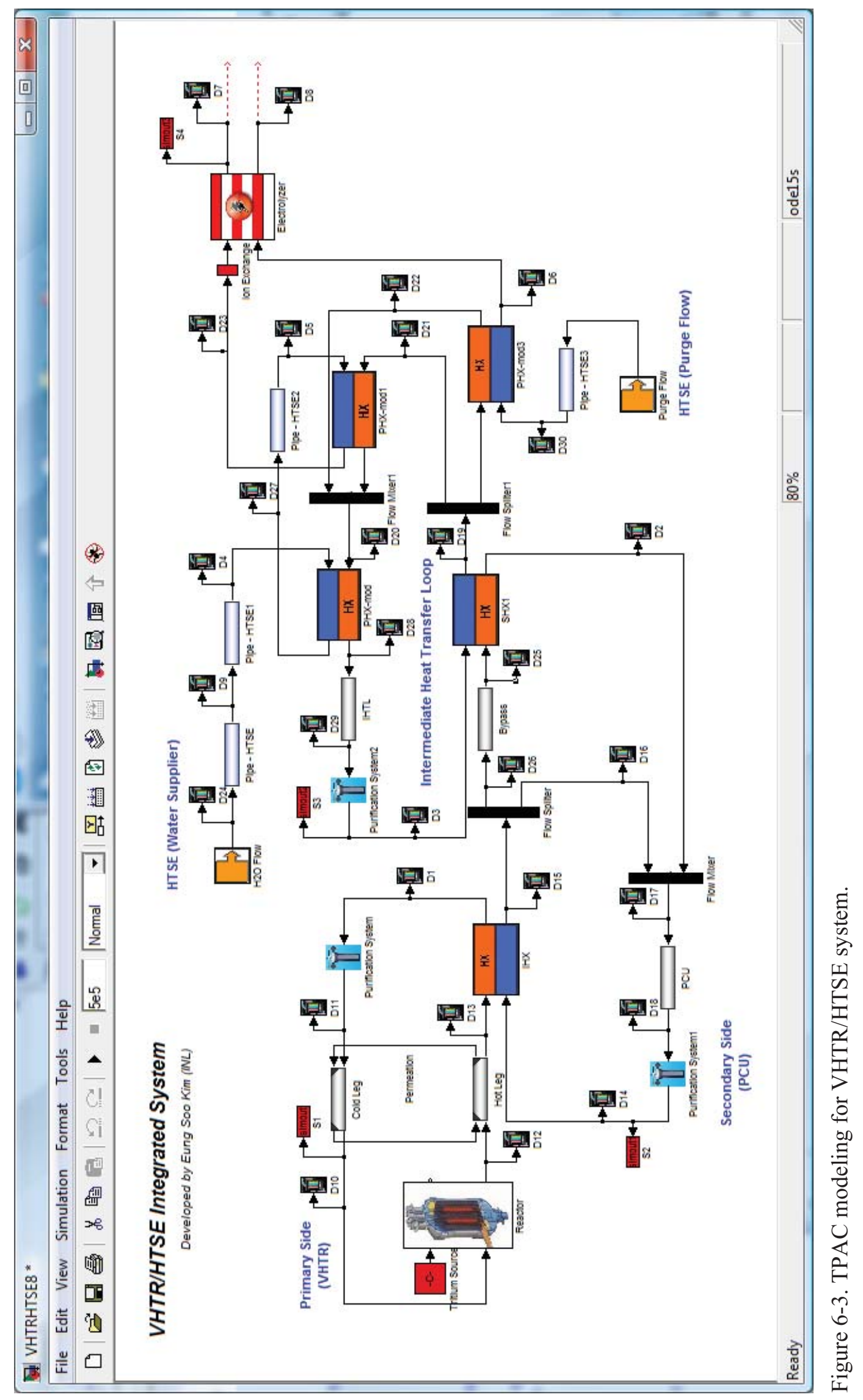




\subsubsection{Tritium Source}

Tritium sources in the reactor system are the most important, but quantitatively, very uncertain parameters in tritium modeling. The tritium sources are significantly affected by impurities $\left({ }^{6} \mathrm{Li},{ }^{7} \mathrm{Li}{ }^{10} \mathrm{~B}\right.$, $\left.{ }^{3} \mathrm{He} . ..\right)$, neutron flux, reactor power, adsorption, etc. In this modeling, these parameters have been determined based on the previous HTGR experience. The reported calculation results on tritium birth rates are well summarized by Ohashi and Sherman (2007) for various reactors: Peach Bottom (USA), Fort St. Vrain (USA), PNP-500 MWth (Germany), and England 1,500 MWth HTGR (UK). Tables 6-1 and 6-2 summarize the computed results. According to these data, the tritium birth rate per unit power (MWth) ranges from $2.14 \times 10^{11}$ to $4.28 \times 10^{11} \mathrm{~Bq} / \mathrm{y} / \mathrm{MWth}$.

Table 6-1. Calculation results for the tritium birth rate in the high-temperature gas-cooled reactor (Ohashi and Sherman 2007).

\begin{tabular}{|c|c|c|c|c|c|c|c|c|}
\hline \multicolumn{2}{|c|}{ Country } & \multicolumn{4}{|c|}{ United States } & \multicolumn{2}{|c|}{ Germany } & England \\
\hline \multicolumn{2}{|c|}{ Reactor Type } & \multicolumn{3}{|c|}{ Fort St. Vrain ${ }^{\mathrm{b}}$} & $\begin{array}{c}\text { 3,000 MWth } \\
\text { HTGR }\end{array}$ & \multicolumn{2}{|c|}{ PNP-500 MWt-plant ${ }^{\mathrm{b}}$} & $\begin{array}{c}\text { 1,500 MWth } \\
\text { HTGR }\end{array}$ \\
\hline \multicolumn{2}{|c|}{$\begin{array}{l}\text { Reactor power } \\
\text { (MWth) }\end{array}$} & $66.5^{\mathrm{c}}$ & \multicolumn{2}{|c|}{$842^{\mathrm{d}}$} & 3,000 & \multicolumn{2}{|l|}{500} & 1,500 \\
\hline \multicolumn{2}{|l|}{ Period } & 1,550 & First year & ear & First & First year & Equili & $\begin{array}{l}\text { After } 5 \text { or } 6 \\
\text { years }\end{array}$ \\
\hline \multicolumn{2}{|c|}{ Service factor $(\%)$} & 100 & 80 & & 80 & 100 & 100 & 90 \\
\hline \multirow[t]{5}{*}{$\begin{array}{l}\text { Annual birth } \\
\text { rate }(\mathrm{Bq} / \mathrm{y})\end{array}$} & Fission & $\begin{array}{l}1.05 \times 1013 \\
(54.7)\end{array}$ & $\begin{array}{l}1.15 \times 1014 \\
(55.3)\end{array}$ & $\begin{array}{l}1.01 \times 1014 \\
(69.8)\end{array}$ & $\begin{array}{l}4.07 \times 1014 \\
(59.7)\end{array}$ & $\begin{array}{l}8.88 \times 1013 \\
(46.3)\end{array}$ & $\begin{array}{l}1.18 \times 1014 \\
(84.0)\end{array}$ & $\begin{array}{l}3.68 \times 1014 \\
(63.4)\end{array}$ \\
\hline & $6 \mathrm{Li}$ & $\begin{array}{l}5.58 \times 1011 \\
(2.9)\end{array}$ & $\begin{array}{l}5.33 \times 1013 \\
(25.6)\end{array}$ & $\begin{array}{l}1.78 \times 1013 \\
(12.3)\end{array}$ & $\begin{array}{l}1.04 \times 1014 \\
(15.3)\end{array}$ & $\begin{array}{l}3.85 \times 1013 \\
(20.1)\end{array}$ & $\begin{array}{l}5.55 \times 1012 \\
(3.9)\end{array}$ & $\begin{array}{l}4.40 \times 1013 \\
(7.6)\end{array}$ \\
\hline & $3 \mathrm{He}$ & $\begin{array}{l}5.43 \times 1011 \\
(39.6)\end{array}$ & $\begin{array}{l}2.37 \times 1013 \\
(11.4)\end{array}$ & $\begin{array}{l}1.37 \times 1013 \\
(9.5)\end{array}$ & $\begin{array}{l}1.36 \times 1014 \\
(20.0)\end{array}$ & $\begin{array}{l}5.48 \times 1013 \\
(28.6)\end{array}$ & $\begin{array}{l}7.40 \times 1013 \\
(5.2)\end{array}$ & $\begin{array}{l}1.68 \times 1014 \\
(29.1)\end{array}$ \\
\hline & $10 \mathrm{~B}$ & $\begin{array}{l}7.63 \times 1012 \\
(2.8)\end{array}$ & $\begin{array}{l}1.61 \times 1013 \\
(7.7)\end{array}$ & $\begin{array}{l}1.22 \times 1013 \\
(8.4)\end{array}$ & $\begin{array}{l}3.40 \times 1013 \\
(5.0)\end{array}$ & $\begin{array}{l}9.62 \times 1012 \\
(5.0)\end{array}$ & $\begin{array}{l}9.62 \times 1012 \\
(6.8)\end{array}$ & $-^{\mathrm{e}}$ \\
\hline & Total & $1.93 \times 1013$ & $2.09 \times 1014$ & $1.44 \times 1014$ & $6.81 \times 1014$ & $1.92 \times 1014$ & $1.41 \times 1014$ & $5.80 \times 1014$ \\
\hline \multirow{5}{*}{$\begin{array}{l}\text { Annual birth } \\
\text { rate per } \\
\text { thermal } \\
\text { megawatt } \\
(\mathrm{Bq} / \mathrm{y} / \mathrm{MWth})\end{array}$} & Fission & $1.59 \times 1011$ & $1.71 \times 1011$ & $1.50 \times 1011$ & $1.70 \times 1011$ & $1.78 \times 1011$ & $2.37 \times 1011$ & $2.71 \times 1011$ \\
\hline & $6 \mathrm{Li}$ & $8.39 \times 109$ & $7.92 \times 1010$ & $2.64 \times 1010$ & $4.34 \times 1010$ & $7.70 \times 1010$ & $1.11 \times 1010$ & $3.24 \times 1010$ \\
\hline & $3 \mathrm{He}$ & $8.16 \times 109$ & $3.52 \times 1010$ & $2.03 \times 1010$ & $5.67 \times 1010$ & $1.10 \times 1011$ & $1.48 \times 1010$ & $1.24 \times 1011$ \\
\hline & 10B & $2.54 \times 109$ & $2.39 \times 1010$ & $1.81 \times 1010$ & $1.42 \times 1010$ & $1.92 \times 1010$ & $1.92 \times 1010$ & $-{ }^{e}$ \\
\hline & Total & $2.90 \times 1011$ & $3.10 \times 1011$ & $2.14 \times 1011$ & $2.84 \times 1011$ & $3.83 \times 1011$ & $2.82 \times 1011$ & $4.28 \times 1011$ \\
\hline
\end{tabular}

The value in parentheses is the percentage

a. annual birth rate calculated from the tritium inventory at the end of each period

b. annual birth rate calculated from the reported value of the birth rate per day (Ci./d) assuming $100 \%$ service factor

c. average power based on rated power of $115 \mathrm{MWth}$ and equivalent full-power days of 897 days during 1,550 days

d. based on calculation condition in the reference, whereas the rated power of the Fort St. Vrain is 760 MWth

e. not estimated

f. at service factor of $100 \%$.

HTGR $=$ high-temperature gas-cooled reactor 
Table 6-2. Additional calculation results for the tritium birth rate in the high-temperature gas-cooled reactor (Ohashi and Sherman 2007).

\begin{tabular}{|c|c|c|c|c|c|}
\hline Reactor Type & Peach Bottom & Fort St. Vrain & $\begin{array}{c}\text { 3,000 MWth } \\
\text { HTGR }\end{array}$ & Germany & $\begin{array}{c}\text { England } \\
\text { 1,500 MWth } \\
\text { HTGR }\end{array}$ \\
\hline Fission yield $\left(\mathrm{n} / \mathrm{cm}^{2} / \mathrm{s}\right)$ & $1.00 \times 10^{-4}$ & $1.00 \times 10^{-4}$ & $1.00 \times 10^{-4}$ & $1.30 \times 10^{-4}$ & $1.55 \times 10^{-4}$ \\
\hline Li content in graphite (ppb) & 7 & 50 & 50 & 10 & 60 \\
\hline${ }^{3} \mathrm{He}$ content in makeup helium (ppm) & 0.16 & 0.2 & 0.2 & 0.137 & 0.3 \\
\hline Primary helium inventory (kg) & 269 & 2,801 & - & - & 4,500 \\
\hline Helium inventory ratio in core $(\%)$ & 3.25 & 4 to 6 & 6 & - & 20 \\
\hline Helium leak rate (1/d) & $9.95 \times 10^{-3 \mathrm{a}}$ & $2.74 \times 10^{-5}$ & - & $1 \times 10^{-4}$ & $2.0 \times 10^{-3}$ \\
\hline Thermal neutron flux $\left(\mathrm{n} / \mathrm{cm}^{2} / \mathrm{s}\right)$ & $2.28 \times 10^{13}$ & $6.00 \times 10^{13}$ & $1 \times 10^{-14}$ & - & $2.8 \times 10^{13}$ \\
\hline Fast neutron flux $\left(\mathrm{n} / \mathrm{cm}^{2} / \mathrm{s}\right)$ & $2.26 \times 10^{13}$ & $3.60 \times 10^{13}$ & - & - & - \\
\hline Cross section for ${ }^{6} \mathrm{Li}(\mathrm{n}, \alpha)^{3} \mathrm{H}\left(\mathrm{cm}^{2}\right)$ & $4.08 \times 10^{-22}$ & $4.08 \times 10^{-22}$ & $4.63 \times 10^{-22}$ & - & $9.30 \times 10^{-22}$ \\
\hline Cross section for ${ }^{3} \mathrm{He}(\mathrm{n}, \mathrm{p})^{3} \mathrm{H}\left(\mathrm{cm}^{2}\right)$ & $2.28 \times 10^{-21}$ & $2.28 \times 10^{-21}$ & $2.80 \times 10^{-21}$ & - & $5.40 \times 10^{-21}$ \\
\hline Cross section for ${ }^{10} \mathrm{~B}(\mathrm{n}, \alpha)^{7} \mathrm{Li}\left(\mathrm{cm}^{2}\right)$ & $1.63 \times 10^{-21}$ & $1.63 \times 10^{-21}$ & - & - & - \\
\hline Cross section for ${ }^{7} \mathrm{Li}(\mathrm{n}, \mathrm{n} \alpha)^{3} \mathrm{H}\left(\mathrm{cm}^{2}\right)$ & $1.53 \times 10^{-25}$ & $7.2 \times 10^{-27}$ & - & - & - \\
\hline Cross section for ${ }^{10} \mathrm{~B}(\mathrm{n}, 2 \alpha)^{3} \mathrm{H}\left(\mathrm{cm}^{2}\right)$ & $5.0 \times 10^{-26}$ & $1.4 \times 10^{-26}$ & - & - & - \\
\hline Reference & $\begin{array}{l}\text { Wichner and } \\
\text { Dyer } 1979\end{array}$ & $\begin{array}{l}\text { Compare, } \\
\text { Freid, and } \\
\text { Nestor } 1974\end{array}$ & Gainey 1976 & $\begin{array}{l}\text { Steinwarz, } \\
\text { Rohrig, and } \\
\text { Nieder } 198\end{array}$ & Forsyth 1974 \\
\hline
\end{tabular}

a. Based on leak rate of $3.2 \mathrm{~kg} / \mathrm{d}$ and primary helium inventory of $232 \mathrm{~m} 3$ (average temperature of $809 \mathrm{~K}$ and pressure of $23 \mathrm{~atm}$ ). HTGR $=$ high-temperature gas-cooled reactor

In our modeling, the tritium birth rate, $4.28 \times 10^{11} \mathrm{~Bq} / \mathrm{y} / \mathrm{MWth}$, was selected in a conservative manner. The tritium release rate was determined based on the previous investigation of the tritium inventory in the core components of the Peach Bottom HTGR performed by Wichner and Dyer (1979). According to their studies, the overall release fraction to the primary coolant is estimated to be 0.32 during 3 years of operation (Burnette and Baldwin 1980). In our modeling, this number ( 0.32) was assumed as the base fraction of tritium release rate. However, since the tritium retention and release mechanisms are still not well understood, the assumed tritium release ratio is basically considered to have large uncertainties. The effect of the tritium release uncertainty on the tritium behaviors in the system will be investigated later by some parametric studies. Based on the above, the tritium source (release rate) in our model was finally determined as $8.28 \times 10^{13} \mathrm{~Bq} / \mathrm{y}\left(=5.49 \times 10^{-11} \mathrm{~m}^{3}\right.$ (STP)/s $)$ for $600 \mathrm{MWth}$ reactor power. This number was implemented to the 'Tritium Source' block attached to the 'Reactor block' shown in Figure 6-3.

\subsubsection{Component Inputs}

This section summarizes input parameters of the component blocks used in the TPAC modeling.

\subsubsection{Component Input Summary in Primary Side}

This section summarizes input parameters of the component blocks that consist of the primary side. The parameters related to the system operating conditions (temperature, pressure, and flow rates) are taken from the flow sheet shown in Figure 6-1. The geometrical information (volume, wall thickness, etc.) has been estimated based on the GTMHR preconceptual designs and many assumptions. However, the geometrical parameters basically do not affect the calculation results assuming the steady-state 
conditions. However, the TPAC has been originally developed for dynamic simulations, so it is also capable of flexible dynamic simulations.

Tables 6-3 through 6-8 summarize the input parameters implemented in the primary loop model. The tritium release rate is set to be $5.49 \times 10^{-11} \mathrm{~m}^{3}(\mathrm{STP}) / \mathrm{s}$ in the 'Tritium Birth' block as already mentioned in the previous section. Initial $\mathrm{HT}$ and $\mathrm{H}_{2} \mathrm{O}$ concentrations in the components were assumed to be $1.0 \times 10^{-20}$ and $1.0 \times 10^{-5}$ in mole fraction, respectively. Since the current simulation is under steady state conditions, the initial concentrations in the components do not affect the final results. Helium leakage was considered in the 'Reactor' block. Fractional helium leak rate was assumed to be $1.15 \times 10^{-7}$, which is the same as that reported for Peach Bottom reactor in Section 5. The IHX design parameters (surface area, wall thickness, etc.) are based on the PCHE design reported by Oh and Kim (2008). The permeation parameters (activation energy, and pre-exponential factor) were based on the Incoloy 800 material data reported by Richards et al. (2006). Permeation of $\mathrm{H}_{2}$ was not considered in the current simulation. Therefore, the pre-exponential factor for $\mathrm{H}_{2}$ permeation was set to be 0.0 . The purification rate was determined to be $16 \% / \mathrm{h}$, which is the average rate between Peach Bottom HTGR $(20 \% / \mathrm{h})$ and Fort St. Vrain $(12 \% / \mathrm{h})$. Purification efficiency for HT was assumed to be $95 \%$ conservatively. The details of the input parameters can be referred to Tables 6-3 through 6-8.

Table 6-3. TPAC input parameters in the primary side (Tritium Birth Block).

\section{Tritium Birth}

\begin{tabular}{|c|l|l|}
\hline \multicolumn{1}{|c|}{ Parameter } & \multicolumn{1}{|c|}{ Unit } & \multicolumn{1}{c|}{ Value } \\
\hline Tritium Release Rate & $\mathrm{Bq} / \mathrm{y}$ & $8.28 \mathrm{E}+13$ \\
\hline & $\mathrm{m}^{3}(\mathrm{STP}) / \mathrm{s}$ & $5.49 \mathrm{E}-11$ \\
\hline
\end{tabular}

Table 6-4. TPAC input parameters in the primary side (Reactor Block).

\begin{tabular}{|c|c|c|}
\hline Parameter & Unit & Value \\
\hline Volume & $\mathrm{m}^{3}$ & 197 \\
\hline Temperature & $\mathrm{K}$ & $1.05 \mathrm{E}+03$ \\
\hline Pressure & $\mathrm{Pa}$ & $7.00 \mathrm{E}+06$ \\
\hline Flow Rate & $\mathrm{m}^{3}(\mathrm{STP}) / \mathrm{s}$ & 2,155 \\
\hline $\mathrm{C}_{\mathrm{HT}}$ Initial & $\mathrm{mf}$ & $1.00 \mathrm{E}-20$ \\
\hline $\mathrm{C}_{\mathrm{H} 2}$ Initial & $\mathrm{mf}$ & $1.00 \mathrm{E}-05$ \\
\hline Leakage & \# & YES \\
\hline Total Inventory in Loop & $\mathrm{m}^{3}(\mathrm{STP})$ & 4,772 \\
\hline Fractional Helium Leak Rate & $1 / \mathrm{s}$ & $1.15 \mathrm{E}-7$ \\
\hline $\begin{array}{l}\text { Sum of Inventory with Helium } \\
\text { Leak }\end{array}$ & $\mathrm{m}^{3}(\mathrm{STP})$ & 4,772 \\
\hline Permeation & $\#$ & $\mathrm{NO}$ \\
\hline
\end{tabular}


Table 6-5. TPAC input parameters in the primary side (Hot Leg Block).

\begin{tabular}{|l|l|l|}
\hline \multicolumn{1}{|c|}{ Pot Leg Unit } & \multicolumn{1}{c|}{ Value } \\
\hline Volume & \multicolumn{1}{c|}{$\mathrm{m}^{3}$} & 12 \\
\hline Temperature & $\mathrm{K}$ & $1.17 \mathrm{E}+03$ \\
\hline Pressure & $\mathrm{Pa}$ & $7.00 \mathrm{E}+06$ \\
\hline Flow Rate & $\mathrm{m}^{3}(\mathrm{STP}) / \mathrm{s}$ & 2155 \\
\hline $\mathrm{C}_{\mathrm{HT}}$ Initial & $\mathrm{mf}$ & $1.00 \mathrm{E}-20$ \\
\hline $\mathrm{C}_{\mathrm{H} 2}$ Initial & $\mathrm{mf}$ & $1.00 \mathrm{E}-05$ \\
\hline Leakage & $\#$ & $\mathrm{NO}$ \\
\hline Permeation & $\#$ & $\mathrm{NO}$ \\
\hline
\end{tabular}

Table 6-6. TPAC input parameters in the primary side (Cold Leg Block).

\section{Cold Leg}

\begin{tabular}{|l|l|l|}
\hline \multicolumn{1}{|c|}{ Parameter } & \multicolumn{1}{c|}{ Unit } & \multicolumn{1}{c|}{ Value } \\
\hline Volume & $\mathrm{m}^{3}$ & 19 \\
\hline Temperature & $\mathrm{K}$ & $9.31 \mathrm{E}+02$ \\
\hline Pressure & $\mathrm{Pa}$ & $7.00 \mathrm{E}+06$ \\
\hline Flow Rate & $\mathrm{m}^{3}(\mathrm{STP}) / \mathrm{s}$ & 2,155 \\
\hline $\mathrm{C}_{\mathrm{HT}}$ Initial & $\mathrm{mf}$ & $1.00 \mathrm{E}-20$ \\
\hline $\mathrm{C}_{\mathrm{H} 2}$ Initial & $\mathrm{mf}$ & $1.00 \mathrm{E}-05$ \\
\hline Leakage & $\#$ & $\mathrm{NO}$ \\
\hline Permeation & $\#$ & $\mathrm{NO}$ \\
\hline
\end{tabular}


Table 6-7. TPAC input parameters in the primary side (IHX Block).

\begin{tabular}{|c|c|c|c|}
\hline Parameter & Unit & Value & \\
\hline Volume & $\mathrm{m}^{3}$ & 13 & \multirow{8}{*}{ Channel 1} \\
\hline Temperature & $\mathrm{K}$ & $1.05 \mathrm{E}+03$ & \\
\hline Pressure & $\mathrm{Pa}$ & $7.00 \mathrm{E}+06$ & \\
\hline Flow Rate & $\mathrm{m}^{3}(\mathrm{STP}) / \mathrm{s}$ & 2,155 & \\
\hline $\mathrm{C}_{\mathrm{HT}}$ Initial & $\mathrm{mf}$ & $1.00 \mathrm{E}-20$ & \\
\hline $\mathrm{C}_{\mathrm{H} 2}$ Initial & $\mathrm{mf}$ & $1.00 \mathrm{E}-05$ & \\
\hline Leakage & $\#$ & NO & \\
\hline Permeation & \# & NO & \\
\hline Volume & $\mathrm{m}^{3}$ & 13 & \multirow{8}{*}{ Channel 2} \\
\hline Temperature & $\mathrm{K}$ & $1.05 \mathrm{E}+03$ & \\
\hline Pressure & $\mathrm{Pa}$ & $7.00 \mathrm{E}+06$ & \\
\hline Flow Rate & $\mathrm{m}^{3}(\mathrm{STP}) / \mathrm{s}$ & 2,155 & \\
\hline $\mathrm{C}_{\mathrm{HT}}$ Initial & $\mathrm{mf}$ & $1.00 \mathrm{E}-20$ & \\
\hline $\mathrm{C}_{\mathrm{H} 2}$ Initial & $\mathrm{mf}$ & $1.00 \mathrm{E}-05$ & \\
\hline Leakage & \# & NO & \\
\hline Permeation & $\#$ & NO & \\
\hline Heat Transfer Area & $\mathrm{m}^{2}$ & $1.35 \mathrm{E}+04$ & \multirow{7}{*}{ Channel Wall } \\
\hline Wall Thickness & $\mathrm{m}$ & 0.02 & \\
\hline HX Wall Temperature & $\mathrm{K}$ & $1.06 \mathrm{E}+03$ & \\
\hline Pre-exponential Factor (HT) & - & $1.36 \mathrm{E}-10$ & \\
\hline Pre-exponential Factor $\left(\mathrm{H}_{2}\right)$ & - & 0 & \\
\hline Activation Energy (HT) & $\mathrm{J} / \mathrm{mol} \mathrm{K}$ & $5.35 \mathrm{E}+04$ & \\
\hline Activation Energy $\left(\mathrm{H}_{2}\right)$ & $\mathrm{J} / \mathrm{mol} \mathrm{K}$ & NONE & \\
\hline
\end{tabular}

Table 6-8. TPAC input parameters in the primary side (Purification System Block).

\section{Purification System}

\begin{tabular}{|l|c|c|}
\hline \multicolumn{1}{|c|}{ Parameter } & Unit & Value \\
\hline $\begin{array}{l}\text { Fractional Mass Flow to } \\
\text { Purification System }\end{array}$ & - & $9.84 \mathrm{E}-05$ \\
\hline HT Purification Efficiency & $(0 \sim 1)$ & 0.95 \\
\hline $\mathrm{H}_{2}$ Purification Efficiency & $(0 \sim 1)$ & 0 \\
\hline $\mathrm{H}_{2} \mathrm{O}$ Purification Efficiency & $(0 \sim 1)$ & 0 \\
\hline HTO Purification Efficiency & $(0 \sim 1)$ & 0 \\
\hline
\end{tabular}




\subsubsection{Component Input Summary in Secondary Side (PCU)}

This section summarizes input parameters of the component blocks used in the secondary side (PCU) modeling. The parameters related to the system operating conditions (temperature, pressure, and flow rates) are taken from the flow sheet shown in Figure 6-1. Tables 6-9 through 6-13 summarize the input parameters implemented in the secondary side model.

Table 6-9. TPAC input parameters in the secondary side (PCU Block).

\begin{tabular}{|l|l|l|}
\hline \multicolumn{1}{|c|}{ PCU Uameter } & \multicolumn{1}{c|}{ Unit } & \multicolumn{1}{c|}{ Value } \\
\hline Volume & $\mathrm{m}^{3}$ & 197 \\
\hline Temperature & $\mathrm{K}$ & $1.02 \mathrm{E}+03$ \\
\hline Pressure & $\mathrm{Pa}$ & $5.41 \mathrm{E}+06$ \\
\hline Flow Rate & $\mathrm{m}^{3}(\mathrm{STP}) / \mathrm{s}$ & 1,679 \\
\hline $\mathrm{C}_{\mathrm{HT}}$ Initial & $\mathrm{mf}$ & $1.00 \mathrm{E}-20$ \\
\hline $\mathrm{C}_{\mathrm{H} 2}$ Initial & $\mathrm{mf}$ & $1.00 \mathrm{E}-05$ \\
\hline Leakage & $\#$ & YES \\
\hline Total Inventory in Loop & $\mathrm{m}^{3}(\mathrm{STP})$ & 3,682 \\
\hline Fractional Helium Leak Rate & $1 / \mathrm{s}$ & $1.15 \mathrm{E}-7$ \\
\hline $\begin{array}{l}\text { Sum of Inventory with Helium } \\
\text { Leak }\end{array}$ & $\mathrm{m}^{3}(\mathrm{STP})$ & 3,682 \\
\hline Permeation & $\#$ & $\mathrm{NO}$ \\
\hline
\end{tabular}

Table 6-10. TPAC input parameters in the secondary side (Purification System Block).

\section{Purification System1}

\begin{tabular}{|l|c|c|}
\hline \multicolumn{1}{|c|}{ Parameter } & Unit & Value \\
\hline $\begin{array}{l}\text { Fractional Mass Flow to } \\
\text { Purification System }\end{array}$ & - & $9.75 \mathrm{E}-05$ \\
\hline HT Purification Efficiency & - & 0.95 \\
\hline $\mathrm{H}_{2}$ Purification Efficiency & - & 0 \\
\hline $\mathrm{H}_{2} \mathrm{O}$ Purification Efficiency & - & 0 \\
\hline HTO Purification Efficiency & - & 0 \\
\hline
\end{tabular}

Table 6-11. TPAC input parameters in the secondary side (Bypass Block).

\begin{tabular}{|l|l|l|}
\hline \multicolumn{1}{|c|}{ Pyarameter } & \multicolumn{1}{c|}{ Unit } & \multicolumn{1}{c|}{ Value } \\
\hline Volume & $\mathrm{m}^{3}$ & 31 \\
\hline Temperature & $\mathrm{K}$ & $1.16 \mathrm{E}+03$ \\
\hline Pressure & $\mathrm{Pa}$ & $7.54 \mathrm{E}+06$ \\
\hline Flow Rate & $\mathrm{m}^{3}(\mathrm{STP}) / \mathrm{s}$ & 141.036 \\
\hline $\mathrm{C}_{\mathrm{HT}}$ Initial & $\mathrm{mf}$ & $1.00 \mathrm{E}-20$ \\
\hline $\mathrm{C}_{\mathrm{H} 2}$ Initial & $\mathrm{mf}$ & $1.00 \mathrm{E}-05$ \\
\hline Leakage & $\#$ & $\mathrm{NO}$ \\
\hline Permeation & $\#$ & $\mathrm{NO}$
\end{tabular}


Table 6-12. TPAC input parameters in the secondary side (SHX Block).

\begin{tabular}{|c|c|c|}
\hline Parameter & Unit & Value \\
\hline Volume & $\mathrm{m}^{3}$ & 1 \\
\hline Temperature & $\mathrm{K}$ & $9.82 \mathrm{E}+02$ \\
\hline Pressure & $\mathrm{Pa}$ & $7.54 \mathrm{E}+06$ \\
\hline Flow Rate & $\mathrm{m}^{3}(\mathrm{STP}) / \mathrm{s}$ & 141.036 \\
\hline $\mathrm{C}_{\mathrm{HT}}$ Initial & $\mathrm{mf}$ & $1.00 \mathrm{E}-20$ \\
\hline $\mathrm{C}_{\mathrm{H} 2}$ Initial & $\mathrm{mf}$ & $1.00 \mathrm{E}-05$ \\
\hline Leakage & \# & $\mathrm{NO}$ \\
\hline Permeation & \# & $\mathrm{NO}$ \\
\hline Volume & $\mathrm{m}^{3}$ & 1 \\
\hline Temperature & $\mathrm{K}$ & $9.71 \mathrm{E}+02$ \\
\hline Pressure & $\mathrm{Pa}$ & $5.00 \mathrm{E}+06$ \\
\hline Flow Rate & $\mathrm{m}^{3}(\mathrm{STP}) / \mathrm{s}$ & 142.23 \\
\hline $\mathrm{C}_{\mathrm{HT}}$ Initial & $\mathrm{mf}$ & $1.00 \mathrm{E}-20$ \\
\hline $\mathrm{C}_{\mathrm{H} 2}$ Initial & $\mathrm{mf}$ & $1.00 \mathrm{E}-05$ \\
\hline Leakage & \# & NO \\
\hline Permeation & \# & NO \\
\hline Heat Transfer Area & $\mathrm{m}^{2}$ & 1,519 \\
\hline Wall Thickness & $\mathrm{m}$ & 0.028 \\
\hline HX Wall Temperature & $\mathrm{K}$ & 999 \\
\hline Pre-exponential Factor (HT) & - & $1.36 \mathrm{E}-10$ \\
\hline Pre-exponential Factor $\left(\mathrm{H}_{2}\right)$ & - & 0 \\
\hline Activation Energy (HT) & $\mathrm{J} / \mathrm{mol} \mathrm{K}$ & $5.35 \mathrm{E}+04$ \\
\hline Activation Energy $\left(\mathrm{H}_{2}\right)$ & $\mathrm{J} / \mathrm{mol} \mathrm{K}$ & NONE \\
\hline
\end{tabular}

Table 6-13. TPAC input parameters in the secondary side (Splitter Block).

\section{Flow Splitter}

\begin{tabular}{|c|c|c|}
\hline \multicolumn{1}{|c|}{ Parameter } & Unit & Value \\
\hline Separation Ratio & & 0.066 \\
\hline
\end{tabular}

\subsubsection{Component Input Summary in Intermediate Heat Transfer Loop}

This section summarizes input parameters of the component blocks used in the intermediate heat transfer loop (IHTL) modeling. The parameters related to the system operating conditions (temperature, pressure, and flow rates) are taken from the flow sheet shown in Figure 6-1. Tables 6-14 through 6-19 summarize the input parameters implemented in the intermediate heat transfer loop model. In the ITL modeling, the PHXs were designed to permeate tritium in one side from the IHTL to the HTSE system. This simplification is based on the quite reasonable assumption that there is no tritium in the inlet water flow in the HTSE system. This simple modification to the heat exchanger model made a large enhancement to the computational speed. 
Table 6-14. TPAC input parameters in the IHTL side (IHTL Block).

\begin{tabular}{|l|l|l|}
\hline \multicolumn{1}{|c|}{ Parameter } & \multicolumn{1}{c|}{ Unit } & \multicolumn{1}{c|}{ Value } \\
\hline Volume & $\mathrm{m}^{3}$ & 40 \\
\hline Temperature & $\mathrm{K}$ & $7.47 \mathrm{E}+02$ \\
\hline Pressure & $\mathrm{Pa}$ & $2.00 \mathrm{E}+06$ \\
\hline Flow Rate & $\mathrm{m}^{3}(\mathrm{STP}) / \mathrm{s}$ & 106 \\
\hline $\mathrm{C}_{\mathrm{HT}}$ Initial & $\mathrm{mf}$ & $1.00 \mathrm{E}-20$ \\
\hline $\mathrm{C}_{\mathrm{H} 2}$ Initial & $\mathrm{mf}$ & $1.00 \mathrm{E}-05$ \\
\hline Leakage & $\#$ & $\mathrm{NO}$ \\
\hline Permeation & $\#$ & $\mathrm{NO}$ \\
\hline
\end{tabular}

Table 6-15. TPAC input parameters in the IHTL side (PHX-mod Block).

\begin{tabular}{|c|c|c|}
\hline PHX-mod & & \\
\hline Parameter & Unit & Value \\
\hline Volume & $\mathrm{m}^{3}$ & 1 \\
\hline Temperature & $\mathrm{K}$ & $7.53 \mathrm{E}+02$ \\
\hline Pressure & $\mathrm{Pa}$ & $2.00 \mathrm{E}+06$ \\
\hline Flow Rate & $\mathrm{m}^{3}(\mathrm{STP}) / \mathrm{s}$ & 53 \\
\hline $\mathrm{C}_{\mathrm{HT}}$ Initial & $\mathrm{mf}$ & $1.00 \mathrm{E}-20$ \\
\hline $\mathrm{C}_{\mathrm{H} 2}$ Initial & $\mathrm{mf}$ & $1.00 \mathrm{E}-05$ \\
\hline Leakage & \# & NO \\
\hline Permeation & \# & $\mathrm{NO}$ \\
\hline Volume & $\mathrm{m}^{3}$ & 12 \\
\hline Temperature & $\mathrm{K}$ & $7.53 \mathrm{E}+02$ \\
\hline Pressure & $\mathrm{Pa}$ & $5.00 \mathrm{E}+06$ \\
\hline Flow Rate & $\mathrm{m}^{3}(\mathrm{STP}) / \mathrm{s}$ & 0.1 \\
\hline $\mathrm{C}_{\mathrm{HT}}$ Initial & $\mathrm{mf}$ & $1.00 \mathrm{E}-20$ \\
\hline $\mathrm{C}_{\mathrm{H} 2}$ Initial & $\mathrm{mf}$ & $1.00 \mathrm{E}-05$ \\
\hline Leakage & $\#$ & NO \\
\hline Permeation & \# & $\mathrm{NO}$ \\
\hline Heat Transfer Area & $\mathrm{m}^{2}$ & 34 \\
\hline Wall Thickness & $\mathrm{m}$ & 0.01 \\
\hline HX Wall Temperature & $\mathrm{K}$ & 753 \\
\hline Pre-exponential Factor (HT) & - & $1.36 \mathrm{E}-10$ \\
\hline Pre-exponential Factor $(\mathrm{H} 2)$ & - & 0 \\
\hline Activation Energy (HT) & $\mathrm{J} / \mathrm{mol} \mathrm{K}$ & $5.35 \mathrm{E}+04$ \\
\hline Activation Energy (H2) & $\mathrm{J} / \mathrm{mol} \mathrm{K}$ & NONE \\
\hline
\end{tabular}


Table 6-16. TPAC input parameters in the IHTL side (PHX-mod1 Block).

\section{PHX-mod1}

\begin{tabular}{|l|l|l|}
\hline Parameter & Unit & Value \\
\hline Volume & $\mathrm{m}^{3}$ & 1 \\
\hline Temperature & $\mathrm{K}$ & $9.53 \mathrm{E}+02$ \\
\hline Pressure & $\mathrm{Pa}$ & $2.00 \mathrm{E}+06$ \\
\hline Flow Rate & $\mathrm{m}^{3}(\mathrm{STP}) / \mathrm{s}$ & 53 \\
\hline $\mathrm{C}_{\mathrm{HT}}$ Initial & $\mathrm{mf}$ & $1.00 \mathrm{E}-20$ \\
\hline $\mathrm{C}_{\mathrm{H} 2}$ Initial & $\mathrm{mf}$ & $1.00 \mathrm{E}-05$ \\
\hline Leakage & $\#$ & $\mathrm{NO}$ \\
\hline Permeation & $\#$ & $\mathrm{NO}$ \\
\hline Volume & $\mathrm{m} 3$ & 1 \\
\hline Temperature & $\mathrm{K}$ & $9.53 \mathrm{E}+02$ \\
\hline Pressure & $\mathrm{Pa}$ & $2.00 \mathrm{E}+06$ \\
\hline Flow Rate & $\mathrm{m}^{3}(\mathrm{STP}) / \mathrm{s}$ & 53 \\
\hline $\mathrm{C}_{\mathrm{HT}}$ Initial & $\mathrm{mf}$ & $1.00 \mathrm{E}-20$ \\
\hline $\mathrm{C}_{\mathrm{H} 2}$ Initial & $\mathrm{mf}$ & $1.00 \mathrm{E}-05$ \\
\hline Leakage & $\#$ & $\mathrm{NO}$ \\
\hline Permeation & $\#$ & $\mathrm{NO}$ \\
\hline Heat Transfer Area & $\mathrm{m}^{2}$ & 1,287 \\
\hline Wall Thickness & $\mathrm{m}$ & 0.01 \\
\hline HX Wall Temperature & $\mathrm{K}$ & 971 \\
\hline Pre-exponential Factor $(\mathrm{HT})$ & - & $1.36 \mathrm{E}-10$ \\
\hline Pre-exponential Factor $(\mathrm{H} 2)$ & - & 0 \\
\hline Activation Energy $(\mathrm{HT})$ & $\mathrm{J} / \mathrm{mol} \mathrm{K}$ & $5.35 \mathrm{E}+04$ \\
\hline Activation Energy $(\mathrm{H} 2)$ & $\mathrm{J} / \mathrm{mol} \mathrm{K}$ & $\mathrm{NONE}$ \\
\hline & & \\
\hline
\end{tabular}


Table 6-17. TPAC input parameters in the IHTL side (PHX-mod2 Block).

\section{PHX-mod2}

\begin{tabular}{|l|l|l|}
\hline Parameter & Unit & Value \\
\hline Volume & $\mathrm{m}^{3}$ & 1 \\
\hline Temperature & $\mathrm{K}$ & $9.53 \mathrm{E}+02$ \\
\hline Pressure & $\mathrm{Pa}$ & $2.00 \mathrm{E}+06$ \\
\hline Flow Rate & $\mathrm{m}^{3}(\mathrm{STP}) / \mathrm{s}$ & 53 \\
\hline $\mathrm{C}_{\mathrm{HT}}$ Initial & $\mathrm{mf}$ & $1.00 \mathrm{E}-20$ \\
\hline $\mathrm{C}_{\mathrm{H} 2}$ Initial & $\mathrm{mf}$ & $1.00 \mathrm{E}-05$ \\
\hline Leakage & $\#$ & $\mathrm{NO}$ \\
\hline Permeation & $\#$ & $\mathrm{NO}$ \\
\hline Volume & $\mathrm{m} 3$ & 1 \\
\hline Temperature & $\mathrm{K}$ & $9.53 \mathrm{E}+02$ \\
\hline Pressure & $\mathrm{Pa}$ & $2.00 \mathrm{E}+06$ \\
\hline Flow Rate & $\mathrm{m}^{3}(\mathrm{STP}) / \mathrm{s}$ & 53 \\
\hline $\mathrm{C}_{\mathrm{HT}}$ Initial & $\mathrm{mf}$ & $1.00 \mathrm{E}-20$ \\
\hline $\mathrm{C}_{\mathrm{H} 2}$ Initial & $\mathrm{mf}$ & $1.00 \mathrm{E}-05$ \\
\hline Leakage & $\#$ & $\mathrm{NO}$ \\
\hline Permeation & $\#$ & $\mathrm{NO}$ \\
\hline Heat Transfer Area & $\mathrm{m}^{2}$ & 2,161 \\
\hline Wall Thickness & $\mathrm{m}$ & 0.01 \\
\hline HX Wall Temperature & $\mathrm{K}$ & 971 \\
\hline Pre-exponential Factor $(\mathrm{HT})$ & - & $1.36 \mathrm{E}-10$ \\
\hline Pre-exponential Factor $(\mathrm{H} 2)$ & - & 0 \\
\hline Activation Energy $(\mathrm{HT})$ & $\mathrm{J} / \mathrm{mol} \mathrm{K}$ & $5.35 \mathrm{E}+04$ \\
\hline Activation Energy $(\mathrm{H} 2)$ & $\mathrm{J} / \mathrm{mol} \mathrm{K}$ & $\mathrm{NONE}$ \\
\hline & & \\
\hline
\end{tabular}

Table 6-18. TPAC input parameters in the IHTL side (Flow Splitter1 Block).

\section{Flow Splitter1}

\begin{tabular}{|l|l|l|}
\hline Parameter & Unit & Value \\
\hline Separation Ratio & - & 0.5 \\
\hline
\end{tabular}

Table 6-19. TPAC input parameters in the IHTL side (Purification System2 Block).

\section{Purification System2}

\begin{tabular}{|l|l|l|}
\hline Parameter & Unit & Value \\
\hline Fractional Mass Flow to PS & - & $1.41 \mathrm{E}-04$ \\
\hline HT Purification Efficiency & - & 0.95 \\
\hline H2 Purification Efficiency & - & 0 \\
\hline H2O Purification Efficiency & - & 0 \\
\hline HTO Purification Efficiency & - & 0 \\
\hline
\end{tabular}




\subsubsection{Component Input Summary in HTSE}

This section summarizes input parameters of the component blocks used in the HTSE loop. The parameters related to the system operating conditions (i.e. temperature, pressure and flow rates) have been taken from the flow sheet shown in Figure 6-1. Tables 6-20 through 6-26 summarize the input parameters implemented in our HTSE model.

Table 6-20. TPAC input parameters in the HTSE components.

\begin{tabular}{|c|c|c|}
\hline Parameter & Unit & Value \\
\hline Flow Rate & $\mathrm{m}^{3}$ & 18.8 \\
\hline Temperature & $\mathrm{K}$ & $3.0 \mathrm{E}+02$ \\
\hline Pressure & $\mathrm{Pa}$ & 101300 \\
\hline $\mathrm{C}_{\mathrm{HT}}$ & $\mathrm{mf}$ & 0 \\
\hline $\mathrm{C}_{\mathrm{H} 2}$ & $\mathrm{mf}$ & 0 \\
\hline $\mathrm{C}_{\mathrm{H} 2 \mathrm{O}}$ & $\mathrm{mf}$ & 1 \\
\hline $\mathrm{C}_{\text {HTO }}$ & $\mathrm{mf}$ & 0 \\
\hline $\mathrm{C}_{\mathrm{H} 2 \mathrm{SO} 4}$ & $\mathrm{mf}$ & 0 \\
\hline $\mathrm{C}_{\mathrm{HTSO} 4}$ & $\mathrm{mf}$ & 0 \\
\hline $\mathrm{C}_{\mathrm{HI}}$ & $\mathrm{mf}$ & 0 \\
\hline $\mathrm{C}_{\mathrm{TI}}$ & $\mathrm{mf}$ & 0 \\
\hline
\end{tabular}

Table 6-21. TPAC input parameters in the HTSE components (Pipe-HTSE Block).

\begin{tabular}{|c|c|c|}
\hline Parameter & Unit & Value \\
\hline Volume & $\mathrm{m}^{3}$ & 10 \\
\hline Temperature & $\mathrm{K}$ & $3.0 \mathrm{E}+02$ \\
\hline Pressure & $\mathrm{Pa}$ & $5.00 \mathrm{E}+06$ \\
\hline Flow Rate & $\mathrm{m}^{3}(\mathrm{STP}) / \mathrm{s}$ & 18.8 \\
\hline $\mathrm{C}_{\mathrm{HT}}$ Initial & $\mathrm{mf}$ & 0 \\
\hline $\mathrm{C}_{\mathrm{H} 2}$ Initial & $\mathrm{mf}$ & 0 \\
\hline $\mathrm{C}_{\mathrm{H} 2 \mathrm{O}}$ Initial & $\mathrm{mf}$ & 1 \\
\hline $\mathrm{C}_{\text {HTO Initial }}$ & $\mathrm{mf}$ & 0 \\
\hline Leakage & $\#$ & $\mathrm{NO}$ \\
\hline Permeation & \# & $\mathrm{NO}$ \\
\hline
\end{tabular}


Table 6-22. TPAC input parameters in the HTSE components (Pipe-HTSE1 Block).

\section{Pipe-HTSE1}

\begin{tabular}{|l|l|l|}
\hline \multicolumn{1}{|c|}{ Parameter } & \multicolumn{1}{c|}{ Unit } & \multicolumn{1}{c|}{ Value } \\
\hline Volume & $\mathrm{m}^{3}$ & 10 \\
\hline Temperature & $\mathrm{K}$ & $3.0 \mathrm{E}+02$ \\
\hline Pressure & $\mathrm{Pa}$ & $5.00 \mathrm{E}+06$ \\
\hline Flow Rate & $\mathrm{m}^{3}(\mathrm{STP}) / \mathrm{s}$ & 18.8 \\
\hline $\mathrm{C}_{\mathrm{HT}}$ Initial & $\mathrm{mf}$ & 0 \\
\hline $\mathrm{C}_{\mathrm{H} 2}$ Initial & $\mathrm{mf}$ & 0 \\
\hline $\mathrm{C}_{\mathrm{H} 2 \mathrm{O}}$ Initial & $\mathrm{mf}$ & 1 \\
\hline $\mathrm{C}_{\mathrm{HTO}}$ Initial & $\mathrm{mf}$ & 0 \\
\hline Leakage & $\#$ & $\mathrm{NO}$ \\
\hline Permeation & $\#$ & $\mathrm{NO}$ \\
\hline
\end{tabular}

Table 6-23. TPAC input parameters in the HTSE components (Pipe-HTSE2 Block).

\section{Pipe-HTSE2}

\begin{tabular}{|l|l|l|}
\hline \multicolumn{1}{|c|}{ Parameter } & \multicolumn{1}{c|}{ Unit } & \multicolumn{1}{c|}{ Value } \\
\hline Volume & $\mathrm{m}^{3}$ & 10 \\
\hline Temperature & $\mathrm{K}$ & $6.40 \mathrm{E}+02$ \\
\hline Pressure & $\mathrm{Pa}$ & $5.00 \mathrm{E}+06$ \\
\hline Flow Rate & $\mathrm{m}^{3}(\mathrm{STP}) / \mathrm{s}$ & 18.8 \\
\hline $\mathrm{C}_{\mathrm{HT}}$ Initial & $\mathrm{mf}$ & 0 \\
\hline $\mathrm{C}_{\mathrm{H} 2}$ Initial & $\mathrm{mf}$ & 0 \\
\hline $\mathrm{C}_{\mathrm{H} 2 \mathrm{O}}$ Initial & $\mathrm{mf}$ & 1 \\
\hline $\mathrm{C}_{\mathrm{HTO}}$ Initial & $\mathrm{mf}$ & 0 \\
\hline Leakage & $\#$ & $\mathrm{NO}$ \\
\hline Permeation & $\#$ & $\mathrm{NO}$ \\
\hline
\end{tabular}

Table 6-24. TPAC input parameters in the HTSE components (Pipe-HTSE3 Block).

\section{Pipe-HTSE3}

\begin{tabular}{|l|l|l|}
\hline \multicolumn{1}{|c|}{ Parameter } & \multicolumn{1}{c|}{ Unit } & \multicolumn{1}{c|}{ Value } \\
\hline Volume & $\mathrm{m}^{3}$ & 10 \\
\hline Temperature & $\mathrm{K}$ & $3.0 \mathrm{E}+02$ \\
\hline Pressure & $\mathrm{Pa}$ & $5.00 \mathrm{E}+06$ \\
\hline Flow Rate & $\mathrm{m}^{3}(\mathrm{STP}) / \mathrm{s}$ & 11.2 \\
\hline $\mathrm{C}_{\mathrm{HT}}$ Initial & $\mathrm{mf}$ & 0 \\
\hline $\mathrm{C}_{\mathrm{H} 2}$ Initial & $\mathrm{mf}$ & 0 \\
\hline $\mathrm{C}_{\mathrm{H} 2 \mathrm{O}}$ Initial & $\mathrm{mf}$ & 1 \\
\hline $\mathrm{C}_{\mathrm{HTO}}$ Initial & $\mathrm{mf}$ & 0 \\
\hline Leakage & $\#$ & $\mathrm{NO}$ \\
\hline Permeation & $\#$ & $\mathrm{NO}$ \\
\hline
\end{tabular}


Table 6-25. TPAC input parameters in the HTSE components (Electrolyzer Block).

\begin{tabular}{|c|c|c|}
\hline Parameter & Unit & Value \\
\hline Steam Conversion Ratio & $\%$ & 90 \\
\hline
\end{tabular}

Table 6-26. TPAC input parameters in the HTSE components (Purge Flow Block).

\begin{tabular}{|l|l|l|}
\hline \multicolumn{1}{|c|}{ Parameter } & \multicolumn{2}{c|}{ Unit } \\
\hline Flow Rate & $\mathrm{m}^{3}$ & 11.2 \\
\hline Temperature & $\mathrm{K}$ & $3.0 \mathrm{E}+02$ \\
\hline Pressure & $\mathrm{Pa}$ & 101,300 \\
\hline $\mathrm{C}_{\mathrm{HT}}$ & $\mathrm{mf}$ & 0 \\
\hline $\mathrm{C}_{\mathrm{H} 2}$ & $\mathrm{mf}$ & 0 \\
\hline $\mathrm{C}_{\mathrm{H} 2 \mathrm{O}}$ & $\mathrm{mf}$ & 1 \\
\hline $\mathrm{C}_{\mathrm{HTO}}$ & $\mathrm{mf}$ & 0 \\
\hline $\mathrm{C}_{\mathrm{H} 2 \mathrm{SO} 4}$ & $\mathrm{mf}$ & 0 \\
\hline $\mathrm{C}_{\mathrm{HTSO} 4}$ & $\mathrm{mf}$ & 0 \\
\hline $\mathrm{C}_{\mathrm{HI}}$ & $\mathrm{mf}$ & 0 \\
\hline $\mathrm{C}_{\mathrm{TI}}$ & $\mathrm{mf}$ & 0 \\
\hline
\end{tabular}

\subsubsection{Simulation and Results of the Base Case}

This section summarizes the results of tritium analyses based on the reference configuration and data described in the previous sections. Figure 6-4 shows the solver setting options used for our analyses. In the current simulation, the ode $15 \mathrm{~s}$ solver was used while the default solver in the MATLAB SIMULINK is ode 45, which is based on an explicit Runge-Kutta $(4,5)$ formula. This is because, in general, ode45 is the best solver to apply as a first try for most problems. However, for a stiff problem, ode45 is inefficient because solutions can change on a time scale that is very short compared to the interval of integration and the ode 45 solver has not been designed for this situation. The ode $15 \mathrm{~s}$ solver is a variable-order solver based on the NDFs (Mathworks 2009). These are related to but are more efficient than the backward differentiation formulas (BDFs) (also known as Gear's method). This simulation is suspected to be a stiff problem because of the large flow rate in the system. Ode $15 \mathrm{~s}$ therefore seems more adequate than ode 45. In the internal benchmark calculations, the ode $15 \mathrm{~s}$ solver showed significantly faster computational speed than the ode 45 solver especially for this input model. Maximum time step, Minimum time step, and Initial time step were automatically decided by the MATLAB code. The simulation time was $5 \times 10^{5} \mathrm{sec}$ ( $\sim 5.79$ days). 


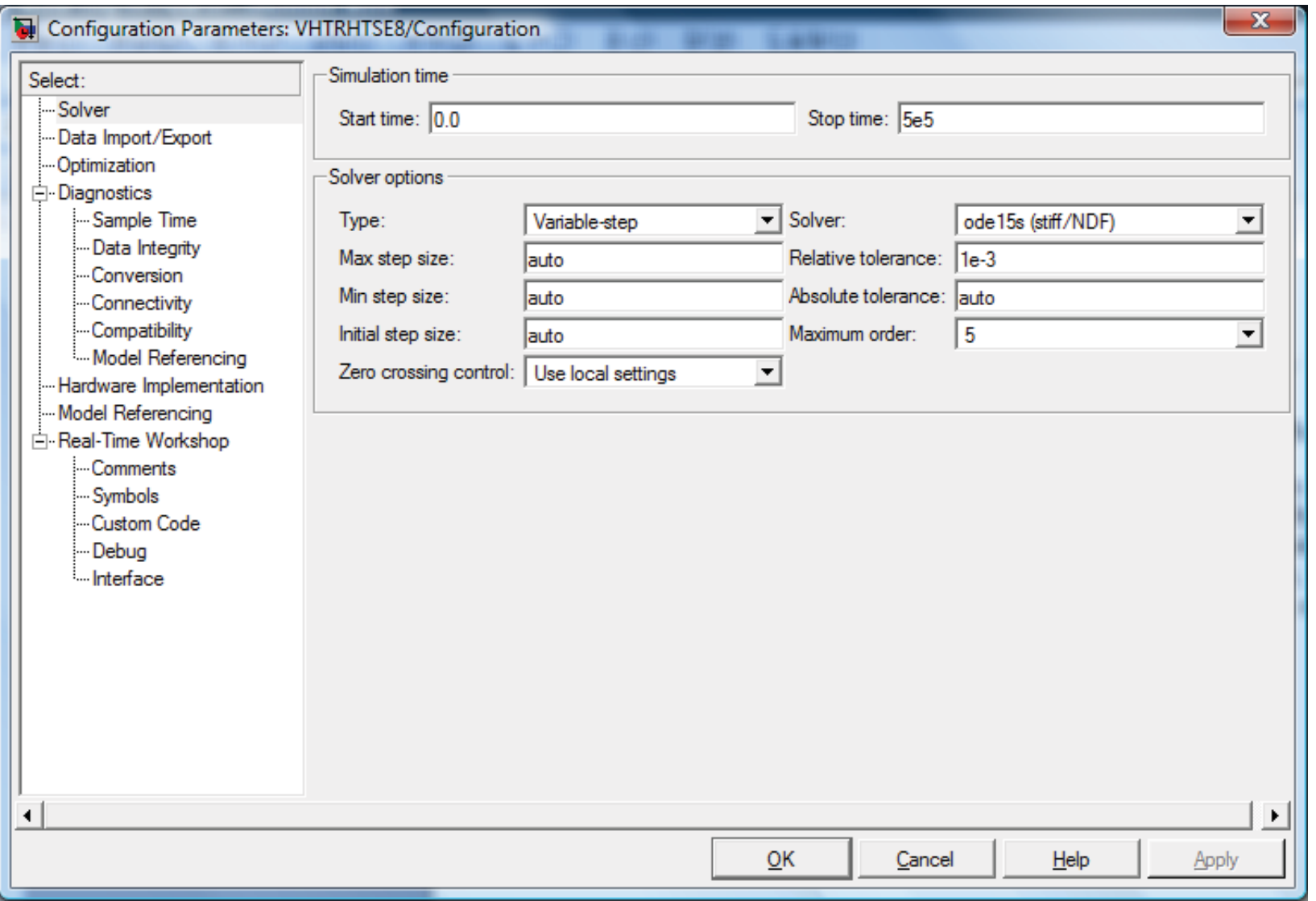

Figure 6-4. TPAC solver setting options for tritium analyses of the VHTR/HTSE system.

Figures 6-5 through 6-8 show time variations of the HT concentrations in the primary side, secondary side, intermediate heat transfer loop, and product hydrogen, respectively. These figures clearly show that the HT concentrations have reached steady-state successfully. In these simulations, steady-state has been achieved in about $2 \times 10^{5} \mathrm{sec}$ after starting.

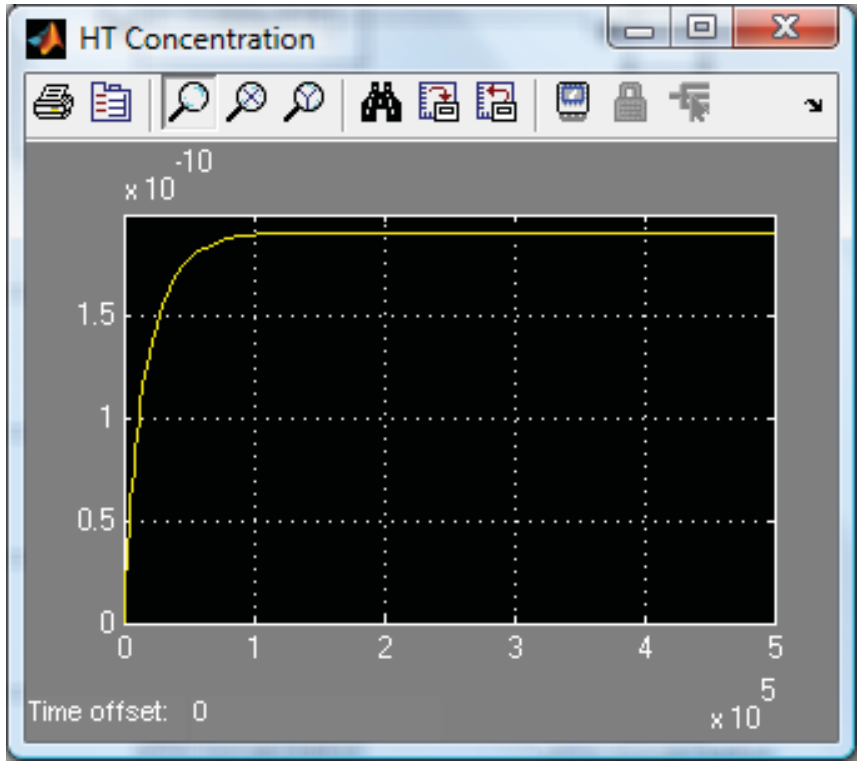

Figure 6-5. HT concentrations in the primary side (Reactor block). 


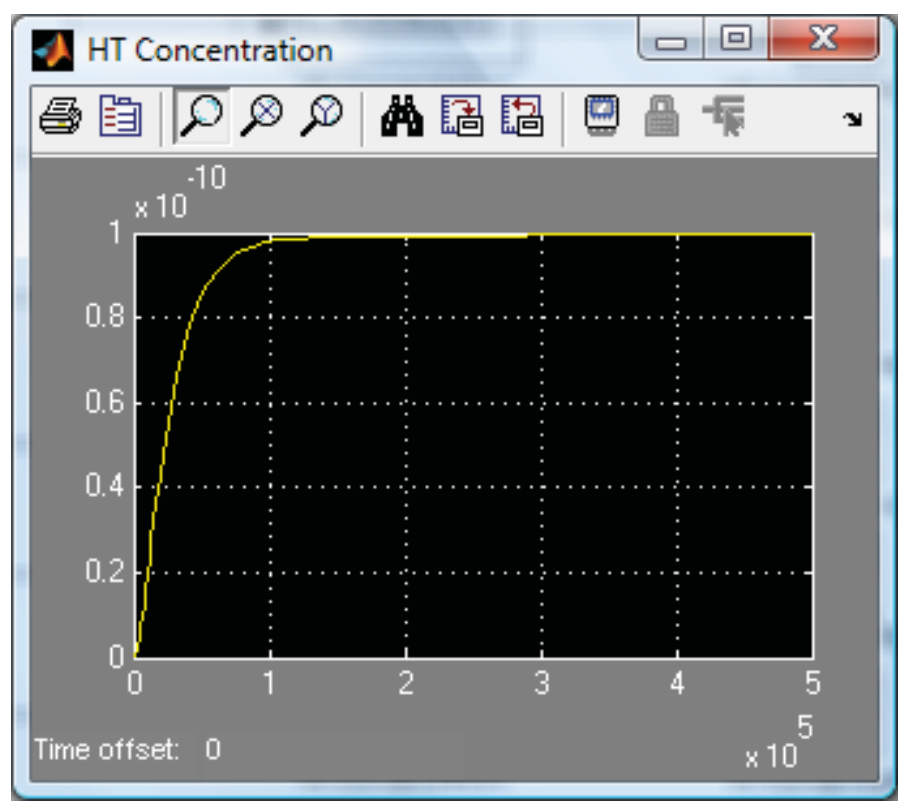

Figure 6-6. HT concentrations in the secondary side (PCU block).

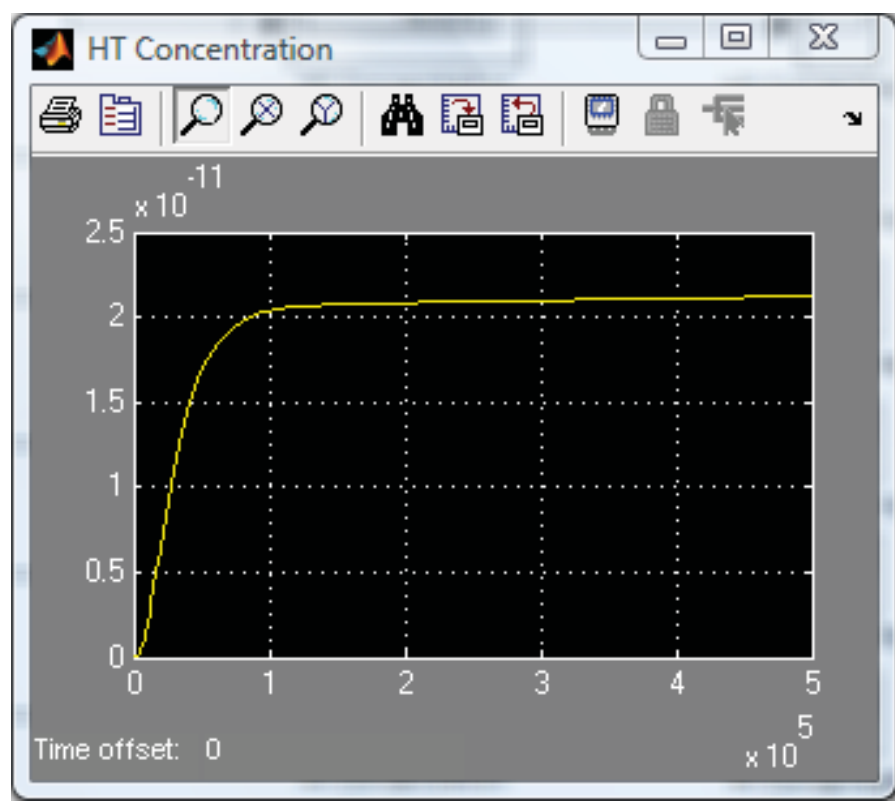

Figure 6-7. HT concentrations in the IHTL side (IHTL block). 


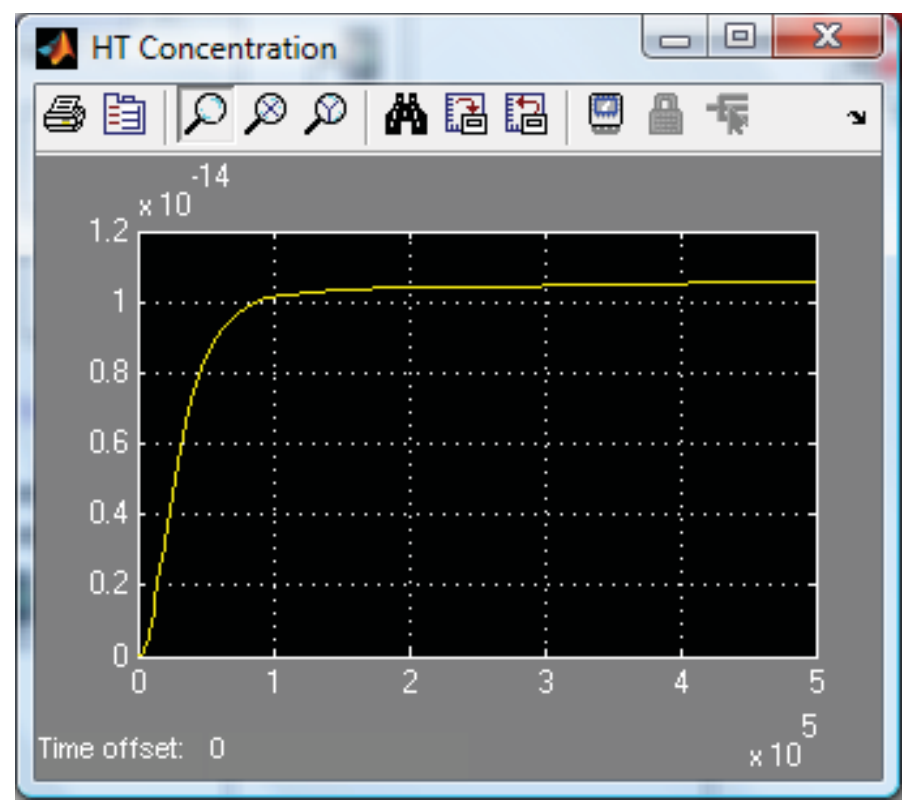

Figure 6-8. HT concentrations in product hydrogen.

Figure 6-9 shows the tritium distribution computed by the TPAC for the VHTR/HTSE system. As shown, about $69.97 \%$ of the released tritium from the core is removed by the purification system installed in the primary side. About $29.99 \%$ of the tritium is transferred to the secondary side through the heat exchanger wall. Only $0.14 \%$ of tritium is released to the containment (or confinement) by helium leakage. In the secondary side, most of the tritium $(28.3 \%)$ is removed by the purification system. Only $1.63 \%$ of the tritium released from the core is transferred to the intermediate heat transfer loop through the heat exchanger. In the intermediate loop, $0.56 \%$ of the tritium released from the core is removed by the purification system. About $0.5 \%$ of the tritium released from the core is transferred to the product hydrogen. According to the calculation results, the purification systems in the primary and secondary system are the most in need of tritium transfer removal and distribution. The effect of leakage from the system looks negligible, which is less than $0.2 \%$ in total. Table $6-27$ summarizes the tritium concentrations in the primary, the secondary, the IHTL, and the product hydrogen. Tritium concentration in gaseous hydrogen $\left(5.65 \times 10^{-4} \mathrm{~Bq} / \mathrm{cm}^{3}[\mathrm{STP}]\right)$ is an order less than the gaseous effluent limit $\left(3.7 \times 10^{-3}\right.$ $\left.\mathrm{Bq} / \mathrm{cm}^{3}[\mathrm{STP}]\right)$.

As already mentioned, the most uncertain parameter based on these analyses is the tritium release rate. Some parametric studies have been performed here for looking at the effect of tritium release rate on the tritium concentration in the hydrogen product. Fractions of tritium release rate to tritium birth rate have been changed from 0.0 to 1.0 in this study. Figure $6-10$ shows the computed results. In this graph, $\mathrm{x}$-axis represents the ratio of tritium release to birth rate, and y-axis represents tritium concentration in the product hydrogen. Our analyses showed that the tritium concentration in the hydrogen product is linearly related to the tritium release ratio. One notable result is that even in the most serious conditions when all the tritium generated from the core is released to the reactor primary coolant (ratio of tritium release to birth rate $=1.0)$, the tritium concentration $\left(1.17 \times 10^{-3} \mathrm{~Bq} / \mathrm{cm}^{3}\right)$ in the product hydrogen is still much lower than that of the gaseous tritium effluent limit $\left(3.7 \times 10^{-3} \mathrm{~Bq} / \mathrm{cm}^{3}\right)$. 


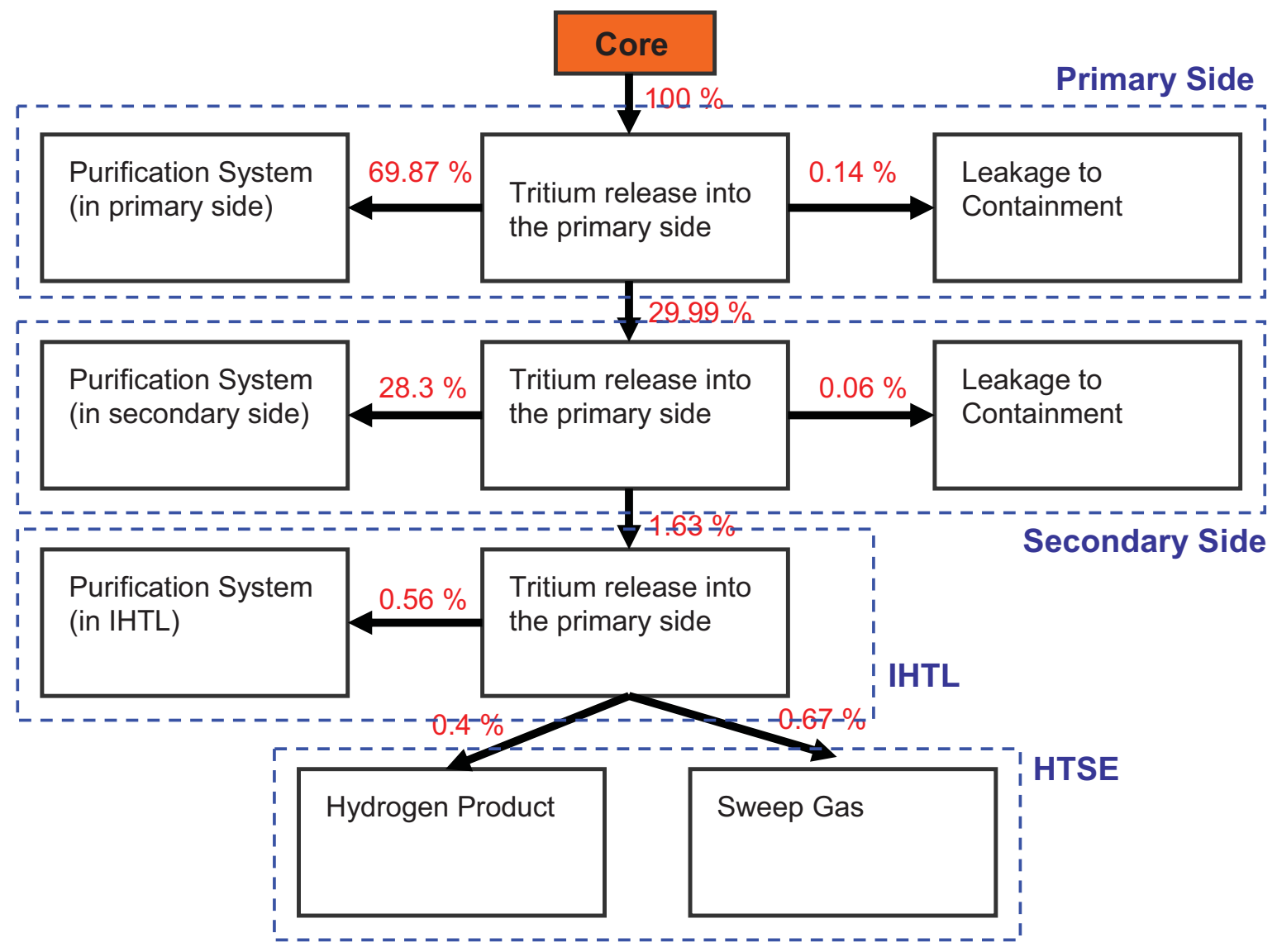

Figure 6-9. Tritium distribution in the VHTR/HTSE system.

Table 6-27. Tritium concentration in the primary, secondary IHTL, and product hydrogen.

\begin{tabular}{|c|c|c|c|c|}
\hline \multirow[b]{2}{*}{ Location } & \multicolumn{3}{|c|}{ Tritium Concentration } & \multirow[b]{2}{*}{ Limit } \\
\hline & [ppb] & {$\left[\mu \mathrm{Ci} / \mathrm{cm}^{3}[\mathrm{STP}]\right]$} & {$\left[\mathrm{Bq} / \mathrm{cm}^{3}[\mathrm{STP}]\right]$} & \\
\hline Primary & $1.906 \times 10^{-1}$ & $2.48 \times 10^{-4}$ & 9.15 & - \\
\hline Secondary & $9.973 \times 10^{-2}$ & $1.30 \times 10^{-4}$ & 4.79 & - \\
\hline IHTL & $2.123 \times 10^{-2}$ & $2.76 \times 10^{-5}$ & 1.02 & - \\
\hline Product Hydrogen & $1.176 \times 10^{-5}$ & $1.58 \times 10^{-8}$ & $5.65 \times 10^{-4}$ & $3.7 \times 10^{-3}$ \\
\hline
\end{tabular}




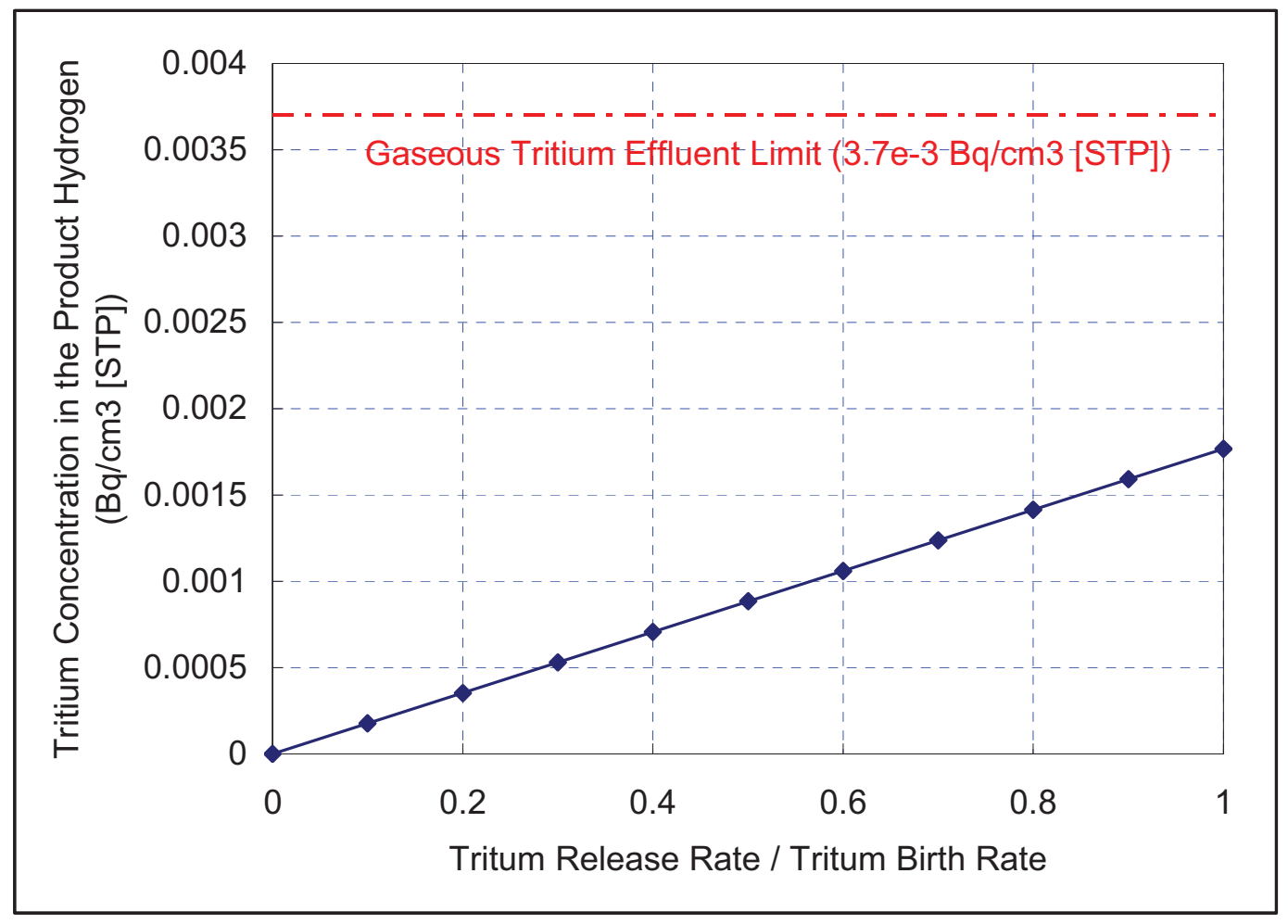

Figure 6-10. Effect of tritium release ratio on the tritium concentration in the hydrogen product. 


\section{SUMMARY}

This study focuses on one important potential issue for application of the VHTRs to hydrogen or process steam production. A serious concern for VHTRs is tritium permeation from the core into the product hydrogen or process steam. Tritium can be easily permeated through high temperature heat exchanger (or steam generator) tubes or heat transfer surfaces, thereby contaminating coolant or product gases. Tritium is mostly generated in the reactor by ternary fission of the fuel and neutron reactions with lithium impurities in the graphite, boron control materials in the reflector block, and ${ }^{3} \mathrm{He}$ naturally occurring in the helium coolant. Tritium that enters or is formed in the helium primary coolant will be circulated or permeate to the secondary coolant and the intermediate heat transfer loop. The permeated tritium then enters the product hydrogen or process steam through contaminated heat exchanger (or steam generator) surfaces.

A computer code was developed using MATLAB SIMULINK to analyze tritium behaviors in the VHTR systems. The code was named TPAC (Tritium Permeation Analyses Code). TPAC is based on the mass and species conservation laws of the tritium or hydrogen containing molecules such as $\mathrm{HT}, \mathrm{H}_{2}$, HTO, $\mathrm{H}_{2} \mathrm{O}, \mathrm{H}_{2} \mathrm{SO}_{4}, \mathrm{HTSO}_{4}$, TI, etc. Various tritium birth models have been implemented into the code. The models are ternary fission and neutron reactions with impurities $\left({ }^{6} \mathrm{Li},{ }^{7} \mathrm{Li},{ }^{10} \mathrm{~B},{ }^{3} \mathrm{He}\right)$ in core structures and coolant. A tritium permeation model using the Arrhenius-type equation form was considered in heat exchanger, vessel, and pipe walls. The default parameters are based on the Alloy-800 materials, but the parameters can be easily modified in the input panel. A leakage model, purification system model, electrolyzer model, and isotope-exchange model are also implemented in the code. Based on these models, various system component models related to VHTRs and hydrogen production systems were developed. The developed components include reactor, vessel, pipe, containment, purification system, heat exchangers, etc. Data access and display blocks are also implemented into the code for post-processing. The basic models used in the code are well described in Chapter 3, and the code details and user-guide are documented in Chapter 4, with some tutorials.

The TPAC has been verified by analytical solutions and experimental data based on the Peach Bottom reactor. Various models were taken into consideration for verification (tritium birth models, leakage model, permeation model, purification system model, isotope-exchange model, etc.). The TPAC calculation results showed good agreement with the analytical and experimental data. The total system model for the Peach Bottom reactor was analyzed by the TPAC and compared with the reported data. The TPAC showed reasonable agreement with the reported data in the Peach Bottom reactor giving a conservative prediction. However, the quality of the measured data was not good enough for validation, and the input conditions seem to have large uncertainties. The verification works are well documented in Chapter 5.

Analyses of tritium behaviors in the VHTR/HTSE system were carried out using the TPAC. The reference reactor configurations and operating conditions were taken from the indirect parallel configuration proposed by $\mathrm{Oh}$ et al. (2007) in their system optimization studies. The geometrical information for the reactor has been referred to the current VHTR preconceptual designs with some assumptions. Heat exchanger designs including IHX, SHX, and PHXs were based on the PCHE-type heat exchangers and the design specifications were taken from the report published by Oh and Kim (2008). Information related to the tritium birth, purification, and leakages were based on various previous literatures (Richards 2006, General Atomics 2006, Ohashi and Sherman 2007), Wichner and Dyer 1979). This analysis showed that only $0.4 \%$ of tritium released from the core is transferred to the product hydrogen. The amount of tritium in the product hydrogen $\left(5.65 \times 10^{-4} \mathrm{~Bq} / \mathrm{cm}^{3}\right)$ was estimated to be about an order of magnitude less than the gaseous effluent limit for tritium $\left(3.7 \times 10^{-3} \mathrm{~Bq} / \mathrm{cm}^{3}\right)$. A parametric study for the tritium release, which has the largest uncertainties for the simulations, showed that even in the most serious conditions - when all of the tritium generated from the core is released to the reactor 
primary coolant (ratio of tritium release to birth rate $=1.0)$ - the tritium concentration $\left(1.17 \times 10^{-3}\right.$ $\left.\mathrm{Bq} / \mathrm{cm}^{3}\right)$ in the product hydrogen is still much lower than the gaseous tritium effluent limit $\left(3.7 \times 10^{-3}\right.$ $\left.\mathrm{Bq} / \mathrm{cm}^{3}\right)$.

\section{REFERENCES}

Atomic Energy Society of Japan, 1982, “Tritium no Kagaku,” Atomic Energy Society of Japan, Vol 31 [in Japanese], 1982.

Burnette and Baldwin, 1980, Primary Coolant Chemistry of the Peach Bottom and Fort St. Vrain HighTemperature Gas-Cooled Reactors, GA-A16163, General Atomic Company, November 1980.

Compare, E. L., Freid, S. H., and Nestor, C. W., 1974, Distribution and Release of Tritium in HighTemperature Gas-Cooled Reactors as a Function of Design, Operational, and Material Parameters, ORNL_TM-4303, Oak Ridge National Laboratory, June.

Dewson and Grady, 2003, HEATRIC Workshop at MIT. Cambridge, MA, U.S.A., October 2nd. 2003.

DOE, 2002, A Technology Roadmap for Generation-IV Nuclear Energy Systems, GIF-002-00, U.S.DOE Nuclear Energy Research Advisory Committee and the Generation IV International Forum, December.

Forsyth, N., 1974, "Tritium production and distribution in High Temperature Gas Cooled Reactors: Tritium generation, retention, distribution, and environmental release in a national 1,500 MW(th) HTR," O.E.C.D. High Temperature Reactor Project DRAGON, DP REPORT 905, October 1974.

Gainey, B. W., 1976, A Review of Tritium Behavior in HTGR Systems, GA A13461, General Atomic Company, April 30, 1976.

General Atomic Company, 1978, Metallurgical Examination of Primary Circuit Components from the Peach Bottom HTGR, GA A14506, General Atomic Company, February 1978.

General Atomics, 2006, TRITGO Code Description and User's Guide, GA Project 20128, 2006.

Heatric ${ }^{\mathrm{TM}}$, 2003, Workshop at MIT on 2nd October 2003, Cambridge: MA.

Oh, C. H., Kim, E. S., Sherman, S. R., Vilim, R., Lee, Y. J. and Lee, W. J., 2007, HyPEP FY-07 Annual Report: A Hydrogen Production Plant Efficiency Calculation Program, INL/EXT-07-13078.

Oh, C.H., and Kim, E.S., 2008, Heat Exchanger Design Options and Tritium Transport Study for the VHTR System, INL/EXT-08-14799.

Ohashi, H. and Sherman, S, 2007, Tritium Movement and Accumulation in the NGNP System Interface and Hydrogen Plant, INL/EXT-07-12746.

Richards, M. B., Shenoy, A. S., Brown, L. C., Buckingham, R. T., Harvego, E. A., Peddicord, K. L., Reza, S. M., and Coupey, J. P., 2006, H2-MHR Pre-conceptual Design Report: SI-Based Plant, GAA25401, General Atomics Company, April 2006.

Sherman and Adams 2008, Tritium Barrier Materials and Separation Systems for the NGNP, WSRC-STI2008-00358.

Steinwarz, W., H. D. Rohrig, and R. Nieder, 1980, “Tritium Behavior in an HTR System Based on AVR Experience," IWGGCR2, International Atomic Energy Agency, Vienna (Austria), pp. 153-160.

The Mathworks, MATLAB 7.8 User Guide, 2009.

Wichner, R. P. and F. F. Dyer, 1979, Distribution and Transport of Tritium in the Peach Bottom HTGR, ORNL 5497, Oak Ridge National Laboratory, August 1979. 
Yang, L., W. A. Baugh, and N. L. Baldwin, 1977, Study of Tritium Permeation Through Peach Bottom Steam Generator Tubes, GA A14376, General Atomics Company, June 1977.

Computer Platform Information

\begin{tabular}{|c|c|c|}
\hline Code and Version & Computer Platform & Operating System \\
\hline MATLAB 7.8.0 (R2009a) & $\begin{array}{l}\text { HPC Cluster (icestorm) } \\
\text { PC (OPTIPLEX 760) }\end{array}$ & $\begin{array}{l}\text { SUSE Linux Enterprise } \\
\text { Server } 10\left(x 86 \_64\right) \\
\text { VERSION }=10 \\
\text { PATCHLEVEL = } 2 \\
\text { SGI ProPack 6SP2 for Linux, } \\
\text { Build 602r4-0812292001 } \\
\text { kernel version: } 2.6 .16 .60- \\
0.37 \_ \text {f594963d-smp } \\
\text { Windows XP version } 5.1 \mathrm{sp} 3\end{array}$ \\
\hline TPAC $1.5 \mathrm{~b}$ & $\begin{array}{l}\text { PC (OPTIPLEX 760) } \\
\text { (Executable in the HPC Cluster) }\end{array}$ & Windows XP version $5.1 \mathrm{sp} 3$ \\
\hline
\end{tabular}

